\title{
Monográfico Especial,
}

Nuevos Formatos en Comunicación

Número 25, marzo 2021

\section{Special Issue, New Forms in Communication} Number 25, March 2021
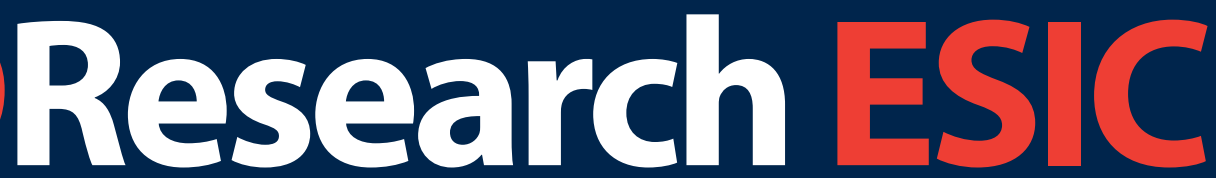

REVISTAINTERNACIONALDEINVESTIGACIÓNENCOMUNICACIÓN INTERNATIONALJOURNALOFCOMMUNICATIONRESEARCH 



\section{Monográfico Especial, Nuevos Formatos en Comunicación}

Número 25, marzo 2021

\section{Special Issue, New Forms in Communication}

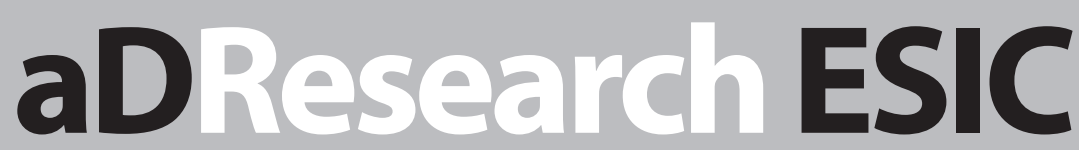

REVISTAINTERNACIONALDEINVESTIGACIÓNENCOMUNICACIÓN INTERNATIONALJOURNALOFCOMMUNICATIONRESEARCH 
Edita: ESIC Editorial

Avda. de Valdenigrales, s/n

28223 Pozuelo de Alarcón (Madrid) España

Tel. +34914524100

editorial@esic.edu

www.esic.edu/editorial

Doble número, Monográfico especial,

marzo 2021

Madrid-España

articulos.adresearch@esic.edu

canje.adresearch@esic.edu

http://adresearch.esic.edu

Condiciones de venta:

España: 40 euros un número.

60 euros suscripción anual.

Extranjero: 50 euros un número.

90 euros suscripción anual.

\section{EDICIÓN SEMESTRAL}

aDResearch ESIC, Revista Internacional de Investigación en Comunicación, no se identifica necesariamente con los juicios y opiniones de sus colaboradores, a quienes corresponde en exclusiva la reponsabilidad de los mismos. Prohibida la reproducción total o parcial del contenido de esta revista sin citar su procedencia. Todos los artículos de esta revista se somenten a revisión por expertos.

Diseño: Gerardo Domínguez

Depósito legal: M34206-2009

aDResearch ESIC N.o 25

ISSN: 1889-7304

Impresión: Gráficas Dehón

La Morera, 23-25

28850 Torrejón de Ardoz (Madrid)
Published by: ESIC Editorial

Avda. de Valdenigrales, $s / n$

28223 Pozuelo de Alarcón (Madrid) España

Tel. +34914524100

editorial@esic.edu

www.esic.edu/editorial

Special Issue, March 2021

Madrid-Spain

articulos.adresearch@esic.edu

canje.adresearch@esic.edu

http://adresearch.esic.edu

Sales terms:

Spain: 40 euros an issue.

60 euros annual subscription.

Other countries: 50 euros an issue.

90 euros annual subscription.

BIANNUAL EDITION

aDResearch ESIC, International Journal of

Communication Research, does not necessarily identify with the opinions and judge-

ments of its collaborators, who are exclusively reponsible for them. Forbidden the partial or total reproduction of this magazine without citing its source. All of the articles are revised by experts.

\section{Design: Gerardo Domínguez}

Dep. legal: M34206-2009

aDResearch ESIC N.0 25

ISSN: 1889-7304

Printed by Gráficas Dehón

La Morera, 23-25

28850 Torrejón de Ardoz (Madrid) 


\section{aDResearch ESIC}

REVISTAINTERNACIONALDEINVESTIGACIÓNENCOMUNICACIÓN

INTERNATIONALJOURNALOFCOMMUNICATIONRESEARCH

ADRESEARCH ESIC ESTÁ INCLUIDA EN LAS SIGUIENTES BASES DE DATOS:

- Latindex 2.0, Sistema Regional de Información en Línea para Revistas Científicas de América Latina, el Caribe, España y Portugal

- Latindex, sistema de información online para revistas científicas de América Latina, el Caribe, España y Portugal.

- Base de datos del CSIC/CCHS de Revistas de Ciencias Sociales y Humanidades.

- Base de Datos de DICE, Difusión y Calidad Editorial de Revistas Españolas de Humanidades y Ciencias Sociales y Jurídicas.

- Dialnet, hemeroteca de artículos científicos hispanos en Internet.

- EBSCO Information Services.

- MIAR - Matriz de Información para el Análisis de Revistas

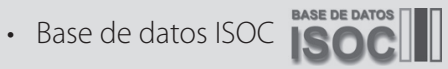

- Base de datos REDIB. Red Iberoamericana de Innovación REDIB y Conocimiento cientíico

\section{MIAR}

OIIIU UNIVRSITATn
AUII BARCELONA 


\section{Índice}

\section{Prólogo}

Graciela Padilla Castillo · Universidad Complutense de Madrid

12 "Shockvertising" as a Method to Advertise Content in Video on Demand Streaming Services

María Dolores Brito-Rhor, Franklin Velasco Vizcaíno y Camila Lopez

Universidad San Francisco de Quito (Ecuador)

26 El engagement y la sorpresa en la comunicación digital de las marcas.

Estudio del impacto emocional de los GIFs en los usuarios de redes sociales.

Idoia Rúa Hidalgo · Universidad Internacional de La Rioja

María Galmes-Cerezo · Universidad Complutense de Madrid

María del Cisne Espinosa Jarrín - Universidad Internacional de La Rioja

44 La estrategia de contenidos en YouTube de los principales anunciantes españoles

Araceli Castelló-Martínez y Cecilia Barrilero-Carpio - Universidad de Alicante

70 Using Virtual Assistants and Chatbots for Crisis Communication

Gema Bonales Daimiel y Eva Citlali Martínez Estrella - Universidad Complutense de Madrid

92 El impacto de las plataformas de podcast en redes sociales: Estudio de caso en las cuentas oficiales de iVoox y Anchor en Instagram, Facebook y Twitter Adrián Caballero-Escusol - Universitat de Vic-Universitat Central de Catalunya, Ruben Nicolas-Sans y Javier Bustos Díaz · ESIC Business and Marketing School

106 Análisis de la comunicación de empresas europeas y norteamericanas en TikTok

Pavel Sidorenko Bautista - Universidad Francisco de Vitoria

José María Herranz de la Casa . Universidad de Castilla-La Mancha

124 Análisis de las estrategias publicitarias digitales de Inbound marketing de las marcas del sector automoción en YouTube en España Gema González Carreño, Ana María Rivas Machota y Claudia Ortega Pickmans Universidad Camilo José Cela

148 Tik Tok medio de divulgación empleado por los viajeros que realizan turismo sostenible

Ariana Paola Herrera Pérez · Universidad Metropolitana de Ecuador 
160 Estrategia de comunicación de los cuerpos de seguridad a través de píldoras audiovisuales en Tik Tok. Policía Nacional y Guardia Civil en España Eglée Ortega Fernández · Universidad Nebrija Jonattan Rodríguez Hernández · Universidad Complutense de Madrid

186 MISCELÁNEA

188 Evaluación de la eficacia de una política de acción comunicativa a través del modelo EPAC Affinity ${ }^{\circledR}$

Jesús Varela Mallou, Teresa Braña Tobío y Antonio Rial Boubeta.

Universidad de Santiago de Compostela

\section{REVISTA DE LIBROS}

Coordinador: Julio Alard Josemaría · ESIC Business \& Marketing School

206 Periodismo en nuevos formatos. Estado del Arte del Ciberperiodismo, Narrativas y Tecnologías Emergentes Por Ignacio Soret Los Santos · ESIC Business \& Marketing School

208 Planificación de la comunicación de eventos. Estrategia e innovación en tiempos de inmediatez

Por Julio Alard Josemaría. ESIC Business \& Marketing School

210 Sobrevivir a la publicidad desde una perspectiva ética Por Oliver Carrero Márquez . ESIC Business \& Marketing School

214 PROYECTOS DE INVESTIGACIÓN EN COMUNICACIÓN Y PUBLICIDAD Coordinadora: Susana Fernández Lores · ESIC Business \& Marketing School

224 TESIS DOCTORALES EN COMUNICACIÓN

Coordinadora: Marta Gimeno Pascual · ESIC Business \& Marketing School

230 AGENDA DE CONGRESOS

Coordinador: Francisco Moreno Rey · ESIC Business \& Marketing School

234 Normas de publicación

244 Política editorial

250 Contenidos de la revista 
Consejo de Dirección

D. Eduardo Gómez Martín

Director General de ESIC

D. Segundo Huarte Martín

Decano del Área Universitaria

\section{Antonio Martín Herreros}

Decano del Área de Postgrado y Executive Education

D. Ignacio Soret Los Santos

Director de la Unidad Corporativa de Investigación
Consejo Editor

D. a Susana Fernández Lores, PhD Editora

D. Julio Alard Josemaría, PhD

Editor Adjunto 


\section{Consejo de Redacción}

\section{D. ${ }^{a}$ M. ${ }^{a}$ Cruz Alvarado López}

Universidad de Valladolid

D. Juan Benavides Delgado

Universidad Complutense (Madrid)

D. Francisco José Blanco Jiménez

Universidad Rey Juan Carlos (Madrid)

Da Ana María Casado Molina

Universidad de Málaga

D. Ángel Luis Cervera Fantoni

ESIC Business \& Marketing School

\section{Jorge Conde López}

ESIC Business \& Marketing School

D. Pedro Cuesta Valiño

Universidad de Alcalá

\section{D. a Susana de Andrés del Campo}

Universidad de Valladolid

D. Raúl Eguizábal Maza

Universidad Complutense (Madrid)

D. Francisco Javier Forcadell Martínez Universidad Rey Juan Carlos (Madrid)

D. José Alberto García Avilés

Universidad Miguel Hernández

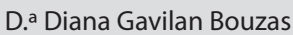

Universidad Complutense (Madrid)

D. ${ }^{a}$ María Guijarro García

ESIC Business \& Marketing School (Valencia)

D. Pablo Gutiérrez Rodríguez

Universidad de León

D. Javier Hernández Ruiz

Universidad San Jorge Zaragoza

D. José Luis Hervás Oliver

Universitat Politècnica de València

D. ${ }^{a}$ Caroline Hodges

Bournemouth University (United Kingdom)

D. Darren Lilleker

Bournemouth University (United Kingdom)
D. a Belén López Vázquez

ESIC Business \& Marketing School

D. ${ }^{a}$ Miryam Martí Sánchez

ESIC Business \& Marketing School (Valencia)

\section{D. a Gema Martínez Navarro}

Universidad Complutense (Madrid)

\section{Alvaro Méndez}

London School of Economics (United Kingdom)

D. ${ }^{a}$ María Jesús Merino Sanz

ESIC Business \& Marketing School

D. ${ }^{a}$ Giorgia Miotto

Universidad Ramón Llull

D. Abel Monfort de Bedoya

ESIC Business \& Marketing School

D. Francisco Moreno Rey

ESIC Business \& Marketing School

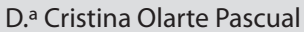

Universidad de La Rioja

\section{D. ${ }^{a}$ Teresa Pintado Blanco}

Universidad Complutense (Madrid)

\section{D. ${ }^{\text {a Ana Pinto Borges }}$}

ISAG - European Business School (Portugal)

D. Jorge Remondes

ISVOUGA - Instituto Superior de Entre Douro e Vouga (Portugal)

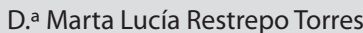

CESA - Colegio de Estudios Superiores en

Administración Bogotá (Colombia)

\section{D. ${ }^{a}$ Vanessa Roger Monzó}

ESIC Business \& Marketing School (Valencia)

\section{Adolfo Sánchez Burón}

Universidad Internacional Isabel I de Castilla

D. Joaquín Sánchez Herrera

Universidad Complutense (Madrid) 


\section{Prólogo}

\section{Nuevos Formatos en Comunicación}

En junio de 2020, por primera vez, la inversión publicitaria digital en España superó la inversión en televisión tradicional (InfoAdex, 2020). El $38,6 \%$ de los fondos invertidos en medios controlados o convencionales se destinó a comunicación digital. Dentro del sector, los formatos de Display y Vídeo (incluidas las redes sociales) fueron los que recibieron un mayor desembolso (InfoAdex, 2020). A estos datos, reveladores de un nuevo paradigma de comunicación, había que añadir la comunicación no convencional o below the line, que sigue creciendo exponencialmente cada año y que contiene la inversión en branded content, influencers o publicidad nativa.

El entorno se ha consolidado definitivamente en marzo de 2021, cuando InfoAdex ha publicado los datos completos del año 2020 y ha podido comparar enero de 2020 con enero de 2021. El sector Digital se consolida en la primera posición de inversión publicitaria para todo el territorio español y es el único que no ha descendido en inversión, en el triste año de crisis socio-sanitaria y confinamiento. Dentro de Digital, se encuentran las Redes Sociales, cuya cifra de inversión se incrementó en un 2,5\%, alcanzando los 38,7 millones de euros (InfoAdex, 2021). La Televisión vuelve a ser el segundo sector en inversión publicitaria, con 116,4 millones de euros, que suponen un 19,8\% menos que los 145,2 millones de euros del mismo periodo del 2020 (InfoAdex, 2021). Radio ocupa el tercer lugar, con una inversión de 23,3 millones y un descenso del $-26,7 \%$; y Diarios, con 15,6 millones de euros de inversión, registra una caída del -33,2 \% sobre la cifra del año anterior. También descienden Exterior, con una caída del 62,4%; y Revistas, con una inversión un 33,5 \% menor a la del 2020 (InfoAdex, 2021).

A la vista de estos datos, el Consejo Editor de aDResearch me confió colaborar en la edición de este número, tan actual, necesario y representativo del cambio paradigmático que hemos vivido y más todavía, de los cambios que todavía están por venir. No puedo dejar pasar la oportunidad de agradecer su extrema confianza y su escrupuloso, puntual y amable trabajo, conmigo, con revisores y con los autores. Es un placer colaborar con una revista excelente, por fuera y por dentro, que aboga por la investigación puntera, rigurosa y humana en Comunicación.

Mis siguientes líneas son de agradecimiento para todos los autores y autoras de este número, por elegir esta revista para compartir y difundir los resultados de sus investigaciones, y por trabajar sus textos con tanta excelencia, honestidad y rigor. Este monográfico será, sin duda, una referencia y un punto de encuentro de investigadores académicos, que estudian y sigan estudiando los nuevos formatos de Comunicación. Como muestra de esa innovación, reseño brevemente sus trabajos por orden de aparición, apuntando sus conclusiones, aportaciones y prospectivas más originales. Espero que esta mínima y humilde muestra ayude a cualquier lector a adentrarse en los textos con mayor profundidad.

Desde la Universidad de San Francisco de Quito, Ecuador, los compañeros María Dolores Brito, Franklin Velasco y Camila López ofrecen un trabajo imprescindible sobre el Shockvertising, método publicitario empleado en los contenidos de vídeo de plataformas de streaming. Esta técnica consiste en la difusión de anuncios, de películas y series, que crean un shock en la audiencia, usando concretamente, la llamada fetichista o sexual. En plataformas con catálogos tan largos, renovados semanalmente, es esencial hacer esta 
publicidad con un efecto llamada, para que el espectador decida rápidamente qué ver. Y los investigadores descubren que la fórmula más efectiva es la del fetichismo, pero activando los sentimientos románticos y la acción concreta en micromomentos.

Idoia Rúa Hidalgo (Responsable en el País Vasco de la Escuela OTEC para la comunicación profesional), María Galmes-Cerezo (Universidad Complutense de Madrid) y María del Cisne Espinosa Jarrín (Instituto de Tecnologías Sudamericano de Ecuador) estudian el engagement y la sorpresa en la comunicación digital de las marcas, desde el impacto emocional de los GIFs. A través de dos estudios, con 30 y 67 participantes, respectivamente, observan las expresiones faciales, la conductancia de la piel y la dirección de la pupila. Los resultados muestran que los GIFs generan engagement y consiguen el «estado de bienestar-placer» (Modelo Circumplejo de Russel, 1980), pero no el entusiasmo. Así, recomiendan a las marcas conocidas que utilicen recursos visuales innovadores de forma sorprendente.

Desde la Universidad de Alicante (España), las compañeras Araceli Castelló-Martínez y Cecilia Barrilero-Carpio investigan la estrategia de contenidos en YouTube de los principales anunciantes españoles. Su corpus abarca el análisis de 1.029 vídeos publicados en YouTube, en 2019, por las diez marcas españolas más importantes según volumen de inversión de ese año (a partir de los datos de InfoAdex). Los resultados concretan que el contenido con mejores resultados en interacción es aquel que aporta un valor añadido al usuario; y que para conseguir esta interacción en YouTube es vital fijar una frecuencia de publicación como compromiso adquirido con la comunidad de seguidores.

Gema Bonales Daimiel y Eva Citlali Martínez Estrella (Universidad Complutense de Madrid) exploran los asistentes virtuales y los chatbots en comunicación de crisis. Concretamente, se centran en el estudio de la pandemia de la COVID-19 en España, entendiendo que hay 43 millones de usuarios de Internet y alrededor de 4,3 millones de familias que usan, diariamente, estos asistentes virtuales. Detectan que se suele emplear una voz femenina; que los expertos recomiendan que se invierta más en inteligencia artificial, para que los asistentes no caigan en errores conversacionales que inquietan a los usuarios; y que el $96 \%$ de las personas que usaron el servicio quedaron satisfechas y un tercio de ellos no necesitó ampliar información con su centro de salud.

Los profesores Adrián Caballero-Escusol (Universitat de Vic y Universitat Central de Catalunya), Ruben Nicolás-Sans y Javier Bustos Díaz (ESIC Business and Marketing School) ahondan en el impacto de las plataformas de podcast en redes sociales. Concretamente, estudian las cuentas oficiales de iVoox y Anchor en Instagram, Facebook y Twitter, a lo largo de todo el año 2020. Este estudio es imprescindible y súper original, teniendo en cuenta que hay más de 10 millones de oyentes de podcast en España y que las empresas dedicadas a esos servicios cuentan con sus propias redes de difusión y promoción, pero también hacen una importante labor de visualización en redes sociales generalistas. Concretamente, los resultados de este estudio destacan Twitter como la red social más elegida y la de mayor frecuencia de publicación.

Pavel Sidorenko Bautista (Universidad Francisco de Vitoria), José María Herranz de la Casa y Alba Soledad Moya Ruiz (Universidad de Castilla-La Mancha) comparten otro estudio actual y necesario sobre TikTok, la red social revolucionaria del 2020 y la de mayor crecimiento durante el confinamiento. Los autores avalan la necesidad de su estudio desde el hecho indiscutible de 
que la red social china es la favorita de millennials y centennials; y las marcas estudiadas, diez empresas norteamericanas y otras diez europeas, eligen esta plataforma para acercarse a este público. Sus resultados muestran una interesante correlación entre el aumento de seguidores y el incremento de publicaciones: crece el alcance cuanto mayor exposición de contenidos se produce. Sin duda, una conclusión interesante y sugestiva para estudiar si ocurre lo mismo en las demás redes sociales, con distintas marcas, y con distintos públicos.

Las profesoras Gema González Carreño, Ana María Rivas Machota y Claudia Ortega Pickmans, de la Universidad Camilo José Cela de Madrid (España), analizan las estrategias publicitarias digitales de inbound marketing del sector automoción español, en la red social de vídeos YouTube, la primera en número de usuarios de todo el mundo. Su sólido corpus contempla 50 vídeos de las diez marcas de coche utilitario más vendidas en España, en 2018 y 2019. A partir de ahí, analizan los vídeos, los mensajes y la interacción del público a través de los «me gusta». Entienden que en la red social hay que proponer contenidos distintos, más allá del spot tradicional de televisión, para llegar al público con una publicidad más inteligente, cercana y atractiva.

Ariana Paola Herrera Pérez, Profesora de la Universidad Metropolitana de Ecuador, también destaca la importancia de estudiar TikTok. En su caso, como vehículo imprescindible de la divulgación del turismo sostenible y del mercado de los viajes, tan perjudicado por la crisis de la COVID-19. Este sector no ha dejado de difundir experiencias de cara a la deseada recuperación de la movilidad internacional y la red social china se erige con la vía más influyente, gracias al UserGenerated Content. El uso de hashtags virales, por parte de los usuarios de TikTok, difunde las bondades del \#turismo, del \#turismosostenible, del \#tiktoktravel y del \#travel, con millones de visualizaciones que crecen cada día y que muestran cómo esos mensaje eco-conscientes se difunden en la red social de mini-vídeos y llegan a jóvenes y adultos jóvenes, que practicarán el turismo de otras forma en el mundo postCOVID.

Cierran el número, de manera redonda, Eglée Ortega Fernández y Jonattan Rodríguez Hernández (Universidad Complutense de Madrid), asimilando el uso de los mini-vídeos o píldoras audiovisuales en las cuentas de TikTok, de la Policía Nacional y la Guardia Civil. Su trabajo no tiene precedentes en España y se adelanta a la existencia de herramientas de análisis, pues los autores han realizado una exploración manual de los vídeos, desde la creación de las cuentas hasta las administraciones de las primeras vacunas contra el virus en nuestro país. Esta investigación es de vital importancia por la viralidad de las dos cuentas; por la función social de los Cuerpos; y sobre todo, porque los mismos tuvieron que enfrentarse a duras críticas por la inauguración de los perfiles, aun cuando responden a una estrategia ineludible, fraterna y necesaria de acercarse a los jóvenes españoles usando el mismo lenguaje y rompiendo estereotipos tradicionales o más anticuados.

Confío, sin duda, en que estas propuestas serán de interés para la comunidad científica internacional y su lectura ayudará a avanzar y mejorar en las Ciencias Sociales.

Graciela Padilla Castillo Profesora Titular del Departamento de Periodismo y Nuevos Medios Facultad de Ciencias de la Información, Universidad Complutense de Madrid Marzo de 2021 


\section{Bibliografía}

InfoAdex (2020). Estudio InfoAdex de la inversión publicitaria en España 2020. Disponible en: https://www.infoadex.es/ home/wp-content/uploads/2020/02/Estudio-InfoAdex-2020-Resumen.pdf
InfoAdex (2021). Estudio InfoAdex de la inversión publicitaria en España 2021. Disponible en: https://www.infoadex.es/ home/wp-content/uploads/2021/02/PDF-2021-Presentaci\%C3\%B3n-Estudio-MADRID.pdf 


\section{다(1) $(5)$}

\section{"Shockvertising" as a Method to Advertise Content in Video on Demand Streaming Services}

\section{Shockvertising como un método para promocionar el contenido de los} servicios de transmisión de video bajo demanda

María Dolores Brito-Rhor, Ph.D.

Universidad San Francisco de Quito USFQ mbrito@usfq.edu.ec

https://orcid.org/0000-0002-0385-0620

Franklin Velasco Vizcaíno, Ph.D.

Universidad San Francisco de Quito USFQ

fvelasco@usfq.edu.ec

https://orcid.org/0000-0002-6561-6741

Camila López, BA

Universidad San Francisco de Quito USFQ

cami.lopez.a@gmail.com

https://orcid.org/0000-0003-1251-6509
Brito-Rhor, M.D, Velasco Vizcaíno, F.y Lopez, C. (2021) "Shockvertising" as a Method to Advertise Content in Video on Demand Streaming Services

Revista Internacional de Investigación en Comunicación aDResearch ESIC. No 25 Vol 25

Monográfico especial, marzo 2021 · Págs. 12 a 25

https://doi.org/10.7263/adresic-025-01 
Purpose: Most thumbnails promoting movies or series in video on demand (VOD) streaming services contain some form of shock advertising. The intention of this type of appeal is to bring immediate attention of viewers. However, little is known if shock advertising persuades consumers to watch series or movies on VOD streaming services such as Netflix or Amazon Prime Video. This study examines more deeply consumer responses to two types of shock advertising appeals: fetishism and sexual, and compares the results to an experimental condition in which there is an absence of shock advertising.

Design / Methodology / Approach:This study empirically tests if shock advertising, in the form of fetishism and sexual appeals, persuades consumers to watch series or movies. In the experimental setting, we manipulated romantic feelings and compared how each shock advertising types of appeals influence consumers when deciding what to watch in VOD streaming services. Analysis of variance was utilized to test the main effect of type of shock advertising appeal (fetishism vs. sexual vs. control condition) and to test the moderating effect of romantic feelings.

Results: Our findings suggest that consumers exposed to fetishism and sexual appeals revealed lower levels of persuasion compared to a control condition. An important finding of the study is the moderating effect of romanticism. When an individual has romantic feelings, conceived as

JEL Classification: M30, M31, M37

Key words:

Fetishism, romantic feelings, sexual advertising shock advertising, video on demand streaming services a transitory mood state, the fetishism appeal becomes more persuasive than the sexual or the neutral appeals

Limitations / Implications: These results are useful for improving the implementation of shock advertising appeals in the form of fetishism or sexual thumbnails for VOD streaming services. The study uses a single experiment to draw conclusions. Future research can test to generalize the results of this study in different settings.

Originality / Contribution: The main contributions derived from this research can be classified into two findings: it improves our understanding of consumer's reactions to shock advertising; and, second advances our knowledge of the influence of positive emotions (romantic feelings) when consumers decide what to watch in video streaming services.

\section{RESUMEN}

\author{
Clasificación JEL: \\ M30, M31, M37 \\ Palabras clave: \\ Apelación fetichista, \\ publicidad de \\ choque, \\ publicidad sexual, \\ romanticismo, \\ servicios de \\ transmisión de vídeo \\ bajo demanda
}

Objetivo: La mayoría de anuncios publicitarios de películas o series en servicios de transmisión de video bajo demanda (VOD) contienen algún tipo de contenido de publicidad de choque. Pero muy poco se conoce sobre este tipo de contenidos publicitarios en las intenciones de la audiencia al elegir una serie o película en los servicios VOD como por ejemplo Netflix o Amazon Prime Video. Este estudio examina las respuestas de los consumidores a dos tipos de publicidad de choque: estímulos fetichistas y sexuales.

Diseño/Metodología/Enfoque: Este estudio examina si la publicidad de choque persuade a los consumidores a ver series o películas. En el experimento se manipularon los sentimientos románticos de los participantes y se comparó cómo cada tipo de publicidad de choque (fetichista vs. sexual vs. condición de control) influye en los consumidores a la hora de decidir qué ver en los servicios VOD.

Resultados: Los hallazgos sugieren que los consumidores expuestos a los estímulos de publicidad de choque fetichistas y sexuales, expresan niveles inferiores de persuasión en comparación con la condición de control en la que no se presenta publicidad de choque. Un hallazgo importante es el rol romanticismo. Cuando un individuo experimenta sentimientos románticos, la apelación publicitaria fetichista se vuelve más persuasiva.

Limitaciones/Implicaciones: Estos resultados son útiles para entender mejor el impacto de la aplicación de estrategias de publicidad de choque en los servicios VOD. El estudio utiliza un experimento para deducir las conclusiones. Futuras investigaciones podrían enfocarse en generalizar los resultados y replicar el estudio incluyendo otras condiciones experimentales.

Originalidad/Contribución: Las principales contribuciones derivadas de esta investigación son mejorar la comprensión de las reacciones de los consumidores a la publicidad de choque; y, avanzar en nuestro conocimiento de la influencia de las emociones positivas (sentimientos románticos) cuando los consumidores deciden qué ver en los servicios VOD. 


\section{Introduction}

Over the years there has been an increase in the use of shock advertising appeals not only in the advertising of consumer goods, but also within new contexts (e.g., video streaming services) that involve different consumer decision-making processes (Reichert \& Lambiase, 2006, p. 14). Consumers have been bombarded by different forms of messages with the purpose of attracting their attention to specific content in video streaming services. We find that in popular video streaming services, shock advertising is a common form of marketing communication. In this context, the use of sexual appeals has become increasingly explicit and a widely used marketing technique (Ruberg, 2020). A quick analysis made by the authors reveals that 20 percent of thumbnails in Netflix or Amazon Prime Video use some form of shock advertising appeals. In particular, sexual appeals are predominant. Since the goal of shock advertising is to draw viewer's immediate attention, the use of this type of advertising appeal seems like a suitable strategy to promote entertainment content. However, there is little evidence in previous marketing communication literature on how shock advertising persuades more (vs less) viewers.

It has long been established that shock advertising, in the form of sexual appeals, is expected to achieve better rates in recognition, recall, and purchase decisions (Alexander \& Judd, 1978, p. 47; Álvarez Domínguez, 2020, p. 25). Complementing these effects, we found that many of the current forms of communication use shock advertising, especially when promoting entertainment products. For example, 59 percent of music videos use sexual appeals (Zhang, Dixon, \& Conrad, 2010, p. 787), 43 percent of women dress very provocative in magazine ads (Carpenter \& Reichert, 2004, p. 825), 41 percent of women on television wear revealing clothing (Downs \& Smith, 2010, p. 729), 23.5 percent of magazine thumbnails in social networks have some level of nudity and 39.5 percent suggest eroticism (Brito-Rhor, 2019, p. 128), 18 percent of the clothing or behavior of prime time actors in television commercials is provocative (Lin, 1998, p. 463), and sexual advertising appeal in Spanish-language television network ads is usually higher than in other languages (Fullerton \& Kendrick, 2001, p. 53). These statistics suggest the belief that "sex sells" is not just a cliché, but that it certainly remains as a valid marketing communication format for various entertainment products. This could be explained by how shock advertising (i.e., sexual appeals) is capable to attract viewers' attention, evoke pleasure, and stimulate purchase intentions (Reichert \& Lambiase, 2006, p. 42).

Although the widespread use of sexual appeals in different media and around the world is evident, there are not enough studies on different forms of sexual appeals. The purpose of this study is to objectively evaluate the response of consumers to shock advertising of both fetishism and sexual nature. Responses from subjects toward the sexual stimulus will be evaluated in function of their intentions to watch TV series. The experimental design is intended to measure and compare consumers' reactions to three different shock advertising appeals (fetishism, sexual and a control condition). Furthermore, this effect will be contrasted with romantic feelings induced by an experimental manipulation. This study aims to contribute, to both theory and practice, on the effects of shock advertising appeals. Figure 1 present our conceptual framework.

Next, we present our literature review, then discuss the methodology, followed by the results, and conclusions of the study. 


\section{Figure 1. Conceptual framework}
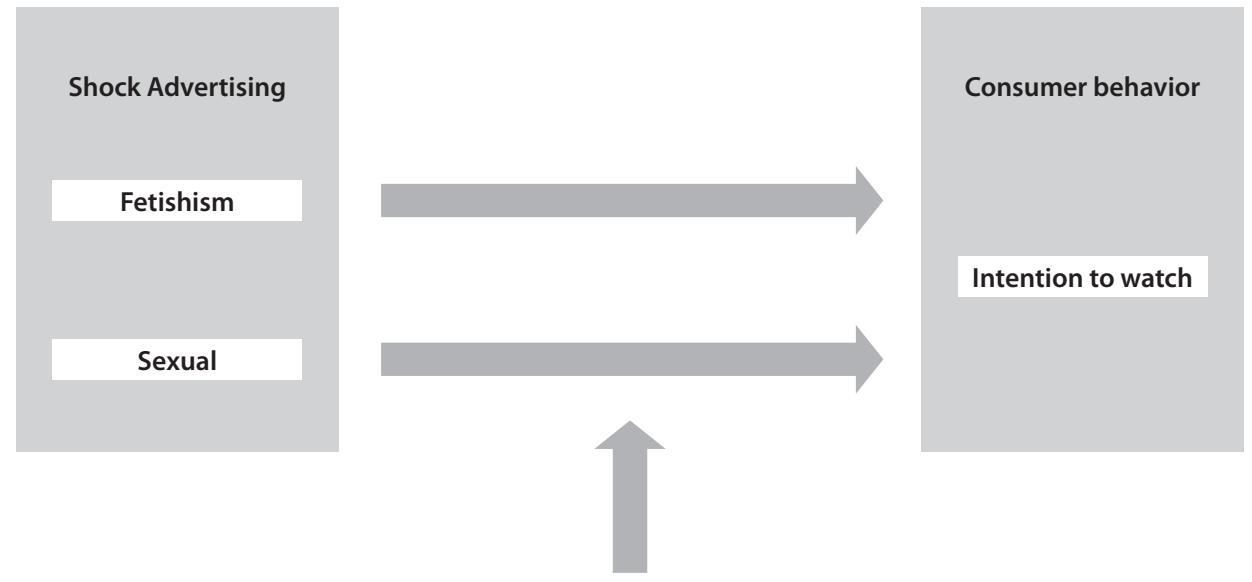

Romantic feelings

\section{Literature Review}

\section{Shock Advertising}

Shock advertising is described as offensive content, that violates norms, values, moral or social codes (Dahl, Frankenberger, \& Manchanda, 2003, p. 268; Srivastava \& Dorsch, 2020, p. 2). This type of advertising is intended to surprise the audience breaking through normal ads, catching consumers' attention and resulting in an intention on the audience to act in a particular way (Lee, Septianto, Frethey-Bentham, \& Gao, 2020 p. 2; Urwin \& Venter, 2014, p. 204). Norm violation refers to a violation of expectations created during the social development learning process (Dahl, Frankenberger, \& Manchanda, 2003, p. 269 - 270). The different types of shock appeals are: disgusting images, sexual references, profanity/obscenity, vulgarity, impropriety, moral offensiveness and religious taboos. Advertising as any other social object, is judged with the rules that people have learned to be acceptable, when the content is offensive it commonly breaks norms of decency, good taste, aesthetic propriety and moral standards (Dahl, Frankenberger, \& Manchanda, 2003, p. 269-270). Shock advertising has been found to be easier to comprehend and to retain in consumers minds. Also, there is evidence that the shocking effect is greater for the themes shown rather than for the products or ideas advertised (Parry, Jones, Stern, \& Robinson, 2013, p. 112). Also, studies have shown that this communication form can be effective when promoting new products and brands (Skorupa, 2014 , p. 69). Other studies implied that the effects of shock advertising are greater when looking for more immediate actions rather than for long- term effects (Parry, Jones, Stern, \& Robinson, 2013, p. 113). This last evidence suggests that it could be an appropriate strategy for viewers of streaming video services, since they decide what to watch in a matter of seconds.

There are some factors that influence the effects and perception of shock advertising. These 
elements can be defined as ethics, culture, language, history and religion (Engelbart, Jackson, \& Smith, 2017, p. 46; Urwin \& Venter, 2014, p. 204; Yan \& Chapa, 2020 p. 11). Above all, religion and social factors are believed to have a stronger relationship with the perception of individuals because of the influence on daily life, concern of moral standards and the presence of more conservative attitudes (Parry, Jones, Stern, \& Robinson, 2013, p. 114). For instance, the higher the level of nudity used in an advertisement, the more negative the ethical attitude towards it is (Brito-Rhor, Rodríguez-Herráez, \& ChachaloCarvajal, 2019, p. 45). Even though the perception differences between genders have not been fully described, there is some evidence of mixed results if women feel more offended when the advertising includes sexual images.

\section{Sexual and Fetishism Appeals in Advertising}

The word sex has different meanings depending on the area of research in which it is used. Sex researchers, social psychologists, and marketers define sexual information as a sexual stimulus to which sexual meaning is attributed (Reichert $\&$ Lambiase, 2012, p. 27). Sex in advertising has been defined as media messages containing sexual information for the persuasive purpose of selling branded goods and/or services (Reichert, Heckler, \& Jackson, 2001, p. 15). Courtney and Whipple (1983) defined sex in advertising as sexuality in the forms of: nudity, sexual images, innuendo, and double meaning (p. 15). Furthermore, advertising itself is an applied form of persuasion that attempts to: inform, position, convince, reinforce and differentiate; to achieve various objectives such as selling products and/or services, improving the image of the brand, educating the public, among others (O'Guinn, Allen, \& Semenik, 2012, p. 87;
Reichert \& Lambiase, 2012, p. 19). In accordance with the definition of sex and advertising, sexual appeals are persuasive resources containing sexual information that is integrated with the overall message (Reichert, Heckler, \& Jackson, 2001, p. 14). Sexual content in advertising is diverse; however, it could be defined as those stimuli within the ad that people interpret as sexual (Reichert \& Ramirez, 2000). Commonly the objective of using the sexual appeal in advertising is to achieve the affective connection or association with the consumer (O'Guinn, Allen, \& Semenik, 2012, p. 61, 208-209).

Over the years it has become obvious that the use of eroticism in advertising has increased in tone and explicitness (Maison \& Pawłowska, 2017, p. 310). As a mechanism to attract the attention of consumers, it is very common to see in the mainstream media, the use of sexual appeals in advertising (Hyllegard, Yan, Ogle, \& Attmann, 2010). Several investigations have pointed to an increase in the use of sexual appeals with women (American Psychological Association, 2007), and there is evidence of the use of more female models who appear with an intense degree of nudity and couples in positions that suggest sexual relations (Zimmerman \& Dahlberg, 2008, p. 76).

Over time, the sexual appeal in advertising seems to have evolved into a new form of sexual appeal: fetishism. Although most advertisements contain forms of fetishism, little is known about this type of appeal that evokes a sense of power and erotica in the individual (Holm, 2016, p. 128). This is how fetishism emerges in advertising as an important marketing tool that creates objects of desire through visual techniques and symbols. The fetish object, typically associated with sexuality, symbolizes contrasting concepts such as liberation and control, power and powerlessness, sexuality and childishness. The fetish object discloses a 
flexible mixture of "three underlying features of categorization and representation characteristic of all thought. These are concretization, animation or anthropomorphization, conflation of signifier with signified, and an ambiguous relationship of control between person and object" (Ellen, 1988, p. 1). Fetishism from a clinical perspective is a dysfunctional response to sexuality since fetish objects eventually substitute human contact for sexual arousal and satisfaction. Sexual needs are projected onto erotic objects. From a psychological perspective, fetishism replaces human relations with relations with objects and, in general, revolves around certain garments. The three qualities of fetish clothing are (1) liminality: a gap that falls between nature and culture (leather, rubber, shoes, boots, corsets, stockings, zones of passion, danger, creativity, uncertainty), (2) color: Black skin or bright red, and (3) de-contextualization and isolation. For example, the shoe that by itself excites, high heels, thigh leather, handcuffs.

\section{The Moderating Role of Romantic Feelings}

The term self-schema refers to the beliefs or ideas that a person has about oneself (Mueller et al., 2016). In general terms, the schemas vary depending on some factors such as culture (BritoRhor, Rodríguez-Herráez \& Trueba, 2020, p. 89) or other elements of the environment (Leite \& Kuiper, 2010). From the studies of Andersen and Cyranowski (1994, p. 1085; 1999, p. 657) four categories of sexual self-schema were defined based on the combination of two independent dimensions for women and one for men. One dimension is related to emotions of romanticism and the other to the negative aspect of shame or conservatism. The sexual self-schema is formed by four factors (1) Eroticism; the sensual component of sexuality. This element is related to the congruent cognitions of the capacity to experiment and provoke sexual desire and pleasure in the other being, (2) Romanticism; the affective-emotional component of sexuality. Cognitions concerning romanticism reflect affection and sensitivity, (3) Sexual openness, the behavioral component of sexuality. In a person's behavior, cognitions are linked to security, openness, assertiveness, and confidence in sexual competence, and (4) Negative affectivity; the affective-emotional and behavioral negative component of sexuality. In this element, congruent cognitions are related to feelings of tension, anxiety and guilt stimulated by sexual aspects that could cause sexual containment behaviors (Brito-Rhor et al., 2020, p.88).

Comparatively, both men and women believe that a sexual human being is one who is sexual by evidencing romantic and loving qualities (Andersen et al, 1999, p. 661). People with higher sexual self-schemas possess characteristics such as romanticism, as well as a more liberal sexual attitude, and increased interest in sexual issues (Cheung et al, 2013, p. 381). A romantic sexual self-schema is a cognitive generalization about romantic aspects of oneself from a sexual perspective.

It has already been mentioned that several studies have confirmed that the use of sexual attractiveness in advertising is increasing. However, very little is known about the influence of different personality sexual traits, such as romanticism, on responses to sexual information. Nevertheless, it is possible to affirm that romantic feelings are evidently an individual level factor that influences attitudes and reactions to a stimulus with sexual content (Hatfield \& Rapson, 1993, p. 90). These elements became central in this study to examine the moderating effects of romantic feelings and preferences for shock advertising appeals. 
Romanticism has its roots in attachment theory (Bowlby, 1969; Holmes, 2014). Attachment motivations, reflecting individual characteristics, have implications in individuals' social behaviors toward others (Simpson \& Rholes, 2012, p. 286). Attachment theory further describes these motivations as having two central dimensions: anxiety and avoidance. According to Simpson et al., (2012), both dimensions play a significant role in how individuals obtain social power in a relationship, as individuals become more (versus less) susceptible to each person's preferences. Thus, depending on how the level of romanticism produces high (versus low) levels of anxiety or avoidance type of orientations, the level of social power and control in the relationship switch. This argument can explain how romanticism can lead to a person, having more social power over his/ her partner, employ a greater influence in decisions and preferences toward sexuality. Using this as a basis, we expect a positive link between romanticism and preference for fetishism sexual appeals.

To sustain our hypothesis that romantic feelings increase the preference toward fetishism appeals we found evidence in literature about varietyseeking behaviors. Huang and Dong (2018) suggest that even short episodes of romanticism, romantic crushes, lead to variety-seeking type of behaviors (p. 232). As the authors further describe, a romantic schema is likely to lower people's sense of control and increase a desire for sensory stimulation. In addition to this finding, experiments that induced a romantic feeling in male participants show they feel greater attraction to dissimilar female partners that evoke a sense of limerence and obsession for fantasies (Gold et al., 1984). Advertising literature has similarly studied romantic schemas. Huang (2014) found that ads showing romantic appeals induce greater attitudes toward the ads; this effect is strengthened by higher levels of arousal and pleasure (p. 69). Since fetishism delivers both types of outcomes, we expect that romantic feelings increase the persuasion from fetishism types of appeal in advertising.

\section{Method}

\section{Pre-Test}

A pre-test was necessary to confirm if certain types of advertising cues (e.g., a whip, handcuffs, red panties, red brassiere, a pole, and so forth) when embedded in an ad generate perceptions of either a fetishism appeal or a sexual appeal. Sixty-four participants (43.2 \% female; Mage $=36.08, \mathrm{SD}=$ 12.64) from a consumer panel accepted the invitation to participate in an advertisement evaluation task. Participants were instructed to associate different types of objects that are representative of either fetishism or sexual advertising appeals. Table 1 shows a list of eight objects presented to participants and their corresponding responses when associating each cue to a type of shock advertising appeal.

\section{Main Study}

Purpose. The objective of this study is to find evidence of the level of persuasion that different types of shock advertising appeals produce inside the mind of consumers. In this study we manipulated romantic feelings and compare how each shock advertising appeals (sexual versus fetishism) influence more (vs. less) consumers when deciding what to watch in paid video streaming services. A control condition was included to compare the effects that these shock advertising appeals provoke.

Design and shock advertisement manipulations. A two factor 3 (shock advertising sexual appeals: fetishism, sexy, and a control condition) x 2 (state 
Table 1. Objects associated with a fetishism or a sexual appeal

\begin{tabular}{|l|c|c|c|}
\hline Objects & Fetishism appeal \% & Sexual Appeal \% & Z-value \\
\hline Whip & 83 & 17 & $14.11^{* * *}$ \\
\hline Leather underwear & 76 & 24 & $11.12^{* * *}$ \\
\hline Handcuffs & 81 & 18 & $13.30^{* * *}$ \\
\hline Venetian mask & 70 & 30 & $8.55^{* * *}$ \\
\hline Red brassiere & 24 & 76 & $-11.11^{* * *}$ \\
\hline Red panties & 25 & 75 & -10.698 .55 \\
\hline High heel shoes & 42 & 58 & $-3.42^{* *}$ \\
\hline Pole & 54 & 46 & $1.71^{\text {ns }}$ \\
\hline Note: & & \\
\hline
\end{tabular}

of mind: positive romantic affect vs. neutral condition) between-subjects experimental design was utilized to investigate how consumers react to video streaming programming that is advertised with shock advertising appeals.

First, participants were randomly instructed to either write a few lines describing one of the most romantic episodes of their lives or write a description of what is their daily routine. This first step was intended to rise feelings of positive romantic affect. These romantic feelings manipulation was adopted from Donato et al. (2018) study (p. 220-229). Second, we manipulated shock advertising appeals promoting a new TV series available in a video stream service. Three versions of the ad were created to exhibit each shock advertising appeal. The fetishism appeal was manipulated by embedding imagery artifacts related to the practice of fetishism in the TV series ad. Following the results of the pre-test, we utilized a black leather pair of handcuffs to be displayed in the ad. The sexual appeal utilized imagery artifacts, such as women's red panties and brassiere. Last, the control advertisement did not include any artificial that can be related to shock advertising appeal. A fictitious name of the TV series (Pearls), a short description of the story, customer ratings, and a young lady laying on the floor served as stimuli included in each of the three versions of the ad. All advertisements were designed by a professional graphic designer who used the same look and feel that a popular paid video stream service uses to promote their programming. Appendix 1 illustrates the three thumbnails related to the experimental conditions of this study.

Sample and Procedure. Consumers from a research panel were invited to participate in a task evaluating advertisements for a consumer good. A sample of 203 adults participated in the study (46.3\% female; Mage $=24.25, \mathrm{SD}=6.31$ ). At the beginning of the study, participants were randomly assigned to our experimental conditions. Then, participants provided answers to a questionnaire that included our main dependent intention variable to watch the TV series. Intentions to 
watch the TV series included two items: (1) "How likely is it that you would watch this TV series? 1 Very unlikely - 7 Very likely; (2) "How interested are you in watching this TV series? 1 Not interested at all -7 Very interested $(r=0.87)$. Then, participants answered the manipulation check questions, a current mood questionnaire, and shared their demographic information.

\section{Results}

Manipulation check. To check for the effectiveness of the romantic feelings manipulation we conducted an ANOVA using as dependent variable the score of a seven-point scale question that asked participants their current feelings ( $7=$ romantic; $1=$ unromantic). As expected, participants in the romantic feelings condition $(\mathrm{M}=4.56, \mathrm{SD}=1.50)$ felt more romantic than those in the control condition $(\mathrm{M}=4.07, \mathrm{SD}=1.82 ; \mathrm{F}(1,202)=4.37$, $\mathrm{p}<.05)$. The result suggests our manipulation on the romantic feelings operated as intended.

Hypotheses testing. To test the hypotheses a 2 (romantic feelings) $\times 3$ (shock advertising appeals) ANCOVA, with intentions to watch the TV series as the dependent variable was conducted and mood as a covariate. Participants in the romantic feelings condition showed higher intentions to watch the TV series $(M=4.12, S D=1.53)$ than participants in the neutral mental state $(\mathrm{M}=3.45$, $\mathrm{SD}=1.37)$; thus, the main effect of romantic feelings reached statistical significance $(F(1,195)$ $=7.26, \mathrm{p}<.001)$. We also found a main effect for shock advertising appeals $(F(2,195)=4.73$, p < .01) that participants in the fetishism appeal condition $(\mathrm{M}=4.33, \mathrm{SD}=1.48)$ showed higher intentions to watch the TV series than those in the control condition $(\mathrm{M}=3.65, \mathrm{SD}=1.38)$, and than those in the sexual appeal condition $(\mathrm{M}=$ $3.39, \mathrm{SD}=1.47$ ). Most importantly, the analyses revealed a significant romantic feeling $\times$ shock advertising 2-way interaction $(F(2,195)=4.34$, $\mathrm{p}<.01)$. For participants induced with romanticism, there is a significance difference in intentions to watch the TV series across the fetishism appeal $(\mathrm{M}=4.93, \mathrm{SD}=1.38)$ compared to the sexual appeal $(\mathrm{M}=3.40, \mathrm{SD}=1.33)$ and control conditions $(\mathrm{M}=3.75, \mathrm{SD}=1.46)$. However, for participants in the non-romantic feelings condition, intentions to watch the TV series were almost the same for all three shock advertising conditions: fetishism appeal $(\mathrm{M}=$ $3.44, \mathrm{SD}=1.17)$, sexual appeal $(\mathrm{M}=3.38, \mathrm{SD}=$ $1.57)$, and control condition $(\mathrm{M}=3.55, \mathrm{SD}=$ 1.30). Post-hoc tests for mean differences, Tuckey HSD, confirmed that there was a significant difference between the fetishism appeal mean and the other conditions. Table 2 presents the mean scores for each condition. Figure 1 shows the interaction effect of romantic feelings and shock advertising.

\section{Table 2. Main Study - mean scores and standard deviations}

\begin{tabular}{|l|c|c|c|c|}
\hline Shock advertising condition & \multicolumn{2}{|c|}{ Romantic feelings } & \multicolumn{3}{c|}{ Control } \\
\hline & Mean & Std. Dev & Mean & Std. Dev \\
\hline Fetishism & 4.93 & 1.38 & 3.44 & 1.17 \\
\hline Sexy & 3.40 & 1.33 & 3.38 & 1.57 \\
\hline Control & 3.75 & 1.46 & 3.55 & 1.30 \\
\hline
\end{tabular}




\section{Figure 2. Interaction effect of romantic feelings and shock advertising}

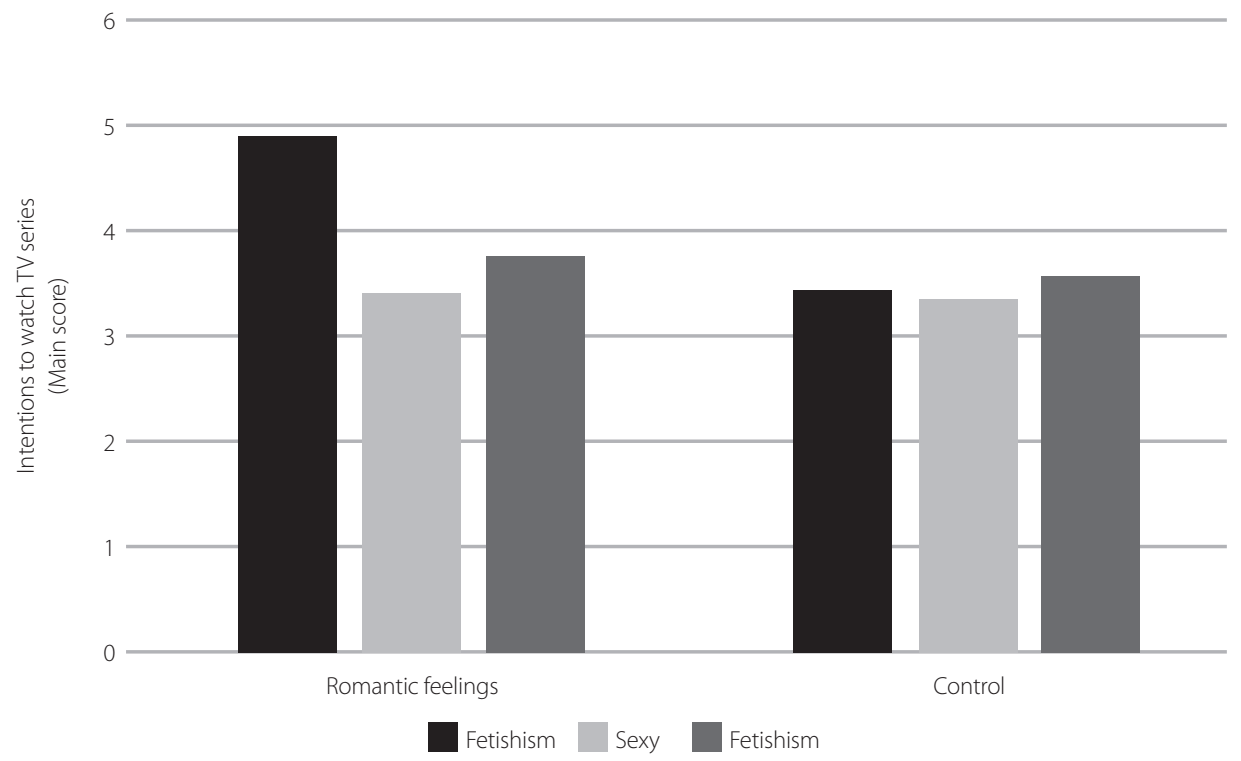

\section{Discussion and Conclusions}

Advertising is a basic element of marketing and as such, it is important to understand how shock advertising influences viewers' decision-making processes and choices. Our experimental study reveals that consumers are more persuaded by fetishism when romantic feelings are activated. Results indicate that consumers show higher intentions to watch video streaming content when shock advertising, in the form of fetishism appeals, are used in the movie thumbnail. Findings also suggest that the level of romanticism, operationalized as a transitory romantic feeling, changes the perceptions toward fetishism appeals. The more romantic a viewer feels, the stronger the level of persuasion expelled by fetishism appeals is.

The main contributions derived from this research can be classified into two areas: improving the understanding of consumer's reactions to shock advertising; and, advancing our knowledge of the influence of a romantic mood on new forms of advertising in a video streaming context.

Individual personality traits are important variables that influence sex-related attitudes and reactions to sexual information. The findings suggest that understanding people's predispositions and tendencies to approach/avoid sexual information is important for understanding how those tendencies influence responses to advertising messages. Our results support Huang's (2014) research that evidenced that ads displaying romantic appeals induce better attitudes toward the ads; this effect is reinforced by higher levels of arousal and pleasure (p. 69). Given that fetishism offers both types of outcomes, romantic feelings increased the persuasiveness of fetishism appeals in ads. Likewise, Reichert and Lambiase (2006), 
evidenced that shock advertising, whether in the form of fetishistic or sexual appeals, is able to attract viewers' attention, evoke pleasure, and stimulate purchase intentions (p. 42). Therefore, the use of fetishism appeals could be an appropriate strategy for viewers of streaming video services, who choose what to watch based on the artwork. According to research by Parry, Jones, Stern, and Robinson (2013), it was established that the effects of shock advertising are greater when more immediate actions are sought than long-term effects, such as choosing to watch a movie on streaming services (p. 113).

Given that customers receive an excessive amount of commercial stimuli, it is paramount to keep looking for new ways to achieve strategic differentiation and fulfill the first basic step of advertising, which is to attract the public's attention. Precisely, emotional ads that appeal to shock not only seek to break with conventional norms, but also aim to make a concrete call to action in micro-moments. In the case of streaming services, the call to action is to get people to click on the thumbnail of the movie they are most interested in watching. In conclusion, If a movie thumbnail combines a fetishism type of appeal and uses elements to activate romanticism, the film being advertised will receive favorable consumer responses.

\section{Limitations}

This research is not without limitations. To support generalizability, more studies should be carried out to test the relationship concerning shock advertising, romantic sexual self-schema, and behavioral intentions for different product categories, market segments, and sexual content in advertisements. For example, future research might examine the role of culture and how it facilitates romantic feelings and influences perceptions toward sexual content in advertisements. Another research question for future studies to address is how other forms of shock advertising, especially threat and drama, influences consumer choices in video streaming services. Last, we suggest that future studies focus on the romantic sexual schema conceptualized as a more stable personality trait. Furthermore, replication research is suggested which leads to the advancement of science. 


\section{Bibliography}

Alexander, M. W., \& Judd, B. (1978). Do nudes in ads enhance brand recall. Journal of Advertising Research, 18(1), 47-50.

Álvarez Domínguez, L. (2020). Shock advertising, a practical analysis of its effectiveness in three trademarks [Bachelor's and Master's thesis, Universidad de León]. Buleria. https://buleria.unileon.es/handle/10612/12777

American Psychological Association. (2007). Report of the APA Task Force on the Sexualization of Girls.

Andersen, B. L., \& Cyranowski, J. M. (1994). Women's sexual self-schema. Journal of Personality and Social Psychology, 67(6), 1079-1100.

Andersen, B. L., Cyranowski, J. M., \& Espindle D. (1999). Men's sexual self-schema. Journal of Personality and Social Psychology, 76(4), 645-671.

Brito-Rhor, M. (2019). The use of the female image in media: A content analysis of magazine thumbnails with presence in social media. Comunicación y Medios, (40), 128 - 138. doi:10.5354/0719-1529.2019.53456

Brito-Rhor, M. D., Rodríguez-Herráez, B., \& ChachaloCarvajal, G. (2019). Does the intensity of sexual stimuli and feminism influence the attitudes of consumers toward sexual appeals and ethical judgment? An ecuadorian perspective. Revista De Comunicación De La SEECI, O(48), 45. doi:10.15198/seeci.2019.48.45-63

Brito-Rhor M.D, Rodríguez-Herráez B. \& Trueba A. (2020). Psychometric Properties and Validation of the Women's Sexual Self-Schema Evaluation in a Young Ecuadorian Sample. Revista Iberoamericana de Diagnóstico y Evaluación - e Avaliação Psicológica, 1(54), 81-91. doi:10.21865/ RIDEP54. 1.07

Bowlby, J. (1969). Attachment and loss v. 3 (Vol. 1). Random House. Furman, W., \& Buhrmester, D. (2009). Methods and measures: The network of relationships inventory: Behavioral systems version. International Journal of Behavioral Development, 33, 470-478.

Carpenter, C., \& Reichert, T. (2004). An Update on Sex in Magazine Advertising: 1983 to 2003. Journalism \& Mass Communication, 81(4), 823-837. doi: 10.1177/1077699 00408100407.

Cheung, M.-C., Chan, A. S., Han, Y. M., Sze, S. L., \& Fan, N. H. (2013). Differential Effects of Chinese Women's Sexual
Self-Schema on Responses to Sex Appeal in Advertising Journal of Promotion Management, 19 (3), 373-391.

Courtney, A. E., \& Whipple, T. W. (1983). Sex Stereotyping in Advertising. Lexington, MA: Lexington Books pp 239.

Cyranowski, J., \& Andersen, B. (2000). Evidence of selfschematic cognitive processing in women with differing sexual self-views. Journal of Social and Clinical Psychology, 19 (4), 519-543.

Dahl, D. W., Frankenberger, K. D., \& Manchanda, R. V. (2003). Does it pay to Shock? Reactions to Shocking and Nonshocking Advertising Content among University Studies. Journal of Advertising Research, 268- 280.

Downs, E., \& Smith, S. L. (2010). Keeping abreast of hypersexuality: A video game character content analysis Sex Roles, 62, 721-733. doi:10.1007/s11199-009-9637-1.

Donato, S., Parise, M., Pagani, A. F., Sciara, S., Lafrate, R., \& Pantaleo, G. (2018). The paradoxical influence of stress on the intensity of romantic feelings towards the partner Interpersona: An International Journal on Personal Relationships, 12(2), 215-231.

Ellen, R. (1988). Fetishism. Man. Royal Anthropological Institute of Great Britain and Ireland New Series, 2(23), 213235.

Engelbart, S. M., Jackson, D. A., \& Smith, S. M. (2017) Examining Asian and European reactions within shock advertising. Asian Journal of Business Research, 7(2), 37-56.

Fullerton, J., \& Kendrick, A. (2001). Comparing Content of Commercials from General Market and Spanish-Language Television. Southwestern Mass Communication, 17(1), 53-62.

Gold, J. A., Ryckman, R. M., \& Mosley, N. R. (1984) Romantic mood induction and attraction to a dissimilar other: Is love blind? Personality and Social Psychology Bulletin, 10(3), 358-368.

Hatfield, E., \& Rapson, R. (1993). Historical and Cross-Cultural Perspectives on passionate love and sexual desire. Annual Review of Sex Research, 4, 67-97.

Holm, N. (2016). Advertising and consumer society: a critical introduction. Macmillan International Higher Education. pp 232.

Holmes, J. (2014). John Bowlby and attachment theory. Routledge. pp 272.

Huang, Ming-Hui. (2014). Romantic love and sex: Their relationship and impacts on ad attitudes. Psychology \& Marketing, 21 (1), 53-73. 
Huang, X., \& Dong, P. (2018). Romantic Crushes Promote Variety-Seeking Behavior. Journal of Consumer Psychology, 29(2), 226-242. doi:10.1002/jcpy. 1070

Hyllegard, K., Yan, R., Ogle, J., \& Attmann, J. (2010). The influence of gender, social cause, charitable support, and message appeal on Gen Y's responses to cause-related marketing. Journal of Marketing Management, 27 (1/2), 100123. doi: 10.1080/02672571003683755

Lee, M. S., Septianto, F., Frethey-Bentham, C., \& Gao, E. (2020). Condoms and bananas: Shock advertising explained through congruence theory. Journal of Retailing and Consumer Services, 57, 102228.

Lin, C. A. (1998). Uses of Sexual Appeals in Prime-Time Television Commercials. Sex Roles, 38, 461-475.

Maison, D., \& Pawłowska, B. (2017). Using the Facereader method to detect emotional reaction to controversial advertising referring to sexuality and homosexuality. In: Nermend K., Łatuszyńska M. (eds) Neuroeconomic and Behavioral Aspects of Decision Making. Springer Proceedings in Business and Economics. Springer, Cham. doi:10.1007/ 978-3-319-62938-4_20

O'Guinn, T., Allen, C., \& Semenik, R. J. (2012). Advertising and Integrated Brand Promotion (6 ed., Vol. nn). (nn, Ed., $\&$ nn, Trans.) EEUU: South-Western Cengage Learning.

Parry, S., Jones, R., Stern, P., \& Robinson, M. (2013). "Shockvertising": An exploratory investigation into attitudinal variations and emotional reactions to shock advertising. Journal of Consumer Behavior, 12, 112- 121.

Reichert, T. (2002). Sex in advertising research: A review of content, effects, and functions of sexual information in consumer advertising. Annual Review of Sex Research 13, 241-273.

Reichert, T., \& Fosu, I. (2005). Women's responses to sex in advertising: Examining the effect of women's sexual selfschema on responses to sexual content in commercials. Journal of Promotion Management, 11(2), 143-153.

Reichert, T., \& Lambiase, J. (2003). How to get "kissably close": Examining how advertisers appeal to consumers' sexual needs and desires. Sexuality \& Culture, 7(3), 120136. doi: 10.1007/s12119-003-1006-6

Reichert, T., \& Lambiase, J. (2006). Sex in Consumer Culture. New York: Routledge.

Reichert, T., \& Lambiase, J. (2012). Sex in Advertising Perspectives on the Erotic Appeal. New York: Routledge.
Reichert, T., \& Ramirez, A. (2000). Defining Sexually Oriented Appeals in Advertising: A Grounded Theory Investigation. Advances in Consumer Research Volume 27, eds. Stephen J. Hoch and Robert J. Meyer, Provo, UT: Association for Consumer Research, 267-273.

Reichert, T., Heckler, S. E., \& Jackson, S. (2001). The Effects of Sexual Social Marketing Appeals on Cognitive Processing and Persuasion. Journal of Advertising 30, 13-27.

Reichert, T., Latour, M. S., \& Kim, J. Y. (2007). Assessing the Influence of Gender and Sexual Self-Schema on Affective Responses to Sexual Content in Advertising. Journal of Current Issues \& Research in Advertising, 29(2), 63-77.

Ruberg, B. (2020). Obscene, pornographic, or otherwise objectionable: Biased definitions of sexual content in video game live streaming. New Media \& Society. Epub ahead of print 11 May 2020. doi: 10.1177/1461444820920759

Simpson, J. A., \& Rholes, W. S. (2012). Adult attachment orientations, stress, and romantic relationships. In Advances in experimental social psychology, 45, 279-328. Academic Press.

Simpson, J. A., Griskevicius, V., \& Rothman, A. J. (2012). Consumer decisions in relationships. Journal of Consumer Psychology, 22(3), 304-314

Skorupa, P. (2014). Shocking contents in social and commercial advertising. Creativity Studies, 7(2), 69-81.

Srivastava, R. K., \& Dorsch, M. J. (2020). Understanding the viability of three types of approach of advertising in emerging markets. Journal of Marketing Communications, 26(8), 799-812.

Urwin, B., \& Venter, M. (2014). Shock advertising: Not so shocking anymore. An investigation among Generation Y. Mediterranean Journal of Social Sciences, 5(21), 203. doi:10.5901/mjss.2014.v5n21p203

Yan, S., \& Chapa, S. (2020). Exploring the use of shock advertising by for-profit and nonprofit organizations in China. Journal of Cultural Marketing Strategy, 5(1), 11-21.

Zhang, Y., Dixon, T., \& Conrad, K. (2010). Female body image as a function of themes in rap music videos: a content analysis. Sex Roles, 62, 787-797.

Zimmerman, A., \& Dahlberg, J. (2008). The Sexual Objectification of Women in Advertising: A Contemporary Cultural Perspective. Journal of Advertising Research. 48(1), 7179. doi:10.2501/S0021849908080094 


\section{Appendix 1 Experimental Conditions}

\section{Movie Thumbnail}

Title: Pearls/Rating: 4.5 stars/2018

Description: College graduate Pearl Courtney begins a relationship with John McClane.

Appeals: Fetishism, sexual, control

\section{Fetishism appeal}

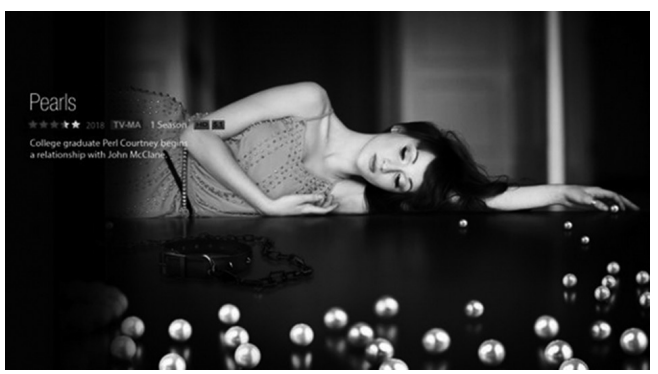

Sexual appeal

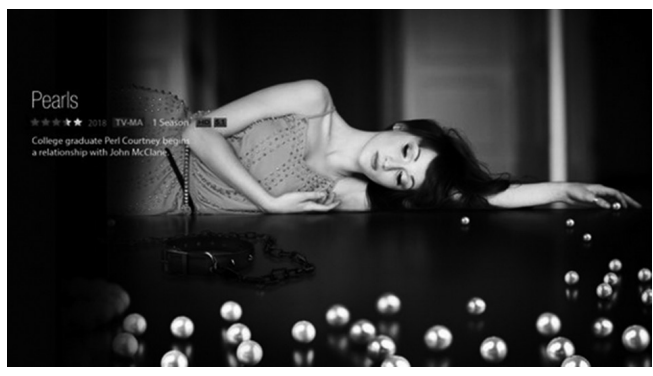

\section{Control condition}

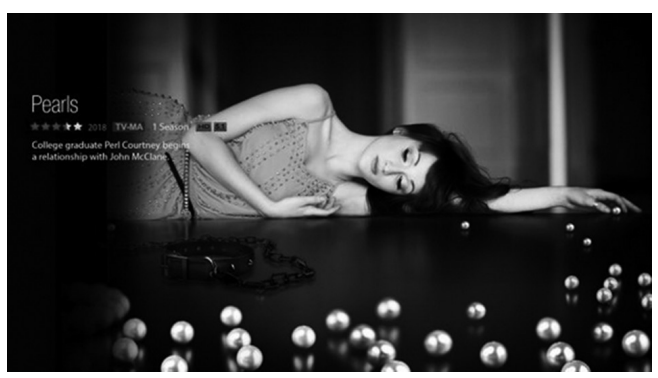




\section{다(1) $(5)$}

\section{El engagement y la sorpresa en la comunicación digital de las marcas}

Estudio del impacto emocional de los GIFs en los usuarios de las redes sociales

\section{Engagement and the Element of Surprise in Digital Communication of Brands A study of the Emotional Impact of GIFs in Social Network Users}

Idoia Rúa Hidalgo

Laboratorio Neuromarketing de la Universidad Internacional de La Rioja. idoia.rua@gmail.com https://orcid.org/0000-0002-0497-8001

Dra. María Galmes-Cerezo

Profesora Dept. Organizacion de Empresas y

Marketing. Universidad Complutense de Madrid mgalmes@ucm.es

https://orcid.org/0000-0002-1520-3703

María del Cisne Espinosa Jarrín Laboratorio Neuromarketing de la Universidad Internacional de La Rioja. maricis.e@gmail.com https://orcid.org/0000-0001-7580-0094
Rúa Hidalgo, I., Galmes-Cerezo, M. y Espinosa Jarrín, M. (2021)

El engagement y la sorpresa en la comunicación digital de las marcas. Estudio del impacto emocional de los GIFs en los usuarios de las redes sociales

Revista Internacional de Investigación en Comunicación aDResearch ESIC. NN 25 Vol 25

Monográfico especial, marzo 2021 · Págs. 26 a 43

https://doi.org/10.7263/adresic-025-02 
RESUMEN

\section{Clasificación JEL: \\ M3}

\section{Palabras clave:}

Comunicación

digital,

GIFs,

Emociones,

Engagement,

Sorpresa,

Marcas,

Neuromarketing,

Asociaciones

implícitas
Objetivo: Se han realizado dos estudios. El objetivo principal del estudio 1 ha sido conocer los efectos emocionales y el engagement que los recursos de comunicación «GIFs» provocan en los usuarios. Como objetivo principal del estudio 2 se ha buscado determinar las actitudes implícitas que tienen los participantes respecto a las marcas muy conocidas.

Diseño metodológico: En el primer estudio se utiliza una combinación de herramientas biométricas de observación automatizada de las expresiones faciales, conductancia de la piel y dirección de la pupila, para observar el estado emocional que los GIFs de marcas renombradas provocan en los participantes, y compararlo con los efectos causados por imágenes estáticas de estas mismas marcas. El segundo estudio emplea el Test de asociación implícita para observar asociaciones inconscientes relacionadas con marcas conocidas.

Resultados: Los resultados del primer estudio muestran que los GIFs consiguen el engagement de los usuarios y provocan un «estado de bienestar-placer» (Modelo Circumplejo de Russel, 1980), pero no el estado entusiasta que se esperaba. Los resultados del segundo estudio indican que los participantes tienen la creencia de que las marcas muy conocidas son marcas de calidad, mientras que no asocian este atributo a las marcas no conocidas. La correlación encontrada entre los resultados de los dos estudios revela que los GIFs, aun provocando emociones positivas y generando engagement, no consiguen un estado entusiasta, cuando las marcas son interiorizadas como marcas de calidad.

Limitaciones e implicaciones: El método de investigación utilizado ha mostrado su utilidad para medir el engagement de los usuarios en la visualización de los GIFs utilizando métricas como el signo y la intensidad de la emoción, y herramientas de neuromarketing. El estudio experimental ha tenido su principal limitación en no poder observar los efectos emocionales que generan los GIFs que permiten interacción del usuario

Originalidad y contribución: Las marcas conocidas, además de utilizar estos recursos visuales innovadores, tienen que usarlos de forma diferente para generar sorpresa y conseguir situar a los clientes potenciales en el «estado emocional entusiasta» del Modelo Circumplejo (Russel,1980).

\section{ABSTRACT}

\section{JEL Classification: \\ M3}

Key words:

Digital communication, GIFs, emotions, engagement, surprise, brands, neuromarketing, implicit associations
Purpose: Two studies were carried out. The main objective of study 1 was to find out the emotional effects and engagement that «GIFs» communication resources provoke in users. The main objective of study 2 was to determine the implicit attitudes that participants have towards well-known brands.

Design / Methodology /Approach: The first study uses a combination of biometric tools of automated observation of facial expressions, skin conductance and pupil direction to observe the emotional state that GIFs of well-known brands elicit in participants, and compare it to the effects caused by static images of the same brands.

The second study uses the Implicit Association Test to observe unconscious associations related to well-known brands.

Results: The results of the first study show that GIFs achieve user engagement and provoke a «feel-good-pleasure state» (Russel's Circumplex Model, 1980), but not the expected enthusiastic state. The results of the second study indicate that participants have the belief that wellknown brands are quality brands, while they do not associate this attribute with non-famous brands. The correlation found between the results of the two studies reveals that GIFs, while provoking positive emotions and generating engagement, do not achieve an enthusiastic state when brands are internalised as quality brands.

Limitations / implications: The research method used has shown its usefulness in measuring user engagement in viewing GIFs using metrics such as the sign and intensity of emotion, and neuromarketing tools. The experimental study had its main limitation in not being able to observe the emotional effects generated by GIFs that allow user interaction.

Originality / contribution: Well-known brands, in addition to using these innovative visual resources, have to use them in a different way to generate surprise and manage to place potential customers in the «enthusiastic emotional state» of the Circumplex Model (Russel,1980). 


\section{Introducción ${ }^{1 \text { y } 2}$}

La comunicación de marketing actual demanda nuevos desafíos ante la presencia de usuarios hiperconectados, sobre-estimulados y saturados de información (Estrella y Segovia, 2016). Por ello seleccionar los recursos comunicacionales a emplear resulta cada vez más necesario (Adami y Jewitt, 2016).

La comunicación digital asume hoy en día una postura protagonista en la comunicación de las marcas (Powers et al., 2012; Scolari, 2012). El entorno digital es cada vez más visual y las empresas, con el propósito de captar la atención de los usuarios, utilizan en las redes sociales recursos visuales creativos y atractivos para comunicar sus marcas, ofertar sus productos y seducir a sus clientes (Zhang y Mao, 2016).
El uso de los GIF puede desencadenar percepciones inconscientes del usuario, a través de las neuronas espejo (Likowski et al., 2012; Cacioppo, Bolmont y Monteleone, 2018). Esta estimulación sensorial ofrece facilidad cognitiva al receptor apelando a su respuesta automática (Kahneman y Tversky, 1979). Los GIFs ayudan a la representación mental en el usuario (Holmes et al., 2008), y al estar en movimiento, representan una acción que está enviando comunicación no verbal y creando significación (Tolins y Samermit, 2016). Son cada vez más utilizados en las estrategias de comunicación digital por su simplicidad, fácil representación y capacidad de provocar empatía con el contenido mostrado (Duffett, 2015; Miltner y Highfield, 2017).

\section{Figura 1. Metodología estudio 1 y estudio 2}

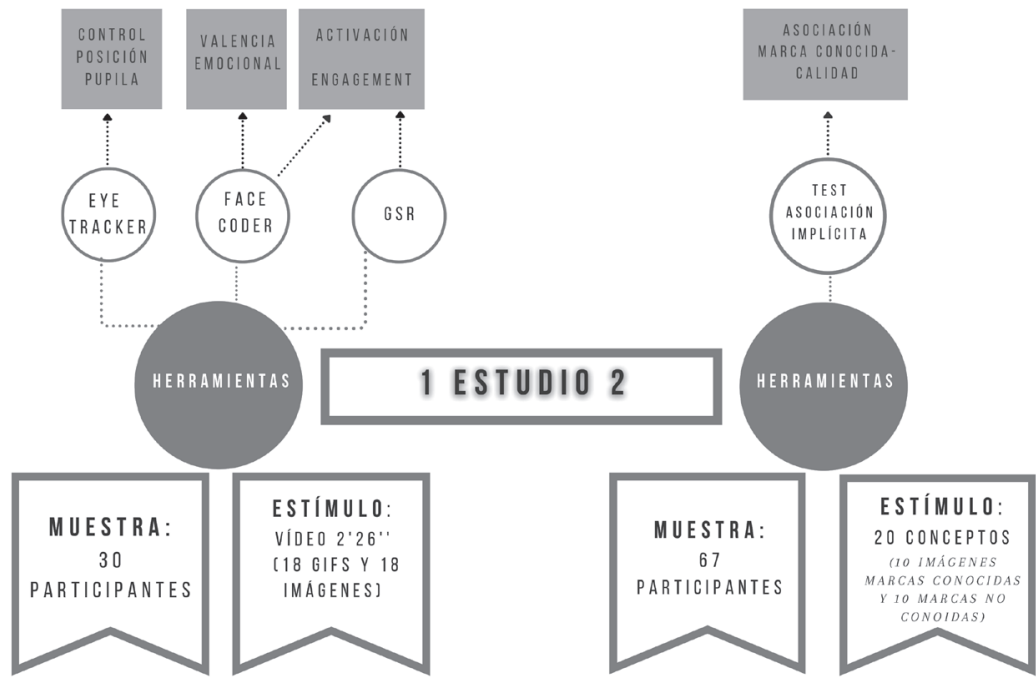

Fuente: Elaboración propia.

1 Graphics Interchange Format (GIF) El GIF es un archivo de imágenes gráficas en un mapa de bits que incorpora animación a las imágenes. Se utiliza fundamentalmente en internet y redes sociales.

2 Agradeciemientos al apoyo prestado por la empresa INTERACTUA+ y por el Laboratorio de neuromarketing de la Universidad Internacional de la Rioja 


\section{Estudio 1}

\subsection{Los GIFs como recursos favorecedores de una experiencia de marca}

Los GIFs, como elementos de comunicación digital, facilitan la comprensión del mensaje a través de la empatía. Ofrecen al receptor una experiencia, a partir de la cual los usuarios construirán sus percepciones sobre las marcas (Novak, Hoffman y Yung, 2000). Las experiencias comienzan siendo algo externo, diseñado por la marca, y una vez vividas se convierten en algo interno para el usuario (Yuang y Wu, 2008; Skandalis, Byrom y Banister, 2019). Las marcas utilizan GIFs para diseñar experiencias con cualidades afectivas (Gürsimsek, 2016) y sensoriales convirtiéndose así, en un excelente proveedor de la experiencia de marca (Brakus, Schmitt y Zarantonello, 2009).

Las experiencias de marca generadas por un GIF, para ser significativas, deben ser memorables, satisfactorias y que conecten con las emociones (Schmitt, 1999; Galmés, 2015; Atwal y Williams, 2017). Fomentar emociones en el usuario incrementa la satisfacción y motiva al usuario a realizar una acción determinada (González-Sánchez y Gil-Iranzo, 2013). Una experiencia de marca tiene como resultado una respuesta emocional de placer o displacer que surge a partir de la activación emocional (FernándezAbascal et al., 2010).

\subsection{Los GIFs proveedores de emociones}

Hay estudios que muestran que los GIFs son un recurso que actúa como detonante emocional en el cerebro del receptor durante su visualización (Jou, Bhattacharya y Chang, 2014; Tianliang et al., 2019). Las imágenes animadas tienen mayor capacidad de engagement en los usuarios que las imágenes estáticas (Chang y Unga, 1993; McKenna et al., 2017). Por ello, las marcas están utilizando los GIFs en sus estrategias de comu- nicación online consiguiendo generar altos niveles de engagement emocional (Cingel y Krcmar, 2014; Calder, Malthouse y Moslowska, 2016; Thurlow, Aiello y Portmann, 2019).

Considerando la relación existente entre la visualización de los GIFs y la respuesta emocional, según el Sistema Internacional de Imágenes Afectivas (IAPS), que estudia la emoción y la atención provocada ante estímulos visuales (Vila, Ramírez, Sánchez y Fernández-Santaella, 2001), la emoción puede sugerir una predisposición a la acción. Esta predisposición resulta de la activación de determinados circuitos cerebrales ante estímulos significativos. Cuando estos circuitos se activan provocan reacciones fisiológicas, conductuales y emocionales que son guiadas por patrones específicos. (Enli, 2017).

Los GIFs podrían actuar como desencadenantes emocionales no permitiendo la adaptación hedónica en el individuo (Ryan y Deci, 2001), sino manteniéndole activo ante su exposición, a través de la sorpresa que se produce de forma rápida mediante sensaciones placenteras espontáneas e inesperadas. (Izard, 1991).

Algunos estudios han demostrado que un mayor engagement y una mayor activación emocional indican una tendencia a la movilización hacia la compra (Brodie et al., 2011; Hollebeek, 2011).

\subsection{Hipótesis del Estudio 1}

A partir de la revisión de la literatura científica, se plantean las siguientes hipótesis:

- $\mathrm{H}_{1}$ Los participantes tendrán emociones positivas (placer) al visualizar los GIFs.

- $\mathrm{H}_{2}$ : Los participantes tendrán emociones más positivas (placer) al visualizar los GIFs que al visualizar las imágenes estáticas.

- H3: Los participantes tendrán emociones positivas e intensas (engagement) al visualizar los GIFs. 
- H4: Los participantes tendrán más emociones positivas de mayor intensidad (engagement) al visualizar los GIFs que al visualizar las imágenes estáticas.

- H5: Los participantes tendrán activación positiva (orientación a la acción) al visualizar los GIFs.

- H6: Los participantes tendrán una mayor activación al visualizar los GIFs que al visualizar las imágenes estáticas.

\subsection{Materiales y Métodos del Estudio 1}

Se ha realizado una investigación experimental con una combinación de tres herramientas de análisis biométrico: Face coder, Eye tracker y Skin conductance. La aplicación de las herramientas Face coder - para la codificación de las emociones registradas - y Eye tracker — para el seguimiento ocular - ha medido la Valencia de las emociones registradas y el nivel de Engagement obtenido. Paralelamente y de forma sincronizada, los participantes fueron monitorizados a través de la herramienta Skin conductance ${ }^{3}$, obteniéndose el nivel de Arousal durante la visualización. Se hace uso de las herramientas biométricas Face Coder y Eye Tracker de la empresa INTERACTÚA +, cedidas por el Laboratorio de Neuromarketing de la Universidad Internacional de la Rioja y la herramienta de Skin Conductance de la marca Esense (Tabla 1).

La selección de los participantes se ha realizado de forma aleatoria, con el único requisito de utilizar habitualmente al menos una red social. El tamaño de la muestra de 30 participantes válidos se considera adecuado para estudios experimentales que utilizan las mismas herramientas biométricas (Ekman, Freisen, y Ancoli, 1980; Vechiato, et al., 2010; Tapia Frade, et al., 2016) y, que como indican Monge-Benito y Fernández-Guerra (2011), ofrecen un margen de error del 1 \%. Para la distribución de la muestra se utilizó el estudio Interactive Advertising Bureau y Elogia (2018), que define los perfiles de usuarios de redes sociales, y su composición es la siguiente: 33 \% para cada rango de edad (16-30; 31-45; 46-55), con un $53 \%$ de mujeres y un $47 \%$ de hombres.

El estímulo utilizado en la investigación experimental fue un vídeo de 2 minutos 26 segundos, formado por la combinación aleatoria de 18 GIFs

\section{Tabla 1. Herramientas del Estudio}

\begin{tabular}{l|l}
\hline Instrumento y antecedentes empíricos & Tipo de registro \\
\hline Eye Tracker (Chang y Chen, 2017; Audrin et al., 2018). & $\begin{array}{l}\text { Seguidor ocular. Registra la mirada del sujeto mientras está } \\
\text { visualizando un estímulo. Registra la posición del ojo y orientación } \\
\text { de la cabeza y proporciona información de lo que el sujeto está } \\
\text { visualizando }\end{array}$ \\
\hline $\begin{array}{l}\text { Face Coder (McDuff, El Kaliouby y Picard, 2012; Bellman, } \\
\text { Wooley y Varan, 2016; Goyal y Singh, 2018; Mundel et al, 2018). }\end{array}$ & $\begin{array}{l}\text { Decodificación del rostro de la persona a través de un software } \\
\text { que analiza la imagen proporcionada por la cámara web. Se } \\
\text { obtienen } 6 \text { posibles emociones (alegría, asco, tristeza, ira, sorpresa } \\
\text { y miedo), las } 6 \text { emociones básicas descritas por Ekman. }\end{array}$ \\
\hline $\begin{array}{l}\text { GSR Galvanic Skin Conductance (Weibel et al, 2019; Walla, } \\
\text { Koller, Brenner y Bosshard, 2017; Guerreiro, Rita y Trigueiros, } \\
\text { 2015; Reimann, Castano, Zaichkowsky y Bechara; 2012). }\end{array}$ & $\begin{array}{l}\text { Medición de la conductancia de la piel a través de electrodos colo- } \\
\text { cados en los dedos de la mano del sujeto. Proporciona información } \\
\text { sobre procesos inconscientes del sujeto ante la exposición a un } \\
\text { estímulo. }\end{array}$ \\
\hline
\end{tabular}

3 Arousal: El constructo arousal (activación) es un término hipotético que describe los procesos que controlan la alerta, la vigilia y la activación (Anderson, 1990). 
y 18 imágenes estáticas de entre 2 y 4 segundos por elemento para evitar un procesamiento consciente. Se han seleccionado 18 GIFs y 18 imágenes estáticas de entre las 100 mejores marcas a nivel mundial según el Ranking anual Best Global Brands 2017 (Interbrand, 2017). Se escogieron los GIFs de estas marcas que mayor número de «me gusta» habían tenido en Instagram (1 marzo. - 10 abril 2019), y la imagen estática correspondiente extraída del GIF. Para evitar sesgos de presentación, se han editado tres vídeos distintos con los elementos ordenados aleatoriamente.

Todos los sujetos fueron expuestos al visionado del estímulo en alguna de las tres versiones. Al mismo tiempo que se registraron las microexpresiones faciales (Ekman,1993), se midió el nivel de conductancia de la piel, obteniéndose de este modo la intensidad de la emoción.

Se han registrado tres variables: Activación emocional, Valencia emocional y Engagement. Todas las variables dependientes ofrecen la medida para cada sujeto y cada GIF e imagen está- tica, y estos datos individuales se añaden a los valores agregados del grupo, obteniendo así un valor cuantitativo de cada variable por cada GIF e imagen estática. La variable Valencia mide el signo de la emoción: positiva o negativa. La variable Activación registra la intensidad de la emoción, que se obtiene midiendo el tipo de emoción registrada (activante o desactivante) y las variaciones del nivel de sudoración de la piel. La variable Engagement indica el estado emocional en el que se encuentra la persona cuando visiona cada GIF e imagen estática y se extrae de la combinación de la Valencia emocional y la Activación (Tabla 2).

\subsection{Resultados y discusión Estudio 1}

La medida de todas las variables analizadas resultó superior para los GIFs que para las imágenes (Valencia: $\mathrm{MGIF}=14.809>\mathrm{MIMG}=14.61$; Activación: MGIF $=-14.46>$ MIMG $=-14.54 ;$ Engagement: $\mathrm{MGIF}=.248>\mathrm{MIMG}=.05$ ). Los resultados se muestran en la tabla 3.

\section{Tabla 2. Variables, Dimensiones e Instrumentos}

\begin{tabular}{|l|l|l|}
\hline Variable & Dimensión & Herramienta \\
\hline Activación & Intensidad de la emoción & Face coder+GSR \\
\hline Valencia Emocional & Signo de la emoción & Face coder \\
\hline Engagement (Valencia + Activación) & Estado emocional & Facecoder+GSR \\
\hline
\end{tabular}

Tabla 3. Resultados de las variables dependientes

\begin{tabular}{|c|c|c|c|c|c|}
\hline & $\begin{array}{l}\text { Tipo } \\
\text { Recurso }\end{array}$ & $\mathbf{N}$ & Media & Desviación tip. & Error promedio \\
\hline \multirow{2}{*}{ Valence } & Imagen & 30 & 14,611667 & 3,4733646 & 8186799 \\
\hline & GIF & 30 & 14,809444 & 3,5661917 & ,8405594 \\
\hline \multirow{2}{*}{ Activation } & Imagen & 30 & $-14,544444$ & 2,0190861 &, 4759031 \\
\hline & GIF & 30 & $-14,463333$ & 2,3245265 &, 5478962 \\
\hline \multirow{2}{*}{ Engagement } & Imagen & 30 &, 050000 & 3,1002030 & ,7307249 \\
\hline & GIF & 30 & ,248333 & 3,0898910 & ,7282943 \\
\hline
\end{tabular}


Todas las variables (Valencia, Activación y Engagement) se aproximan a la normalidad tanto en el caso de las imágenes como para los recursos GIFs según la prueba de normalidad ShapiroWilk (Valencia: p>.05 PImagen=.651 y $\mathrm{P}_{\text {Gif }}=.779$; Activación: $\mathrm{p}>.05 \mathrm{P}_{\text {Imagen }}=.165$ y $\mathrm{P}_{\mathrm{Gil}}=.346$; Engagement: $\mathrm{p}>.05 \mathrm{P}_{\text {Imagen }}=.299$ y $\mathrm{P}_{\mathrm{Gi}_{\mathrm{f}}}=.772$ ), presentando sus varianzas en todos los casos homogeneidad, atendiendo a los resultados obtenidos en la prueba de Levene de igualdad de varianzas

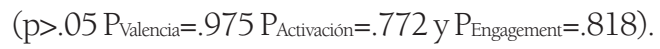

Dado que se cumple el criterio de normalidad y homocedastidad para todas las distribuciones de las variables cuantitativas, se utiliza la prueba t de Student para muestras independientes a fin de comparar las medias. La prueba T para igualdad de medias indica que no hay asociación entre la Valencia, la Activación o el Engagement y el tipo de recurso imagen estática o GIF. En todos los casos se aceptó la hipótesis nula de no diferencia significativa entre las medias de las variables continuas cuando se trata de imágenes o de GIFs (p>.05 PValencia=.867 PActivación=.912 y $\mathrm{P}_{\text {Engagement=.849). }}$ En las tres variables dependientes la media es mayor para los GIFs que para las imágenes estáticas, aunque no significativamente superior.

Para las variables Valencia y Engagement las medias presentan un valor positivo. Sin embargo, la Activación presenta una media de signo negativo.

Atendiendo a los resultados obtenidos el contraste de las hipótesis sería el siguiente:

- $\mathrm{H}_{1}$ : La media de la variable Valencia ante los GIFs ha resultado positiva, por lo que se confirma la hipótesis de que los participantes tienen emociones positivas al visualizar los GIFs.

- $\mathrm{H}_{2}$ : La media de la variable Valencia ante los GIFs ha sido superior a la de las imágenes estáticas, pero teniendo en cuenta que la di- ferencia no ha sido estadísticamente significativa, no es posible confirmar la hipótesis de que los participantes tienen emociones más positivas al visualizar los GIFs que al visualizar las imágenes estáticas.

- $\mathrm{H}_{3}$ : La media de la variable Engagement ante los GIFs ha resultado positiva, por lo que se confirma la hipótesis de que los participantes han tenido emociones positivas e intensas al visualizar los GIFs.

- $\mathrm{H}_{4}$ : La media de la variable Engagement ante los GIFs ha sido superior a la de las imágenes estáticas, pero teniendo en cuenta que la diferencia no ha sido estadísticamente significativa, no es posible confirmar la hipótesis de que los participantes han tenido más emociones positivas y de mayor intensidad al visualizar los GIFs que al visualizar las imágenes estáticas.

- $\mathrm{H}_{5}$ : La media de la variable Activación ante los GIFs es de signo negativo. Por tanto, se refuta la hipótesis de que los participantes estarán activados hacia la compra al visualizar los GIFs.

- H6: La media de la variable Activación ha resultado superior para los GIFs que para las imágenes estáticas, pero al no ser la diferencia estadísticamente significativa no se puede confirmar la hipótesis de que los participantes están más activados al visualizar los GIFs que al visualizar las imágenes estáticas.

La correlación inversa encontrada entre la variable Valencia y la variable Activación nos ha llevado a preguntarnos cuál podría ser la causa de que los GIFs estén generando en los consumidores sensación de bienestar (Valencia positiva), y al mismo tiempo estén provocando una Activación negativa. Se plantea un segundo estudio con el objetivo de explicarlo. 


\section{Estudio 2}

\subsection{Marcas conocidas, calidad percibida y emociones hedónicas}

El concepto de Valor de marca (brand equity) hace referencia al valor que los consumidores atribuyen a una marca. Aaker fue pionero en identificar unas dimensiones para calcular el valor de las marcas: el conocimiento de la marca, las asociaciones a la marca, la calidad percibida y la fidelidad (Aaker, 1991).

La calidad percibida es la evaluación subjetiva de la excelencia de una marca por parte de los consumidores. Para realizar esta evaluación, las personas utilizan indicios externos y asociaciones internas (Aaker, 1996; Klaus y Maklan, 2007). Los consumidores no pueden hacer juicios completos y absolutamente objetivos sobre la calidad objetiva de una marca y utilizan asociaciones para inferir calidad a una marca o producto (Ophuis y Van Trijp, 1995).

Aaker (1991) mostró la existencia de relación directa entre una marca bien conocida y la calidad percibida y estudios posteriores, que investigan el Valor de marca, han confirmado que los consumidores tienden a asociar calidad a las marcas que conocen (Yoo y Donthu, 2001; Pawle y Cooper, 2006). Un mayor conocimiento de la marca y unas asociaciones de marca más fuertes conducen a una mayor calidad percibida (Lavidge y Steiner, 1961; Ding y Tseng, 2015).

La emoción hedónica ha sido descrita como un estado mental que surge a partir de evaluaciones de eventos o pensamientos. Puede desencadenar acciones específicas para reafirmar o contrarrestar la emoción (Bagozzi et al., 1999). Los consumidores tienden a sentir emociones hedónicas positivas en el proceso de compra y de consumo (Hirschman y Holbrook, 1982; Havlena y Holbrook, 1986). Las estrategias de marketing experiencial tratan de provocar emociones hedó- nicas en los compradores, en los momentos en que se produce un contacto con la marca ya sea durante la compra, el consumo o en el proceso de comunicación (Galmés, 2012; Schmitt, Brakus, y Zarantonello, 2015). Cuando el consumidor siente que la marca puede ayudarle a alcanzar sus objetivos, se genera un estado placentero. Es así como una experiencia de la marca puede servir como un evento subjetivo que provoca una valoración positiva de la marca por parte de los consumidores. (Zeithaml, 1988; Ding y Tseng, 2015)

\subsection{Las emociones positivas son necesarias pero no suficientes para movilizar al usuario hacia la compra}

Lo que buscan las marcas es posicionarse en la mente y en el corazón de sus clientes y la involucración de los sentidos es fundamental para influir en su estado emocional (Prescott, 2017). La principal experiencia de valor es la emoción (Smith y Bolton, 2002). Cuando existe una respuesta emocional se detectan dimensiones como la Valencia y la Intensidad o Arousal (Lang, 1995). Para que las emociones deriven en una movilización hacia la compra, es necesario que estas no solamente sean de Valencia positiva, sino que además exista una Activación de signo positivo. Todo ello de acuerdo al Modelo Circumplejo de las emociones (Russell, 1980) que explica como la combinación de los valores Activación y Valencia nos permite diferenciar los distintos estados emocionales en los que se encontraría el usuario como consecuencia del estímulo presentado (Plutchik y Conte, 1997; Jaeger et al., 2018). (Véase figura 2 en pág. 34).

Las emociones positivas son más habituales que las negativas en los usuarios de redes sociales (He et al., 2016), y las experiencias emocionales del mundo real pueden transferirse al entorno 


\section{Figura 2 Estados emocionales según el Modelo Circumplejo. Russell (1980)}

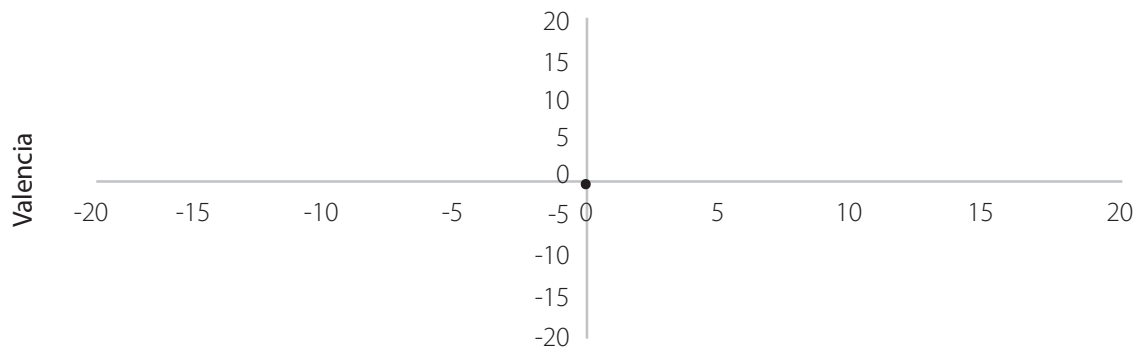

Activación

Fuente: Elaboración propia.

virtual (Kafetsios et al., 2017). Las emociones influyen en las decisiones del individuo a nivel personal o en su rol de consumidor (Burnett y Lunsford, 1994). Por ello, las marcas buscan puntos de contacto, como el GIF, para emocionar a sus clientes mediante las experiencias diseñadas provocando altos niveles de engagement que les movilice hacia la compra.

El valor que el consumidor atribuye a la marca conocida ${ }^{4}$, le lleva a anticipar el uso de recursos innovadores en sus estrategias de comunicación. Sin embargo, las marcas no conocidas por el usuario tienen una mayor probabilidad de provocar, a través de estímulos novedosos, una reacción de tipo afectiva inconsciente (Öhman, 1987; Godey et al., 2016). Es muy posible que las marcas conocidas estén en desventaja a la hora de provocar sorpresa en los usuarios.

\subsection{Hipótesis y preguntas de investigación} La revisión de la literatura académica ha servido para contextualizar una nueva hipótesis, y los

4 El concepto «marca conocida», en este artículo hace referencia a la idea de marca famosa o marca renombrada. resultados del estudio 1 han desencadenado una nueva pregunta de investigación:

- $\mathrm{H}_{7}$ : Los consumidores asocian de forma inconsciente las marcas conocidas con alta calidad y asocian las marcas no conocidas con menor calidad.

- RQ1: ¿Es posible explicar el estado emocional de los usuarios ante los GIFs de marcas conocidas, a partir de las correlaciones entre los resultados de las variables del Estudio 1 y la Variable $\mathrm{D}_{\text {(IAT) }}$

\subsection{Materiales y métodos del Estudio 2}

Se lleva a cabo un experimento con el Test de Asociación Implícita (IAT) con el fin de descubrir posibles asociaciones no conscientes en los sujetos entrevistados. Esta prueba, diseñada por los investigadores Greenwald y Banaji (1995), diagnostica las preferencias actitudinales que una persona tiene pero de las que no es plenamente consciente (Blanton y Jaccard 2006). Permite obtener una evaluación de la fuerza de las asociaciones automáticas. El IAT ha sido utilizado y testada su validez en otros estudios relacionados con la percepción implícita de las marcas (Chang, 
Ko y Carlson, 2018; Sharma, 2018; Vriens, Chen y Schomaker, 2019). Las asociaciones implícitas tienen su origen en la evaluación automática o inconsciente del cerebro. Se miden a través de la latencia o tiempo de respuesta ante la presentación de un estímulo. La prueba consiste en discriminar entre estímulos visuales y palabras con valencias positivas y negativas lo más rápidamente posible, detectando así la asociación entre conceptos basándose en el tiempo de reacción.

Los sujetos son los mismos participantes del estudio 1 y se han añadido 37 sujetos nuevos con el fin de obtener el tamaño muestral validado en otras investigaciones con IAT (Maison, Greenwald y Bruin, 2004; Gibson, 2008). La distribución según género y rango de edad es similar a la del estudio 1.

El estímulo ha consistido en 20 conceptos, compuestos por diez imágenes de marcas conocidas y diez de marcas blancas. Para la selección de las marcas conocidas se ha acudido al estudio Brand Footprint Report 2018 (Kantar Worldpanel, 2018) que elabora un ranking con las marcas mas populares. Del que se extrajeron las 10 mar- cas más elegidas en España. En concreto, se han utilizado las dos primeras marcas más populares de cada uno de los siguientes sectores «Alimentación», «Bebidas», «lácteos», «Droguería»e «Higiene y cuidado personal» (Figura3).

Estas marcas se asocian con 20 atributos: diez palabras relacionadas con el concepto «calidad» y diez con el concepto «ausencia de calidad». Se diseñan un total de veinte presentaciones combinadas por usuario y etapa, de acuerdo con la metodología descrita por Greenwald (Greenwald et al., 2003). Durante la prueba todos los sujetos cumplimentaron el test compuesto de las 5 etapas en las que se combinaron conceptos a través de imágenes y atributos mediante palabras. Todos los participantes fueron informados de que debían responder de forma rápida, pero sin cometer excesivos errores.

Se ha medido el tiempo de respuesta de cada participante calculando el lapso entre la presentación del estímulo y la elección de la respuesta. Esta medida ha servido para calcular «el efecto IAT» o D(IAT) para cada sujeto. La D (IAT) es el algoritmo que mide la latencia de respuesta y se

\section{Figura 3. Marcas conocidas incluidas en la investigación. Kantar Worldpanel, 2018}

\section{Top5 marcas por sectores}
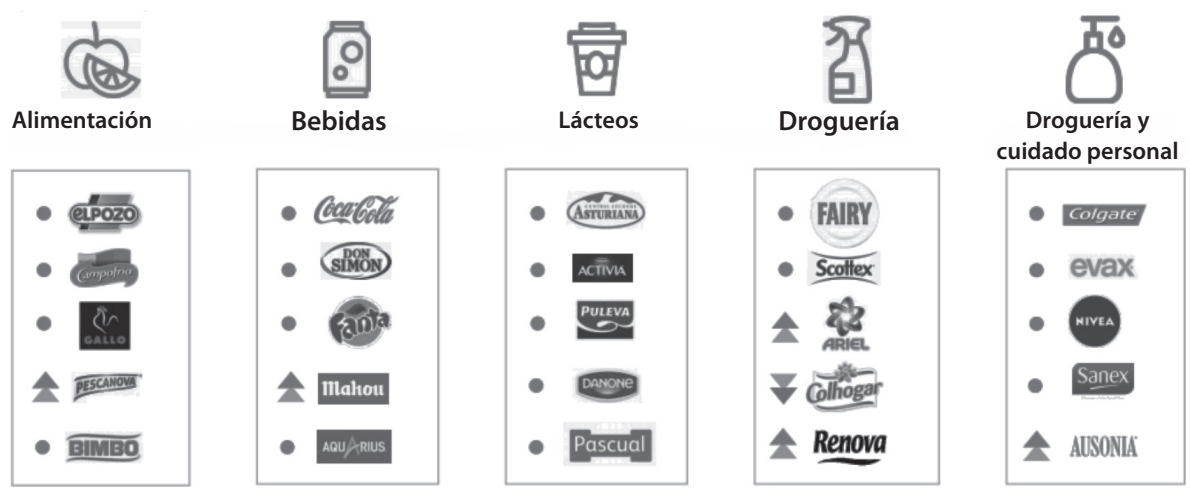
calcula como la diferencia entre el promedio de las velocidades de reacción (milisegundos) de los sujetos en cada bloque, dividido entre la desviación estándar de las latencias para cada bloque.

\subsection{Resultados y discusión Estudio 2}

El resultado obtenido en el Test de Asociación Implícita ( $\mathrm{D}_{(\mathrm{IAT})=.59)}$ indica una asociación moderada alta entre marca conocida y «calidad».

Para comprobar si existe una relación entre la variable DIAT y la emoción Sorpresa se ha aplicado el índice de correlación de Pearson. El resultado ha registrado una correlación significativa en el nivel .05 de signo negativo (-.437) que indica una relación inversa entre ambas variables. Por tanto, una mayor asociación im- plícita entre marca reconocida y calidad generaría una menor emoción de sorpresa en el consumidor (Tabla 4).

Por otra parte, al observar en el Estudio 1 que todos los GIFs analizados presentaban valores negativos para la variable Activación, se decide seguir buscando relaciones entre las variables emocionales que puedan explicar estos resultados. El coeficiente de correlación de Pearson para analizar si existe correlación entre la variable Activación y la Sorpresa, mostró una correlación elevada y significativa en el nivel .01 de signo positivo ( $\mathrm{r}=.601)$ entre ambas variables. Este resultado indica que cuanta mayor sorpresa genera un recurso en el usuario, mayor activación provoca en él (Tabla 5).

\section{Tabla 4. Correlación entre la variable $D_{I A T}$ (índice asociación implícita) y la emoción sorpresa}

\section{Correlaciones}

\begin{tabular}{|c|c|c|c|}
\hline & & Activación & Sorpresa \\
\hline \multirow{3}{*}{ IAT } & Correlación de Pearson & 1 &,$- 437^{*}$ \\
\hline & Sig. (bilateral) & &, 033 \\
\hline & $\mathrm{N}$ & $+^{*}$ & 30 \\
\hline \multirow{3}{*}{ Sorpresa } & Correlación de Pearson &,$- 437^{*}$ & 1 \\
\hline & Sig. (bilateral) & ,033 & \\
\hline & $\mathrm{N}$ & 30 & 30 \\
\hline
\end{tabular}

**. La correlación es significativa en el nivel 0,05 (bilateral).

\section{Tabla 5. Correlación entre la variable activación y la emoción sorpresa}

\section{Correlaciones}

\begin{tabular}{|c|c|c|c|}
\hline & & Activación & Sorpresa \\
\hline \multirow{3}{*}{ Activación } & Correlación de Pearson & 1 &, $601^{* *}$ \\
\hline & Sig. (bilateral) & &, 002 \\
\hline & N & $+^{*}$ & 30 \\
\hline \multirow{3}{*}{ Sorpresa } & Correlación de Pearson &, $601^{* *}$ & 1 \\
\hline & Sig. (bilateral) &, 002 & \\
\hline & N & 30 & 30 \\
\hline
\end{tabular}

**. La correlación es significativa en el nivel 0,01 (bilateral) 
Por tanto, la $\mathrm{H}_{7}$ se ha confirmado con el resultado del Test de Asociación implícita que muestra una asociación moderada-alta. Esto indica que los consumidores tienen una creencia inconsciente de que las marcas que conocen bien son marcas de calidad.

Respecto a la pregunta de investigación $\left(\mathrm{RQ}_{1}\right)$ en la que nos planteábamos la posibilidad de explicar el estado emocional de los usuarios ante los GIFs de marcas conocidas, efectivamente se puede responder a través de la correlación entre la variable Activación y la variable Sorpresa; y a partir de la correlación entre la variable Sorpresa y la variable DIAT,

- La existencia de una correlación positiva entre la variable Activación y la emoción Sorpresa explica que las marcas, para conseguir activar a los consumidores, tienen que sorprenderles. Los GIFs analizados, a pesar de ser un recurso diferente, no logran generar sorpresa y por ello, el estado emocional conseguido es de bienestar-placer (cuarto cuadrante del modelo circumplejo) y no el estado entusiasta que se esperaba.
- La correlación inversa entre la variable Sorpresa y la variable DIAT indica, que ante una marca conocida el consumidor se siente tranquilo y confiado, pues asocia la misma con la idea de calidad. Por tanto, esta asociación provoca estados de ánimo positivos (placer) debido a la seguridad que aporta una marca conocida, pero no está provocando sorpresa.

\section{Conclusiones}

Todos los GIFs ofrecieron puntuaciones positivas en la Valencia y valores negativos en la variable Activación (Estudio 1), situándose en el cuarto cuadrante del modelo circumplejo. En este cuadrante el consumidor se halla en un estado de calma y relajación, ya que el neocortex disminuye su nivel de activación para ahorrar energía, al tiempo que el área cerebral correspondiente a las emociones cobra mayor importancia (Michael, Ramsoy, Stephens y Kotsi, 2019; Modica, et al., 2018).

Por otra parte, la visualización de los GIFs ofreció valores negativos para la variable Sorpresa, y el Estudio 2 mostró que los participantes asociaron de forma inconsciente marca conocida a calidad. Esto nos ha llevado a concluir que el

\section{Figura 4. Posicionamiento GIFs estudiados conforme Modelo Circumplejo. Russell (1980)}

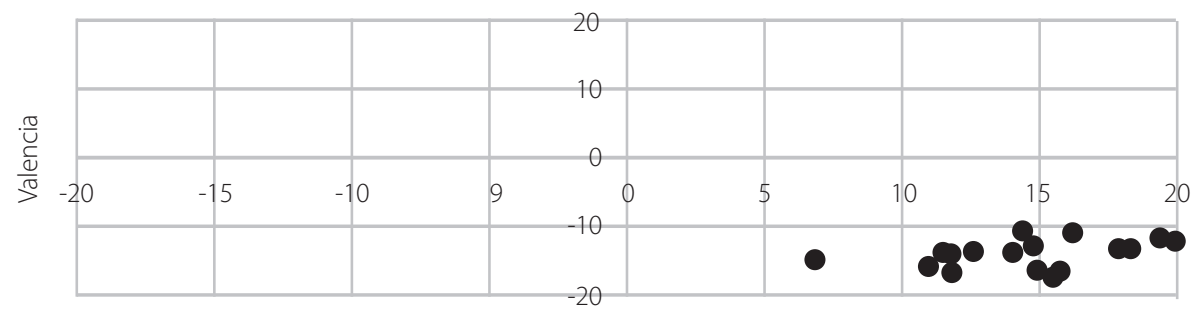


uso de GIFs en las estrategias de comunicación, al tratarse de una marca conocida por el usuario, no asegura situar al consumidor en un estado emocional entusiasta que le impulse hacia la compra. Aunque sí se esté generando un estado de placer y tranquilidad que se ha relacionado con la percepción implícita de calidad. Por tanto, los GIFs de marcas conocidas no están consiguiendo provocar sorpresa en los usuarios de las redes sociales, a pesar de considerar al GIF como un recurso innovador en sí mismo.

Se concluye que las marcas conocidas, para conseguir una respuesta emocional entusiasta, necesitan no solo usar recursos visuales innovadores, sino utilizarlos de forma sorprendente para situar a los usuarios en un estado emocional entusiasta (primer cuadrante del modelo Circumplejo de Russell, 1980). Este hecho se podría considerar como una paradoja de la fama.

Se ha mostrado que conseguir engagement de los usuarios no es suficiente para obtener éxito en las estrategias de comunicación digital de las marcas conocidas. Hay que dar un paso más e implicar activamente al consumidor sorprendiéndole con el diseño de los recursos utilizados. En el caso de los GIFs, el diseño de la interacción de la visualización (McKenna et al., 2017) podría ser una de las propuestas para conseguir GIFs que sorprendan al usuario.

\section{Limitaciones e implicaciones}

El método de investigación utilizado ha mostrado su utilidad para medir el engagement de los usuarios en la visualización de los GIFs; utilizando métricas como el signo y la intensidad de la emoción, y herramientas de neuromarketing.

Desde el principio se decidió limitar el estudio 1 a marcas consideradas como de gran valor (Interbrand,2017) para tener un objeto de estudio concreto que permitiera resultados significativos.
Sin embargo, el hecho de no haber podido comparar los efectos emocionales de GIFs de estas marcas tan populares con GIFs de marcas menos conocidas ha supuesto una limitación para las conclusiones del estudio. Por ello, consideramos que sería muy interesante poder realizar una nueva investigación con el mismo diseño metodológico, para observar el impacto emocional de GIFs de marcas menos populares.

Otra de las limitaciones del estudio ha sido el tener que grabar en un video los GIFs para poder realizar el diseño experimental. Esto ha supuesto una limitación a la interacción de los usuarios con los GIFs. A partir de la conclusión de que las marcas conocidas tienen que utilizar los recursos visuales digitales de forma sorprendente para activar a los consumidores, proponemos una investigación que compare los efectos emocionales generados por GIFs con diferentes diseños de interacción (Boy, Detienne, y Fekete, 2015). De llevarse a cabo esta investigación, se podría observar si alguno de los modelos de interacción provoca sorpresa; y cuál de estos diseños de la experiencia interactiva (MacKanna et al., 2017) conseguiría generar un mayor engagement, activando emociones de signo positivo mas intensas.

El estudio ha permitido mostrar que la utilización de formas nuevas de comunicación no siempre genera sorpresa en los usuarios. Es decir, las marcas renombradas no deben dar por sentado que, utilizando herramientas innovadoras en sus estrategias de comunicación, van a llamar la atención y motivar al usuario hacia la compra. Consideramos que esta implicación del estudio puede ser muy relevante para el diseño de GIFs. Por ello, nos proponemos realizar una nueva investigación que compare los efectos emocionales que ha provocado cada GIF, y determinar qué elementos comunes de diseño comparten los GIFs de mayor impacto emocional. 


\section{Bibliografía}

Aaker, David (1991). Managing brand equity. Capitalizing on the Value of a Brand Name. The Free Pres. New York.

Aaker, D. (1996). Measuring brand equity across products and markets. California management review, 38(3), 102-120 Adami, E. y Jewitt, C. (2016). Special issue: Social media and the visual. Visual Communication, 15(3), 263-270

Anderson, K. J. (1990). Arousal and the inverted-u hypothesis: A critique of Neiss's "Reconceptualizing arousal".

Atwal, G. y Williams, A. (2017). Luxury brand marketingthe experience is everything! In Advances in luxury brand management. Brand Management Vol. 16, 5/6, 338-346

Audrin, C., Brosch, T., Sander, D. y Chanal, J. (2018). More than meets the eye: the impact of materialism on information selection during luxury choices. Frontiers in behavioral neuroscience, 12,172

Bagozzi, R.; Gopinath, M. y Nyer, P. (1999). The role of emotions in marketing. Journal of the academy of marketing science, 27(2), 184-206.

Bellman, S., Wooley, B., y Varan, D. (2016). Program-ad matching and television ad effectiveness: A reinquiry using facial tracking software. Journal of Advertising, 45(1), 72-77.

Blanton, H., Jaccard, J., Gonzales, P. y Christie, Ch. (2006). Decoding the implicit association test: Implications for criterion prediction. Journal of Experimental Social Psychology, 42(2), 192-212.

Boy, J., Detienne, F. y Fekete, J.D. (2015). Storytelling in information visualizations: Does it engage users to explore data? In Proceedings of the 33rd Annual ACM Conference on Human Factors in Computing Systems. pp. 1449-1458.

Brakus, J., Schmitt, B., y Zarantonello, L. (2009). Brand experience: what is it? How is it measured? Does it affect loyalty? Journal of Marketing, 73: 52-68.

Brodie, R. J., Hollebeek, L. D., Jurić, B., y Ilić, A. (2011). Customer engagement: Conceptual domain,

fundamental propositions, and implications for research. Journal of service research, 14(3),

252-271

Burnett, M. S. y Lunsford, D. A. (1994) Conceptualizing guilt in the consumer decision-making process.Journal of Consumer Marketing, 11(3), 33-43
Cacioppo, S., Bolmont, M. y Monteleone, G. (2018). Spatio-temporal dynamics of the mirror neuronsystem during social intentions. Social neuroscience, 13(6), 718-738.

Calder, B. J., Malthouse, E. C. y Maslowska, E. (2016) Brand marketing, big data and social innovation as future research directions for engagement. Journal of Marketing Management, 32(5-6), 579-585

Chang, C. T., y Chen, P. C. (2017). Cause-related marketing ads in the eye tracker: it depends on how you present, who sees the ad, and what you promote. International Journal of Advertising, 36(2), 336-355.

Chang, Y., Ko, Y. J. y Carlson, B. D. (2018). Implicit and explicit affective evaluations of athlete brands: The associative evaluation-emotional appraisal-intention model of athlete endorsements. Journal of Sport Management, 32(6), 497 510 .

Chang, B. W., y Ungar, D. (1993, December). Animation from cartoons to the user interface. In Proceedings of the 6th annual ACM symposium on User interface software and technology (pp. 45-55)

Cingel, D. P. y Krcmar, M. (2014). Understanding the experience of Imaginary Audience in a social media environment. Journal of Media Psychology.

Ding, C. y Tseng, T. (2015). On the relationships among brand experience, hedonic emotions, and brand equity, European Journal of Marketing, Vol. 49 No. 7/8, pp. 994 1015.

Duffett, R. (2015). Facebook advertising's influence on intention-to-purchase and purchase amongst Millennials. Internet Research, 25(4), 498-526

Enli, G. (2017). Twitter as arena for the authentic outsider Exploring the social media campaigns of Trump and Clinton in the 2016 US presidential election. European journal of communication, 32(1), 50-61.

Ekman, P. (1993). Facial expression and emotion. American psychologist, 48(4), 384-392

Ekman, P., Freisen, W. V., y Ancoli, S. (1980). Facial signs of emotional experience. Journal of Personality and Social Psychology, 39(6), 1125-1134

Estrella, A., y Segovia, C. (2016). Comunicación Integrada de Marketing. Madrid: ESIC.

Fernández-Abascal, E., García, B., Jiménez, M.P., Martín, M.D., y Domínguez, F. (2010). Psicología de la Emoción. Madrid: Centro de estudios Ramón Areces, S.A 
Galmés, M. y Victoria, J (2012). La organización de eventos en el contexto de las Comunicaciones Integradas de Marketing (IMC): el valor de la experiencia. Pensar la Publicidad, 2012, vol. $6, n^{\circ} 1,15-34$.

Galmés, M. (2015) Comunicación y marketing experiencial: aproximación al estado de la cuestión. Opción,31(1),974-999. From https://www.redalyc.org/pdf/310/31043005054.pdf González-Sánchez, J.L., y Gil-Iranzo, R. M. (2013). Factores hedónicos y multiculturales que mejoran las experiencias de usuario en el diseño de productos. El profesional de la información, 22(1).

Gibson, B. (2008). Can evaluative conditioning change attitudes toward mature brands? new evidence from the implicit association test. Journal of Consumer Research, 35(1), 178-188. Godey, B., Manthiou, A., Pederzoli, D., Rokka, J., Aiello, G., Donvito, R., y Singh, R. (2016). Social mediamarketing efforts of luxury brands: Influence on brand equity and consumer behavior. Journal of business research, 69(12), 5833-5841.

Goyal, G. y Singh, J. (2018, April). Minimum Annotation identification of facial affects for Video Advertisement. In 2018 International Conference on Intelligent Circuits and Systems (ICICS) (pp. 300-305). IEEE.

Greenwald, A. y Banaji, M. (1995). Implicit social cognition: attitudes, self-esteem, and stereotypes. Psychological review, 102(1), 4-27

Greenwald, A. G., Nosek, B. A., y Banaji, M. R. (2003). Understanding and using the implicit associationtest: I. An improved scoring algorithm. Journal of personality and social psychology, 85(2), 197.

Guerreiro, J., Rita, P. y Trigueiros, D. (2015). Attention, emotions and cause-related marketing effectiveness. European Journal of Marketing, 49(11-12), 1728-1750.

Gürsimsek, Ö. (2016). Animated GIFs as vernacular graphic design: producing Tumblr blogs. Visual Communication, 15(3), 329-349.

Havlena, W. y Holbrook, M. B. (1986). The varieties of consumption experience: comparing two typologies of emotion in consumer behavior. Journal of consumer research, 13(3), 394-404.

He, S., Zheng, X., Zeng, D., Luo, C. y Zhang, Z. (2016). Exploring entrainment patterns of human emotion in social media. Plos one, 11(3).
Hirschman, E. y Holbrook, M. B. (1982). Hedonic consumption: emerging concepts, methods and propositions. Journal of marketing, 46(3), 92-101.

Hollebeek, L (2011) Exploring customer brand engagement: definition and themes, Journal of Strategic Marketing, 19:7, 555-573.

Holmes, Emily, M., Andrew, M., Bundy y Dalgleish, T. (2008). The causal effect of mental imagery on emotion assessed using picture-word cues. Emotion, 8(3), 395.

Interactive Advertising Bureau y Elogia (2018): Estudio anual de redes sociales 2018. IAB Spain. Versión reducida. Disponible en https://iabspain.es/estudio/estudio-anual-de-redes-sociales-2018/

Interbrand (2017): Interbrand releases 2017 Best Global Brands report. September 24, 2017 Disponible en https:// www.interbrand.com/newsroom/bgb-report-2017/

Izard, C. E. (1991). The Psychology of Emotions. Nueva York: Plenum Press.

Jaeger, S. R., Spinelli, S., Ares, G. y Monteleone, E. (2018). Linking product-elicited emotional associations and sensory perceptions through a circumplex model based on valence and arousal: Five consumer studies. Food research international, 109, 626-640.

Jou, B., Bhattacharya, S. y Chang, S. (2014, November). Predicting viewer perceived emotions in animated GIFs. In Proceedings of the 22nd ACM international conference on Multimedia. pp. 213-216.

Kafetsios, K., Chatzakou, D., Tsigilis, N. y Vakali, A. (2017). Experience of emotion in face to face and computer-mediated social interactions: An event sampling study. Computers in Human Behavior, 76, 287-293.

Kahneman, D. y Tversky, A. (1979). Prospect theory: An analysis of decision under risk. En Handbook of the fundamentals of financial decision making: Part I. 2013. p. 99-127.

Kantar Worldpanel (2018). Brand Footprint. A Global ranking of the most chosen consumer brands (6). Disponible en www.kantarworldpanel.com/brandfootprint

Klaus, P. y Maklan, S. (2007). The role of brands in a service-dominated world. Journal of Brand Management, 15(2), 115-122.

Lang, P. J. (1995). The Emotion Probe: Studies of Motivation and Attention. American Psychologist. 50, 372-385. 
Lavidge, R. y Steiner, G. (1961). A model for predictive measurements of advertising effectiveness. Journal of marketing, 25(6), 59-62

Likowski, K. U., Mühlberger, A., Gerdes, A., Wieser, M. J., Pauli, P. y Weyers, P. (2012). Facial mimicry and the mirror neuron system: simultaneous acquisition of facial electromyography and functional magnetic resonance imaging. Frontiers in human neuroscience, 6, 214-

Maison, D., Greenwald, A. G. y Bruin, R. H. (2004). Predictive validity of the implicit association test in studies of brands, consumer attitudes, and behavior. Journal of Consumer Psychology, 14(4), 405-415

McDuff, D., El Kaliouby, R. y Picard, R. W. (2012). Crowdsourcing facial responses to online videos. IEEE Transactions on Affective Computing, 3(4), 456-468.

McKenna, S.; Henry Riche, N.; Lee, B.; Boy, J.; Meyer, M. (2017). "Visual narrative flow: Exploring factors shaping data visualization story reading experiences". Eurographics conference on visualization (EuroVis), v. 36, n. 3, pp. 377 387.

Michael, I., Ramsoy, T., Stephens, M., y Kotsi, F. (2019). A study of unconscious emotional and cognitive responses to tourism images using a neuroscience method. Journal of Islamic Marketing, 10(2), 543-564.

Miltner, K. M. y Highfield, T. (2017). Never gonna GIF you up: Analyzing the cultural significance of the animated GIF. Social Media y Society, 3(3).

Modica, E., Cartocci, G., Rossi, D., Martínez, A. C., Cherubino, P., Maglione, A. G., . . Babiloni, F. (2018). Neurophysiological responses to different product experiences. Computational Intelligence and Neuroscience, Volume 2018, Article ID 9616301, 10 pages.

Monge-Benito, S. y Fernández-Guerra, V. (2011). Neuromarketing: Tecnologías, Mercado y Retos. Pensar la publicidad, 5(2), 19-25.

Mundel, J., Huddleston, P., Behe, B., Sage, L. y Latona, C. (2018). An eye tracking study of minimally branded products: Hedonism and branding as predictors of purchase intentions. Journal of Product and Brand Management, 27(2), 146-157.

Novak, T., Hoffman, D. y Yung, Y. (2000). Measuring the Customer Experience in Online Environments: A Structural Modeling Approach. Marketing Science, 19(1), 22-42.
Öhman, A. (1987). Psychophysiology of emotion: An evolutionary cognitive perspective. En T.K. Ackles, J.R. Jennings y M.G.H. Coles (Eds.), Advances in Psychophysiology, volumen 2, 79-127.

Ophuis, P. y Van Trijp, H. (1995). Perceived quality: A market driven and consumer oriented approach. Food quality and Preference, 6(3), 177-183.

Pawle, J. y Cooper, P. (2006). Measuring emotion-Lovemarks, the future beyond brands. Journal of advertising research, 46(1), 38-48.

Plutchik, R. E. y Conte, H. R. (1997). Circumplex models of personality and emotions. American Psychological Association.

Powers, T., Advincula, D., Austin, M. S., Graiko, S., y Snyder, J. (2012). Digital and social media in the purchase decision process: A special report from the Advertising Research Foundation. Journal of advertising research, 52(4), 479-489.

Prescott, J. (2017). Some considerations in the measurement of emotions in sensory and consumer research. Food Quality and Preference, 62, 360-368.

Reimann, M., Castano, R. Zaichkowsky, J. y Bechara, A (2012). How we relate to brands: Psychological and neurophysiological insights into consumer-brand relationships. Journal of Consumer Psychology, 22(1), 128-142.

Russell, J. A. (1980). A circumplex model of affect. Journal of Personality and Social Psychology, 39(6), 1161-1178.

Ryan, R. M. y Deci, E. L. (2001). On happiness and human potentials: A review of research on hedonic and eudaimonic well-being. Annual review of psychology, 52(1), 141-166.

Schmitt, B. (1999). Experiential marketing. Journal of marketing management, 15(1-3), 53-67.

Schmitt, B., Brakus, J. y Zarantonello, L. (2015). From experiential psychology to consumer experience. Journal of Consumer Psychology, 25(1), 166-171.

Scolari, C. (2012). Comunicación Digital. Recuerdos de futuro. El Profesional de la Información. 2012; 21 (4): 337-340 Sharma, N. (2018). Decoding the effects of a product's cast shadow in brand advertising. Journal of Product and Brand Management, 27(2), 103-114.

Skandalis, A., Byrom, J. y Banister, E. (2019). Experiential marketing and the changing nature of extraordinary experiences in post-postmodern consumer culture. Journal of Business Research, 97, 43-50. 
Smith, A. K. y Bolton, R. N. (2002). The effect of customers' emotional responses to service failures on their recovery effort evaluations and satisfaction judgments. Journal of the academy of marketing science, 30(1), 5-23.

Tapia Frade, A., Martín Guerra, E. y Puente, J. E. (2016). Neurociencia y publicidad. Atención, emoción y su relación con los premios obtenidos en el Festival Internacional de Publicidad de Cannes. Anàlisi: quaderns de comunicació i cultura, 0075-95.

Tianliang, L., Junwei, W., Xiubin, D., Feng L., Quanzeng, Y. y Jiebo L. (2019). Sentiment Recognition for Short Annotated GIFs Using Visual-Textual Fusion. IEEE Transactions on Multimedia, vol. 22, no. 4, pp. 1098-1110, April 2020. 10.1109/TMM.2019.2936805.

Thurlow, C., Aiello, G. y Portmann, L. (2019). Visualizing teens and technology: A social semiotic analysis of stock photography and news media imagery. New Media y Society. 2020, Vol. 22(3) $528-549$.

Tolins, J. y Samermit, P. (2016). GIFs as embodied enactments in text-mediated conversation. Research on Language and Social Interaction, 49(2), 75-91.

Vecchiato, G., Fallani, F. D. V., Astolfi, L., Toppi, J., Cincotti, F., Mattia, D., ... y Babiloni, F. (2010). The issue of multiple univariate comparisons in the context of neuroelectric brain mapping: an application in a neuromarketing experiment. Journal of neuroscience methods, 191(2), 283-289.

Vila, J., Ramírez, I., Sánchez, M. y Fernández-Santaella, M.

C. (2001). El Sistema Internacional de Imágenes Afectivas
(IAPS): Adaptación española. Revista de psicología general y aplicada, 08-21.

Vriens, M., Chen, S. y Schomaker, J. (2019). The evaluation of a brand association density metric. Journal of Product and Brand Management, 28(1), 104-116.

Walla, P., Koller, M., Brenner, G. y Bosshard, S. (2017). Evaluative conditioning of established brands: Implicit measures reveal other effects than explicit measures. Journal of Neuroscience Psychology and Economics, 10(1), 24-41.

Weibel, D., di Francesco, R., Kopf, R., Fahrni, S., Brunner, A., Kronenberg, P., . . . y Wissmath, B. (2019). TV vs. YouTube: TV advertisements capture more visual attention, create more positive emotions and have a stronger impact on implicit long-term memory. Frontiers in Psychology, 10, 626.

Yoo, B. y Donthu, N. (2001). Developing and validating a multidimensional consumer-based brand equity scale. Journal of business research, 52(1), 1-14.

Yuang, Y. H. E. y Wu, C. K. (2008). Relationships among experiential marketing, experiential value, and customer satisfaction. Journal of Hospitality y Tourism Research, 32(3), 387-410.

Zeithaml, V. (1988). Consumer perceptions of price, quality, and value: a means-end model and synthesis of evidence. Journal of marketing, 52(3), 2-22.

Zhang, J. y Mao, E. (2016). From Online Motivations to Ad Clicks and to Behavioral Intentions: An Empirical Study of Consumer Response to Social Media Advertising. Phsychology y Marketing, 33(3), 155- 164. 



\section{(ㄷ)(1) $(2)$}

\section{La estrategia de contenidos en YouTube de los principales anunciantes españoles}

The content strategy on YouTube of the main Spanish advertisers

Dra. Araceli Castelló-Martínez

Profesora titular de la Universidad de Alicante.

Departamento de Comunicación y Psicología Social. araceli.castello@ua.es

https://ORCID: 0000-0001-5783-344X

Cecilia Barrilero-Carpio

Graduada en Publicidad y RR.PP.

Universidad de Alicante.

cbc.cecilia@gmail.com

https:/ORCID: 0000-0002-3144-7484
Castelló-Martínez, A. y Barrilero-Carpio, C., (2021) La estrategia de contenidos en YouTube de los principales anunciantes españoles Revista Internacional de Investigación en Comunicación aDResearch ESIC. No 25 Vol 25

Monográfico especial, marzo 2021 · Págs. 44 a 69

https://doi.org/10.7263/adresic-025-03 
RESUMEN

\section{Clasificación JEL: M31, M37, D83}

Palabras clave:

YouTube,

Marketing,

comunicación,

publicidad,

branded content,

redes sociales,

InfoAdex
Objetivo: YouTube se ha convertido en uno de los espacios más rentables a la hora de realizar inversión publicitaria y captar a públicos cada vez más jóvenes, de gran interés para las marcas. Los objetivos de la investigación son estudiar el uso que los anunciantes españoles realizan de su canal en YouTube e identificar rasgos comunes en los contenidos que publican en esta plataforma.

Diseño/metodología/enfoque: Se realiza un estudio descriptivo, utilizando como herramienta metodológica el análisis cuali-cuantitativo de contenido y del discurso. La muestra está formada por los 1.029 vídeos publicados en YouTube en 2019 por las diez marcas españolas más importantes según volumen de inversión en 2019, de acuerdo con InfoAdex (2020). A partir de nueve preguntas de investigación, se analizan variables relativas a cuatro dimensiones: presencia, audiencia, interacción y discurso.

Resultados: Nueve de las diez compañías tienen canal en YouTube. Aunque los canales de E Corte Inglés, Orange y Telefónica son los que realizan más publicaciones, el de L'Oréal es el que obtiene más interacciones. El tipo de contenido de marca en YouTube más habitual entre los principales anunciantes españoles es el branded content, especialmente de información/educación, seguido del spot corto y de los vídeos corporativos.

Limitaciones/implicaciones: Las limitaciones del estudio radican en la diversidad de sectores de las marcas analizadas, circunstancia que influye en los resultados, y en la amplia variabilidad en lo que a la publicación de contenidos en YouTube por parte de las marcas se refiere.

Originalidad/contribución: El valor del estudio radica en el tamaño muestral. Los resultados demuestran que la estrategia de contenidos de estas marcas necesita de una mayor definición, al encontrarse en estado de desarrollo intermedio, con publicaciones escasas, periodicidad de publicación irregular y poca adaptación de contenidos a las particularidades del canal, lo cual resta creatividad a las publicaciones.

\section{ABSTRACT}

\section{JEL Classification: M31, M37, D83}

\section{Key words:}

YouTube,

marketing, communication, advertising, branded content, social networks, InfoAdex
Purpose: YouTube has become one of the most profitable spaces when it comes to making advertising investments and attracting increasingly young audiences, of great interest to brands. The objectives of the research are to study the use that Spanish advertisers make of their channel on YouTube and identify common features in the content they publish on this platform.

Desing / Methodology / Approach: A descriptive study is carried out, using as a methodological tool the qualitative analysis of content. The sample consists of the 1,029 videos posted on YouTube in 2019 by the top ten Spanish advertisers by investment volume in 2019, according to InfoAdex (2020). From nine research questions, variables relating to four dimensions are analyzed: presence, audience, interaction and discourse.

Results: Nine of the ten brands have a YouTube channel. Although the channels of El Corte Inglés, Orange and Telefónica are the ones that make the most publications, L'Oréal's is the one that gets the most interactions. The most common YouTube content format among major Spanish companies is branded content, especially information/education, followed by short spot and corporate videos.

Limitations / Implications: The limitations of the study lie in the diversity of sectors of the brands analyzed, a circumstance that influences the results, and the wide variability in terms of the publication of content on YouTube by the brands.

Originality / Contribution: The value of the study lies in the sample size. The results show that the content strategy of these brands needs greater definition, being in a state of intermediate development, with few publications, irregular publication periodicity and little adaptation of content to the particularities of the channel, which detracts from creativity to publications. 


\section{Introducción}

\subsection{La institucionalización de YouTube}

La visualización online de vídeos es la segunda actividad más habitual para los internautas españoles (78 \%), tras la lectura de noticias (81\%) (AIMC, 2019, p. 86). YouTube es la plataforma de vídeo digital más conocida de forma espontánea (IAB Spain, 2018). Desde que se difundiera el primer vídeo el 23 de abril de $2005^{1}$, YouTube ha crecido de manera exponencial. Debemos contextualizar el nacimiento y éxito de YouTube en el cruce de tres revoluciones: la de producción de vídeo, la de la Web 2.0 y la revolución cultural o de hábitos de consumo audiovisual (García-Cay et al., 2013). La plataforma cuenta con varias vertientes de uso — educativas, informativas, deportivas, entretenimiento, reproducción musical, publicitarias, etc.- (Aznar-Díaz et al., 2019, p. 114), entre las cuales cada vez cobran más peso las que tienen un fin comercial con el desarrollo de figuras como los YouTuber (ElorriagaIllera y Monge-Benito, 2018).

El YouTuber es un influencer con la capacidad de crear opinión, de ahí su atractivo para las marcas. Gracias a su experticia en un determinado tema, genera una numerosa audiencia a la que busca entretener, con contenidos en los que se integran aquellas marcas que pretenden comunicar de forma más eficaz y empática (Tur-Viñez y González-Río, 2019, p. 1293). La comunidad de seguidores que forja en torno a sus vídeos es la clave de su éxito, si bien es crucial mantener la balanza equilibrada entre los contenidos especializados y los que tienen un interés comercial (Ramos-Serrano y Herrero-Diz, 2016, p. 115).

YouTube se ha institucionalizado de tal manera que los contenidos generados profesionalmente ocupan las posiciones más visibles en los resultados

1 Puede verse el primer vídeo en http://bit.ly/me-at-the-zoo-yt de búsqueda, en detrimento de aquellos generados por los usuarios - User Generated Content- de manera amateur (Kim, 2012), es decir, por aquellos usuarios que no persiguen fines económicos, sino principalmente de entretenimiento, y no son profesionales de la comunicación.

El negocio de los usuarios se encuentra en la posibilidad de monetizar el contenido subido a la plataforma a partir de la publicidad, ya sea directa a través de la insertada por YouTube o indirecta, con contratos publicitarios empresariales (Lobato, 2016, p. 358; Aznar-Díaz et al., 2019, p. 114). «A diferencia de otras compañías over the top (OTT) con modelos de negocio basados en la suscripción y el pago por visión, YouTube fundamenta su base comercial sobre la actividad del usuario y la publicidad» (De Aguilera-Moyano, Castro-Higueras y Pérez-Rufí, 2018, p. 4).

La evolución que ha sufrido la página de inicio de YouTube así lo demuestra (De Aguilera-Moyano, Castro-Higueras y Pérez-Rufí, 2018, p. 10). Desde 2017 se realiza una promoción equilibrada de los contenidos de usuarios de industrias culturales y creativas - tradicionales y nativas digitales_y de aquellos publicados por usuarios pro-ams (Leadbeater y Miller, 2004), considerados como aquellos usuarios que han pasado su etapa de aficionados en la publicación de vídeos y han profesionalizado su actividad, expertos comunicadores con un elevado nivel en la gestión de las tecnologías digitales.

Entre las marcas, YouTube es la red social más popular a la hora de difundir contenidos relacionados (Castelló-Martínez, Del Pino-Romero y Tur-Viñes, 2016). Aunque los primeros estudios sobre la plataforma destacaban su enfoque filántropo y colaborativo (Arthurs, Drakopoulou y Gandini, 2018), De Aguilera-Moyano, CastroHigueras y Pérez-Rufí (2018) corroboran la profesionalización que ha alcanzado YouTube. La 
plataforma ha pasado de representar la cultura participativa a orientarse hacia la creación y difusión de contenidos audiovisuales siguiendo objetivos de rentabilidad comercial (Holland, 2016).

\subsection{YouTube en la comunicación persuasiva integrada}

Del total de la inversión publicitaria en medios digitales, las redes sociales, entre las que se incluye YouTube, representaron el 25,6 \% en 2019 (IAB Spain, 2020a). El medio digital suma el 38,6 \% de la inversión publicitaria controlada en España, ocupando la segunda posición tras la televisión (InfoAdex, 2020). A pesar de la evolución que ha vivido YouTube, la plataforma sigue ejemplificando muchas de las características propias del actual paradigma de la comunicación persuasiva integrada (Castelló-Martínez y Del Pino-Romero, 2019). Algunas de éstas son la interacción entre usuarios en tiempo real (Sabich y Steinberg, 2017; Sánchez-Vera, Solano-Fernández y Recio-Caride, 2019), la transmedialidad, la convergencia mediática y la difusión de contenidos empáticos y conversables, basados en el storytelling, que integran al consumidor en las historias (De MiguelZamora y Toledano-Cuevas-Mons, 2018). Con estos contenidos las marcas buscan dar respuesta a las tensiones culturales con el propósito de convertirse en marcas útiles.

Pese a todo, diversos estudios han evidenciado que a las empresas todavía les queda mucho por hacer en el uso de los medios sociales en aras de la transparencia, la conversación y la coherencia entre el decir y el hacer (Gómez-Vásquez, 2013; Aced-Toledano y Lalueza-Bosch, 2016; MarianoDa-Rocha-Barichello y Scheid, 2017; Capriotti, Zeler y Oliveira, 2019; Zeler y Capriotti, 2019). El vídeo puede ser un formato óptimo para la comunicación del compromiso de la marca para con la sociedad y para la construcción de una relación con los usuarios basada en la escucha social (Costa-Sánchez y Túñez-López, 2019, p. 224). Sin embargo, la realidad demuestra que las marcas suelen publicar en YouTube contenidos comerciales centrados en el producto, que no fomentan la conversación con el usuario. De hecho, lo más habitual es que se vuelquen a la plataforma, sin modificación alguna, los vídeos usados en las campañas en medios tradicionales, como los spots (Costa-Sánchez y Túñez-López, 2019, p. 234).

Por otro lado, son destacables iniciativas de marcas que han empleado sus canales en YouTube para difundir mensajes dialógicos y participativos, basados en fórmulas de contenidos de marca como el branded content (Castelló-Martínez y Del PinoRomero, 2014; Castelló-Martínez, Del Pino-Romero y Tur-Viñes, 2016, p. 150). El diseño de mensajes híbridos (De Aguilera-Moyano, BañosGonzález y Ramírez-Perdiguero, 2016) se basa en contenidos de información y/o entretenimiento al servicio de los intereses de la marca que presentan su ventaja diferencial, sus valores y/o su vocación para con la sociedad de manera atractiva y sugerente. «Los contenidos de los espacios de branded content están al servicio de la marca desde el momento de su concepción, aunque ésta no siempre tenga presencia explícita en ellos» (Castelló-Martínez y Del Pino-Romero, 2019, p. 268). La clave está en el diseño de los contenidos, de manera que transmitan la personalidad de la marca y los usuarios puedan identificarlos con ella.

\subsection{El discurso de las marcas en YouTube}

Ubicar al consumidor en el centro del proceso, como un interlocutor activo (Solana, 2010: 21) conlleva comprender y respetar sus actitudes, comportamientos, necesidades y expectativas para poder diseñar mensajes que, en lugar de basarse en anuncios persecutorios, aporten contenidos empáticos y experimentables. 
Con respecto al discurso de las marcas en YouTube, Osorio, Rodríguez y Moreno (2021) destacan que las estrategias de contenido se caracterizan por ser funcionales y emocionales. CostaSánchez (2014) ya destacaba la comunicación de acciones de responsabilidad social corporativa como tendencia al alza. A través de la difusión de contenidos mediante el branded content, las marcas se comprometen con las cuestiones importantes de su época (Rodríguez-Rabadán, 2021), construyendo un discurso que conecta con las inquietudes o tendencias de un determinado segmento de individuos, no necesariamente identificado a partir de variables sociodemográficas.

Con sus soluciones comunicativas, las marcas ya no sólo cuentan historias, sino que buscan hacer la vida más fácil y contribuir a un mundo mejor, desde la coherencia entre el decir — storytelling - y el hacer — storydoing — (De Miguel-Zamora y Toledano-Cuevas-Mons, 2018), «dando respuesta con un compromiso franco y duradero a las realidades demográficas, sociales y culturales del contexto, para integrar así al consumidor en el discurso» (Castelló-Martínez y Barrilero-Carpio, 2021, p. 188).

Medios propios y compartidos son el escenario idóneo para ello (Sicilia y Merino, 2020). El llamado marketing de contenidos se ha convertido en una alternativa más que válida para la construcción de un universo simbólico en torno a la marca y para la comunión con el consumidor (Wang y Chan-Olmsted, 2020). Estudios como los de Ashley y Tuten (2015) ya evidenciaban la importancia de la frecuencia en la publicación y los incentivos de participación en las estrategias creativas en redes sociales. Otros académicos como De Blasio, Mazerant y Scharlott (2019) reflexionan sobre la importancia de la argumentación emocional en los vídeos de marcas en YouTube para generar engagement con el usuario.
En este estudio se analiza la estrategia de contenidos de las marcas en la plataforma YouTube poniendo el foco en cuatro dimensiones: la presencia, la audiencia, la interacción y el discurso.

\section{Metodología}

Los objetivos de la investigación son estudiar el uso que los anunciantes españoles realizan de su canal en YouTube e identificar rasgos comunes en los contenidos que publican en esta plataforma. Se realiza un estudio descriptivo, utilizando como herramienta metodológica el análisis cuali-cuantitativo de contenido y del discurso. La muestra está formada por los 1.029 vídeos publicados en YouTube en 2019 por las diez marcas españolas más importantes según volumen de inversión en 2019, de acuerdo con InfoAdex (2020). Pueden verse en la tabla 1. Los vídeos suman un total de 77 horas, 1 minuto y 13 segundos.

\begin{tabular}{l|l|c|}
\hline \multicolumn{3}{|c|}{$\begin{array}{l}\text { Tabla 1. Principales anunciantes españoles } \\
\text { según volumen de inversión en } \mathbf{2 0 1 9}\end{array}$} \\
\hline Anunciante & $\begin{array}{l}\text { Inversión en } \\
2019 \text { (mil- } \\
\text { lones de } € \text { ) }\end{array}$ & $\begin{array}{l}\text { Cuota } \\
\text { sobre total } \\
\text { inversión }\end{array}$ \\
\hline Volkswagen & 84,5 & $2,0 \%$ \\
\hline El Corte Inglés & 74,0 & $1,7 \%$ \\
\hline L'Oréal & 69,6 & $1,6 \%$ \\
\hline PSAG & 67,9 & $1,6 \%$ \\
\hline Procter \& Gamble & 67,0 & $1,6 \%$ \\
\hline Orange & 64,3 & $1,5 \%$ \\
\hline Línea Directa Asegu- \\
radora
\end{tabular}

Fuente: InfoAdex (2020).

Las preguntas de investigación se organizan en cuatro dimensiones diferentes y se plasman en indicadores para su medición, como muestra la tabla 2: 
Tabla 2. Preguntas de investigación, dimensiones e indicadores del estudio

\begin{tabular}{|c|c|c|c|c|}
\hline Cuestión (RQ) & $\begin{array}{l}\text { Ámbito } \\
\text { temporal }\end{array}$ & Dimensión & Indicador & Referencia \\
\hline $\begin{array}{l}\text { 1. ¿Las principales marcas españolas } \\
\text { cuentan con un canal en YouTube, } \\
\text { con descripción y URL personalizada? }\end{array}$ & $\begin{array}{l}\text { Desde } \\
\text { creación } \\
\text { del canal }\end{array}$ & \multirow{3}{*}{ Presencia } & $\begin{array}{l}\text { Existencia de canal propio, } \\
\text { número de suscriptores, número } \\
\text { de vídeos totales, número de } \\
\text { visualizaciones totales, inclusión } \\
\text { de descripción, URL persona- } \\
\text { lizada }\end{array}$ & \multirow[t]{6}{*}{ YouTube } \\
\hline $\begin{array}{l}\text { 2. ¿Cuál es la fecha de creación del canal } \\
\text { y con qué periodicidad se publica? }\end{array}$ & & & Fecha de creación & \\
\hline 3. ¿Cuántos vídeos se han publicado? & \multirow[t]{8}{*}{2019} & & $\begin{array}{l}\text { Número de vídeos totales, } \\
\text { duración, fecha de publicación } \\
\text { (día y mes) }\end{array}$ & \\
\hline $\begin{array}{l}\text { 4. ¿Qué audiencia tienen los contenidos y } \\
\text { cuáles son los de mayor audiencia? }\end{array}$ & & Audiencia & $\begin{array}{l}\text { Número de } \\
\text { visualizaciones }\end{array}$ & \\
\hline $\begin{array}{l}\text { 5. ¿Qué tipo de interacción reciben los } \\
\text { contenidos y cuáles son los que } \\
\text { obtienen una participación del } \\
\text { usuario más elevada? }\end{array}$ & & Interacción & $\begin{array}{l}\text { Número de «me gusta», núme- } \\
\text { ro de «no me gusta», número } \\
\text { de comentarios }\end{array}$ & \\
\hline $\begin{array}{l}\text { 6. ¿Los vídeos incluyen título y descripción } \\
\text { y qué duración tienen? }\end{array}$ & & \multirow[t]{5}{*}{ Discurso } & $\begin{array}{l}\text { Título, descripción, } \\
\text { duración }\end{array}$ & \\
\hline $\begin{array}{l}\text { 7. ¿Qué tipos de contenidos difunden } \\
\text { los anunciantes españoles en sus } \\
\text { canales de YouTube? }\end{array}$ & & & Tipo de formato & Costa-Sánchez (2017) \\
\hline \multirow[t]{2}{*}{$\begin{array}{l}\text { 8. ¿Qué rasgos formales tienen los } \\
\text { contenidos publicados? }\end{array}$} & & & $\begin{array}{l}\text { Tipo de personaje protago- } \\
\text { nista, presencia de elementos } \\
\text { textuales, presencia de iden- } \\
\text { tidad visual, tipo de género, } \\
\text { nivel de creatividad }\end{array}$ & $\begin{array}{l}\text { Arroyo-Almaraz, } \\
\text { Baños-Gonzálezy } \\
\text { Rodríguez-García (2009) } \\
\text { Tur-Viñes (2018) }\end{array}$ \\
\hline & & & $\begin{array}{l}\text { Especialización temática, } \\
\text { llamada a la acción, saludo } \\
\text { de entrada y salida al usuario, } \\
\text { discurso de marca útil }\end{array}$ & $\begin{array}{l}\text { Propuesta de autoras } \\
\text { Solana (2010) }\end{array}$ \\
\hline $\begin{array}{l}\text { 9. ¿Qué tipo de contenidos de marca } \\
\text { se publican? }\end{array}$ & & & $\begin{array}{l}\text { Información/educación o en- } \\
\text { tretenimiento }\end{array}$ & $\begin{array}{l}\text { Castelló-Martínez y } \\
\text { Del Pino-Romero (2019) }\end{array}$ \\
\hline
\end{tabular}


Las cuestiones relativas a presencia, audiencia e interacción, por un lado, y dentro del discurso, título, descripción y duración, por otro, se obtienen del canal de cada compañía en YouTube. Para la identificación del formato de los vídeos se sigue el modelo de Costa-Sánchez (2017), que lo clasifica en: spot, publirreportaje, noticias, vídeos corporativos, microvídeos, declaraciones, cobertura informativa, responsabilidad social corporativa, branded content, brutos de imágenes, entrevistas, making of, otros.

Se analizan las siguientes variables formales y de contenido propuestas por Arroyo-Almaraz, Baños-González y Rodríguez-García (2009): tipo de personaje protagonista, existencia de elementos textuales, presencia de elementos de identidad visual corporativa y género. Para el análisis del nivel de creatividad se sigue la propuesta de TurViñes (2018), a partir de los criterios de divergencia y pertinencia.

A estas variables proponemos incorporar cuatro relativas al discurso: a) la especialización temática, entendida como la relación de los contenidos con el sector de actividad de la empresa; b) la inclusión de una llamada a la acción que anime a los usuarios a participar o realizar alguna acción; c) la existencia de un saludo de entrada y/o salida del vídeo dirigido a los seguidores y d) el enfoque de marca útil, entendido como la transmisión de una vocación de servicio por parte de la marca, al aportar soluciones a los usuarios, a través de diferentes formatos y/o contenidos, como: tutoriales, consejos, retos, narración de historias, análisis de producto, mensajes hibridados con tendencias del consumidor o historias que alimentan el hambre de asombro o de risa del usuario (Solana, 2010). Por último, la identificación de contenido de marca se realiza atendiendo a la propuesta taxonómica de Castelló-Martínez y Del Pino-Romero (2019:
274), diferenciando entre branded entertainment y branded information.

El trabajo de campo consistió en la identificación de los canales de los principales anunciantes españoles en YouTube y el análisis de los vídeos publicados en 2019. La recogida de datos sobre los canales y los vídeos de la muestra se llevó a cabo del 22 al 30 de junio de 2020 y su codificación en el mes de julio del mismo año, mediante una herramienta de análisis de contenido diseñada ad hoc.

\section{Resultados}

\subsection{Canales en YouTube, descripción y enlace personalizado}

Los 1.029 vídeos de la muestra pertenecen a 9 de las 10 compañías (90 \%) seleccionadas; únicamente PSAG no tiene canal en YouTube. Todos estos canales tienen la URL del canal personalizada, a excepción de Procter \& Gamble (8; 88,9\%). En la tabla 3 pueden verse el número de suscriptores, vídeos totales y visualizaciones totales de estos canales

Como vemos, el canal de YouTube con más suscriptores (299.000; 48,5 \%) y más visualizaciones totales $(122.269 .851 ; 39,3 \%)$ es el de L'Oréal. El canal de Orange, segundo en número de suscriptores y de visualizaciones totales, ocupa la primera posición en número de vídeos publicados desde su creación (1.375; 25,3\%), seguido por El Corte Inglés (1.330; 24,5 \%). Junto con estas empresas, Volkswagen, Telefónica y Vodafone también destacan en las primeras posiciones de estas variables.

Todas las marcas con canal en YouTube incluyen descripción del mismo en la pestaña «Más información». Además, en 7 de los 9 canales la descripción está personalizada para el canal de YouTube, presenta una vocación de servicio y/o concede el protagonismo al usuario. Las descrip- 
Tabla 3. Datos de los canales en YouTube de los principales anunciantes españoles

\begin{tabular}{|c|c|c|c|}
\hline Anunciante & Suscriptores & Vídeos totales & $\begin{array}{c}\text { Visualizaciones totales } \\
(23 / 06 / 2020)\end{array}$ \\
\hline Volkswagen & 79.600 & 115 & 8.125 .602 \\
\hline El Corte Inglés & 36.300 & 1.330 & 36.076 .793 \\
\hline L’Oréal & 299.000 & 317 & 122.269 .851 \\
\hline Procter \& Gamble & 267 & 13 & 416.429 \\
\hline Orange & 123.000 & 1.375 & 79.679 .988 \\
\hline Línea Directa Aseguradora & 2.180 & 197 & 561.229 \\
\hline Telefónica & 15.500 & 840 & 8.706 .898 \\
\hline Mutua Madrileña & 5.340 & 221 & 9.742 .665 \\
\hline Vodafone & 55.700 & 1.028 & 45.308 .470 \\
\hline Total & 616.887 & 5.436 & 310.887 .925 \\
\hline
\end{tabular}

Fuente: Elaboración propia a partir de YouTube.

ciones de los canales de Orange y de Línea Directa Aseguradora no presentan este enfoque al centrarse en la compañía y el producto.

\subsection{Fecha de creación del canal y periodicidad de publicación}

Los canales más longevos son los de Telefónica — creado el 02/11/2005- y El Corte Inglés — creado el 29/05/2006 — . La fecha de Telefónica es destacable si tenemos en cuenta que YouTube se creó en abril de ese mismo año. Los canales de Procter \& Gamble y Orange son los únicos $(7 ; 77,8 \%)$ que se crearon con posterioridad a 2015, ambos de 2018. El de Orange es el segundo canal en YouTube más reciente entre las principales compañías españolas y, sin embargo, es el segundo anunciante con más seguidores y el que más vídeos totales publicados tiene. A excepción de Orange, la media de vídeos publicados al mes por todas las marcas oscila entre 1 -el único ratio inferior es el de Procter \& Gamble, con 0,6- y 8 vídeos. El segundo canal más antiguo (El Corte Inglés) es también el segundo en número de vídeos totales publicados.

\subsection{Vídeos publicados en 2019}

Los canales de YouTube de los principales anunciantes españoles publicaron en 2019 un total de 1.029 vídeos, con el reparto que muestra la tabla 4 en la página 52.

La compañía que más vídeos ha publicado en 2019 es El Corte Inglés (353; 34,3 \%), seguida de Orange (256; 24,9 \%) y de Telefónica (188; $18,3 \%$ ). Los canales de estas tres marcas suman el 77,5\% de los vídeos. Con respecto al tiempo, los 188 vídeos de Telefónica alcanzan el 45,7 \% del tiempo de los vídeos analizados, con 35 horas, 10 minutos y 46 segundos de contenido en YouTube en 2019. Los 256 vídeos de Orange representan el 19,9\% del tiempo de los vídeos visio- 
Tabla 4. Vídeos publicados en 2019 por los canales de YouTube de los diez principales anunciantes

\begin{tabular}{|c|c|c|c|c|c|c|}
\hline Anunciante & $\begin{array}{c}\text { Vídeos } \\
\text { publicados } \\
\text { en } 2019\end{array}$ & $\begin{array}{c}\% \text { respecto a } \\
\text { total vídeos } \\
\text { de } 2019\end{array}$ & $\begin{array}{l}\text { \% respecto } \\
\text { a vídeos } \\
\text { totales del } \\
\text { anunciante }\end{array}$ & $\begin{array}{l}\text { Vídeos } \\
\text { al mes en } \\
2019\end{array}$ & $\begin{array}{c}\text { Duración } \\
\text { total de los } \\
\text { vídeos }\end{array}$ & $\%$ tiempo \\
\hline Volkswagen & 59 & $5,7 \%$ & $51,3 \%$ & 4,9 & $1 \mathrm{~h} 55^{\circ} 03^{\prime \prime}$ & $2,5 \%$ \\
\hline El Corte Inglés & 353 & $34,3 \%$ & $26,5 \%$ & 29,4 & 7h $59^{\prime} 12^{\prime \prime}$ & $10,4 \%$ \\
\hline L’Oréal & 93 & $9 \%$ & $29,3 \%$ & 7,8 & 1h $57^{\prime} 23^{\prime \prime}$ & $2,5 \%$ \\
\hline Procter \& Gamble & 5 & $0,5 \%$ & $38,5 \%$ & 0,4 & $9^{\prime} 14^{\prime \prime}$ & $0,2 \%$ \\
\hline Orange & 256 & $24,9 \%$ & $18,6 \%$ & 21,3 & $15 \mathrm{~h} 19^{\prime} 35^{\prime \prime}$ & $19,9 \%$ \\
\hline $\begin{array}{l}\text { Línea Directa } \\
\text { Aseguradora }\end{array}$ & 15 & $1,5 \%$ & $7,6 \%$ & 1,3 & th $25^{\prime} 38^{\prime \prime}$ & $1,9 \%$ \\
\hline Telefónica & 188 & $18,3 \%$ & $22,4 \%$ & 15,7 & $35 h 10^{\prime} 46^{\prime \prime}$ & $45,7 \%$ \\
\hline Mutua Madrileña & 25 & $2,4 \%$ & $11,3 \%$ & 2,1 & $12 \mathrm{~h} 01^{\prime} 10^{\prime \prime}$ & $15,6 \%$ \\
\hline Vodafone & 35 & $3,4 \%$ & $3,4 \%$ & 2,9 & 1h $3^{\prime} 12^{\prime \prime}$ & $1,4 \%$ \\
\hline Total & 1.029 & $100 \%$ & $18,9 \%$ & 85,8 & $77 \mathrm{~h} 1^{\prime} 13^{\prime \prime}$ & 100 \\
\hline
\end{tabular}

Fuente: elaboración propia a partir de YouTube. art.

nados, de manera que estas dos compañías de telecomunicaciones suman el 65,6\% del tiempo. Encontramos 19 vídeos cuya duración excede la hora: 9 de Mutua Madrileña, 7 de Telefónica y 3 de Orange.

Analizamos también la frecuencia de publicación por meses, días de la semana y periodos mensuales — del 1 al 10, del 11 al 20 y del 21 al 31 de cada mes-. En el total de la muestra es el mes de diciembre el que suma más vídeos (121; 11,8 \%). Si bien los dos principales anunciantes (Volkswagen y El Corte Inglés) coinciden en esta distribución, con el mayor número de vídeos publicados en el mes de diciembre (12 y 63 vídeos, respectivamente), no se observan pautas de frecuencia de publicación mensual en el resto de marcas. El mes de agosto es el que cuenta con menos publicaciones (29; 2,8 \%). Destacamos el caso de Telefónica, con 55 vídeos publicados en febrero—con motivo del Mobile World Congress la marca publica 43 vídeos en tres días- y 37 en el mes de octubre -relacionados con el evento EnlightED-, de manera que estos dos meses suman el 48,9\% de sus publicaciones en YouTube en 2019.

Con respecto al día de la semana, lunes, martes y jueves suman el 66,9\% de las publicaciones (688) y, a excepción de Procter \& Gamble —con 5 publicaciones_-, son los días con más publicaciones para todas las empresas. En fin de semana se publican 23 vídeos (2,2 \%). Por periodos mensuales no se observan pautas de publicación en el total de la muestra, de manera que los vídeos se reparten de manera similar para cada periodo: 321 vídeos publicados del 1 al 10 de cada mes (31,2\%), 305 publicaciones del 11 al 20 de cada mes (29,6\%) y 403 vídeos del 21 al 31 de cada mes (39,2\%). En la figura 1 puede verse el reparto de vídeos publicados por meses y días de la semana: 


\section{Figura 1. Vídeos publicados por meses y días de la semana}
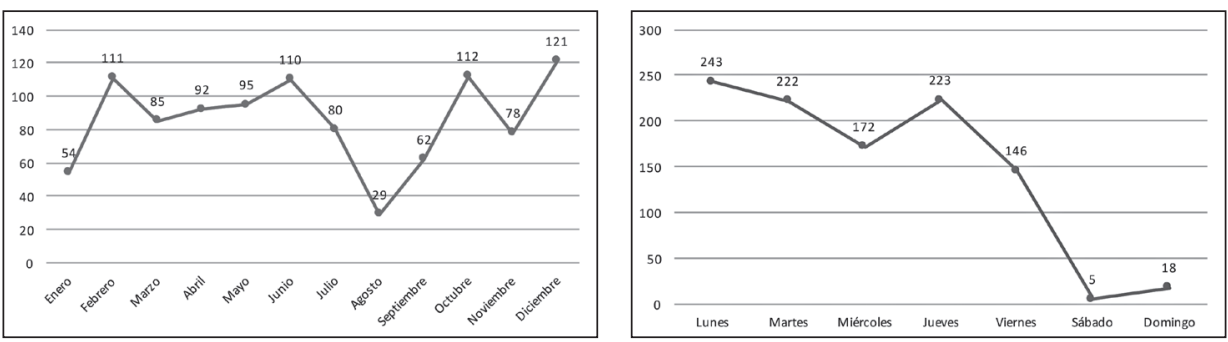

Fuente: elaboración propia a partir de YouTube.

\subsection{Audiencia de los contenidos} publicados en YouTube por los principales anunciantes españoles

Los 1.029 vídeos analizados sobrepasan los 107,4 millones de visualizaciones, con una media de 104.377 visualizaciones por vídeo. Aunque es el cuarto canal en número de vídeos publicados en 2019, el canal con más suscriptores, el de L'Oréal, es también el que aglutina el mayor porcentaje de visualizaciones $(47,7 \%)$. Le siguen Orange, El Corte Inglés y Vodafone, con el 24,6 \%, el $12,1 \%$ y el 10,5 \% de las visualizaciones, respectivamente. Los cinco canales restantes no sobrepasan el 2,2 \% de las visualizaciones. Siete de los diez vídeos con más visualizaciones son de L'Oréal, el primero de ellos con 8,1 millones de visualizaciones ${ }^{2}$. Se trata en todos los casos de spots cortos que no sobrepasan los 20 segundos protagonizados por celebridades famosas y en los que se exhibe el producto, con los géneros demostración, problema-solución y testimonial.

2 https://bit.ly/loreal-yt-35
El vídeo que ocupa la segunda posición del ranking de visualizaciones, con más de 4,6 millones, es de Vodafone, también un spot bajo el género de problema-solución, protagonizado por personas corrientes ${ }^{3}$. De esta marca es el quinto vídeo más visto de la muestra, con 3,5 millones de visualizaciones: el spot de Navidad «Tiempo de uso» ${ }^{4}$, de la agencia Sra. Rushmore, se publicó en YouTube el 19 de diciembre de 2019 y narra una historia protagonizada por personas corrientes, con argumentación emocional y género basado en el trozo de vida. El sexto vídeo más visto de la muestra es de Orange $^{5}$, un spot corto de la campaña «Retos virales», creada por la agencia Comunica+A, de responsabilidad social corporativa para concienciar sobre la peligrosidad de los retos virales. En la figura 2 puede verse el ranking de marcas por visualizaciones y de vídeos con más visualizaciones:

\footnotetext{
3 https://bit.ly/vodafone-yt-7

4 https://bit.ly/vodafone-yt-35

5 https://bit.ly/orange-yt-23
} 


\section{Figura 2. Ranking de marcas por visualizaciones y vídeos con más visualizaciones}
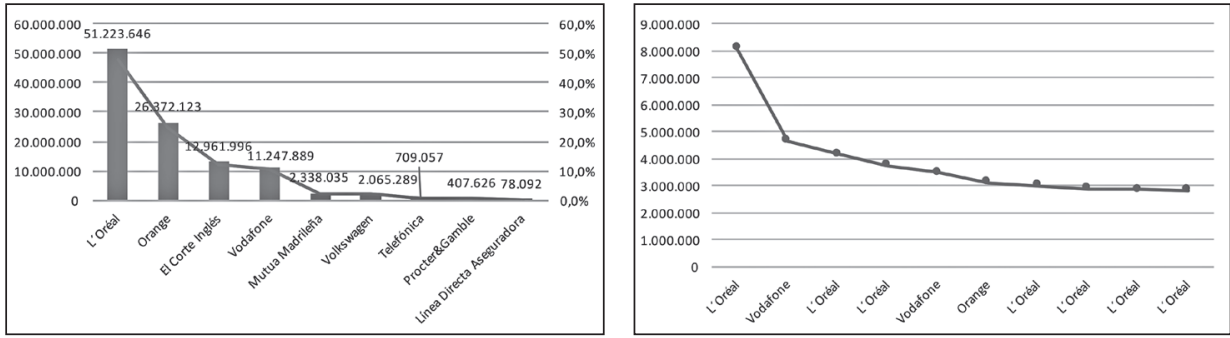

3.5. Interacción en los contenidos publicados en YouTube por los principales anunciantes españoles

En total, los 1.029 vídeos analizados alcanzan 75.680 interacciones, con una media de 73,5 interacciones por vídeo. El 82,5\% de estas interacciones (62.435) son «me gusta», el 11,4\% son «no me gusta» (8.619) y el 6,1 \% son comentarios (4.626). Si el de L’Oréal es el canal con más visualizaciones en 2019, el de Orange — segundo canal en número de visualizaciones- es el que suma más interacciones, con el 42,9\% de los «me gusta», el 38,5\% de los «no me gusta» y el 45,6 \% de los comentarios.

El canal de El Corte Inglés, tercer canal en número de visualizaciones, ocupa también la tercera posición en los tres tipos de interacción. Por tanto, tres de las cuatro marcas con más vídeos publicados en 2019 son también las que tienen más visualizaciones y más interacciones. No sucede así con el canal de Telefónica — tercer canal en número de vídeos publicados en 2019 , con 188-, cuyos contenidos reciben el 0,7\% de las visualizaciones y el 11,3\% de las interacciones. En 29 vídeos (2,8 \%) los comentarios están desactivados: quince de El Corte Inglés, siete de Orange, tres L'Oréal, dos de Vodafone y dos de Telefónica. La figura 3 ilustra la media de visualizaciones e interacciones por vídeo para cada canal:

En las primeras posiciones del ranking de publicaciones con más interacciones encontramos diez vídeos de Orange, dos de Telefónica ${ }^{6}$ — con cobertura informativa y noticias relacionadas con la compañía- y uno de El Corte Inglés ${ }^{7}$-spot navideño—, L'Oréal ${ }^{8}$ — de cobertura informativay Vodafone — el spot de Navidad-. Ocho de los diez vídeos de Orange son publirreportajes con tutoriales y análisis de productos ${ }^{9}$. Cuentan, además, con la figura de un presentador que introduce y cierra el vídeo realizando llamadas a la acción a los usuarios, como solicitar seguir el canal o dejar comentarios. Los otros dos vídeos de Orange son un spot de sensibilización sobre el riesgo de los mensajes a los que se exponen los

\footnotetext{
6 https://bit.ly/telefonica-yt-60 y https://bit.ly/telefonica-yt-121

7 https://bit.ly/eci-yt-295

8 https://bit.ly/loreal-yt-9

9 Puede verse un ejemplo en https://bit.ly/orange-yt-87
} 


\section{Figura 3. Media de visualizaciones e interacciones por vídeo para cada canal}

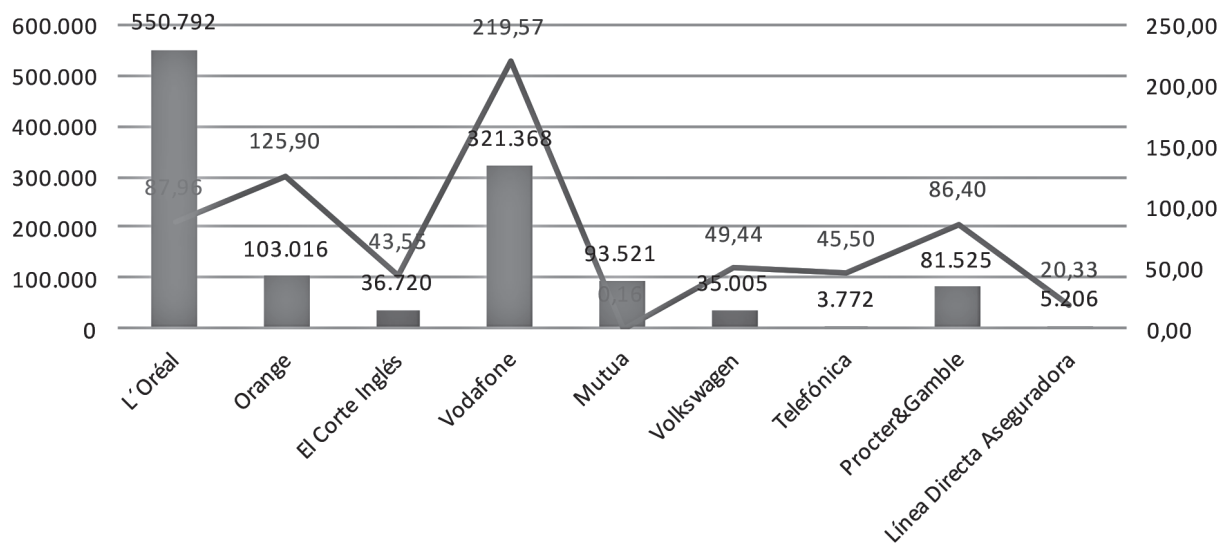

Media visualizaciones/vídeo

Media interacciones / vídeo

Fuente: elaboración propia a partir de YouTube.

adolescentes en redes sociales sobre la anorexia y la bulimia ${ }^{10}$ y un espacio de branded content de información y educación sobre la percepción de la identidad en redes sociales ${ }^{11}$. En estos vídeos se recurre a la dramatización y a la narración de historias, con testimoniales de personas corrientes, y en ambos casos la marca aporta contenidos útiles al conectar su mensaje con tendencias actuales, como los peligros que pueden entrañar las redes sociales para los jóvenes.

\subsection{Título, descripción y duración de los vídeos}

Todos los vídeos de la muestra tienen título, mientras que la descripción aparece en el 96,3 \% de los casos (991). Es frecuente también el empleo

\footnotetext{
10 https://bit.ly/orange-yt-187

11 https://bit.ly/orange-yt-53
}

de etiquetas, que aparecen tanto encima del título del vídeo como integrados en la descripción. Tras la descripción del contenido, todos los vídeos de Línea Directa Aseguradora incluyen enlaces a las páginas web y a las redes sociales — «Síguenos en Facebook, Twitter y LinkedIn»—.

La figura 4 incluye el reparto de los vídeos según la duración. El 46,3 \% de los vídeos (476) dura hasta 1 minuto y el 42,7 \% (439) hasta 5 minutos y más de 1 minuto. Encontramos 53 vídeos (5,2\%) con una duración superior a los 15 minutos. El $66 \%$ de estos vídeos (35) son de Telefónica, de manera que 18,6 \% de los vídeos publicados por esta compañía en 2019 exceden los 15 minutos. También Mutua Madrileña suele publicar vídeos largos, con 9 publicaciones en 2019 que superan los 15 minutos, cifra que representa el $17 \%$ de los vídeos de la muestra con esta duración y el 36 \% del total de sus publicaciones. 


\section{Figura 4. Duración de los vídeos analizados}

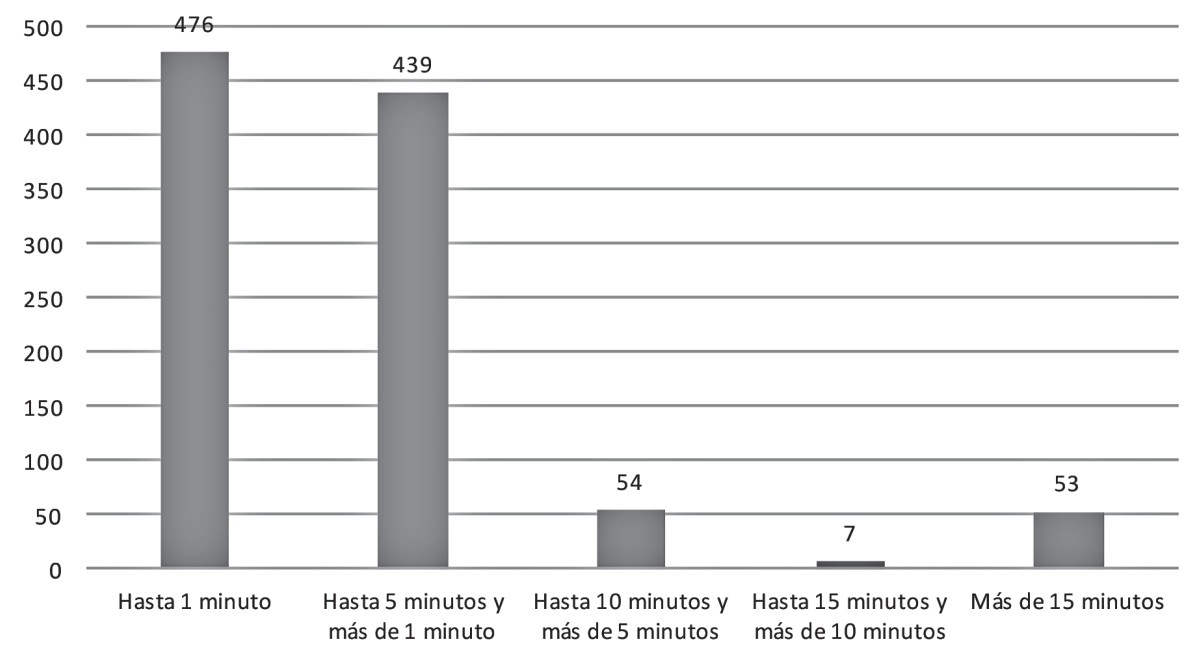

Fuente: elaboración propia a partir de YouTube.

\subsection{Formatos de contenidos en YouTube}

Siguiendo la clasificación propuesta por CostaSánchez (2017), el tipo de contenido en YouTube más habitual entre los principales anunciantes españoles es el branded content (334; 16,5\%), seguido del spot corto $(235 ; 11,6 \%)$ y de los vídeos corporativos (101; $5 \%)$. La cobertura informativa de eventos como ruedas de prensa o congresos relacionados con el sector de actividad de la empresa suma 83 vídeos $(4,1 \%)$ y publirreportajes alcanza los 63 vídeos (3,1 \%). El resto de formatos suman el 10,5 \% (213). Puede verse el desglose del formato de vídeo por empresa en la tabla 5.

Por compañías, el branded content es el tipo de contenido más popular en los casos de Volkswagen, El Corte Inglés, Procter \& Gamble y Mutua Madrileña. El spot corto —con una duración inferior a un minuto- es el formato más utilizado por L’Oréal, Orange y Vodafone. La categoría otros suma en Orange 46 vídeos —el 18 \% de los vídeos publicados por esta marca en YouTube en 2019_ puesto que es frecuente la publicación de tráilers de los contenidos disponibles en su plataforma de televisión de pago, Orange TV, como películas, series o documentales. También hacen lo propio Vodafone y Telefónica, aunque con menos frecuencia.

En el canal de Orange también son populares los publirreportajes ( $41 ; 16 \%)$; de hecho, el $65 \%$ de los vídeos con este formato pertenecen a esta compañía. Se trata de vídeos que cuentan con un presentador y que incluyen tutoriales o análisis de producto, con una duración no superior a los cinco minutos y con llamadas a la acción —animar a seguir el canal o a dejar comentarios- Las otras 
Tabla 5. Formatos de vídeos publicados en YouTube por anunciante

\begin{tabular}{|c|c|c|c|c|c|c|c|c|c|c|c|}
\hline 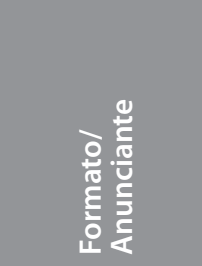 & 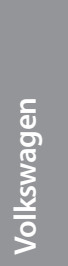 & 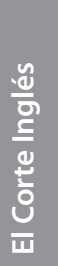 & 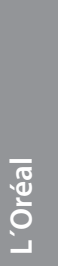 & $\begin{array}{l}\mathbf{y} \\
\& \\
\Omega\end{array}$ & $\frac{d}{\frac{1}{0}}$ & 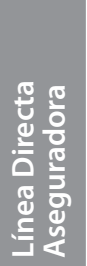 & 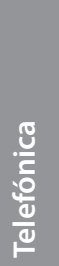 & 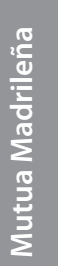 & $\begin{array}{l}\frac{y}{2} \\
\frac{0}{\pi} \\
\frac{\pi}{0} \\
\text { j }\end{array}$ & \multicolumn{2}{|c|}{ 홍 } \\
\hline Branded content & 30 & 208 & 35 & 3 & 29 & & 19 & 10 & & 334 & $16,5 \%$ \\
\hline $\begin{array}{l}\text { Bruto de } \\
\text { imágenes }\end{array}$ & & 1 & & & 3 & & & & & 4 & $0,2 \%$ \\
\hline $\begin{array}{l}\text { Cobertura } \\
\text { informativa }\end{array}$ & 3 & 8 & 5 & & 18 & 1 & 47 & & 1 & 83 & $4,1 \%$ \\
\hline Declaraciones & & 3 & 1 & & 8 & & 1 & & & 13 & $0,6 \%$ \\
\hline Entrevistas & & 13 & & & 8 & 4 & 6 & & & 31 & $1,5 \%$ \\
\hline Making of & & 4 & & & & & 1 & & 1 & 6 & $0,3 \%$ \\
\hline Microvídeos & & & 7 & & & & & & & 7 & $0,3 \%$ \\
\hline Noticias & & & & & 3 & 1 & 8 & 1 & & 13 & $0,6 \%$ \\
\hline Otros & & 1 & & & 46 & 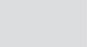 & 2 & & 7 & 56 & $2,8 \%$ \\
\hline Publirreportaje & & & & & 41 & 2 & 11 & 3 & 6 & 63 & $3,1 \%$ \\
\hline RSC & & 20 & & 2 & 11 & & 13 & 8 & & 54 & $2,7 \%$ \\
\hline Spot corto & 10 & 80 & 43 & & 73 & 5 & 8 & 2 & 14 & 235 & $11,6 \%$ \\
\hline Spot largo & 2 & 2 & 2 & & 13 & & 5 & & 5 & 29 & $1,4 \%$ \\
\hline Vídeo corporativo & 14 & 13 & & & 3 & 2 & 67 & 1 & 1 & 101 & $5 \%$ \\
\hline Total & 59 & 353 & 93 & 5 & 256 & 15 & 188 & 25 & 35 & 1.029 & $100 \%$ \\
\hline
\end{tabular}


dos marcas del sector telecomunicaciones, Telefónica y Vodafone, también publican vídeos de este tipo.

Telefónica dedica la mayoría de sus publicaciones a los vídeos corporativos $(67 ; 35,6 \%)$ y a la cobertura informativa $(47 ; 25 \%)$ de ruedas de prensa y competiciones o eventos patrocinados. Los vídeos corporativos se caracterizan por un discurso centrado en la empresa y sus productos, en primera persona del plural. En muchos de ellos el protagonista es el presidente de la compañía, que informa de resultados trimestrales o actividades de Telefónica. Pueden verse ejemplos de vídeo corporativo y de cobertura informativa en la figura 5:

\section{Figura 5. Vídeo corporativo de Telefónica y vídeo con cobertura informativa de Vodafone}
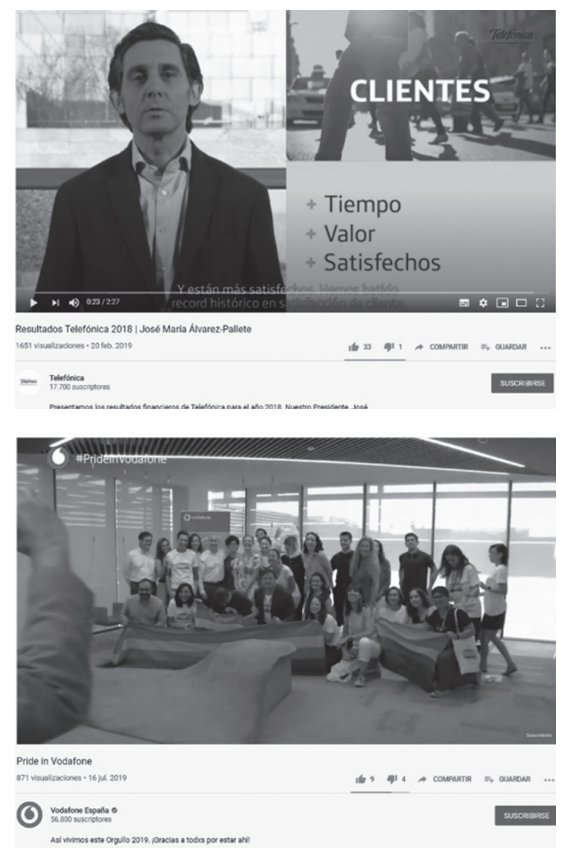

Fuente: YouTube (https://bit.ly/telefonica-yt-19 y https:// bit.lyNodafone-yt-20).
De media, los spots (cortos y largos) son los que obtienen más visualizaciones por vídeo, seguidos de las declaraciones, los publirreportajes y los vídeos de responsabilidad social corporativa. En la media de interacciones por vídeo destacan los formatos spot largo, publirreportaje, noticias y spot corto. Si calculamos el ratio interacciones/visualizaciones para cada tipo de formato, los vídeos de noticias son los que alcanzan el porcentaje más elevado (15,3\%); el resto de formatos no alcanza el $1 \%$ en este índice. Los vídeos de cobertura informativa suelen tener una duración superior a 15 minutos mientras que en todos los tipos de formatos la duración más frecuente es entre 1 y 5 minutos. Pueden verse estos datos en la tabla 6 :

\subsection{Rasgos formales de los contenidos publicados}

Nos detenemos en los elementos formales y de contenido de los vídeos de la muestra, a partir de la propuesta de Arroyo-Almaraz, Baños-González y Rodríguez-García (2009). La persona corriente (315; 30,6 \%), el experto (226; 22 \%) y el famoso $(133 ; 12,9 \%)$ son los personajes protagonistas más repetidos. La aparición de empleados también es habitual (59; 5,7 \%), como en los vídeos de la sección «Un café con...» de Línea Directa Aseguradora, con entrevistas a cargos de la empresa. En 159 vídeos (15,5 \%) no aparecen personajes protagonistas.

El Corte Inglés es el anunciante con más vídeos con clientes reales $(12 ; 70,6 \%)$ y personas corrientes $(114 ; 36,2 \%)$ como protagonistas y Telefónica hace lo propio con los empleados (41; 69,5\%). Esta marca también cuenta con contenido de branded content de entretenimiento con un personaje de animación. El 49,6 \% de los vídeos con expertos como protagonistas (112) es de El Corte Inglés y la marca con más vídeos prota- 


\section{Tabla 6. Ratio de interacciones/visualizaciones y duración más frecuente para cada tipo de formato}

\begin{tabular}{|c|c|c|c|c|c|}
\hline 옹 & $\begin{array}{l}y \\
\frac{d}{0} \\
\frac{0}{3}\end{array}$ & 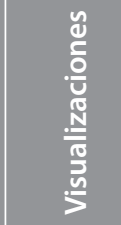 & 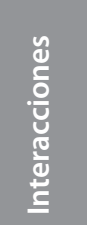 & 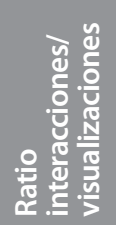 & 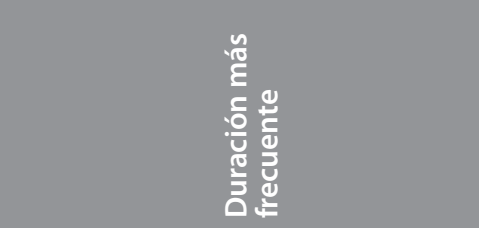 \\
\hline Branded content & 334 & 3.786 .837 & 14.462 & $0,4 \%$ & Menos de 5 minutos y más de 1 minuto (53\%) \\
\hline Bruto de mágenes & 4 & 746 & 7 & $0,9 \%$ & Menos de 1 minuto (100\%) \\
\hline Cobertura informativa & 83 & 1.374 .964 & 6.623 & $0,5 \%$ & Más de 15 minutos $(50,6 \%)$ \\
\hline Declaraciones & 13 & 3.025 .441 & 197 & $0,0 \%$ & Menos de 5 minutos y más de 1 minuto $(61,5 \%)$ \\
\hline Entrevistas & 31 & 130.061 & 248 & $0,2 \%$ & Menos de 5 minutos y más de 1 minuto $(51,6 \%)$ \\
\hline Making of & 6 & 28.366 & 265 & $0,9 \%$ & Menos de 5 minutos y más de 1 minuto (50\%) \\
\hline Microvídeos & 7 & 34.595 & 226 & $0,7 \%$ & Menos de 1 minuto (100\%) \\
\hline Noticias & 13 & 11.761 & 1.795 & $15,3 \%$ & Menos de 5 minutos y más de 1 minuto $(84,6 \%)$ \\
\hline Otros & 56 & 234.914 & 1.434 & $0,6 \%$ & Menos de 5 minutos y más de 1 minuto $(69,7 \%)$ \\
\hline Publirreportaje & 63 & 2.549 .922 & 14.580 & $0,6 \%$ & Menos de 5 minutos y más de 1 minuto $(65,1 \%)$ \\
\hline RSC & 54 & 1.887.234 & 636 & $0,0 \%$ & Menos de 5 minutos y más de 1 minuto $(57,4 \%)$ \\
\hline Spot corto & 235 & 84.084 .090 & 20.628 & $0,0 \%$ & Menos de 1 minuto (100\%) \\
\hline Spot largo & 29 & 8.493 .805 & 12.950 & $0,2 \%$ & Menos de 5 minutos y más de 1 minuto $(93,1 \%)$ \\
\hline Vídeo corporativo & 101 & 1.761 .017 & 1.629 & $0,1 \%$ & Menos de 5 minutos y más de 1 minuto $(52,5 \%)$ \\
\hline
\end{tabular}

Fuente: elaboración propia a partir de YouTube.

gonizados por famosos es L'Oréal (58; 43,6 \%). El vídeo con un presentador como personaje protagonista es habitual en el canal de Orange (34; 89,5 \%). En la figura 6, pág. 60, pueden verse ejemplos de los personajes protagonistas:

El 89,7 \% de los vídeos incluye elementos textuales (923) y en el 94,8 \% existen elementos de la identidad visual corporativa de la marca (976).
En la mayoría de vídeos aparece más de un tipo de elemento textual (653; 63,5 \%); 131 de estos vídeos combinan los subtítulos con elementos como texto sobreimpreso, entrada y/o cierre del vídeo. El 15,2 \% de los vídeos de la muestra incorpora subtítulos.

El género más utilizado es la demostración (273; 26,5 \%). La mayoría de los vídeos de Volk- 


\section{Figura 6. Empleado y famosa como personajes protagonistas}
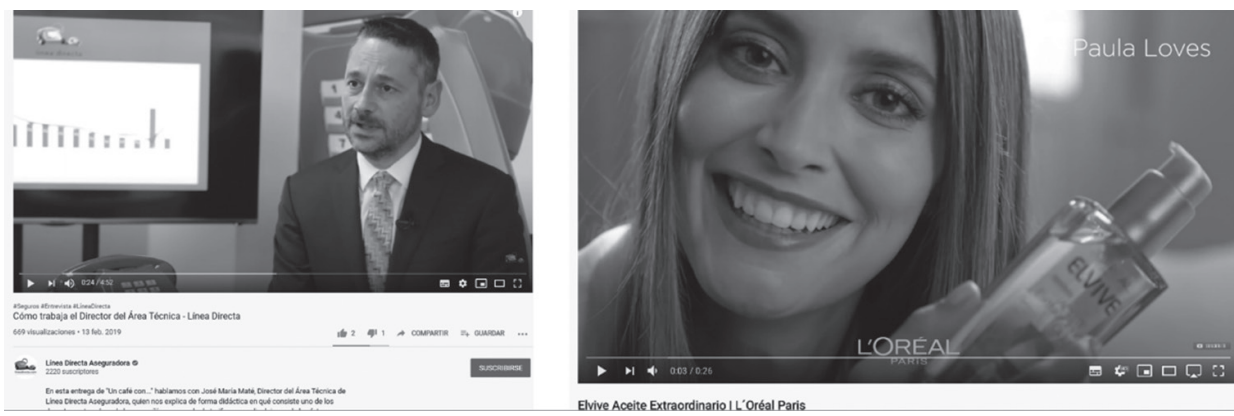

Fuente:YouTube (https://bit.ly/lda-yt-1 y https://bit.ly/loreal-yt-68).

swagen, El Corte Inglés, L'Oréal y Orange son de este género. Le sigue el testimonial, con 164 vídeos (15,9\%). El trozo de cine aparece en vídeos de Orange, Telefónica y Vodafone debido a los tráilers que difunden de contenidos de sus plataformas de televisión. Es el género más común en los canales de Orange y Vodafone, con 59 y 10 vídeos (23 \% y 28,6 \%), respectivamente. En el canal de Telefónica el género más popular es el testimonial, con 70 vídeos (37,2\%), propio de los vídeos en los que aparecen empleados —vídeos corporativos-. El segundo género más utilizado por esta marca es el presentador (27; $14,4 \%$ ), como en los vídeos de cobertura informativa. Además de la demostración, los spots y contenidos de marca de L'Oréal, protagonizados en su mayoría por celebridades, emplean también el género problema-solución (16; 17,2%).

A partir de las variables propuestas por TurViñes (2018) para valorar la creatividad de las piezas publicitarias, en base a la divergencia y la pertinencia, se han identificado únicamente 123 vídeos (12\%) con un nivel de creatividad elevado. Los contenidos son pertinentes para la marca, el producto y el sector de actividad: en 894 vídeos (86,9 \%) se identifica esta especialización temática. Sin embargo, los contenidos resultan poco divergentes o disruptivos para el público destinatario y, especialmente, las particularidades del canal.

Otros elementos que se han propuesto para este análisis son la llamada a la acción, el saludo de entrada y salida y la consideración de marca útil. Encontramos llamadas a la acción en 310 vídeos (30,1\%), la mayoría de ellos de El Corte Inglés (119; 38,4 \%), L’Oréal (75; 24,2 \%) y Orange (56; 18,1 \%). Sin embargo, los anunciantes que más llamadas a la acción incluyen en los vídeos publicados en YouTube son Volkswagen y L'Oréal: el 81,4 \% y el 80,6 \% de sus publicaciones en 2019 en esta plataforma hacen al usuario algún tipo de llamada a la acción. La llamada a la acción más habitual es animar a suscribirse al canal de YouTube y/o a seguir a la marca en redes sociales (143; 46,1 \%), aunque también se requieren compartir el vídeo, se hacen preguntas a seguidores y se invita a dejar comentarios.

Estas llamadas a la acción suelen ubicarse en la descripción del vídeo (228; 73,5 \%) o en el propio vídeo $(51 ; 16,5 \%)$. Únicamente encon- 
tramos llamadas a la acción en el título en cinco casos (1,6\%), todos de Orange, con preguntas y llamadas a la acción como: «iHasta dónde llegarías por un reto viral?», «¿Eres la misma persona en redes sociales?», «Happy days. Ven a visitarnos los viernes y llévate hasta $60 €$ de descuento» o «Ven al Orange Black Friday. ¿Dónde si no?».

Los saludos de entrada y salida no son habituales en los vídeos publicados en YouTube por las principales compañías españolas (72; 7 \%). Estos saludos se sitúan, sobre todo, tanto en la entrada como en la salida del vídeo (44; 61,1 \%) y las marcas que los insertan en sus vídeos son precisamente los que tienen más publicaciones en YouTube en 2019: Orange, El Corte Inglés, Telefónica, Volkswagen y L'Oréal. Orange acumula el 43 \% (31) de los vídeos con saludos de entrada y/o de salida y El Corte Inglés suma 20 vídeos con este rasgo (27,8\%).

Las llamadas a la acción dentro tanto del propio vídeo - especialmente con la figura del presentador- como en la descripción y los saludos de entrada y/o salida son frecuentes en los vídeos con formato publirreportaje, como sucede en los tutoriales y análisis de producto que realiza Orange. En los vídeos con contenidos de branded content, cobertura informativa y spot corto la llamada a la acción se ubica únicamente en la descripción de los vídeos.

Por último, se analiza la estrategia creativa de los vídeos de la muestra para valorar si, gracias al contenido que aportan, la marca puede considerarse útil, en tanto en cuanto transmite vocación de servicio a la comunidad, aporta información útil o de entretenimiento, difunde un mensaje que sorprende o hace reír, soluciona algún problema al usuario o conecta con tendencias del consumidor.

Todos los vídeos de tipo branded content (334) son considerados de marca útil, al aportar con- tenidos con algún tipo de valor añadido para el usuario, ya sean de información/educación o de entretenimiento. En total, se identifica este estadio en 672 vídeos (el 65,3\% de la muestra), de manera que el 50,3\% de los vídeos considerados de marca útil tienen formato diferente al branded content, como los vídeos con publirreportajes y spots o de cobertura informativa y responsabilidad social corporativa. No se consideran de marca útil las publicaciones con tráilers de películas, series o documentales, como los que publican Orange, Telefónica o Vodafone, puesto que no son historias que ofrezca la propia marca de manera directa. Por el contrario, las comparaciones entre películas o las selecciones de películas que realiza Orange en algunos de sus vídeos con motivo del Día de San Valentín o el Día del Padre sí aportan un valor añadido al usuario.

La transmisión de vocación de servicio (214; $31,8 \%$ ) - especialmente en vídeos corporativos y de responsabilidad social corporativa- y el análisis de producto $(97 ; 14,4 \%$ ) y los tutoriales $(93 ; 13,8 \%)$ en formatos como los publirreportajes son los contenidos de marca útil más habituales: «¿Quieres más pantalla, más batería o tal vez un asistente inteligente o una consola en tu salón? Pues atento a este vídeo porque te contamos lo fácil que es renovar con Orange y motivos de peso para hacerlo ahora mismo. ¡No te lo pierdas!» ${ }^{12}$. En los spots es frecuente la conexión con tendencias $(86 ; 12,8 \%$ ) y la narración de historias (80; 11,9\%). Consejos, retos a los usuarios y contenidos que alimentan el hambre de asombro y de risa (Solana, 2010). En la figura 7, pág. 62, se incluyen dos ejemplos de vídeos con tutoriales:

12 https://bit.ly/orange-yt-2 


\section{Figura 7. Vídeos con tutoriales de L'Oréal y Orange}

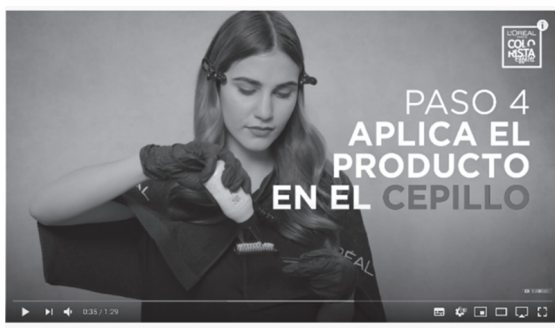

Cómo hacer mechas ombré en casa $\mid L-$ 'oreal Paris

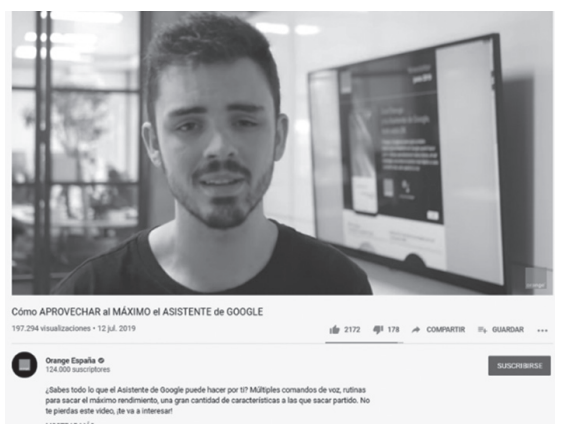

Fuente:YouTube (https://bit.ly/loreal-yt-51 y https://bit.ly/ orange-yt-144).
Los vídeos publicados en YouTube por Telefónica, Orange, Vodafone y Línea Directa no alcanzan el $50 \%$ de contenido de marca útil. Por su parte, los cinco vídeos publicados por Procter \& Gamble aportan utilidad al usuario (100\%), así como el 98,3 \% de los vídeos de Volkswagen (58), el 96 \% de las publicaciones de Mutua Madrileña (24), el 94,6 \% de los vídeos de L'Oréal (88) y el 84,7 \% de las publicaciones de El Corte Inglés (299). Pueden verse estos datos en la figura 8. Mutua Madrileña dedica diversas publicaciones al acoso escolar y a la violencia de género, con la etiqueta \#nosdueleatodos.

Las tendencias del consumidor más repetidas entre los mensajes de los principales anunciantes en YouTube son la desintoxicación digital y los riesgos del uso de los dispositivos móviles —en los vídeos de Orange, Telefónica y Vodafone-, la diversidad de género, el empoderamiento de la mujer —especialmente en L’Oréal y El Corte Inglés_- la ecología —Volkswagen - o el reparto igualitario de las tareas del hogar — caso de Procter \& Gamble_-. Puede verse un ejemplo en la figura 9:

Figura 8. Contenidos de marca útil por marca

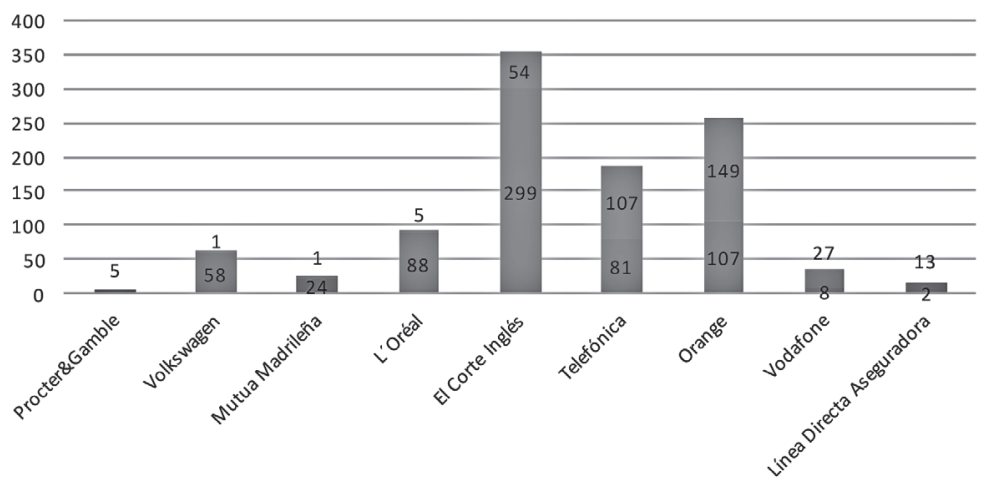

Marca útil $\quad$ No marca útil 


\section{Figura 9. Consejos y conexión con tendencias en vídeo de Orange}

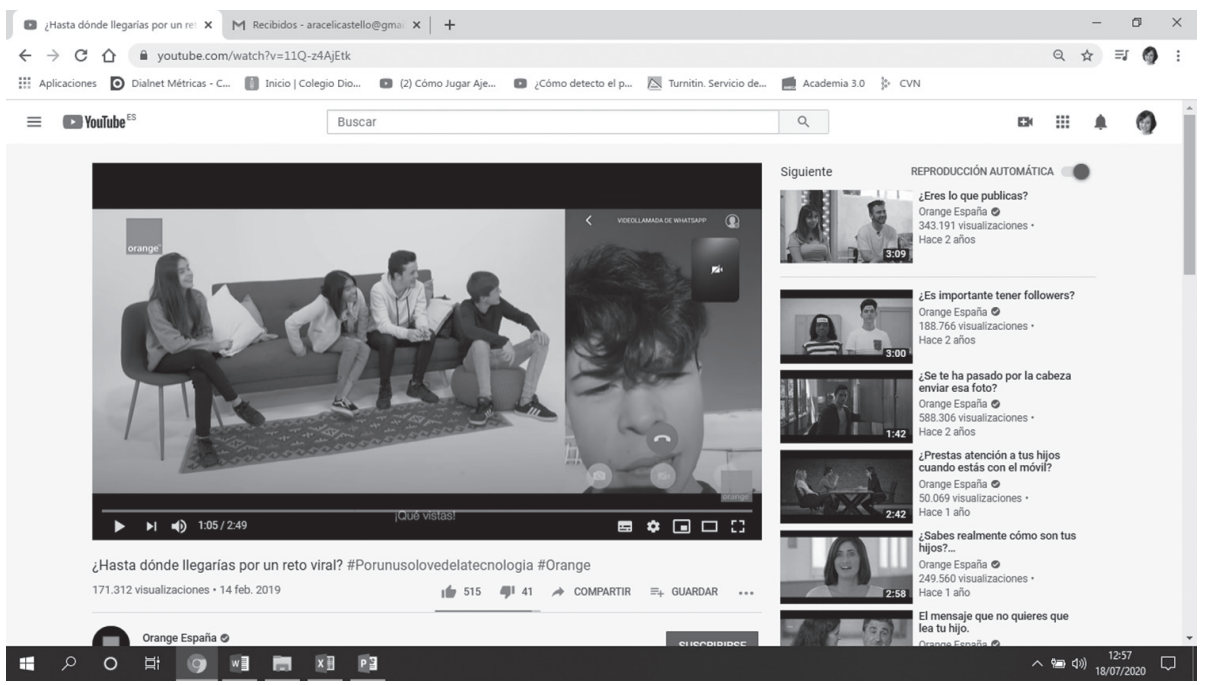

Fuente: YouTube (https://bit.ly/orange-yt-22).

\subsection{Tipo de contenido de marca}

De los 334 vídeos identificados como branded content, el más popular en la muestra (16,5\%), 187 corresponden a información/educación (56 \%) y
147 son de entretenimiento (44\%). En la figura 10 puede verse este reparto para cada una de las compañías que publica en YouTube contenidos de este tipo:

\section{Figura 10. Tipo de contenido de marca publicado por anunciante}

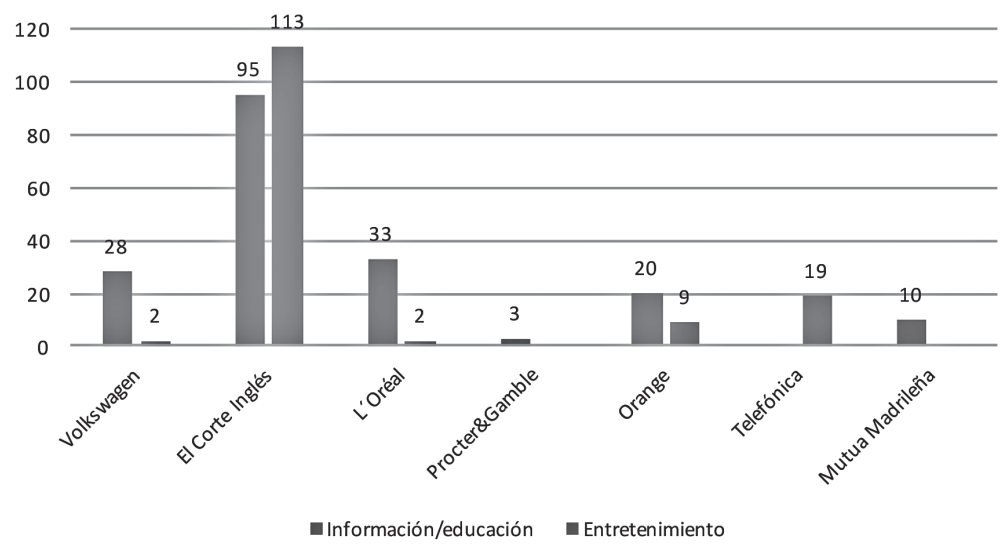




\section{Figura 11. Contenido de marca de El Corte Inglés y de Mutua Madrileña}
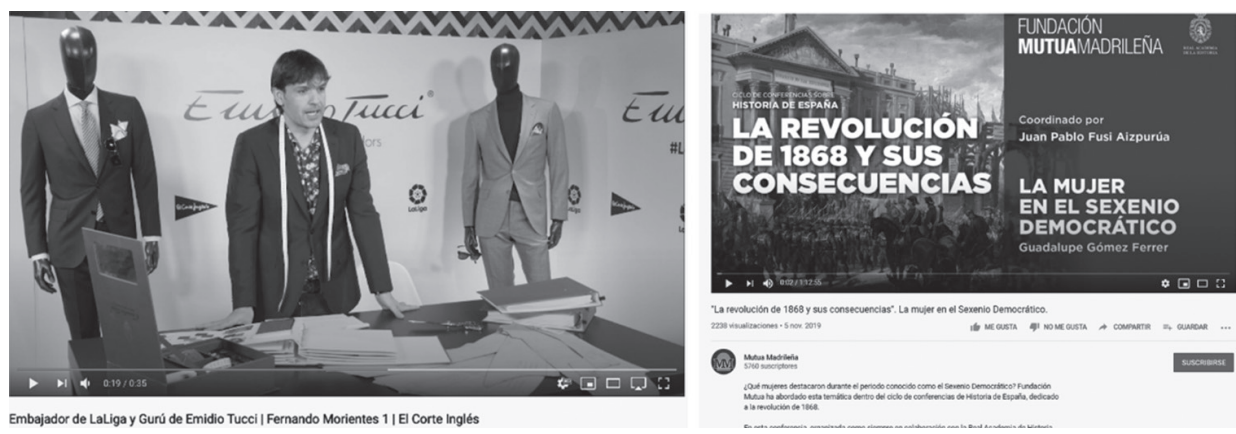

Fuente:YouTube (https://bit.ly/eci-yt-224 y https://bit.ly/mutua-yt-23)

El 76 \% de los vídeos de contenido de marca de entretenimiento son de El Corte Inglés. Todos los vídeos de branded content de Telefónica son también de este tipo. En los canales de Volkswagen, L'Oréal y Orange los contenidos de marca de información representan el $93 \%$, el $94 \%$ y el 69 \% de los vídeos clasificados como branded content. Destaca el caso de Mutua Madrileña, con un ciclo de conferencias sobre historia y novela negra. En la figura 11 pueden verse dos ejemplos de branded content. Pueden consultarse más ejemplos de vídeos de la muestra para las diferentes variables analizadas en el enlace https://bit.ly/ejemplos-yt.

\section{Discusión y conclusiones}

Los contenidos más vistos en los canales de YouTube de los principales anunciantes españoles son los spots, es decir, formatos publicitarios destinados generalmente al medio televisión que se vuelcan a la plataforma. Esto se debe a que las empresas contratan medios pagados en espacios digitales como el propio YouTube y otras redes sociales para generar tráfico a los mismos. Sin embargo, las publicaciones que generan más in- teracción son las de Orange, especialmente aquellas catalogadas como de marca útil: publirreportajes con tutoriales y análisis de productos.

Podemos ver, por tanto, una clara diferenciación en el tipo de contenidos publicados en lo que a audiencia e interacción se refiere: el contenido con mejores resultados en cuanto a interacción es aquel que aporta un valor añadido al usuario, mientras que los formatos tradicionales difundidos en este canal forman parte de una planificación publicitaria que genera una mayor cobertura.

Por otro lado, los contenidos identificados con un elevado nivel de creatividad coinciden, en general, con aquellos con formato spot, mientras que los contenidos diseñados ad hoc para YouTube se caracterizan por bajos niveles de creatividad, a partir de valores de pertinencia y divergencia (Tur-Viñes, 2018). La mayoría de vídeos están directamente relacionados con la marca y/o la empresa — especialización temática-y, en aquellas publicaciones de tipo publirreportaje o branded content, la empresa ofrece contenido de información, educación o entretenimiento de ámbitos relacionados con su sector de actividad. Este tipo 
de mensajes centrados en marca, empresa o sector resultan pertinentes pero poco divergentes y no comulgan con la filosofía de plataformas sociales como YouTube.

En general y con la excepción de Telefónica debido al contenido de corte corporativo que suele publicar, las marcas con más publicaciones coinciden con las que tienen más visualizaciones e interacciones. El Corte Inglés, Orange y L’Oréal son las compañías con una estrategia de contenidos en YouTube más definida. En los canales del resto de anunciantes las publicaciones son escasas o con una periodicidad irregular - Procter \& Gamble publica en 2019 únicamente cinco vídeos, entre febrero y marzo - . Por tanto, podemos inferir que la frecuencia de publicación influye en la audiencia y la interacción, al tratarse de una cuestión clave en la estrategia de contenidos en redes sociales para construir comunidad de marca, teniendo siempre en cuenta la importancia del enfoque de los contenidos publicados.

Es destacable el caso de Orange, con la estrategia de contenidos mejor adaptada a las características de la plataforma y enfocada hacia el usuario, con llamadas a la acción y saludos de entrada y/o salida en sus vídeos. Los publirreportajes con tutoriales y análisis de productos y las campañas de sensibilización — la mayoría de spots publicados por la marca son de este tipo- son sus publicaciones más atractivas para los usuarios. La marca dedica también numerosos vídeos a experimentos sociales inspirados en las historias de sus spots de concienciación sobre el uso de la tecnología ${ }^{13}$ y a charlas entre autónomos para comentar sus campañas dedicadas a este colectivo ${ }^{14}$.

Por el contrario, la audiencia de los vídeos de Telefónica en YouTube y la interacción que éstos

13 Se incluye un ejemplo en https://bit.ly/orange-yt-80 14 Puede verse un ejemplo en https://bit.ly/orange-yt-61 reciben son reducidas: sus publicaciones se basan en mensajes corporativos, con un discurso centrado en la empresa, una duración que en muchos casos supera la hora y casi la mitad de sus publicaciones concentradas en dos meses - febrero y octubre - por la cobertura informativa de dos eventos. Esta dicotomía ilustra cómo compañías de un mismo sector de actividad y, además, ambas de un sector muy ligado a las nuevas tecnologías como es el de telecomunicaciones, cuentan con una estrategia de contenidos en YouTube totalmente diferente. A partir del análisis del discurso que se ha realizado podemos decir que, independientemente del sector de actividad, no todas las marcas con mayor inversión publicitaria en España emplean YouTube de manera estratégica para generar comunidad, aportar valor al usuario y fomentar el engagement.

Los personajes protagonistas de los vídeos, personas corrientes con las que el público puede verse identificado, junto con la presencia de empleados y clientes reales, ejemplifican el ejercicio de transparencia de las marcas propio de la comunicación persuasiva integrada (Castelló-Martínez y Del Pino-Romero, 2019). Las publicaciones con los comentarios desactivados son escasas y casi todos los vídeos tienen implementados el título, la descripción y las etiquetas. Los vídeos se caracterizan por su breve duración, adaptada a los patrones de consumo de los medios digitales: la mayoría de publicaciones no exceden los cinco minutos.

Como se ha comprobado, los objetivos comunicativos y creativos de la estrategia de contenidos en YouTube de las principales marcas españolas parecen ser distintos así como, relacionado intrínsecamente con ellos, el público al que se dirigen: mientras que anunciantes como Telefónica emplea el canal con un discurso corporativo, otros difunden mensajes comerciales o contenidos en- 
focados al usuario. Cuestiones como la época del año - especialmente destacable es la época navideña, en la que los anunciantes difunden en su canal de YouTube sus campañas publicitarias-o la cobertura de eventos patrocinados también influyen en la actividad que las compañías tienen en YouTube, una red social cuyo principal objetivo es la generación de cobertura y no tanto la interacción, la conversación o la viralidad, como puede suceder en otras redes como Instagram, Twitter o TikTok (IAB Spain, 2020b).

Hay que tener en cuenta que los menores de 40 años son quienes utilizan más las redes sociales para seguir a marcas y que YouTube es la tercera red en la que se siguen influencers (IAB Spain, 2020c). De ahí que el tipo de contenidos que difunden compañías como Orange o L'Oréal sean los más afines a las características sociodemográficas y de estilos de vida de la audiencia mayoritaria en YouTube.

Con todo, del análisis de variables como la frecuencia de publicación, el formato y los rasgos formales de los contenidos se detecta la escasa adaptación de los contenidos que se publican en YouTube a las particularidades de la plataforma, lo cual resta creatividad a las publicaciones. Además, las publicaciones se realizan de manera un tanto improvisada, conforme se van generando contenidos, sin una planificación previa. Incluir en la descripción del canal una estructura de contenidos, organizando las publicaciones en bloques temáticos o formatos, sería de utilidad para el usuario.

Aunque la mayoría de los canales en YouTube de los principales anunciantes españoles se crearon antes de 2015 - lo cual supone una presencia ya prolongada en la plataforma - y la mayoría de las descripciones de los canales presentan un discurso enfocado al usuario, podemos decir que la madurez de las estrategias de contenidos se encuentra en un estadio intermedio. Direcciones web sin personalizar, meses sin publicaciones o contenidos duplicados así lo corroboran. Estos hallazgos avalan los resultados obtenidos por Costa-Sánchez (2014) tras el análisis de la presencia en YouTube de las empresas españolas con mejor reputación: las compañías se encontraban en una fase de experimentación con el canal, con una falta de interés por generar diálogo. Esta realidad contrasta con lo que sucede, por ejemplo, en los canales de menores YouTuber, que se caracterizan por su elevada profesionalización (AznarDíaz et al., 2019; López-Villafranca y OlmedoSalar, 2019, p. 9).

No se han observado pautas comunes en la muestra de vídeos analizados, lo cual contrasta con los estudios realizados por López-Villafranca y Olmedo-Salar (2019) o Tur-Viñes y GonzálezRío (2019) a propósito de otro tipo de canales de YouTube, como los de menores YouTuber o los YouTuber con más suscriptores, con patrones similares de funcionamiento. El volumen de suscriptores de los canales de los principales anunciantes españoles dista mucho de las cifras de seguidores de estos dos tipos de canales: si con 299.000 suscriptores el de L'Oréal es el canal con la mayor comunidad, el canal de Las Ratitas supera los 20,2 millones de suscriptores y el de elrubiusOMG sobrepasa los 38,2 millones de seguidores.

Los hallazgos de este estudio avalan los resultados de Costa-Sánchez y Túñez-López (2019, p. 234): las marcas suelen publicar en YouTube contenidos comerciales centrados en el producto, sin fomentar la conversación con el usuario. Volcar a la plataforma los vídeos de las campañas en medios tradicionales parece ser, en muchos casos, la solución a la gestión de un canal en YouTube. No obstante, las iniciativas de branded content como estrategia para generar contenidos adicionales se abren paso en la plataforma de vídeos, 
como demostraron Castelló-Martínez, Del PinoRomero y Tur-Viñes (2016).

En esta investigación se ha puesto el foco en las compañías con mayor volumen de inversión publicitaria en España. Los resultados demuestran que la estrategia de contenidos de estas marcas necesita de una mayor definición, al encontrarse en estado de desarrollo intermedio, con publicaciones escasas, periodicidad de publicación irregular y poca adaptación de contenidos a las particularidades del canal. Las limitaciones del estudio radican en la diversidad de sectores de las marcas analizadas, circunstancia que influye en los resultados, en la selección de nueve marcas y en la amplia variabilidad en lo que a la publicación de contenidos en YouTube por parte de las marcas se refiere. Este aspecto es ya en sí mismo un resultado destacable del estudio: siendo los diez anunciantes españoles con mayor inversión en publicidad — se entiendo que, sobre todo, en medios controlados-, no tienen planteamiento de presencia en YouTube similar ni en todos los casos estratégico.

Futuras líneas de investigación se centran en estudiar la evolución interanual de las publicaciones, con el fin de identificar el progreso en la profesionalización de la estrategia de contenidos en YouTube. El valor del estudio radica en el tamaño muestral de los vídeos analizados (1.029 vídeos) y la originalidad del artículo viene dada por el estudio del uso que los principales anunciantes españoles realizan de su canal en YouTube, identificando rasgos comunes en los contenidos que publican en esta plataforma.

\section{Bibliografía}

Aced-Toledano, C. y Lalueza-Bosch, F. (2016). ¿Qué contenidos publican las empresas en los medios sociales? Análisis crítico del discurso de las compañías del IBEX 35 y del Fortune 500 en blogs corporativos, Facebook y Twitter. Revista internacional de relaciones públicas, 6(11), 135-154. https:// doi.org/10.5783/RIRP-11-2016-08-135-154

AIMC (2019). Navegantes en la Red. Disponible en: http:// bit.ly/navegantes-2019

Arroyo-Almaraz, I., Baños-González, M. y Rodríguez-García, T. C. (2009). Publicidad social en las ONG de Córdoba (Argentina). Perfiles de la construcción del mensaje. Revista latina de comunicación social, 64, 1011-1029. https://doi. org/10.4185/RLCS-64-2009-877-1.011-1.029

Arthurs, J., Drakopoulou, S. y Gandini, A. (2018). Researching YouTube. Convergence, 24(1), 3-15. https://doi. org/10.1177/1354856517737222

Ashley, C. y Tuten, T. (2015). Creative Strategies in Social Media Marketing: An Exploratory Study of Branded Social Content and Consumer Engagement. Psychology E Marketing, 32(1), 15-27. https://doi.org/10.1002/mar.20761
Aznar-Díaz, I., Trujillo-Torres, J. M., Romero-Rodríguez, J. M. y Campos-Soto, M. N. (2019). Generación Niños YouTubers: análisis de los canales YouTube de los nuevos fenómenos infantiles. Píxel-BIT, 56, 113-128. https://doi.org/10.12795/ pixelbit.2019.i56.06

Capriotti, P., Zeler, I. y Oliveira, A. (2019). Comunicación dialógica 2.0 en Facebook. Análisis de la interacción en las organizaciones de América Latina. Revista latina de comunicación social, 74, 1094-1113. https://doi.org/10.4185/RLCS2019-1373

Castelló-Martínez, A., y Barrilero-Carpio, C. (2021). La presencia de marca en los contenidos de belleza de YouTube dirigidos al público sénior femenino. AdComunica, 21, 185210. https://doi.org/10.6035/2174-0992.2021.21.10

Castelló-Martínez, A. y Del Pino-Romero, C. (2019). De la publicidad a la comunicación persuasiva integrada. Estrategia y empatía. Madrid: Esic.

Castelló-Martínez, A. y Del Pino-Romero, C. (2014). Conectando con el público joven a través de los contenidos: el 
caso de Coca-Cola. En Ron, R., Álvarez, A. y Núñez, P. (Coords.). Bajo la influencia del branded content (pp. 167188). Madrid: Esic.

Castelló-Martínez, A., Del Pino-Romero, C. y Tur-Viñes, V. (2016). Estrategias de contenido con famosos en marcas dirigidas a público adolescente. Icono14, 14(1), 123-154. https://doi.org/10.7195/ril4.v14il.883

Costa-Sánchez, C. y Túñez-López, M. (2019). Contenidos audiovisuales en social media. Análisis comparativo de Facebook y Youtube. Fonseca, journal of communication, 19, 223-236. https://doi.org/10.14201/fjc201919223236

Costa-Sánchez, C. (2017). Estrategias de videomarketing online: tipología por sectores de negocio. Communication $\mathcal{E}$ Society, 30(1), 17-38. http://bit.ly/costasanchez-2017

Costa-Sánchez, C. (2014). Audiovisual y Web 2.0. Empleo de YouTube por las empresas españolas con mejor reputación. Chasqui. Revista Latinoamericana de Comunicación, 126, 31 41. https://doi.org/10.16921/chasqui.v0i126.264

De Aguilera-Moyano, J., Baños-González, M. y RamírezPerdiguero, F. J. (2016). Los Mensajes Híbridos en el marketing postmoderno: una propuesta de taxonomía. Icono14, 14(1), 26-57. https://doi.org/10.7195/ril4.v14il.890

De Aguilera-Moyano, M., Castro-Higueras, A. y Pérez-Rufí, J. P. (2018). Entre broadcast yourself y broadcast whatever: la página de inicio de YouTube como síntesis de su estrategia empresarial. El profesional de la información, 28(2), e280206. https://doi.org/10.3145/epi.2019.mar.06

De Blasio, G.G., Mazerant, K. y Scharlott, B. (2019). Entrancing Ourselves with YouTube: Emotion-producing Practices Amplify the Impact of Branded Video. En Frandsen, F. et al., (Eds.). Big Ideas in Public Relations Research and Practice. Advances in Public Relations and Communication Management, Vol. 4. (pp. 39-56). Brussels: Euprera. https://doi. org/10.1108/S2398-391420190000004004

De Miguel-Zamora, M. y Toledano-Cuevas-Mons, F. (2018). Storytelling y Storydoing: técnicas narrativas para la creación de experiencias publicitarias. En García-García, F, Tur-Viñes, V., Arroyo-Almaraz, I. y Rodrigo Martín, L. (Eds.). Creatividad en publicidad. Del impacto al comparto (pp. 215232). Madrid: Dykinson.

Elorriaga-Illera, A. y Monge-Benito, S. (2018). La profesionalización de los YouTubers: el caso de Verdeliss y las marcas. Revista latina de comunicación social, 73, 37-54. https:// doi.org/10.4185/RLCS-2018-1244
García-Cay, A., García-Peña, M., Kendall-López, L. G. y Lima-Florido, C. I. (2013). YouTube: la clave de los canales con mayor número de suscriptores en España. En Pérez Rufí, J. P. (Coord.). Industrias audiovisuales: Producción y consumo en el siglo XXI (pp. 6-28). Málaga: Universidad de Málaga. Disponible en: https://bit.ly/perez-rufi-2013

Gómez-Vásquez, L. M. (2013). Me gusta o te sigo: Análisis de la comunicación de prácticas de Responsabilidad Social Corporativa a través de los medios sociales. Correspondencias E análisis, 3, 89-109. https://doi.org/10.24265/cian.2013. n3.04

Holland, M. (2016). How YouTube developed into a successful platform for user-generated content. Elon journal of undergraduate research in communications, 7(1), 52-59. Disponible en: http://bit.ly/holland-2016

IAB Spain (2020a). Inversión Publicitaria en Medios Digitales 2019. Disponible en: http://bit.ly/inversion-iab-2020

IAB Spain (2020b). Observatorio de Marcas en Redes Sociales 2020. Disponible en: http://bit.ly/iab-observatorio-2020 IAB Spain (2020c). Estudio de Redes Sociales 2020. Disponible en: http://bit.ly/iab-redes-2020

IAB Spain (2018). Estudio Anual Vídeo Online 2018. Disponible en: http://bit.ly/video-iab-2018

InfoAdex (2020). Estudio InfoAdex de la Inversión Publicitaria en España 2020. Disponible en: http://bit.ly/infoadex-2020

Kim, J. (2012). The institutionalization of YouTube: From user generated content to professionally generated content. Media, culture \& society, 34(1), 53-67. https://doi. org/10.1177/0163443711427199

Leadbeater, C. y Miller, P. (2004). The pro-am revolution: How enthusiasts are changing our society and economy. London: Demos.

Lobato, R. (2016). The cultural logic of digital intermediaries: YouTube multichannel networks. Convergence, 22(4), 348-360. https://doi.org/10.1177/1354856516641628

López-Villafranca, P. y Olmedo-Salar, S. (2019). Menores en YouTube, ¿ocio o negocio? Análisis de casos en España y EUA. El profesional de la información, 28(5), e280520. https://doi.org/10.3145/epi.2019.sep.20

Mariano-Da-Rocha-Barichello, E. y Scheid, D. (2017). Visibilidade organizacional nas redes sociais digitais: contexto indicios e reflexoes. Revista internacional de relaciones públicas, 
7(13), 101-122. https://doi.org/10.5783/RIRP-13-2017-08$123-140$

Osorio Andrade, C. F., Rodríguez Orejuela, A. y Moreno Betancourt, F. (2021). Efectos de las características de videos en YouTube que aumentan su popularidad: un análisis empírico. Tendencias, 22(1), 18-38. https://doi.org/10.22267/ rtend.202102.153

Ramos-Serrano, M. y Herrero-Diz, P. (2016). Unboxing and brands: YouTubers phenomenon through the case study of evantubehd. Prisma Social. Revista de Ciencias Sociales, 1, 90120. Disponible en https://bit.ly/ramos-herrero-2016

Rodríguez-Rabadán, M. (2021). El papel de la técnica publicitaria Branded Content para generar nuevos vínculos de compromiso entre marca y sociedad. Questiones publicitarias: revista internacional de comunicación y publicidad, 4(21), 31-37. https://doi.org/10.5565/rev/qp.350

Sabich, M. A. y Steinberg, L. (2017). Discursividad youtuber: afecto, narrativas y estrategias de socialización en comunidades de Internet. Revista mediterránea de comunicación, 8(2), 171-188. https://doi.org/10.14198/MEDCOM2017.8.2.12

Sánchez-Vera, M. M., Solano-Fernández, I. M. y Recio-Caride, S. (2019). El storytelling digital a través de videos en el contexto de la educación infantil. Píxel-BIT, 54, 165-184. https://doi.org/10.12795/pixelbit.2019.i54.09
Sicilia Piñero, M. a y Merino Sánchez, J. (2020). Integración de la estrategia de comunicación en canales propios: El Caso de El Corte Inglés. Revista Internacional de Investigación en Comunicación aDResearch ESIC, 21(21), 8-26. https://doi. org/10.7263/adresic-021-01

Solana, D. (2010). Postpublicidad. Reflexiones sobre una nueva cultura publicitaria en la era digital. Barcelona: Postagencia.

Tur-Viñes, V. (2018). Valoración de las producciones creativas en comunicación persuasiva. En García-García, F., TurViñes, V., Arroyo-Almaraz, I. y Rodrigo Martín, L. (Eds.). Creatividad en publicidad. Del impacto al comparto (pp. 265 294). Madrid: Dykinson.

Tur-Viñes, V. y González-Río, M. J. (2019). Youtubers y estrategias de gestión de comunidades. Revista Latina de Comunicación Social, 74, 1291-1307. https://doi.org/10.4185/ RLCS-2019-1384

Wang, R. y Chan-Olmsted, S. (2020). Content marketing strategy of branded YouTube channels. Journal of Media Business Studies, 17(3-4), 294-316. https://doi.org/10.1080/16 522354.2020 .1783130

Zeler, I. y Capriotti, P. (2019). Communicating corporate social responsibility issues on Facebook's corporate fan pages of latin American companies. El profesional de la información, 28(5), e280507. https://doi.org/10.3145/epi.2019.sep.07 
다 (1) $(5)$

\section{Using Virtual \\ Assistants and \\ Chatbots for Crisis \\ Communication}

\section{Uso de asistentes}

virtuales y chatbots

para la comunicación

de crisis

Gema Bonales Daimiel, Ph.D.,

Associate professor at the department

of Applied Communication Sciences,

Complutense University of Madrid

gbonales@ucm.es

https:/orcid.org/0000-0003-2085-2203

Eva Citlali Martínez Estrella, Ph.D. student, Complutense University of Madrid

evacmart@ucm.es

https://orcid.org/0000-0001-6599-1050
Bonales Daimiel, G. y Martínez Estrella, E. (2021)

Using virtual assistants and chatbots for crisis communication

Revista Internacional de Investigación en Comunicación aDResearch ESIC. No $25 \mathrm{Vol} 25$

Monográfico especial, marzo 2021 · Págs. 70 a 91

https://doi.org/10.7263/adresic-025-04 
ABSTRACT

\section{JEL Classification: \\ M31}

Key words:

communication

channel,

chatbot,

virtual personal

assistant,

technology,

usability
Purpose: To study the role of bots and the main virtual assistants as communication tools and support for citizenship. The goal is to observe if this type of technology achieves the designed objectives, if it is useful for the users and to know how they have contributed to the communication crisis strategies of the government and other institutions in the context of the Covid-19 pandemic

Design / Methodology / Approach: The current study therefore pursued a mixed method: a qualitative fieldwork whit a quantitative assessment by adding an additional measurement from user's interest. In order to achieve the objectives, the research has a comparative analysis that contrasts the data collected in surveys, interviews with experts and in the fieldwork done on the selected platforms, which have been analyzed from seven different dimensions: predetermined questions, initial greeting, privacy policies, languages, data on the health center, health recommendations and a diagnosis option.

Results: The result of this work shows that 30\% of the analyzed sample uses bots, and that those who have used this type of assistants during the health crisis have done so mainly for informational purposes, being the months of April and October the ones that have reflected the greatest activity in this regard; while 38.3\% claim to use virtual assistants, Google is the virtual assistant most used in Spain.

Limitations / Implications:The study is focused on the Spanish environment in specific time during health crisis.

Originality / Contribution: Chatbots and virtual assistants are considered as a communication channel that can help to strengthen sanitary measures.

\section{Clasificación JEL: \\ M31}

Palabras clave:

Canal de comunicación, chatbot, asistente virtual, tecnología, usabilidad
Objetivo: Estudiar el papel de los bots y los principales asistentes virtuales como herramientas de comunicación y apoyo a la ciudadanía. El objetivo es observar si este tipo de tecnología consigue los propósitos pensados, si es útil para los usuarios y conocer cómo han contribuido a las estrategias de comunicación de crisis por parte del gobierno y de otras instituciones en el contexto de la pandemia de la Covid-19.

Diseño/Metodología/Enfoque: El presente estudio ha seguido un método mixto: un trabajo de campo cualitativo con una evaluación cuantitativa, añadiendo una métrica adicional a partir del interés de los usuarios. Para lograr los objetivos, la investigación cuenta con un análisis comparativo que contrasta los datos recogidos en las encuestas, las entrevistas a expertos y en el trabajo de campo realizado en las plataformas seleccionadas, que han sido analizadas desde siete dimensiones diferentes: preguntas predeterminadas, el saludo inicial, políticas de privacidad, idiomas, datos sobre centros de salud, recomendaciones sanitarias y opción de un diagnóstico.

Resultados: El resultado de este trabajo señala que el $30 \%$ de la muestra analizada utiliza bots, y que quienes han utilizado este tipo de asistentes durante la crisis sanitaria lo han hecho con fines informativos, en este sentido, fueron los meses de abril y octubre los que han reflejado mayor actividad; mientras que el 38,3\% afirma utilizar asistentes virtuales, siendo Google el asistente virtual más utilizado en España.

Limitaciones/Implicaciones: El estudio se centra en el entorno español en un momento concreto de crisis sanitaria.

Originalidad/Contribución: Los chatbots y asistentes virtuales se consideran un canal de comunicación que puede ayudar a reforzar las medidas sanitarias. 


\section{Introduction}

During the last years and specially with the lockdown established in Spain, as a consequence of the state of alarm decreed in March 2020, the new information technologies have played a relevant role thanks to their immediacy and coverage possibilities. These have emerged in the field of health communication, as in other areas, providing a change in the way of conceiving medicine and, consequently, new terms have emerged such as eHealth or telemedicine.

In this context, conversational platforms have become one of the most used tools by institutions in order to alleviate the lack of resources in telephone and face-to-face attention when dealing with the first consultations made by citizens who suffer from symptoms, or by those who request some other type of urgent information related to the disease. This demand for agility was attended to by different companies that offered the development of bot services in record time. "Chatbots are a solution that allows for the rapid implementation of an immediate response to users" (Aguilar et al., 2020). This article analyzes the level to which conversational platforms have had the decongestion of health services in Spain and whether their availability has been useful for citizens. For this purpose, a sample of eight conversational platforms has been taken: four virtual assistants and four chatbots in order to review their particular characteristics and contributions. It also integrates the data obtained through a survey to users and from several interviews with experts.

The result of this research shows that the level of use of specific health chatbots for the Covid-19 currently reaches about 30\% of the sample analyzed and that people who have used this type of assistance have done so for information purposes, reflecting greater activity in this regard during April and October. Previously chatbots were present for ecommerce activities, but now conversational attendees have gained strength in the Covid-19 pandemic. In this way, they are no longer just a technological development, because they are transforming into another communication channel that works for the dissemination of important information for citizens, helping to decongest the health system and with a possibility of taking a step towards "telemedicine".

The role of technology in crisis situations has been shown to be fundamental and even more so when it affects health on a global level, as is currently the case. Technological developments in the area of communications technology and, in particular, the implementation of bots can contribute significantly to improving health care and optimizing its resources, solving problems of communication and information and mitigating other problems of various kinds, including psychological problems or those arising from isolation. However, conducting the literature review for this study, it has been observed that there is no research focused on the effectiveness and real scope of these applications (Zarouali et al., 2018, Brandtzaeg and Folstad, 2017). Nor any studies have been found that relate the role of conversational platforms in health emergencies or during the collapse of health systems.

Consequently, it seems entirely relevant that the experience acquired in this extreme situation should serve to stimulate the development of studies related to the evolution on digital technology, and, specifically, on the use of different conversational platforms, which will be very useful for the development and improvement of tools related to the communication processes between men and machines, promoting a prevention culture. 


\section{Al application in the communica- tion between human-machine}

When talking about the human-machine topic, especially about Artificial Intelligence, it is important to take into account the Restless Valley Theory, which assures that the degree of preference of the human being for an artificial intelligence will depend on whether the latter becomes more human. If this is not the case, the inclination for it diminishes. There is a great affinity of systems that use avatars with human forms, because it is easier for the user to identify with the technological development in question (Mori, 1970; Wilks, 2010).

Bots, according to Ferrara (2016), are computer robots that operate online and remotely. However, depending on the specific function for which they have been designed, they adopt one name or another and the term chatbot refers to a "machine conversation system that interacts with human users through a natural conversation language" (Shawar and Atwell, 2005, p. 489).

Since the creation of human-computer interface applications, the use of social keys in the interaction with the computer has had a continuous development (Prendinger and Shizuka, 2004). In this sense, it is important to go deeper into the functions of bots and virtual assistants in communication acts or processes in a period as serious as the current one. Intelligent machines have appropriate computer programs to solve some problems and not others, and although they use the syntactic elements of the language, they do not use semantics (Malpica, 2016, p.9), and this is where their main difficulty lies in communicating with man and imitating him one hundred percent. Their algorithms are logical, they are not human; so they do not form part of the conscious reasoning process of the machine. Consciousness is the capacity of the human to debate, reflect and realize his own existence.

In recent years, studies about communication and technology have focused on finding more advanced ways to measure the usefulness and effectiveness resulting from human-computer interaction, and at the same time, to know how the user responds. Through different studies such as those of Lind and Salomonson (2006), Brandtzaeg and Folstad, (2017), Van den Broeck et al., (2019), among other researchers, it has been proven that conversational robots can improve the experience of online customers, especially because they enhance the feeling of being attended to at the precise moment, they need it. Currently, however, it is difficult to analyze the degree of interaction that exists between these assistants and consumers as well as the level of real understanding that users have of the information provided by this media.

One of the main advantages of conversational platforms is that they can be used by different organizations for individual communication with the consumer, achieving — despite an automated process - optimal levels of personalization and interaction (Van den Broeck et al., 2019 and Kunse, 2016). This is possible because chatbots are specifically designed to be able to have highly personalized conversations with users, using pre-programmed dialogue schemes where the client can make use of natural language or use certain buttons with proposed options and thus obtain particular recommendations and relevant information.

The interaction between the user and the bot is framed within conversational genres, based on direct communication with the audience through dialogue (Trillo-Domínguez et al., 2017). Due to this connection, a relationship of trust is sought to be established in order to respond to their 
preferences and concerns. These conversational media dominate digital rhetoric through natural language, which should be as close as possible to that of a human being: "the potential of bots lies in their personalized distribution and in their conversational power with audiences, through instant messaging applications" (SánchezGonzález et al., 2017: 67).

Chatbots embody four fundamental characteristics that detail their form and behavior: the ability to act autonomously, full or partial automation, which require initial orientation, and are used through online media (Grimme et al., 2017, Hofeditz et al., 2020). In addition, its operation system is very simple, and anyone is trained to operate it as the program is ready to answer your questions (Dahiya, 2017). Overall, part of its appeal lies in the fact that these bots are instantly available 24 hours a day, 7 days a week. The chatbot can make information available on a larger scale and also improves customer service by providing a quick response to the interested party (Van den Broeck et al., 2019 and Herriman et al., 2020)

When a user inputs any question the program employs artificial intelligence (AI) to give the answer immediately, presenting the text in a conversational way. This facilitates the collaboration with researchers and help centers, because thanks to the set of information collected in human-computer conversations, it is possible to have a high level of automation and enrich the databases.

The conversational flow of chatbots based on a linguistic model, as shown in Figure 1, is

\section{Figure 1. Chatbot working: conversational flow}

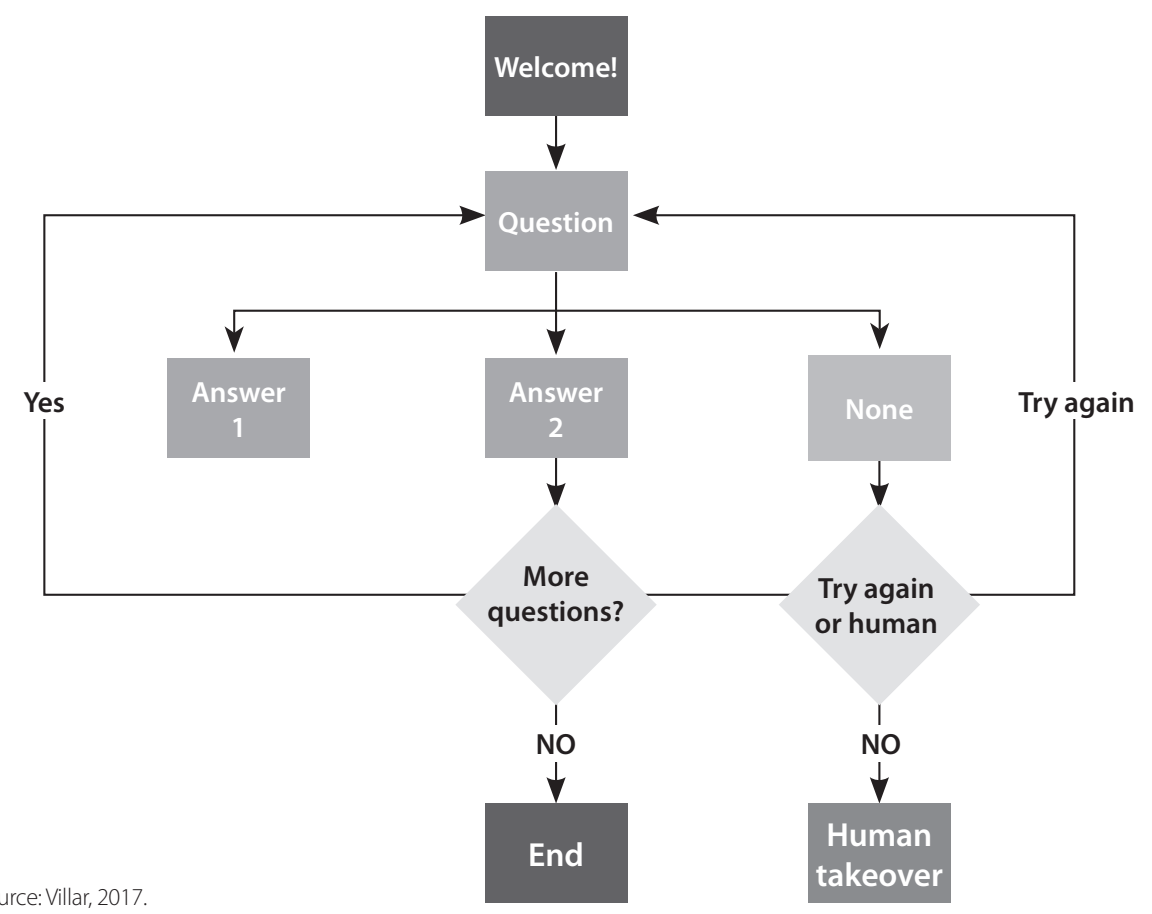


designed to be based on a linear block-structured dialogue. These diagrams always begin with a welcome message and a default answer. However, the answers they provide are limited to answering frequently asked questions (FAQs). The possibility of generating more intelligent and versatile answers that go beyond that predefined script would require constant updating. This automatic learning is achieved by robots that use AI in their design, requiring, therefore, a greater investment. There are also hybrid models, which have the advantage of allowing solutions to be developed even in the absence of data and which can go beyond the scope of linguistic rules to make intelligent interferences in contexts where it is complicated, or impossible, to use language tools exclusively (Artificial Solutions, 2020). An effective chatbot provides results by helping patients to do something without human intervention.

A virtual personal assistant in technical terms, it is a software go-between that interacts with individuals through voice, and can perform tasks or services for us. The process is the result of a merger of artificial intelligence (AI), linguistics, and computer science (Heneveld, 2018). So, these tasks or services are based on user input data, location recognition, process human speech, as well as the ability to access information from a variety of online resources.

"Combining NLP with machine learning, personal assistants' home on who we are, what we like, and deliver personalized responses" (Heneveld, 2018). The interaction that occurs between a virtual assistant and a person should be natural.

A person communicates using voice and the virtual assistant processes, interprets and responds in the same way. One of the key aspects of an intelligent personal assistant is its ability to organize and maintain information. organize and maintain information. This includes the management of emails, calendar events, files, to-do lists calendar, files, to-do lists, etc. Having virtual assistants on smart devices is now commonplace. The assistant interacts with the user using the device through a speech-based interface to answer questions, make recommendations or perform actions in other digital services to which it is able to connect on demand, providing results in an individualized and targeted way to the user with whom it interacts (Guzman, 2017).

Some examples of personal assistants are Apple's Siri; Google Assistant and Google Now; Amazon Echo; Microsoft Cortana; Voice Mate from LG; Silvia and Hidi from HTC; Bixby from Samsung and Braina. Siri is perhaps the best-known and most popular of the virtual assistants, along with Cortana, Cortana virtual assistants, along with Cortana, Alexa and Google Assistant. These are used in tablets, smartphones, cars, speakers' smartphones, cars, speakers and electronic devices of all kinds. Their function is to help users with certain tasks to users. By means of a simple voice command, they can carry out certain open a certain application, making life easier. People just have to give them the order of what is needed. "Many believe consumers will increasingly become more dependent on smart speakers and their ilk, because they will offer news in a much more interactive manner than traditional news sources and even query the assistant for specific topics and further customize and personalize the experience over time", (Martin, 2017).

An example of the workflow of these virtual assistants is shown in Figure 2. Its computational characteristic is that they respond to a specific user's intention, which is the main purpose that the each virtual assistant has.

Thus, virtual personal assistants are innovations that allow the user to interact with a computer 


\section{Figure 2. Virtual assitants's workflow}

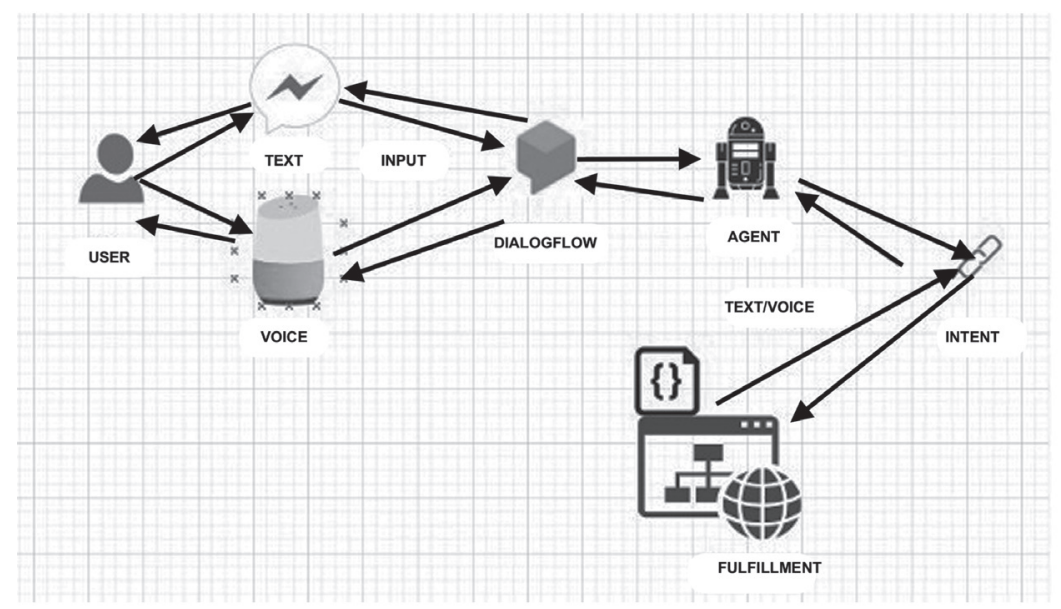

Source: Paul, 2018.

textually and/or verbally and whose interactions are digitized to be subsequently stored, analyzed and processed through various AI techniques (Tabarés, 2020). This opens up a natural path to add more smart home products, enhance the customer experience, and build customer loyalty through the empowerment of voice control (Heneveld, 2018). Currently this technology uses female voices -so present in IOT technology nowadays- as authority, referring us to gender stereotypes (Piñeiro-Otero, 2011). Therefore, it is of interest to study why only female voices are used in these technologies and what is the scope they have.

Nevertheless, virtual assistants do not yet have the ability to recognize a certain illness through voice analysis; however, technological developments are working on it to achieve the application of "telemedicine". "Chatbots will play a leading role by embodying the function of a virtual assistant and bridging the gap between patients and clinicians. Powered by AI and machine learning algorithms, chatbots are forecasted to save healthcare costs when used in place of a human or assist them as a preliminary step of helping to assess a condition and providing selfcare recommendations" (Fadhil, 2018).

Additionally, it offers a simple, low-friction experience (Jenkins et al., 2007). Thus, this digital development transforms the alternatives in the communication processes and speeds up the delivery of information. In this context, it can be said that bots avoid the congestion of communication networks and health system facilities, especially in care centers, and consequently contribute to minimizing the risk of contagion by contact. Furthermore, the development of these platforms based on artificial intelligence can also collaborate in the health education of the population, for example, reducing the possibility of spreading false information about Covid-19. Similarly, the presence of this type of technology helps institutions to have a friendlier and closer approach to concerned citizens (Ahuja et al., 2020). 
So, we are facing a techno-social ecosystem, extended by various platforms, devices, protocols, algorithms and interfaces that seek at all times to digitize and enhance the interactions of its users with the environment. Therefore, both conversational assistants have unique possibilities to strengthen general well-being, because they can mitigate the emotional burden that infectious diseases cause in the short and long term in pandemics and thus, promote an active communication between health authorities or managers with each individual.

\section{Use of virtual assistants and bots}

According to a study conducted by HubSpot (2019), the $48 \%$ of consumers would instead connect with a company via live chat than any other means of contact; besides, $63 \%$ of people would consider messaging an online chatbot to communicate with a business or brand (Joseph, 2019). So, the chatbot can give the opportunity of boosting a brand perception, because the consumer has a friendly experience that offers a visual interaction.
With Statista's 2019 results, 78\% of service organizations are taking advantage of chatbots in simple self-service scenarios. Just in second place with $77 \%$ is the use of bots to evaluate the type and difficulty of a query before passing it on to the commercial agents. It should be noted that this communication channel has surpassed the use of social networks between brand and consumer.

In Spain there are 43 million internet users, of which 52\% use social networks and 62\% make online purchases, with product and travel inquiries being the main information sought to be answered by a chatbot (We are social, 2019).

As for virtual assistants, around 4.3 million families use them on a daily basis, which is equivalent to $10.7 \%$ of the Spanish population, according to the results of the 1st Wave of the General Media Study 2019 (EGM) and the Association for Media Research (AIMC). The leading virtual assistant is Siri, owned by Apple, while the assistant of Google, Alexa (Amazon), Cortana (Microsoft) and Bixby (Samsung) have an average share between $7 \%$ and 12\%. Aura (Movistar) is beginning to be used.

\section{Figure 3. Virtual assistant insertion in Spain}

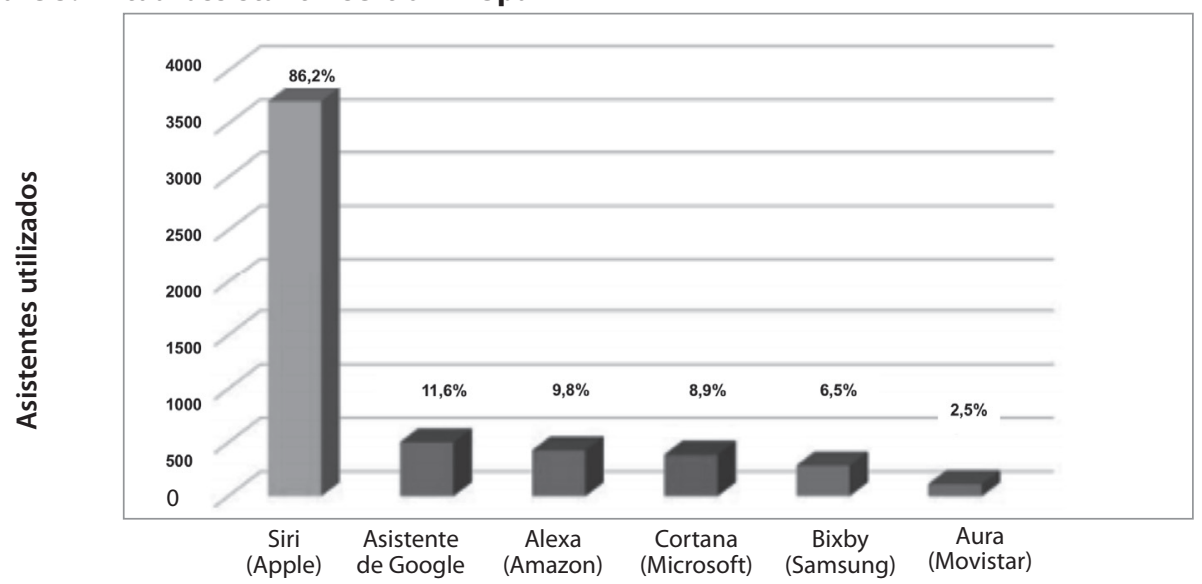

Source: Estudio General de Medios (EGM). 
Furthermore, during 2020, only 8\% of the Spanish population said they use virtual assistants several times a day; while almost 20\% said they use conversational platforms a couple of times a week (Statista, 2021). Virtual assistants become an important channel for generating two-way communication in emergency management (Bird et al., 2012), in which there is a need to disseminate accurate information to combat rumors, give warnings and recommendations for action; as well as communicate data on specific situations (Hofeditz et al., 2020).

Another benefit of a virtual assistant is that it can be used in text or voice format, thus helping people with disabilities, or elderly people without sufficient knowledge to search manually for the required information on the web. According to a study carried out by the Digital Marketing Agency Trend (2020) in Spain, assistants are used mainly to ask questions, check the weather, find places or listen to music and their presence represents 4.3 million homes in this country.

For these reasons, the conversational platforms have been a key piece in this crisis because they have provided information, follow-up, monitoring and health control to the citizen in the first phase of the detection of the contagion, when the health system was especially saturated with sick people and people who presented some symptoms compatible with the Covid-19 infection.

\section{Influence of conversational platforms on a crisis communication}

Natural disasters and pandemics are unforeseeable and pose unique challenges to health care delivery; as a result, the Covid-19 pandemic has been a huge undertaking for both researchers and technology developers, as technical teams around the world have sought digital solutions to help relieve the pressure on medical issues in healthcare facilities.
Researchers Miner, Laranjo and Kocaballi (2020) believe that pandemics have three unique characteristics that make them susceptible to personalized interventions through these robots. First, individual actions can significantly worsen outcomes in these crises, as a single individual can infect more people, depending on their behavior. Second, there is a fear of infection and a "stigma associated with the disease, as a result, people may feel personally responsible for poor outcomes during a pandemic and also hide symptoms" (Miner, Laranjo, \& Kocaballi, 2020). The third feature is that during such a situation, many people should avoid physical gatherings, which may worsen the risk of future mental health problems.

For this reason, several government organizations and health institutions have used social media platforms such as Facebook, WhatsApp, Instagram and Twitter to provide specific information about Covid-19 to the population. WhatsApp is one of the main methods of providing information about Covid-19 in many countries (Hutchinson, 2020). An example is the governments of Australia, India, Singapore and the United Kingdom.

The creation of all Covid-19 applications has served to collect and register data related to the user's health. The first to be developed and widely distributed were the contact tracking applications, which were created to notify users if they had crossed paths with another person infected with the coronavirus. The first of these was developed in Singapore (Baharudin, 2020). Later, applications were developed to monitor the compliance of citizens with the lockdown, as well as conversational assistants that answered the frequent questions of the population.

The applications of symptom surveillance have been useful in identifying disease trends 
Table 1. Conversational robots in Spain.

\begin{tabular}{|c|c|c|c|}
\hline Company & Media & Chatbot & Institution \\
\hline 1. 1 millionbot & Web and WhatsApp & Carina Bot & $\begin{array}{l}\text { Ayuntamiento de Alicante } \\
\text { y Elche }\end{array}$ \\
\hline 2. Hubtype & WhatsApp and Telegram & gencatBot & Generalitat de Catalunya \\
\hline 3. Chatbot Chocolate & Web & Maia & Servicio Vasco de Salud \\
\hline $\begin{array}{l}\text { 4. CARTO, ForceManager y } \\
\text { Mendesaltaren, con el apoyo } \\
\text { de Telefónica, Ferrovial, } \\
\text { Google y Googo. }\end{array}$ & Web and WhatsApp & CoronaMadrid & Comunidad de Madrid \\
\hline
\end{tabular}

Source: Own elaboration.

and possible areas of high transmission. Most countries made the applications and chatbots based on the disease symptom manual and on the questionnaires that users were answering (Hanson et al., 2020).

Table 1 lists some of the bots that emerged in Spain (2020) to join the health struggle in the pandemic corresponding to the institutions contacted for this study.

Carina has been developed by 1 Millionbot in Spain. It is a free conversational platform about coronavirus based on AI that uses official sources such as the World Health Organization (WHO) and official government sources. This technology, launched in the first half of March 2020, has been inserted by different entities in their web pages. Like Carina in Spain, this company developed a month later for the Republic of Ecuador, the Catalina chatbot. The United Nations Development Programme (UNDP) awarded this Alicante-based company the development of Catalina to provide an urgent response to the demands of the citizens of Ecuador. This bot is hosted in 79 official pages, and in three months of operation had an interaction of 135,000 users (Torre Juana, 2020).
Hubtype has created, along with the Ministry of Health, a conversational robot on the coronavirus for the Generalitat through instant messaging applications such as WhatsApp. This company defines itself as a company that "creates quality conversational experiences" (Hubtype, 2020). The bot, available since June 2020, shares content on health and civil protection, as well as data on those affected, advice, lockdown measures and information on the evolution of the pandemic for free.

Chatbot Chocolate is "the leading agency in the design, development and training of chatbots and voice apps" (Chatbot Chocolate, 2020). Maia, conversational assistant launched by this company in early April 2020, is capable of answering more than 125 different questions asked in more than 50,000 different ways in Basque and Spanish (Planeta Chatbot, 2020).

The Community of Madrid decided to create a platform inspired in South Korea, which was launched at the end of March 2020. The function of CoronaMadrid is to evaluate through a series of questions the clinical situation of the citizen. So, the user can know the magnitude of his symptoms and is guided on the procedure to follow in each 
case. The evaluation can be done again every 12 hours to incorporate the new developments that could have happened in his evolution. In addition, this system allows to obtain epidemiological data and to offer personalized information, and to offer the best preventive and evaluation measures, it includes a geolocalization system" (Pérez, 2020).

\section{Methodology}

The technologies from the virtual assistants need massive amounts of data, which include algorithms to learn from data input and become each time even better at predicting the user's needs. The current study therefore pursued a mixed method: a qualitative fieldwork whit a quantitative assessment by adding an additional measurement from user's interest. The main goal is to find patterns of usability and to know which virtual assistant has the higher human speech understanding. Also, the collected data was used to determine the content quality of the answers and to know if the virtual assistants and bots could provide a diagnosis of a possible Covid-19 infection.

A field work was made to obtain firsthand information from four virtual assistants with the largest market share in Spain: Siri, Alexa, Cortana and Google; as well as four conversational platforms that emerged during the Covid-19 and were used by Spanish people. This work consisted of making a list of generic questions about the virus information, then the answers of this AI technologies will show the understanding level and its ability to help in a health crisis. For these reasons, the following parameters were used to explore both kind of platforms:

- Privacy Policy.

- The initial greeting.

- Languages that have.
- Information: battery of questions and answers you have.

- Recommendations about the disease.

- If there is a diagnosis of Covid-19.

- Information about health centers.

These criteria were chosen because through them, it was possible to determine its functionality, whether it was possible to have a fluid conversation between the program and the user and also, to know if the information provided by the virtual assistants was useful and helped the user's doubts. With the language criteria, the inclusive possibilities provided were established, while the initial greeting and privacy policies are important elements for building trust with the user. These parameters have provided the necessary data (qualitative and quantitative) to make a comparative analysis between virtual assistants and chatbots.

Then, an in-depth interview was conducted with four experts representing the abovementioned companies, which took place during July and August (2019). This type of interview is defined as a "social technique that puts into a relationship of direct face-to-face communication a researcher/interviewer and an individual interviewed with whom a peculiar relationship of knowledge is established that is dialogical, spontaneous, concentrated and of variable intensity" (Canales, 2006, p. 219). This research technique produces information of a qualitative nature, seeking to generate greater richness in the linguistic material collected.

And finally, in order to complete the analysis, a survey was carried out, because it was important to explore if both programs achieve their initial objective. So, the survey participants added validation to the data collected in the fieldwork. The purpose of any survey is to 
measure the degree or the way in which the subjects possess certain variables and concepts of interest for the research. In order to facilitate the process of carrying out and later measuring, the questionnaire had closed answers. This was conducted online in September and October (2020). The sample universe $(n=100)$ was 18 to 65 years of age and was intended to be simple random to minimize the probability of bias. Participating people were from five Spain's Autonomous Communities: Madrid, Valencia, País Vasco, Castilla la Macha and Andalucía. All people participating in the study have a smartphone. This ensured that they are familiar with some type of AI technology.

Then, six categories were reviewed by the survey: use of specific chatbots during covid, evaluation of their performance, usability, handling, usefulness to replace face-to-face assistance and proposed improvements to the platforms; as well as a general assessment of the tool used during the pandemic and possible suggestions for improvement. In this way, the aim was to contrast the experts' point of view about the bots with the users' own assessments.

Throughout research described, the study aimed to examine the complex interaction between the strengths and weaknesses of current AI conversational technology. Through the use of both quantitative and qualitative data, this text provides a comprehensive examination of user's interest experiences of usability and health information quality.

\section{Results}

The following tables show the most relevant results of the experiments carried out on the four virtual assistants used in the study.

\section{Table 2. Comparison of the conversational robots}

\begin{tabular}{|c|c|c|c|c|}
\hline & Carina Bot & gencatBot & Maia & CoronaMadrid \\
\hline Privacy Policy & no & no & yes & yes \\
\hline Initial greeting & yes & yes & yes & yes \\
\hline Languages & $\begin{array}{l}\text { Spanish } \\
\text { and English }\end{array}$ & Catalan & $\begin{array}{l}\text { Spanish and } \\
\text { Euskera }\end{array}$ & $\begin{array}{l}\text { Spanish, English, French } \\
\text { and German }\end{array}$ \\
\hline Questions & preset & preset & preset & preset \\
\hline Answers & preset & preset & preset & only yes or no \\
\hline Recommendations & yes & yes & yes & yes \\
\hline Background/Profile & yes & no & no & yes \\
\hline Diagnosis & no & no & no & yes \\
\hline Information about health centers & no & no & no & yes \\
\hline
\end{tabular}


Table 3. Comparison of virtual assistants

\begin{tabular}{|l|c|c|c|c|}
\hline & Siri & Google & Alexa & Cortana \\
\hline \% Preset Answers & $69 \%$ & $56 \%$ & $49 \%$ & $38 \%$ \\
\hline \% Complete answers & $75 \%$ & $32 \%$ & $20 \%$ \\
\hline \% Humor & $0,8 \%$ & $0,3 \%$ & $0,1 \%$ & $0 \%$ \\
\hline Recommendations & Yes & NO & Yes & NO \\
\hline
\end{tabular}

Source: Own elaboration.

Table 4. Comparison between bots and virtual assistants

\begin{tabular}{|l|l|l|}
\hline & Bots & Virtual Assistants \\
\hline Privacy Policy & Yes & no \\
\hline Initial greeting & Yes & It only has it if the user requests it. \\
\hline Languages & Several & Depending on the programming. \\
\hline Questions & Preset & No questions asked \\
\hline Answers & Preset & Preset \\
\hline Background/Profile & Yes & no \\
\hline Diagnosis & Yes & no \\
\hline Information about health centers. & Yes & It only has it if the user requests it. \\
\hline
\end{tabular}

Source: Own elaboration.

\section{Table 5. Functionality of chatbots}

\begin{tabular}{|l|l|}
\hline Question & Answer \\
\hline Did the chatbots help in the health crisis? & $100 \%$ - Yes \\
\hline Which is the advantage of a chatbot? & $100 \%$ - Accessibility of information \\
\hline When was it used the most? & $\begin{array}{l}50 \% \text { - at the peaks of the pandemic. } \\
50 \% \text { - at the beginning of the lockdown }\end{array}$ \\
\hline Do you think that in time this technology will be implemented? & $100 \%$ - Yes \\
\hline & $\begin{array}{l}\text { Adapted for people with disabilities. } \\
\text { Possible improvements }\end{array}$ \\
\hline
\end{tabular}


According with the Table 2, CoronaMadrid is the more complete chatbot, because it has several languages and also provides health centers information.

As shown in Table 3, Siri is the virtual assistant that has the highest understanding of language, because it can provide answers with a more complete grammatical structure and even adds some humorous phrases.

The following table shows the main differences between bots and virtual assistants in terms of the criteria that had been evaluated.
Later, From the interviews conducted with experts, the following answers can be highlighted:

The survey measures the user's interest about Covid- 19 chatbots. More than half of the participants answered that these technologies have helped them with "useful" information about the Covid- 19 sickness. While, a 15\% answered that with the chatbot they knew which health protocol have to follow. Only a 4\% mention that the chatbot was useful to identify the infected people who were nearby.

\section{Figure 4. Percentage of responses to the question Did it help?}

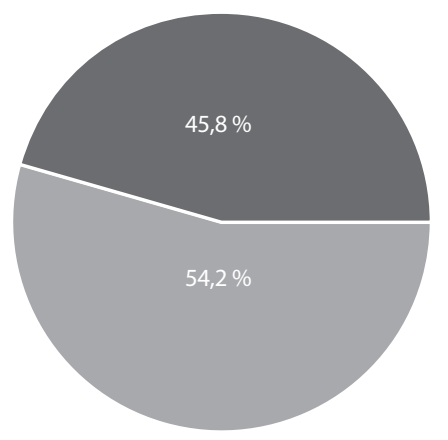

Source: Own elaboration.

\section{Figure 5. Usability of Covid-19's Chatbots}

\section{source Own elaboration.}

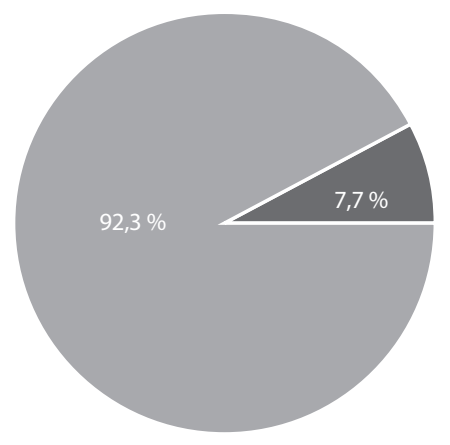


In terms of usability, almost $100 \%$ of the sample found easy to use the Covid-19 chatbot.

Following, 30,8\% indicates that this kind of chatbots were very useful to provide information on the disease. Only the 15,4\% replied that it was "not useful at all".

The next figure shows how the bots were used in relation to the request for information on covid during 2020. We can appreciate the peaks during 2 months: April and October.
Then, $38.3 \%$ of the participants said they use some virtual assistant, usually that of their own cell phone.

In general, there is a closed relationship between the age and the interaction with any AI programs, because people in their 20s and $35 \mathrm{~s}$ are the ones who use them the most.

Afterwards, once the results are analyzed, the paper will be closed showing the usability

\section{Figure 6. Bots usage curve (2020)}

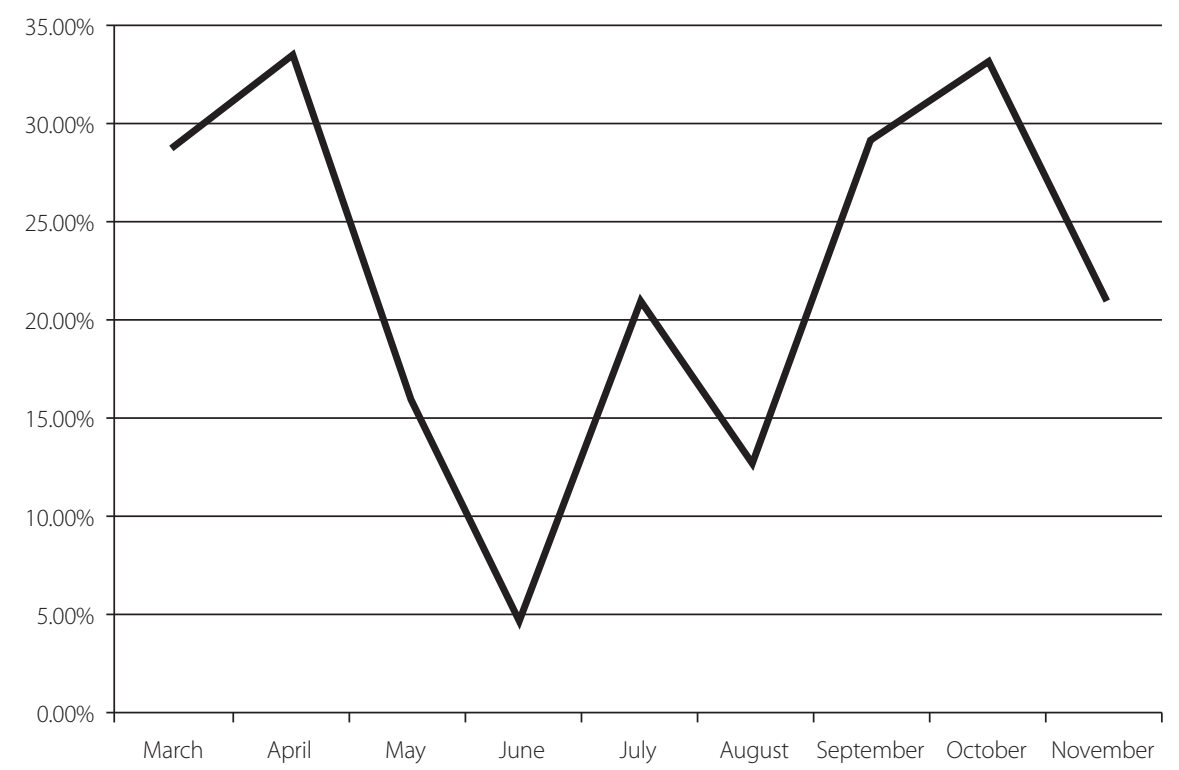

Source: Own elaboration

According whit the participants, the chatbots are just fine, because the $70 \%$ of the sample answered that the do not make changes in the platforms. A $2 \%$ said that may will be a good option to review the health terms and use some less complex for having an easy understanding. patterns of the platforms and the main conclusions.

\section{Discussion and Conclusions}

This study has yielded several conclusions. Firstly, it has been observed that all the bots analyzed coincide in several of their 


\section{Figure 8. Changes in Covid-19 chatbots}

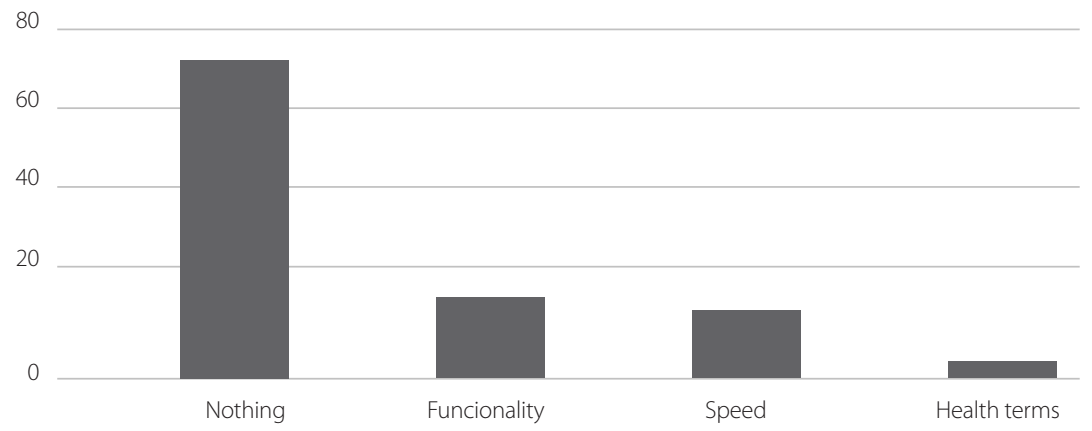

Source: Own elaboration.

\section{Figure 9. Use of virtual personal assistants}
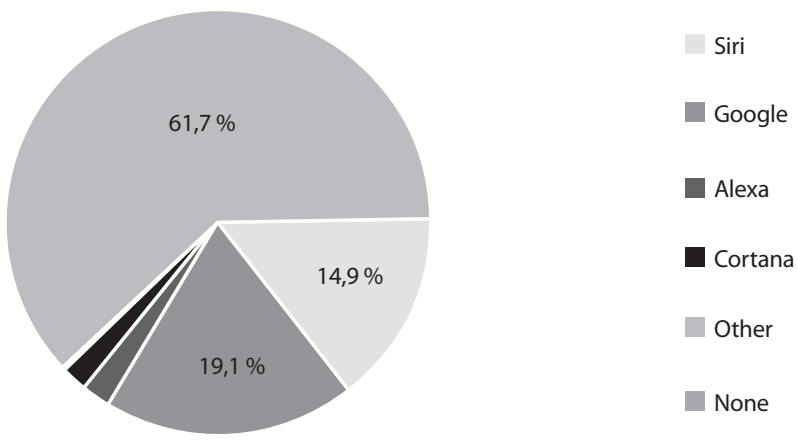

characteristics. Two of the platforms studied -Carina and Maia, which do not belong to the same company, have a similar look \& feel (green and white color) and bot use a female voice and name, coinciding with the research made by Piñeiro-Otero (2011), for the users. which stablished that female voices are used as an authority reference. The rest of the platforms have an assistant that is not based on the virtualization of a human being. However, this fact doesn't make a difference for the users. 


\section{Figure 9. Use of virtual personal assistants Figure 10. Conversational robots that have the look of a woman}

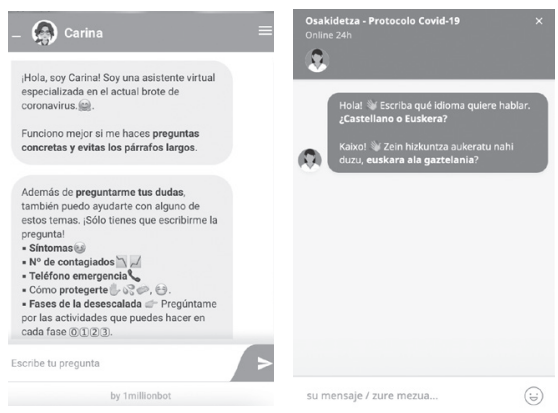

Source: Carina y Maia, 2020

On the other hand, the interview carried out has been fundamental to know the opinions of the professionals who are behind the development of this technology. This study's results provide a picture of the importance of the chatbots in this health crisis and the first thing that can be deduced, once the answers have been analyzed, is the informative nature that most of these conversational robots have, in addition to the fact that all the interviewees emphasize the importance of their work during the first weeks of the state of alarm. It has been detected through this analysis that the systems incorporate a low degree of Artificial Intelligence, especially when it comes to the use of natural language in the interaction between chatbot-user; in several cases it happened that the bot did not understand the questions asked, which means that the options in the conversational flow are limited.

Other conclusion derived from the in-depth interviews with the experts and protagonists of the design of these platforms is that the $96 \%$ were satisfied with the fulfillment of the objectives that had been proposed in their design, specifically those of being a reliable informative tool that would collaborate to create new communicative channels that would manage to decongest the traditional ones. In contrast, as reflected in the user surveys, only $29 \%$ of the participants stated that they did not contact their health center after making the consultations through these means. Despite the fact that these tools were designed to decongest a health system that was beginning to collapse, the reality is that they have not significantly prevented people from going to their health centers, since these tools -still in the first phase of development in terms of Artificial Intelligence (AI)- are not prepared to respond to certain complex questions or to do so with the security that person-to-person contact provides when explaining their problems in detail.

Likewise, the surveys have helped to complete the study and to get the perspective of the citizens' use experience. In this sense, it is clear the main reason why the respondents have come to these platforms and that is the search for information. Specifically, there are two peaks of use corresponding to the months of April and October, which also coincide with the two waves of infections in Spain so it can be deduced that the worsening of the figures of infections and deaths is related to the demand for access to such sources of information. Additionally, experts agree that these periods were the ones when the platforms were most used.

It is also found that the lockdown - released in March 2020, as a result of the state of alarmaccelerated the adoption of this technology in health care area. During these months, the bots have improved; for example, they have included: recommendations, profile information and data to contact health centers. However, they still follow a tree of answers and one of their clearest limitations is that they only answer certain predefined questions. 
The information provided by the sample about the most used platform places CoronaMadrid in first place, a fact that is in agreement with the origin of most of the respondents, although others said they do not remember the name of the chatbot used. It is noteworthy that some people pointed to RadarCovid as the platform. Nevertheless, this is an app that requires downloading and is primarily intended to register infected people to warn users of having been in contact with a positive case, but it is not a chatbot. This indicates that users are unaware about the difference between AI technologies and the services offered by each one. Currently, most people install different applications on their cell phones for entertainment, professional and even educational use, but one of the things that distinguishes conversational robots from other apps is that they do not need to be downloaded, as they work online through websites or social networks.

Then, as a summary of the results obtained in the series of questions asked to the four assistants, it can be concluded that the answers of Alexa and Cortana are the most elaborated grammatically. Therefore, they are more advanced in terms of intellect. Alexa, especially, is one step ahead in terms of natural language. Siri is the only one who calls you by your name when answering. Alexa has order information, has the bank details, address and name, but does not address the user by name, as Siri does. And none of the four attendees includes invasive advertising of the type of conventional advertising such as spots or banners on the Internet.

Subjectively, assistants fall short in intellect because they give very primary answers to the most open or complex questions. Their artificial intelligence, despite appearing complex, is still very simple and leaves a lot of margin for improvement. It can be said that the level of language comprehension is basic. Occasionally, they do not respond to questions formulated in natural language that have an average level of complexity because they do not understand them or know how to process them, in addition to not distinguishing properly between statements and questions. Their intonation is simple, and they should work on using it to communicate the results more effectively. Likewise, they do not process the information in a logical way, their answers are determined; therefore, they limit themselves to giving standard answers, since they respond in the same way to different questions and say the same thing to some and to others, there is no difference between interlocutors. Virtual assistants can perform voice recognition awkwardly. In addition, they do not remember whether they have been asked the same question five or ten times. So, this lack of memory may make the virtual assistant less useful for people with disabilities.

So, it can be concluded that all these conversational platforms have collaborated to disseminate the preventive measures established by the health authorities such as the promotion of the famous "Stay at home", a recommendation that all include. Furthermore, due to the type of language used and the structuring of the programmed responses, they are a reinforcement tool that emphasizes the messages regarding how to act in case of contagion and, by maintaining an informative tone, they also manage to transmit a reassuring sensation, preventing users from panicking and acting in a chaotic way that is not very effective for their interests and those of the rest of the citizens. For these reasons, the analyzed conversational assistants are positioned as another useful means of communication to be used in communication strategies in case of crisis. 
In general, and for all that has been mentioned, it seems pretty evident that a transformation is taking place in the semiotic patterns of culture and of advertising in particular around this technology. A transformation that has only just begun, since such motivations have not yet completely taken. At his moment, there is a lot of space for innovation and development of these assistants. We are very close to the real transformation. However, as devices become more interconnected to the social network profiles of each user and can collect more data, privacy and security concerns will increase. The way companies choose to balance their customers' privacy with this abundance of data will be a crucial factor in maintaining user confidence and may even be marked as a competitive advantage among conversational platforms.

While it is true that the processing of natural language in virtual assistants and chatbots still has much to improve, what nobody doubts is that the great opportunity they will provide to advertising, since through a conversational business you can establish a relationship with a more personal level with the brand. The future, without a doubt, is going that way, where the stars of the ads are not the celebrities who star, but the product being promoted. The brand itself is mutating, because in this case, the conversational assistants will talk about their values and their advantages to the consumers, providing more credibility.

A possible scenario for these AI tools is that they will be used to enhance human capabilities even further and that they can spend more time on strategic rather than operational activities. With these technological developments, a path is being promoted in flow automation projects, especially within the health sector, since thanks to the user experience and data collection, there is a constant improvement in software performance. In the long term, when this crisis is over, it is likely that chatbots will become digital portals for interactive health care, helping patients and doctors and thus facilitating the first care in a health emergency. Consequently, monitoring the development and implementation of conversational robots in the health area and their application in crisis situations is still a very new field that undoubtedly invites researchers to remain alert and open new avenues of research. 


\section{Bibliography}

Agencia Digital Marketing Trend (2020). Mobile en España y en el Mundo. https://www.amic.media/media/files/ file_352_2531.pdf

Aguilar, J \& Villegas, O. (2020). COVID-19 y sus implicaciones sociales: una mirada desde las ciencias computacionales. https://tinyurl.com/y58k32x2

Ahuja, A., Reddy, V. \& Marques, O. (2020). Artificial Intelligence and COVID-19: A

Multidisciplinary Approach, Integrative Medicine Research, 9(3) doi.org/10.1016/j.imr.2020.100434.

Artificial Solutions. Chatbots: la guía definitiva (2020). https:// www.artificial-solutions.com/es/chatbots-pdf/

Baharudin, H. (2020). Coronavirus: Singapore Government to make its contact-tracing app freely available to developers worldwide. https://tinyurl.com/yyz7ldwk

Bird, D., Ling, M., \& Haynes, K. (2012). Flooding Facebook -the use of social media during the Queensland and Victorian floods, Australian Journal of Emergency Management, 27(1), 27-33.

Brandtzaeg P., Folstad A. (2017). Why People Use Chatbots. Internet Science. https://doi.org/10.1007/978-3-319-70284$1 \_30$.

Canales, M. (2006). Metodologías de investigación social. Chile: Lom Ediciones.

Dahiya, M. (2017). A Tool of Conversation: Chatbot, International Journal of Computer Sciences and Engineering, 5(5).

Fadhil, A. (2018). Beyond Patient Monitoring: Conversational Agents Role in Telemedicine \& Healthcare Support For Home-Living Elderly Individuals. Cornell University. https:// arxiv.org/pdf/1803.06000.pdf

Ferrara, B; Varol, O; Davis, C; Menczer, F \& Flammini, A. (2016). The Rise of Social Bots, Communications of the Acm, 59(7).

Grimme, C., Preuss, M., Adam, L., \& Trautmann, H. (2017). Social Bots: Human-Like by Means of Human Control?, Big Data, 5(4), 279-293, doi: 10.1089/big.2017.0044.

Guzman, A. L. (2017). Making AI safe for humans: A conversation with Siri. In R. W. Gehl \& M. Bakardjieva (Eds.), Socialbots and Their Friends: Digital Media and the Automation of Sociality (pp. 69-85). New York: Routledge. https://doi.org/10.4324/9781315637228
Hanson, J., Couch, D., \& Yap, K. (2020). Mobile Health Apps That Help With COVID-19 Management: Scoping Review. JMIR Nursing. 3(1). https://www.nursing.jmir.org/2020/1/ e20596/\#ref75.

Heneveld, H. M. (2018). Let's talk about embracing voice technology. Sdm, 48(2), 40-40.

Herriman, M., Meer E., Rosin R., Lee V., Washington V., \& Volpp, K. (2020). Asked and Answered: Building a Chatbot to Address Covid-19-Related Concerns, NEJM Catalyst. doi: 10.1056/CAT.20.0230

Hofeditz, L., Ehnis, C., Bunker, D., Brachten, F., \& Stieglitz, S. (2019). Meaningful use of social bots? Possible applications in crisis communication during disasters. En Proceedings of the 27th European Conference on Information Systems (ECIS), Stockholm y Uppsala, Suecia, Junio 8-14 2019. ISBN978-1-7336325-0-8 Research Papers. https:// aisel.aisnet.org/ecis2019_rp/138.

Hubtype. (2020). Mensajería escalable. https://www.hubtype.com/es/.

Hutchinson, A. (2020). WhatsApp launches new COVID-19 info hub amid concerns around misinformation being shared inapp. https://tinyurl.com/y6hj3pll.

Jenkins, M., Churchill R., Cox S., \& Smith D. (2007) Analysis of User Interaction with Service Oriented Chatbot Systems. Computer Science, 4552. Doi: 10.1007/978-3-54073110-8_9.

Joseph, R. (2019). Chatbot Statistics All the Data You Need. https://www.intellectyx.com/blog/chatbot-statstics-2019/

Lind, M., \& Salomonson. N. (2006). The Role of Virtual Servants in e-Interaction. https://tinyurl.com/y2ybrnhv.

Martin, E. (2017). How Echo, Google Home, and Other Voice Assistants Can Change the Game for Content Creators. E.Content, 40(2),4-8

Miner, A., Laranjo, L., \& Kocaballi, A. (2020). Chatbots in the fight against the covid-19 pandemic, Npj Digital Medicine, 3(1). doi.org/10.1038/s41746-020-0280-0

Mori, M. (1970). The Uncanny Valley. Energy, 7(4), 33-35. Doi:10.1109/MRA.2012.2192811

Paul, S. (2018). How to build a Google Home App with Dialogflow |Overview. Medium. shorturl.at/demRU

Pérez, J. (2020, 18 de marzo). Madrid lanza una web para atender a posibles afectados de coronavirus. https://tinyurl $\mathrm{com} / \mathrm{y} 3 \mathrm{f} 4 \mathrm{tvxm}$. 
Piñeiro-Otero, M. (2011). La utilización de la voz femenina como autoridad en la publicidad radiofónica española. https://www.researchgate.net/publication/279500825

Planeta Chatbot. (2020, 28 de abril). Tecnología de chatbot Chocolate en Osakidetza. https://tinyurl.com/y3mxxbdn.

Prendinger, H. \& Ishizuka, M. (2004). Life-like characters: Tools, affective functions, and applications. Springer Science \& Business Media.

Sánchez-Gonzales, Hada M.; Sánchez-González, María (2017). Los bots como servicio de noticias y de conectividad emocional con las audiencias. El caso de Politibot. Doxa comunicación, 25, 63-84.

Sayobo. (2019). Chatbot COVID- 19. www.sayobo.io.

Shawar, A. \& Atwell, E. (2005). Using corpora in machinelearning chatbot systems, International Journal of Corpus Linguistics, 10(4), 489-516.

Statista. (2020). Frecuencia de uso de asistentes virtuales de voz en España en 2019. https://es.statista.com/estadisticas/1018541/uso-de-asistentes-virtuales-de-voz-en-espana/ Stieglitz, S., Bunker, D., Mirbabaie, M. \& Ehnis, C. (2017). Sense-Making in Social Media During Extreme Events, Journal of Contingencies and Crisis Management, 26(1), 4-15.

Tabarés, R.(2020). Conversando con cajas negras; sobre la aparición de los interfaces conversacio-nales. Teknokultura.
Revista de Cultura Digital y Movimientos Sociales, 17(2), 179186.

Torre Juana. (2020, 25 de julio). Naciones Unidas y 'Catalina': ayudando más allá de los sintomas de COVID-19. https:// tinyurl.com/y4voya46.

Trillo-Domínguez, Magdalena; Alberich-Pascual, Jordi (2017). Deconstrucción de los géneros periodísticos y nuevos medios: de la pirámide invertida al cubo de Rubik. El profesional de la información, 26(6),1091-1099. doi. org/10.3145/epi.2017.nov.08

Van den Broek, E., Zarouali, B., \& Poels, K. (2019). Chatbot advertising effectiveness: When does the message get through?, Computers in human behaviour, 98. doi. org/10.1016/j.chb.2019.04.009.

Villar, C. (2017). Creating Conversational Experiences. Landbot.io. https://medium.com/landbot-io/creating-conversational-experiences-ii-build-and-design-20ac88d7ee 72 We are social (2019). Digital en 2019 en España. https:// wearesocial.com/es/digital-2019-espana

Wilks, Y. (2010). Close Engagements with Artificial Companions. Key social, psychological, ethical and design issues. Holanda: John Benjamins.

World Health Organization. (2020, 12 de marzo). WHO announces COVID-19 outbreak a pandemic. https://tinyurl. com/y48wdsed. 



\section{El impacto de las}

plataformas de podcast

en redes sociales:

Estudio de caso en las cuentas

oficiales de iVoox

y Anchor en Instagram,

Facebook y Twitter

The impact of podcast platforms on social networks: A case study on the official accounts of iVoox and Anchor on Instagram, Facebook and Twitter

Adrián Caballero-Escusol

Universitat de Vic-Universitat Central de Catalunya adrian.caballero@uvic.cat https://orcid.org/0000-0003-1694-7808

Dr. Ruben Nicolas-Sans

ESIC Business and Marketing School

ruben.nicolas@esic.edu

https://orcid.org/0000-0002-9234-5764

Dr. Javier Bustos Díaz

ESIC Business and Marketing School

javier.bustos@esic.edu

https://orcid.org/0000-0001-7932-7986
Caballero-Escusol, A., Nicolas-Sans, R. y Bustos Díaz, J.

(2021)

El impacto de las plataformas de podcast en redes sociales: Estudio de caso en las cuentas oficiales de iVoox y Anchor en Instagram, Facebook y Twitter

Revista Internacional de Investigación en Comunicación aDResearch ESIC. No 25 Vol 25

Monográfico especial, marzo 2021 · Págs. 92 a 105

https://doi.org/10.7263/adresic-025-05 
Objetivo: El propósito del presente trabajo es analizar la presencia e impacto de las plataformas especializadas en el almacenaje y difusión de podcast Anchor e iVoox en las principales redes sociales, Facebook, Instagram y Twitter.

Diseño/metodología/enfoque: Este estudio se basa en una metodología cuantitativa apoyada en la herramienta Fanpage Karma, que permite realizar un correcto seguimiento y recopilación de los distintos aspectos que dan forma a un perfil en redes sociales y que, adicionalmente, es aplicable a las plataformas indicadas. El periodo de estudio comprende desde el 1 de enero de 2020 al 15 de noviembre de 2020

Resultados: Los resultados obtenidos confirman la relevancia que tienen las redes sociales para la difusión de los contenidos de podcast, al mismo tiempo que descubrimos que la red social más empleada por ambas compañías es Twitter, un hecho que destaca esta investigación, ya que Instagram es una de las redes sociales con más crecimiento en los últimos años.

Clasificación JEL: Z13, O33, M31, M32, M37

Palabras clave: Redes sociales, podcast, multimedia, plataformas de distribución digital, impacto social, consumo digital.
Limitaciones/implicaciones: Dado que las empresas definidas en el objeto de estudio tienen réplicas especificas en varios países, sería interesante hacer un estudio comparado entre el impacto y presencia en España y en otros países.

Originalidad/contribución: Cerca de 10 millones de usuarios en España escuchan podcast, un dato que revela la importancia que tiene este formato dentro de la audiencia española. Si se atiende a la naturaleza de esta clase de contenido, es decir, consumido a través de internet, su difusión a través de las redes sociales es esencial para obtener una mayor penetración, ya que España cuenta con 26 millones de personas que utilizan redes sociales según el último informe de lab.Spain. En consecuencia, estudiar la relación e impacto de las principales plataformas de podcast en redes sociales resulta un tema de interés para la comunidad científica, al mismo tiempo que se presenta una radiografía del panorama actual sobre esta cuestión.

\section{ABSTRACT}

\section{JEL Classification: \\ Z13, O33, M31, M32, M37}

Key words: Social networks, podcast, multimedia, digital distribution platforms, social impact, digital consumption
Purpose: The purpose of this paper is to analyze the presence and impact of the platforms specialized in the storage and diffusion of podcasts, Anchor and iVoox, on the major social networks, Facebook, Instagram and Twitter.

Design / Methodology / Approach: This study is based on a quantitative methodology supported by the Fanpage Karma tool, which allows a correct monitoring and compilation of the different aspects that shape a profile on social networks and which, additionally, is applicable to the indicated platforms. The study period was from January 1, 2020 to November 15, 2020.

Results: The results obtained confirm the relevance of social networks for the diffusion of podcast content, while we discovered that the social network most used by both companies is Twitter, a fact that highlights this research, since Instagram has been one of the fastest growing social networks in recent years.

Limitatios / Implications: Given that the companies defined in the object of study have specific replicas in several countries, it would be interesting to make a comparative study between the impact and presence in Spain and in other countries.

Originality / Contribution: Nearly 10 million users in Spain listen to podcasts, a figure that reveals the importance of this format to the Spanish audience. If we consider the nature of this type of content, i.e., consumed over the Internet, its diffusion through social networks is essential to obtain greater penetration, since in Spain, there are 26 million people who use social networks according to the latest lab.Spain report. Consequently, studying the relationship and impact of the main podcast platforms on social networks is a topic of interest for the scientific community, while at the same time presenting an x-ray of the current panorama on this issue. 


\section{Introducción}

Como señala Berry (2015), en los últimos diez años el fenómeno podcasting se ha convertido en un ecosistema que no requiere de grandes inversiones en infraestructuras, y, al mismo tiempo, los creadores de podcast son personas con un alto nivel profesional.

En línea con Berry (2015), parece que el podcast, («emisión o archivo multimedia, en especial de audio, concebido fundamentalmente para ser descargado y escuchado en ordenadores o en reproductores portátiles" (Fundeu, 2018)), por su forma de comunicar y por sus productores, han tenido un impacto considerable dentro de la sociedad española y ha alcanzado los 10 millones de personas en España según el informe presentado por Dentsu X (2020). «El podcasting es un mercado incipiente aún en España que nacía como una tecnología de distribución y que requiere de tiempo y esfuerzo entre todos los agentes para construirlo» (Moreno, 2017, p. 358). Una cifra que muestra el interés que despierta esta clase de formato entre el público español, así como dentro de las estrategias para la difusión de información y estrategias de campaña de marketing la encontramos entre los especialistas de marketing que planean «aumentar el uso de videos (77\%), imágenes (68\%), videos en vivo (63\%), blogs (57\%) y podcasting (25\%)» (Stelzner, 2018, p. 39).

En este sentido, el «podcasting se utiliza cada vez más como una herramienta para la distribución de información por una variedad de organizaciones y asociaciones, como escuelas de medicina y odontología, instituciones de investigación y revistas científicas» (Bruno et al., 200, p.280;), educación o enfermería entre otros (Andrejco y otros, 2017). En definitiva, «los podcasts ofrecen el potencial para desarrollar contenido educativo y promover la difusión de la investigación» (Nwosu, 2016, p. 216).
Florini argumenta que el éxito del podcasting viene determinado por su propia idiosincrasia, es decir, a los usuarios «les permite proporcionar contenido sin restricciones por parte de los guardianes corporativos y que ellos y sus oyentes consideran menos artificial y más auténtico» (Florini, 2015, p. 212). Parlatore et al., (2020) describen las características de los podcasts y señalan son libres, en cuanto a las restricciones temáticas y sin restricciones de tiempo, lo que, en palabras de los autores, «puede decirse que el podcast es democratizador» (Parlatore y otros, 2020, p. 10). Entre las múltiples opciones que ofrecen los podcasts, «los presentadores y / o productores de podcasts pueden permitir las voces de los ponentes secundarios, ya sea directamente como invitados al podcast o indirectamente citando a la audiencia» (Lundström y Lundström, 2020, p. 3).

Algunos autores argumentan que el incremento del uso de los podcasts responde a una tendencia en la evolución del uso de las nuevas tecnologías, así «los profesionales han adoptado claramente las herramientas más establecidas e institucionales (correo electrónico, Intranet), pero también parecen muy cómodos con los blogs y los podcasts» (Eyrich, Padman y Sweetser, 2008, p.414). Lo que se evidencia como parte de su naturaleza es que «son formatos novedosos que aportan un plus a otras tramas en otros soportes y medios» (López, 2018, p. 76).

Más allá de la propia naturaleza y funcionalidad de los podcasts y de cómo estos afectan a la transformación de la comunicación, se evidencia que las redes sociales forman parte indisoluble de la estrategia de difusión de los contenidos: «las redes sociales, como la base misma de las relaciones públicas, construyen relaciones. Las redes sociales son intrínsecamente interactivas, comunicativas y sociales» (Avery et al., 2010, p. 337). 
El podcasting involucra tres componentes esenciales: capturar, publicar y distribuir medios electrónicos / contenido digital (Bruno et al., 2007, p.280). En definitiva, «las redes sociales se refieren a cualquier tecnología que facilite la difusión y el intercambio de información a través de Internet» (Robbins y Singer, 2014, p. 387).

Por todo ello, el propósito del presente trabajo es analizar el impacto que tienen los perfiles de las principales redes sociales (Facebook, Instagram y Twitter) de las plataformas almacenadoras de podcasts iVoox y Anchor.

\section{Marco teórico}

En este artículo el objeto de estudio es el podcast, un término cuyo origen genera división entre la Literatura. Por un lado, tenemos quienes consideran que originalmente se acuñó por la contracción de iPod (reproductor de música digital de Apple) y broadcasting («radiodifusión» en inglés) pero que en la actualidad se usa como un concepto en sí mismo, desligado de la marca comercial Apple. (Leiva Aguilera, 2007; p. 163). Otros autores argumentan que el podcast es también una contracción, pero entre POD (Public On Demand, «público bajo demanda» en inglés) y, aquí también, broadcasting (Parlatore et. al., 2020, p. 7).

El podcast es un audio digital que incluye una serie de etiquetas o un enlace RSS para su sindicación, esto es, para permitir a cualquier usuario suscribirse a dicho podcast, que suele ofrecerse en formato de episodios. Con esa suscripción, el usuario puede recibir los nuevos episodios de los diferentes podcasts a los que se ha suscrito sin necesidad de visitar constantemente la página web donde se aloje el podcast (Blanco 2006, p.1935).

Situamos los inicios populares del podcast a inicios del siglo XXI, en la década de los 2000s.
En concreto, en 2005, ya que ese año el término «podcast» fue escogido como palabra del año por la Universidad de Oxford. Coincide el surgimiento de los podcasts con el auge un par de años antes de los blogs, espacios en Internet donde cualquier usuario puede publicar artículos escritos que en sus inicios se podían acompañar de fotografías e hipervínculos y que actualmente pueden incluir cualquier tipo de contenido multimedia, desde vídeos incrustados a elementos interactivos.

Desde mediados de la década de los 2000s, ante la importancia que cobraron en Internet estos blogs, muchos medios de comunicación tradicional los incorporaron y alojaron bitácoras no solo de firmas destacadas en esos medios sino también de usuarios anónimos y lectores del medio. A pesar de esta inclusión, gran parte del éxito del blog se explica porque se convertía en una vía de participación para una ciudadanía cada vez más descontenta con el periodismo tradicional (Blanco, 2006, p. 1933).

Autores como Orihuela (2011) indican que, desde la irrupción de los blogs en la escena mediática con motivo de la Invasión de Iraq en 2003 y las crónicas de Salam Pax en el blog Where is Raed?, ninguna otra plataforma en línea había tenido tanto impacto sobre los medios y el periodismo, hasta la llegada de Twitter en 2006.

Los blogs más exitosos han sido desde un inicio o bien firmas reconocidas por su presencia anterior en medios de comunicación o aquellos usuarios convertidos en especialistas de un tema, que encuentran en un blog un espacio donde divulgar o expresar sus opiniones e ideas. Este mismo fenómeno se traslada al podcasting. A partir de la popularización de reproductores de archivos sonoros digitales como el formato mp3 (precisamente el iPod fue uno de esos reproductores más conocidos), la idea de suscribirse a un podcast 
para descargar episodios que serán reproducidos en el momento que el usuario decida se hizo más atractiva (Frigola y otros., 2008, p. 4).

Los episodios de un podcast son sindicados y almacenados en lo que se conoce como host, el espacio web donde los archivos de audio digital quedan almacenados y desde donde cada usuario puede suscribirse y descargar aquellos episodios que les interese. Los archivos, por otro lado, también pueden subirse a la página web del propio autor, y ofrecer desde ahí la posibilidad de descarga. El usuario va a necesitar un agregador, un software que ofrece, de manera ordenada, todo el contenido procedente del host y lo presenta al usuario en forma de feed, esto es, ordenados (según decida el autor, aunque normalmente de forma cronológica reciente) a través de los formatos RSS o ATOM, formatos para redifusión de contenido que se actualiza con frecuencia. Este tipo de formatos fueron muy usados inicialmente por los medios de comunicación, pero rápidamente se convirtieron en la herramienta más efectiva para que los usuarios pudieran seguir sus blogs y podcasts favoritos sin necesidad de acudir constantemente a la fuente primaria, al host (Frigola et. al., 2008, p. 7).

En los últimos años la expansión del podcast no se ha concentrado solo en las noticias y el entretenimiento. El podcast, como canal de comunicación ha sido empleado por muchos por su potencial. Sin ir más lejos, son cada vez más las empresas que optan por el podcast como un nuevo canal de comunicación corporativo. A pesar de que la página web y las redes sociales, más allá de la relación con la prensa, se mantienen como los canales preferidos y más usados en comunicación corporativa, autoras como Virginia Aguayo han elaborado extensas tesis en las que se recogen casos relevantes en el uso corporativo de un podcast (Aguayo, 2015). A su vez, las posibilidades del podcast también pasan por la divulgación, incluso en centros educativos, siendo el podcast, de nuevo, un nuevo canal, en este caso para el profesorado, de transmitir los conocimientos y de captar la atención del alumno (Solano Fernández y Sánchez Vera, 2010), tal y como muestran Chacón y Clevia (2011) en su trabajo titulado «el podcast como innovación en la enseñanza del inglés como lengua extranjera» donde emplean el podcast como metodología docente para desarrollar competencias entre los estudiante de inglés, como la expresión oral.

Pero, sin duda, son los medios de comunicación los que ven en el podcast un reto y a la vez un canal más de comunicación. Según el informe Digital News Report del Reuters Institute, en 2020 el $41 \%$ de los internautas españoles consumía podcast, la mayoría de ellos para informarse y para profundizar en el tratamiento de los temas que les interesa. Esto es asumido por los principales medios de comunicación, especialmente las radios, que han trasladado a las plataformas de podcast sus contenidos, con el objetivo de sumar una mayor audiencia ya que cada programa deja de estar ligado a la necesidad de ser consumido en un día y franja horaria determinada. Debe ser mencionada aquí la iniciativa de Podium Podcast, productora de podcast de la Cadena SER, la emisora más escuchada en España.

Para las radios tradicionales (así como otros medios que se han sumado a la creación de podcast como ampliación de su oferta informativa), el auge del podcast está repercutiendo positivamente a la hora de ampliar el espectro y tipología de su público, aunque presenta también algunos retos, como el hecho de la asociación que el público general hace de la radio con el 'directo' mientras que se considera al podcast «una nueva forma de escuchar audio». En consecuencia, aun- 
que el formato podcasting bebe de las rutinas y la forma de hacer radio, debe adaptarse a un público que, aun siendo o no el mismo, demanda algo diferente al consumir este tipo de contenido (Parlatore y otros., 2020, p. 8)

\section{1. iVoox}

El auge hace unos años y consolidación actual del podcast como elemento de comunicación e información trae la natural consecuencia del surgimiento de múltiples plataformas de podcasting. Sus funciones son diversas y cada plataforma escoge qué rol (o roles) juega en el proceso de creación, almacenamiento, distribución, consumo, interacción y monetización de los episodios del podcast (Parra y Onieva, 2020, p. 13).

Una de las principales plataformas en el mundo hispanohablante es iVoox. En ella, cualquier usuario, de manera gratuita, puede alojar, publicar, compartir y escuchar cualquier audio, desde los podcasts a programas de radio, audiolibros, conferencias y otro tipo de audio. Todo se puede consumir a través de su web (https://www.iVoox.com) y su aplicación descargable en teléfonos inteligentes. La plataforma fue creada en 2008 por el ingeniero y emprendedor español Juan Ignacio Solera y en 2019 contaba con alrededor de 500.000 podcasts alojados y contaba con 50 millones de escuchas mensuales (Villanueva, 2019).

Desde sus inicios, la plataforma se ha caracterizado por la sencillez y la indexación de los contenidos. Esto es, a diferencia de lo comentado al inicio, con iVoox el usuario puede usar el buscador o la clasificación temática para llegar a un audio determinado, que puede escuchar sin necesidad de ser descargado ni de suscribirse a ningún podcast (Sellas, 2012, p. 207). Por su parte, el creador o podcaster tiene la posibilidad de alojar su contenido en esta plataforma, que hará de host y le proporcionará el sistema RSS necesario para poder difundir sus contenidos en otras plataformas conocidas, como Spotify, Apple Podcast o Souncloud, sin necesidad de alojar el contenido en estas plataformas.

Algo que destaca de iVoox es la gratuidad. Tanto el consumo de podcast como la creación, alojamiento y gestión de estos se puede hacer de manera gratuita, lo que ha facilitado su auge en el mundo hispanohablante en los últimos años. No obstante, en 2018 iVoox creó un programa de monetización para los productores. Esto es: a partir de un botón de suscripción, cualquier usuario puede hacer una aportación mensual económica de carácter voluntario. A cambio de esta, el productor puede ofrecer adelantos de episodios o contenido en exclusiva.

Esta iniciativa se enmarca en el programa iVoox Plus, que trata de facilitar la monetización del podcast a través del micro mecenazgo, ya que permite a los usuarios evitar la publicidad en los contenidos pagando también una cantidad al mes (y los productores recibirán una parte por cada reproducción desde una cuenta iVoox Plus). Al mismo tiempo, como productor existe la posibilidad de pagar para obtener ciertas ventajas, como poder monetizar el podcast, la programación del día y hora de publicación o la subida ilimitada de contenido.

Por último, cabe destacar que en 2019 iVoox lanzó iVoox Originals, precisamente para conseguir atraer creadores a la plataforma y que éstos suban sus podcasts de manera exclusiva, evitando así lo que se conoce como «multisindicación», fenómeno que provoca que sea más complejo elaborar analítica sobre la audiencia real total de cada podcast (Parra y Onieva, 2020, p. 15).

\subsection{Anchor}

La otra plataforma en la que centra la atención el presente estudio es Anchor, también conoci- 
da como Anchor.fm por su dirección web (https://anchor.fm/). Adquirida por la plataforma de música y podcast Spotify, Anchor, a diferencia de iVoox, expande su éxito más allá del mundo hispanohablante. Prueba de ello es que, de todos los podcasts que se podían escuchar en Apple Podcast en 2018, un 1,4\% estaban alojados en iVoox mientras que un 9,4\% lo estaban en Anchor (Sullivan, 2019).

Anchor permite también el alojamiento, no solo la distribución, de los podcasts y lo hace también de manera gratuita. Además, a diferencia de iVoox, en esta plataforma el productor puede grabar en línea y editar su contenido.

Uno de los principales servicios que ofrece es el de la analítica de los podcasts, esto es, un servicio para el productor que le permite analizar en todo momento el rendimiento de sus audios a partir de variables como el total de escuchas en un periodo temporal determinado o la audiencia estimada del podcast, aunque, de nuevo, debemos remitirnos a la dificultad de agregar de manera fiel y creíble el total de escuchas de las diferentes plataformas donde se esté distribuyendo el podcast (Centeno y Falcon, 2019, p. 32).

De todas maneras, si a la gratuidad de sus servicios se le suma la universalidad en cuanto a su potencial de crecimiento, es lógico entender cómo la literatura señala a Anchor.fm como una de las principales plataformas que están permitiendo el auge del podcasting debido a una «baja barrera de entrada para nuevos productores».

Incluso Anchor.fm podría ser una referencia en cuanto a la monetización del podcasting. Aunque en 2020 solo era una realidad en Estados Unidos, Anchor.fm ya ofrecía desde 2019 la posibilidad de monetización a través de su plataforma para los productores, más allá de micro mecenazgo, a través de la publicidad insertada en los episodios (Sullivan, 2019, p.10).

\section{Metodología}

El propósito de este trabajo es analizar la presencia que tienen, en las principales redes sociales (Facebook, Instagram y Twitter), iVoox y Anchor, dos de las principales plataformas para alojar podcast. En este sentido, el periodo de análisis se ha limitado desde el 1 de enero de 2020 al 31 de octubre de 2020, lo que permite tener una visión real de la evolución de que tenido cada una de las plataformas seleccionadas para el estudio en cada una de las redes sociales estudiadas.

El trabajo se basa en una metodología cuantitativa cuya naturaleza se enfoca en pretender conocer los hechos reales tal y como se dan objetivamente, tratando de señalar sus características comunes con otros hechos semejantes, sus orígenes y sus consecuencias (Ruiz Olabuénaga, 2012). En concreto, este estudio emplea el software informático Fanpage Karma, que permite la recolección de datos de los perfiles públicos en redes sociales de marcas, compañías, personalidad o influencers. Es decir, posibilita conocer la gestión de contenido y la actividad (Túñez y otros, 2015) estableciendo las siguientes variables: la frecuencia de publicación, el número de seguidores, las principales palabras y los principales hashtags utilizados. Las variables no comunes hacen referencia a la tipología del contenido empleado, que varía según la naturaleza de cada red estudiada. Así, la tipología de contenido en Facebook se divide en: Imágenes, Vídeos y Estados, mientras que en Instagram existen: Imágenes, Vídeos y Carrusel. Finalmente, Twitter contiene: Solo texto, enlace más imagen, enlace e imagen.

\section{Resultados}

Como se ha descrito en el apartado de metodología se presentan dos grandes bloques de variables: en primer lugar, aquellas que son comunes a todas las redes sociales y, por otro lado, las va- 
Tabla 1. Representación de las variables

\begin{tabular}{|l|l|}
\hline Variables comunes & Variables Facebook \\
\hline Frecuencia de publicación & Imágenes \\
\hline Número de seguidores & Vídeos \\
\hline Palabras más usadas & Estados \\
\hline Hashtags más utilizados & Variables Instagram \\
\hline & Imágenes \\
\hline & Vídeos \\
\hline Carrusel \\
\hline & Variables Twitter \\
\hline & Solo texto \\
\hline
\end{tabular}

riables que nacen debido al funcionamiento de cada una de las redes sociales. Para contextualizar el bloque, como se puede ver en la Tabla 1, se presentan de forma esquemática los aspectos comunes a los perfiles de Anchor e iVoox en Facebook, Instagram y Twitter.

\section{Tabla 2 Variables comunes a Facebook, Instagram y Twitter}

Facebook 1 enero 2020 a 31 de octubre 2020

\begin{tabular}{|l|c|c|c|c|}
\hline & $\begin{array}{l}\text { No de } \\
\text { Publicaciones }\end{array}$ & Fans & $\begin{array}{l}\text { Publicaciones } \\
\text { diarias }\end{array}$ & $\begin{array}{l}\text { Total de } \\
\text { reacciones }\end{array}$ \\
\hline Anchor & 32 & $49 \mathrm{k}$ & 0.1 & $1.8 \mathrm{k}$ \\
\hline iVoox & $1.3 \mathrm{~K}$ & $38 \mathrm{k}$ & 4.1 & $7.6 \mathrm{k}$ \\
\hline
\end{tabular}

Instagram 1enero 2020 a 31 de octubre 2020

\begin{tabular}{|c|c|c|c|c|}
\hline & $\begin{array}{l}\text { No de } \\
\text { Publicaciones }\end{array}$ & Fans & $\begin{array}{l}\text { Publicaciones } \\
\text { diarias }\end{array}$ & $\begin{array}{l}\text { Total de } \\
\text { reacciones }\end{array}$ \\
\hline Anchor & 47 & $67 k$ & 0.1 & $26 k$ \\
\hline iVoox & 65 & $4.6 \mathrm{k}$ & 0.2 & $5.8 \mathrm{k}$ \\
\hline \multicolumn{5}{|c|}{ Twitter 1enero 2020 a 31 de octubre 2020} \\
\hline & $\begin{array}{l}\text { No de } \\
\text { Publicaciones }\end{array}$ & Fans & $\begin{array}{l}\text { Publicaciones } \\
\text { diarias }\end{array}$ & $\begin{array}{l}\text { Total de } \\
\text { reacciones }\end{array}$ \\
\hline Anchor & $3.4 k$ & $77 k$ & 11 & $30 \mathrm{k}$ \\
\hline iVoox & $1.5 \mathrm{k}$ & $29 k$ & 4.8 & $26 k$ \\
\hline
\end{tabular}

Tabla de elaboración propia. Fuente: Fanpage Karma. 
De la Tabla 1 se desprenden los siguientes aspectos. Anchor es la plataforma con más influencia en las tres redes sociales analizadas, entendida la influencia en base al número de seguidores en sus perfiles oficiales en dichas redes. En segundo lugar, a excepción de Twitter, no existe una relación causa efecto entre el número de publicaciones y el engagement con el público. Tanto en Facebook como en Instagram, no se aprecia una vinculación directa entre el esfuerzo diario de la marca y su resultado en número de seguidores.

En este caso, Anchor tiene una media de publicaciones diarias en Facebook de 0.1 publicación al día y ha obtenido un total de 49.000 seguidores, al mismo tiempo, iVoox tiene una media de 4.1 publicaciones diarias, y solo alcanza los 38.000 seguidores. Este hecho se repite en Instagram, donde iVoox solo alcanza los 4.600 seguidores en la red de la imagen con 0.2 publicaciones diarias de media, frente a los 67.000 seguidores de Anchor en Instagram por tan solo 0.1 publicación diaria durante el periodo analizado.

Finalmente, Anchor también lidera en Twitter con 77.000 seguidores frente a los 29.000 de iVoox, sin embargo, en este caso si aparece una relación causa efecto entre la actividad que tiene la plataforma en la red social y el número de seguidores. En este sentido, Anchor publica desde su cuenta oficial en Twitter una media de 11 publicaciones diarias frente a las 4.8 de iVoox.

En cuanto al número de reacciones, es decir, comentarios, me gusta, compartidos o retuits si hablamos de Twitter, se establece una relación vinculada, de forma mayoritaria, a la cantidad de publicaciones, ocurriendo un efecto inverso al caso anterior. En consecuencia, Anchor provoca un total de 1.800 reacciones en Facebook frente a las 7.600 de iVoox, no obstante, como se ha indicado con anterioridad, iVoox tiene una media de publicación diaria en Facebook de 4.1 frente al 0.1 de Anchor. Este efecto se traslada al caso de Twitter, donde Anchor publica una media de 11 tuits diarios frente a los 4.8 de iVoox, produciendo Anchor en este caso 30.000 reacciones vinculadas a sus tuits frente a las 26.000 de iVoox.

Por último, en el caso de Instagram parece determinante el número de seguidores más que el número de publicaciones diarias. Así, Anchor ha producido 26.000 reacciones en Instagram frente a las 5.800 de iVoox, sin embargo, Anchor tiene un total de 67.000 seguidores acumulados durante el periodo analizado frente a los 4.600 de iVoox.

\subsection{Tipología de contenidos en Facebook}

Facebook permite la publicación de cuatro tipos de contenido esencialmente: vídeos, imágenes, estado y enlace. En este caso, antes de comenzar con el análisis en sí, destaca que ninguna de las dos plataformas hace uso del estado. Tras destacar este primer dato, y como se ha descrito en el punto anterior, existe una superioridad en todos los tipos de publicaciones por parte del perfil de iVoox y en detrimento de Anchor.

Como se puede observar en la Tabla 2, cabe destacar la importancia de publicaciones basadas en enlaces, es decir, aquellas que llevan al usuario directamente a la página señalada. Tanto Anchor, con 19 publicaciones de este tipo, como iVoox, con 1135 publicaciones de este tipo, centran su estrategia en ofrecer al usuario la comodidad de acceder directamente al contenido.

Más allá de destacar las pocas publicaciones de Anchor, sí se puede afirmar que iVoox apuesta por una estrategia basada en la imagen en lugar del vídeo, publicando 80 post del primer tipo y 34 del segundo.

Los días que más publicaciones acumulan ambas plataformas en Facebook, en base al periodo estudiado, destaca que iVoox ha centrado su es- 
Tabla 3. Análisis variables propias de Facebook

\begin{tabular}{|l|c|c|c|}
\hline & \multicolumn{2}{|c|}{ Tipología de contenido en Facebook } & Enlace \\
\hline Anchor & Imágenes & Vídeos & 19 \\
\hline iVoox & 6 & 5 & 1135 \\
\hline
\end{tabular}

Tabla de elaboración propia. Fuente: Fanpage Karma.

trategia en dos días principalmente: jueves y viernes. En ambos casos, desde el perfil oficial de la plataforma se ha superado a cualquier día de la semana. Según los datos obtenidos, en total, desde iVoox se han publicado 194 publicaciones los jueves y 191 los viernes, cuando el resto de los días de la semana no acumulan más de 179 en el mayor de los casos.

Aunque debido a la baja frecuencia de publicación no se puede trazar una estrategia de publicación por parte de Anchor, cabe destacar que los lunes, sábados y domingos solo acumula 1 publicación por cada uno de estos días durante todo el periodo de estudio. El resto de los días de la semana acumula entre 6 y 7 publicaciones.

\subsection{Tipología de contenidos en Instagram}

La red social Instagram ofrece tres tipos básicos de publicaciones: Imágenes, vídeos y carrusel. Este último es la suma de varias imágenes o vídeos. En este caso, en ambos perfiles estudiados, destaca el poco uso que se hace de la tipología carrusel. En el caso de Anchor, durante el periodo analizado, solo se han publicado 6 post de este tipo frente a los 9 de iVoox, tal y como se recoge en la Tabla 3.

Al uso de las imágenes y los vídeos, encontramos dos estrategias diferenciadas. En primer lugar, Anchor apuesta por un uso equilibrado de ambas tipologías, publicando 20 imágenes y 18 vídeo. Por otro lado, iVoox se centra en la publicación de imágenes, distanciándose de los vídeos, con 45 publicaciones del primer tipo y $11 \mathrm{del}$ segundo.

Por lo que respecta a la estrategia de publicación, ambas redes sociales siguen una línea similar a la descrita en el punto anterior en el caso de Facebook. En concreto, desde el perfil oficial de Anchor se apuesta por una publicación constante en los días de diario y no ofrecer contenido a sus seguidores durante el fin de semana. Durante el periodo de estudio, solo se ha registrado una publicación que haya tenido lugar en domingo. Por su parte, iVoox repite estrategia y el día que más publicaciones acumula es el jueves. Finalmente, a diferencia de Anchor, si publica los fines de semana, aunque con una frecuencia muy baja.

\section{Tabla 4. Análisis variables propias de Instagram}

\begin{tabular}{|l|c|c|c|}
\hline & \multicolumn{2}{|c|}{ Tipología de contenido en Instagram } & Carrusel \\
\hline & Imágenes & Vídeos & 6 \\
\hline Anchor & 20 & 18 & 9 \\
\hline
\end{tabular}

Tabla de elaboración propia. Fuente: Fanpage Karma. 


\section{Tabla 4. Análisis variables propias de Twitter}

\begin{tabular}{|l|c|c|c|c|}
\hline \multicolumn{7}{|c|}{ Tipología de contenido en Twitter } \\
\hline Imágenes & Enlace & Enlace + Imagen & Solo texto \\
\hline Anchor & $6,9 \%$ & $32,5 \%$ & $4,2 \%$ & $56,5 \%$ \\
\hline iVoox & $4,6 \%$ & $83,7 \%$ & $2,3 \%$ & $9,5 \%$ \\
\hline
\end{tabular}

Tabla de elaboración propia. Fuente: Fanpage Karma.

\subsection{Tipología de contenidos en Twitter}

Twitter ofrece a los usuarios, marcas y empresas la posibilidad de publicar cuatro tipos de contenido principalmente: Imágenes, enlaces, enlace más imagen y solo texto. Estos cuatro tipos de tuits, como se denominan las publicaciones en esta red social, son básicamente los que han empleado Anchor e iVoox en esta red social.

En primer lugar, y a diferencia de Facebook e Instagram, destaca que ha sido la red social que más han utilizado desde ambas plataformas como se puede apreciar en la Tabla 1. Más allá de los resultados obtenidos o de los logros alcanzados, resulta un hecho muy interesante y que cabe mencionar.

En cuanto a la estrategia seguida, observamos tendencias inversas entre ambas plataformas de podcast. En este sentido, Anchor se centra en los tuits basados en texto, el 56,5\% de las publicaciones durante el periodo de estudio son de esta tipología, así como en aquellas basadas en el enlace con un 32,5\% de tuits publicados, tal y como se refleja en la Tabla 4. En cuanto al resto de tipos de tuits, solo cuenta con un 6,9\% dedicado a imágenes y el 4,2 \% dedicado a la suma de enlace más imagen.

iVoox se centra de nuevo en la estrategia aplicada en Facebook (Tabla 2) donde el uso de enlaces se vuelve el eje central de las publicaciones realizadas por el perfil oficial de esta plataforma. Así, durante el periodo de análisis muestra que el 83,7\% de los tuits publicados desde la cuenta oficial de iVoox en Twitter son en sí mismo un enlace. Tan solo un 4,6 \% son imágenes, un 2,3\% enlace más imagen y el 9,5\% solo contienen texto.

Los días que más publicaciones acumulan, en el caso de iVoox destaca el martes como día preferente de publicación con 261 tuits acumulados en ese día durante el periodo de estudio. El resto de los días la acumulación oscila entre los 179222 tuits, siendo el sábado el día que menos repercusión tiene, con 179 y el viernes el que más con 222 tuits acumulados durante el periodo de estudio.

En esta ocasión, si encontramos estrategias contrapuestas entre una plataforma y otra. En este sentido, Anchor se centra, sobre todo, en el sábado, día en el que se han publicado un total de 812 tuits durante el periodo de estudio. Los siguientes días con más impacto son el miércoles, con 566 tuits y el domingo con 555. Por su parte, el jueves con 225 y el viernes con 171 son los días que menor incidencia acumulan en cuanto a número de tuits publicados.

\section{Conclusiones}

El propósito de este trabajo es analizar la presencia que tienen, en las principales redes sociales (Facebook, Instagram y Twitter), iVoox y Anchor, dos de las principales plataformas para alojar podcast. De lo que se extraen las siguientes conclusiones principales: en primer lugar, no existe una relación causa efecto entre la cantidad de publi- 
caciones y el número de seguidores. Como se ha expuesto en el apartado Resultados, tener una frecuencia de publicación menor no implica un mayor impacto en redes sociales, al menos, en términos de audiencia.

Se constata la conclusión de Florini (2015) al afirmar que «la red de podcasts se mantiene en parte a través de interacciones en las redes sociales, particularmente en Twitter» (Florini, 2015, p. 216). En este sentido, es la red social que acumula mayor número de publicaciones por parte de Anchor e iVoox, así como donde se ha registrado una frecuencia de publicación más elevada.

Sin embargo, y esto es llamativo, la red social que menos publicaciones acumula, así como una frecuencia de publicación muy baja por parte de ambas plataformas de podcast, es Instagram. En el contexto actual, donde Instagram es una de las redes sociales con mayor crecimiento según el último informe de Iab.Spain (2020), así como la que más público joven acumula, parece un error no dedicar más recursos a esta red social.

Ambas plataformas de podcast han creado una comunidad muy activa en Twitter, lo que justifica la alta actividad en esta red social. Sin embargo, Instagram, como señala el informe de las redes sociales elaborado por Iab.Spain, es una de las redes sociales más empleada por los jóvenes al igual que la que más crecimiento tiene. Por lo tanto, no generar una comunidad derivada de esta red social impide la creación de nuevos oyentes, que además tienen una edad media más baja que los de Twitter, lo que podría generar una comunidad más duradera en el tiempo.

\section{Bibliografía}

Aguayo López, V. (2015). El podcast como herramienta de comunicación empresarial. Málaga: Publicaciones y Divulgación Científica. Universidad de Málaga.

Andrejco, K., Lowrance, J., Morgan, B., Padgett, C., \& Collins, S. (2017). Social Media in Nurse Anesthesia: A Model of a Reproducible Educational Podcast. AAN A Jo u rn a l, 10-16.

Avery, E., Lariscy, R., Amador, E., Ickowitz, T., Primm, C., \& Taylor, A. (2010). Diffusion of Social Media Among Public Relations Practitioners in Health Departments Across Various Community Population Sizes. Journal of Public Relations Research(22), 336-358.

Blanco, S. (2006). «El podcast: situación actual en el mundo hispanohablante». XIII Jornadas Internacionales de Jóvenes Investigadores en Comunicación, pp. 1931-1944.

Berry, Richard (2015) Serial and Ten years of Podcasting: Has the Medium Finally Grown Up. In: Radio, Sound and Internet. LASICS, Braga, Portugal, pp. 299-309. ISBN 978-9898600-37-0
Bruno C. Jham, D. M., Gabriela V. Duraes, D., Howard E. Strassler, D., \& Luis G. Sensi, D. M. (2007). Joining the Podcast Revolution. Journal of Dental Education, 72(3), 278287.

Chacón, Carmen, Pérez, Cleiva J. (2011) El podcast como innovación en la enseñanza del inglés como lengua extranjera. Pixel-Bit. Revista de Medios y Educación, 39, pp.41-54.

Eyrich, N., Padman, M. L., \& Sweetser, K. (2008). PR practitioners' use of social media tools and communication technology. Public Relations Review, 34, 412-414. doi:10.1016/j. pubrev.2008.09.010

Florini, S. (2015). The Podcast «Chitlin' Circuit»: Black Podcasters, Alternative Media, and Audio Enclaves. Journal of Radio \& Audio Media, 22(2), 209-219. doi:10.1080/193765 29.2015.1083373

Fundeu, https://www.fundeu.es/ [06/02/2021]

IAB.Spain. (2020). Estudio de Redes Sociales 2020. [Informe] 
Frigola, J.; Grané, M. y Barolomé, A. (2008). «Distribuyendo información bajo demanda, el podcasting». Actas del I Congreso I+C. Investigar la Comunicación [Recurso electrónico] https://ae-ic.org/santiago2008/Congreso08/Actas/contents/pdf/comunicaciones/348.pdf

Leiva Aguilera, J. «Podcast». Anuario ThinkEPI, 2007, pp. 163-166

López Villafranca, P. (2019). Estudio de casos de la ficción sonora en la radio pública, rne, y en la plataforma de podcast del Grupo Prisa en España. Anuario Electrónico de Estudios en Comunicación Social «Disertaciones», 12(2), 65-78. doi:http://dx.doi.org/10.12804/revistas.urosario.edu.co/ disertaciones/a.6547

Lundström, M., \& Lundström, T. P. (2020). Podcast ethnography. International Journal of Social Research Methodology. doi:10.1080/13645579.2020.1778221

Moreno Cazalla, L. (2017). Podium Podcast, when podecasting has spanish accent. Prisma Social, 334-364.

Nwosu, A., Monnery, \& D, R. V. (2017). Use of podcast technology to facilitate education, communication and dissemination in palliative care: the development of the AmiPal podcast. BMJ Supportive \& Palliative Care, 212-217.

Orihuela, J. L. 2011. Mundo Twitter. Grupo Planeta. Barcelona (España).

Parlatore, B.; Delménico, M.; Beneitez, M. E. y Clavellino, M. (2020). «El podcast y el desafío de repensar lo radiofónico», Question/Cuestión, 2 (66) [Recurso electrónico] http:// sedici.unlp.edu.ar/bitstream/handle/10915/104525/Documento_completo.pdf?sequence=1

Parra, D. y Onieva, C. (2020). «El uso de podcast para la difusión del patrimonio cultural en el entorno hispanohablante: análisis de las plataformas iVoox y SoundCloud». Naveg@mérica (24). [Recurso electrónico] https://revistas. um.es/navegamerica/article/download/416541/281021/

Pavelko, R. L., \& Myrick, J. G. (2020). Muderinos and Media Effects: How the My Favorite Murder Podcast and its
Social Media Community May Promote Well-being in Audiences with Mental Illness. Journal of Radio $E$ Audio Media, 27(1), 151-169. doi:10.1080/19376529.2019.1638925

Robbins, S. P., \& Singer, J. B. (2014). From the Editor-The Medium the Message: Integrating Social Media and Social Work Education. Journal of Social Work Education, 50(3), 387-390. doi:10.1080/10437797.2014.916957

Ruiz Olabuénaga, J. I. (2012). Teoría y Prácitca de la Investigación Cualitativa. Bilbao: Deusto Digital.

Sellas, T. (2012). «Repositorios sonoros y recomendación de contenidos. El caso iVoox». El profesional de la información, 21 (2), pp. 206-209.

Solano Fernández, I. y Sánchez Vera, M. (2010). «Aprendiendo en cualquier lugar: el podcast educativo». Revista de Medios y Educación, (36), pp. 125-139.

Stelzner, M. A. (2018). Social Media Marketing Industry Report. Social Media Examiner.

Sullivan, J. (2019). «The Platforms of Podcasting: Past and Present», Social Media + Society, Octubre 2019. DOI: $10.1177 / 2056305119880002$

Thoma, B., Murray, H., Huang, S., Milne, W., Martin, L., Bond, C., \& .. .. (2018). The impact of social media promotion with infographics and podcasts on research dissemination and readership. CJEM, 20(2), 300-306. doi:doi:10.1017/ cem.2017.394

Túñez López, Miguel; Valdiviezo Abad, Cesibel; Martínez Solana, Yolanda Las redes sociales en la gestión de la comunicación universitaria Opción, vol. 31, núm. 6, 2015, pp. 852-874

Villanueva, X. (2019). «Qué es iVoox con Juan Ignacio Solera»[Recurso electrónico] https://abismofm.com/que-esiVoox/

Wired Magazine. Oxford Dictionary Names «Podcast» 2005 Word of the Year: https://www.wired.com/2005/12/ oxford-dictional 

()ㅜ(1) $\odot$

\section{Análisis de la comunicación de empresas europeas y norteamericanas en TikTok}

Communication analysis of European and North American companies on TikTok

Dr. Pavel Sidorenko Bautista

Profesor de la Facultad de Ciencias de la Comunicación de la Universidad Francisco de Vitoria pavel.sidorenko@ufv.es https://orcid.org/0000-0002-8094-3089

Dr. José María Herranz de la Casa Profesor Titular de la Facultad de Comunicación de la Universidad de Castilla-La Mancha josemaria.herranz@uclm.es https://orcid.org/0000-0002-3667-2664

Alba Soledad Moya Ruiz

Graduada en Periodismo y doctoranda de la Facultad de Comunicación de la Universidad de Castilla-La Mancha albasoledad.moya@alu.uclm.es
Sidorenko Bautista, P., Herranz de la Casa, J.M. y Moya Ruiz, A.S. (2021)

Análisis de la comunicación de empresas europeas y norteamericanas en TikTok aDResearch ESIC. № 25 Vol 25

Monográfico especial, marzo 2021 · Págs. 106 a 123 https://doi.org/10.7263/adresic-025-06 
RESUMEN

\author{
Clasificación JEL: \\ M39, 033 \\ Palabras clave: \\ Consumidores, \\ comunicación \\ empresarial, \\ publicidad, \\ comunicación digital, \\ marketing
}

Objetivo: Esta investigación analiza la comunicación que están desarrollando empresas y marcas en TikTok, red social que representa hoy una tendencia global y donde confluyen diversos segmentos de usuarios-clientes, especialmente los que corresponden a los Millennials y la Generación Z. Específicamente, busca observar la capacidad de éxito o fracaso de formatos como la publicidad y el marketing convencional frente a fórmulas emergentes y novedosas como el «anti-marketing», que propone contenidos de acompañamiento para los usuarios sin promoción explícita de productos o servicios.

Diseño/metodología/enfoque: Para realizar este estudio exploratorio inicial se han seleccionado diez empresas y marcas norteamericanas y otras diez europeas, con el fin de establecer un análisis comparativo de cómo comunican a través de dicha plataforma. Asimismo, se ha analizado la narrativa comunicativa empleada en esta red por parte de las empresas y marcas, a fin de delimitar las propuestas más utilizadas y si existe innovación al respecto.

Resultados: Los resultados muestran una correlación entre el aumento de seguidores y el incremento de publicaciones, es decir, crece el alcance cuanto mayor exposición de contenidos se produce. Igualmente se corrobora una prevalencia del «anti-marketing» como estrategia de acompañamiento de empresas y marcas con los usuarios-clientes y la evidencia de que no existen limitantes en dicha red social para la exposición de cualquier tipo de producto o actividad económica.

Originalidad/contribución: pese a que aún son pocas las empresas y marcas que comunican a través de TikTok, se aprecia una tendencia importante a innovar narrativamente lejos de fórmulas publicitarias y de marketing convencionales, lo que abre una vía a nuevas investigaciones relacionadas.

\section{ABSTRACT}

\section{JEL Classification: M39, 033 Key words: Consumers, business communication, advertising, digital communication, marketing}

Purpose: This research analyzes the communication that companies and brands are developing in TikTok, a social network that represents today a global trend and where different segments of users-customers converge, especially those corresponding to Millennials and Generation Z. Specifically, it seeks to observe the capacity for success or failure of formats such as advertising and conventional marketing versus emerging and novel formulas such as 'anti-marketing', which proposes accompanying content for users without explicit promotion of products or services.

Design / Methodology / Approach:To carry out this initial exploratory study, ten North American and ten European companies and brands were selected to establish a comparative analysis of how they communicate through this platform. Likewise, the communicative narrative used in this network by the companies and brands has been analyzed, to delimit the most used proposals and if there is any innovation in this regard.

Results: The results show a correlation between the increase in followers and the increase in publications, i.e., the greater the exposure of content, the greater the reach. It also corroborates the prevalence of'anti-marketing' as a strategy to accompany companies and brands with userscustomers and the evidence that there are no limits in this social network for the exposure of any type of product or economic activity.

Originality / Contribution: although there are still few companies and brands that communicate through TikTok, there is an important tendency to innovate narratively away from conventional advertising and marketing formulas, which opens the way for further related research. 


\section{Introducción}

La comunicación digital ha impactado en la publicidad y la imagen de empresas y marcas, procurando que los usuarios se apropien de los contenidos y produzcan nuevos mensajes a partir de ellos (Romero y Fanjul, 2010; Gil y Miquel, 2017; Marzal y Casero, 2017). Los usuarios-clientes deciden si aceptan o no ese mensaje, por lo que es imprescindible innovar al respecto.

Las personas adquieren hoy un rol más activo, convirtiéndose en drivers, con los que las empresas dialogan en gran medida a través de estos canales (Muñiz y Schau, 2011). Estos netizens exigen cada vez más vías para expresarse ( $\mathrm{Li}$, Xiaohui y Zhengwu, 2019, p. 60-61).

Las redes sociales promueven un modelo en el que la reputación de marcas y empresas se encuentra en gran medida en manos de los usuarios, categorizados como crosumers, prosumers, persumers o fansumers (Del Pino, Castelló y RamosSoler, 2013, p. 184).

Se trata de un contexto online en mayor medida, con preeminencia de lo multimedia e interactivo, procurando la construcción de nuevas narrativas alternativas donde empresas e instituciones redefinen y crean nuevos perfiles profesionales orientados a la atención y desarrollo de la imagen corporativa y la promoción en el ámbito digital, recurriendo a narrativas basadas en inteligencia artificial, chatbots, streaming, neuromarketing o inbound marketing (Herranz, Caerols, Sidorenko, 2019, p. 181).

\subsection{Audiencias interconectadas y nuevas narrativas}

En este proceso, las audiencias son redefinidas en segmentos etarios categorizados como generaciones, determinadas en líneas muy generales por fenómenos relacionados que producen brecha en correspondencia con otros grupos sociales, al tiempo que experimentan otro grupo de sucesos compartidos, especialmente de índole cultural y a escala global (Parry y Urwin, 2011).

Según Visual Capitalist con base en el Global Web Index de abril de 2020 (Jones, 2020), durante los cuatro primeros meses de la pandemia del COVID-19, los «Boomers» (57-64 años) se caracterizaron por un consumo mayoritario de contenidos a través de medios tradicionales (televisión, radio y periódico) aunque con algunas excepciones, pues algunos individuos empezaron a tener mayor presencia en medios digitales, que no es el caso de la «Generación X» (38-56 años) que, si bien ha consumido mucha televisión convencional, en términos digitales ha crecido de manera paulatina y notoria mediante vídeos en línea y televisión bajo demanda en streaming. Los «Millennials» (24-37 años) se perfilaron en torno a un consumo mayoritariamente de vídeos en línea, televisión bajo demanda, música bajo demanda, videojuegos y contenidos noticiosos e informativos a partir de fuentes digitales.

La última segmentación documentada es la llamada «Generación $\mathrm{Z}$ », «Centennials» o «nativos digitales» (16-23 años), definidos por haber nacido y crecido -en la mayoría de los casos- con pleno acceso a Internet inalámbrico y de alta velocidad, lo cual condiciona la manera en que se comunican, entretienen y consumen contenidos (Baysal, 2014; Prensky, 2001; Turner, 2015). La «Generación Z» es considerada la primera generación de usuarios completamente móviles (Palley, 2012, Seymour, 2019).

El uso intensivo que estos individuos hacen de smartphones y tablets, junto a los Millennials, ha determinado la narrativa y los tiempos de muchas plataformas digitales. Para Viens (2019) actualmente la mayoría de los consumidores interconectados a nivel mundial pertenecen a estos dos segmentos de público específicamente, mientras 
que, para el caso específico de España, ya representan el $50 \%$ (IAB, 2020).

\subsection{El formato vertical y efímero}

La verticalidad de formatos se ha definido a partir de la imposición del smartphone como el principal instrumento de comunicación, información y entretenimiento de la sociedad global actual (Lijun et al., 2019) con una penetración de hasta el 97 \% (Fundación Telefónica, 2020; IAB, 2020).

Snapchat redefinió la verticalidad multimedia móvil y la cultura digital proponiendo la lógica efímera de contenidos a partir de 2011, inspirando así a otras plataformas como Instagram, a asumir el formato denominado «story».

Para Hernández (2019) es un formato a pantalla completa, que abstrae al usuario de otros estímulos provenientes del dispositivo como notificaciones, estado de la batería, información horaria, fecha y clima. Shery Sanberg, gerente de operaciones de Facebook (en Hammil, 2018) enfatiza que es el formato ideal para enganchar a los consumidores-usuarios más digitales, que invita a niveles mayores de creatividad para los creadores. A lo que valdría agregar que inevitablemente implica un complejo proceso de atención y procesamiento de información por parte de los receptores, por lo condensado y rápido del mensaje (Bayer et al., 2016; Shuai, Yuzhen y Yifang, 2019).

Se trata de una transformación tecnológica que no afecta solo a los usuarios, sino también a los procesos de comunicación de las empresas, en su código, los canales e inclusive los interlocutores (Hernández, 2011).

A ello otra red, Dubsmash, propuso en 2014 mayor interactividad y entretenimiento al formato a partir de playbacks de canciones, lo que fue rápidamente emulado por la red social china Musical.ly (ByteDance), proponiendo video-selfies de 15 segundos en promedio. Sumando también elementos narrativos de Snapchat e Instagram y ante el rápido crecimiento y popularidad en muy corto tiempo (200 millones de usuarios en 2018) ( Zwarts, 2018). ByteDance se animó a unificarla con Douyin en 2017, conocida internacionalmente a partir de 2018 como TikTok, trasladando así su base de usuarios, superando así los 500 millones de perfiles activos y 1.500 millones de descargas en el último trimestre de 2019 (González, 2019).

\subsection{TikTok: nuevo espacio digital y nuevo código de mensaje}

TikTok es una social cuyos usuarios aún corresponden mayoritariamente a la «Generación Z» (Li, Xiaohui y Zhengwu, 2019; Shuai, Yuzhen y Yifang, 2019) aunque en el transcurso de 2020 reportó un incremento de usuarios «Millennials» e inclusive de la «Generación X» a propósito de los confinamientos sociales producidos por la COVID-19, que se ha mantenido al alza en el transcurso de dicho año (Sidorenko, Herranz y Cantero, 2020).

Para Dan Seavers de la consultora Talk Walker (Merca2.0, 2020), es una plataforma compleja por tiempo y formato, por lo que las empresas y marcas deben aplicar la fórmula del «anti-marketing», es decir, estrechar la relación con los usuarios-clientes desde propuestas menos formales y más entretenidas, sin abandonar la imagen corporativa y publicitaria. Tienen que apostar por el acompañamiento de la audiencia sin saturar el perfil con fórmulas publicitarias tradicionales.

En otras palabras, son publicaciones sin intención publicitaria expresa, que relacionan a la marca con un contexto o segmento específico a partir de relatos y propuestas multimedia poco convencionales con la imagen corporativa y en tono entretenido. No buscan vender sino acom- 
pañar a los usuarios-clientes y estrechar relación con ellos.

Por este motivo existen muchas marcas y empresas que hoy no tienen presencia en dicha red, o han reservado el perfil, pero continúan sin publicar nada, dado que el código de mensaje que se impone no siempre pareciera ir acorde a la imagen e identidad de estos actores.

Es una red social que insta al dinamismo, con la rapidez de producción, consumo de contenidos y exigencia creativa que esto conlleva (Li, Xiaohui, y Zhengwu, 2019), cuyos formatos narrativos principales -de momento- son los playbacks, historias divertidas y contenidos «relajantes a la mente» (Yu-Liang, Chun-Chin y Shu-Ming, 2019). Sus 15 segundos de grabación propuestos por defecto suponen una innovación hacia un modelo «micronarrativo» (Chaoudhary, Gautam y Vivek, 2020, p. 196), que ya se aprecia en otros ámbitos como la comunicación de la salud (Chengyan et al., 2019) o el periodismo (Sidorenko, Herranz y Cantero, 2020; Vásquez, Negreira y López, 2020).

Por su veloz crecimiento, TikTok ha desarrollado una plataforma para la contratación expresa de contenidos publicitarios, que no obliga a las empresas a contar con perfil activo, lo cual la diferencia de otras redes sociales. «TikTok for Business» persigue rentabilizar la enorme y cada vez más heterogénea cantidad de usuarios que hacen vida en dicha red, ofreciendo diferentes maneras para darle mayor visibilidad al mensaje deseado, a partir de la publicidad convencional, pero con un estilo narrativo diferente como ya se ha descrito.

Asimismo, como ocurre con otras plataformas sociales digitales, en TikTok no solo confluye una importante cantidad de influencers, sino que la facilidad con la que el algoritmo muestra los contenidos a través del feed general ha promovido el surgimiento de los nanoinfluencers o microinfluencers asociados a perfiles con seguidores que oscilan entre los 1.000 y 100.000, aunque en promedio hay autores que los sitúan en 5.000 (Rakoczy et al., 2018, p. 141), cuyos contenidos tienen eventualmente alto rendimiento de engagement, siendo un fenómeno reservado a la publicación y no a la figura específica del emisor (Merca2.0, 2020).

Actualmente, la importancia de esta red social viene reforzada por el hecho de ser incluida como una de las 100 empresas más valiosas del mundo, por la plataforma de valor de marca Brand Z (Kantar, 2020). Se trata de la aplicación con la mayor cantidad de descargas acumuladas en un trimestre (enero-marzo 2020), alcanzando más de 315 millones de instalaciones a nivel mundial (Ditrendia, 2020).

Este éxito se ha traducido en que haya superado los 800 millones de perfiles activos en el segundo semestre de 2020, convirtiéndola en la sexta aplicación social más utilizada a nivel global según Hootsuite (Sehl, 2020).

\section{Metodología}

Hoy existen estrategias en torno a la construcción y mantenimiento de la reputación online, con el fin de posicionar la empresa o marca en los motores de búsqueda, así como la administración del feedbak con los usuarios de manera dinámica y permanente (Vaquero, 2012). Asimismo, se identifican estrategias de marketing digital, con el fin de visibilizar la institución y su producto, al tiempo de ganar clientes a partir de relaciones digitales (Wymbs, 2011).

TikTok ha supuesto un nuevo escalafón en el desarrollo del marketing de influencia, muy presente en otros entornos digitales como Instagram y YouTube, donde las marcas centran sus esfuerzos en figuras populares con alto impacto 
en la opinión de sus seguidores, en lugar de dirigirse de forma directa a su mercado objetivo (Hall, 2016). Se trata sin duda de una red social con un crecimiento veloz que cuenta con un importante poder de persuasión sobre consumidores potenciales y segmentos de público atípicos.

Esta investigación tiene como objetivo principal, analizar cómo comunican las empresas y marcas a través de este nuevo «fenómeno digital». Como objetivos secundarios se establece: 1 . Llevar a cabo una observación de las características de los perfiles empresariales y comerciales activos en TikTok, 2. Observar la dinámica de engagement en los casos estudiados, 3. Identificar las estrategias de comunicación implementadas por los perfiles estudiados y las posibilidades que hoy permite la red social para cuentas de empresas y marcas.

Las hipótesis de partida para la investigación son:

H1. Desde un aspecto narrativo, es difícil que todas las empresas y marcas tengan cabida en esta red social.

H2. La popularidad en esta red social exige por parte de empresas y marcas tener que recurrir más a influencers y colaboraciones de usuarios, que a elaborar contenidos propios.

H3. Hay una correlación entre el incremento de contenidos de las marcas y empresas y el aumento de seguidores.

Con el fin de obtener una visión más amplia del fenómeno en términos globales, se plantea un análisis comparativo entre las acciones llevadas a cabo por diez empresas norteamericanas y otras diez europeas, considerando que se trata de dos vastos territorios con una importante proyección comercial y económica. Así, procurando un abanico amplio de sectores y actividades, se ha establecido estudiar las siguientes empresas:
- Norteamérica: NBA, Netflix, Zoo de San Diego, Nike, Chipotle, The Washington Post, Tarte Cosmetics, Crocs, Foot Locker y Old Navy.

- Europa: Red Bull, LaLiga, Gucci, Sephora, Movistar Plus, Los 40, Deichmann, Reebok, Bluebanana, Port Aventura World.

Realizado un estudio de investigación exploratorio (Stebbins, 2001), la muestra se ha seleccionado procurando coincidencia entre las actividades económicas o propuestas entre los perfiles norteamericanos y los europeos, y sobre dos indicadores de engagement, teniendo en cuenta que todavía no hay muchas empresas en esta red:

- Perfiles de empresas y marcas que tuvieran entre 10.000 y 100.000 seguidores, por un lado, y perfiles con más de 100.000 seguidores por otro, dado que, en diferentes portales sobre influencia en redes sociales referencian este mínimo para empezar a tener impacto en el público de TikTok.

- Niveles de engagement por encima de 100.000 «likes», lo cual indica que el mensaje está llegando a los usuarios-clientes y estos están reaccionando en consecuencia.

La construcción de la tabla de análisis se realizó considerando las siguientes variables:

- Empresa o marca con perfil verificado

- Tipo de producto o sector económico al que pertenece

- Número de seguidores

- Total de «likes» (engagement) que acumula el perfil

- Cantidad de contenidos publicados

- Contenido propio (CP) o colaboraciones con creadores de contenidos de la platafor$\mathrm{ma}(\mathrm{COL})$ 
- Tipos de comunicación aplicados a través de esos contenidos: informativa (INFO), publicidad (PUB), marketing (MKT), «antimarketing» (AMKT)

Los contenidos informativos (INFO) se refieren a mensajes con datos precisos sobre lugares, horarios, nuevos lanzamientos o cambios de algunos de ellos. La publicidad (PUB) alude a contenidos en tono de anuncio y promoción de productos y servicios. La categoría de marketing (MKT), hace referencia a publicaciones con alusión a precios o a eventos específicos en determinadas locaciones, así como descripciones detallas de productos y servicios. En contraparte, el «antimarketing» (AMKT) refiere, tal y como afirma Seavers (Merca2.0, 2020), a publicaciones que intentan conciliar el código imperante en TikTok (muy conciso, de humor y entretenimiento) y adaptarlo al mensaje de mercadeo tradicional.

La observación fue realizada en cada perfil desde que comenzaron a publicar hasta el 31 de diciembre de 2020, entendiendo que hubo un repunte importante de nuevos usuarios en TikTok entre el primero y segundo semestre de dicho año. Esto ha obligado a muchas empresas a apurar su presencia en dicha plataforma para aprovechar las posibilidades de llegar a nuevos segmentos de público y más usuarios.

Para la comprobación de la tercera hipótesis se propone una tabla donde la periodización propuesta sea dividida en dos bloques temporales: desde la creación del perfil hasta el 30 de junio 2020 y desde el 1 julio hasta el 31 de diciembre 2020, cuyas variables a considerar son: nombre de la empresa o marca, período, número de seguidores hasta la fecha, número de contenidos hasta la fecha y el porcentaje que representa la eventual evolución de dichos indicadores.

Se elaboró también una tabla sobre la presencia de las mismas marcas en Instagram, contrapar- te digital donde cohabitan mayoritariamente la «Generación Z»y «Millennials», con el fin de contrastar hasta qué punto la presencia de empresas a través de TikTok puede eventualmente superar a la de otras redes sociales, así como comparar el nivel de importancia a la hora de considerar una u otra. Las variables en este caso son: número de seguidores, total de publicaciones, obtención de perfil verificado, presencia de contenidos de TikTok en el «feed» y si han desarrollado «Reels».

Con este último indicador se busca verificar si existe un trabajo diferenciado en cuanto creación de contenidos a través de una propuesta que ha sido una réplica exacta de TikTok. Esto tiene la intención de observar si las empresas vuelcan contenido de la red social china en este apartado de Instagram, o, por el contrario, suman un esfuerzo de comunicación adicional.

No solo se procura un análisis del estilo narrativo, sino también un marco de reflexión entre esa necesidad que tienen marcas y empresas por copar actualmente la mayor cantidad de escenarios digitales posible -sobre todo si gozan de tanta popularidad- a fin de llegar a más cantidad de personas, procurando así un incremento de su alcance.

\section{Resultados}

El 100 \% de las marcas y empresas norteamericanas de TikTok analizadas posee perfil verificado, lo que asegura a los usuarios-clientes que los contenidos publicados son confiables y corresponden a los valores e identidad corporativa (Tabla 1).

En ninguno de los casos, hasta la fecha de observación, las colaboraciones con otros usuarios de la red social superan a los contenidos propios de cada perfil. Sin embargo, en el caso particular de Chipotle (Tabla 1), la tendencia parece irse inclinando poco a poco hacia esta manera de comunicación colaborativa. 
En los 10 casos norteamericanos la fórmula del «anti-marketing» está presente como estilo narrativo. Se aprecia la búsqueda de relacionar la marca o empresa a un estilo de vida concreto, idiosincrasia o a experiencias específicas con presencia del producto. Asimismo, el marketing explícito se aprecia en 8 de los 10 casos referenciados.

En menor proporción (7 casos) se aprecia publicidad explícita, o contenidos informativos sobre productos y servicios ofrecidos (6 casos).

\section{Tabla 1. Datos de empresas norteamericanas en TikTok hasta el 31 de diciembre 2020}

\begin{tabular}{|c|c|c|c|c|c|c|c|}
\hline $\begin{array}{l}\text { Empresa o marca } \\
\text { y fecha de inicio } \\
\text { en TikTok }\end{array}$ & $\begin{array}{c}\text { Perfil } \\
\text { verificado }\end{array}$ & $\begin{array}{l}\text { Tipo de } \\
\text { producto } \\
\text { / Sector } \\
\text { económico }\end{array}$ & $\begin{array}{c}\text { No.de } \\
\text { seguidores }\end{array}$ & Total «likes» & $\begin{array}{c}\text { Total } \\
\text { contenidos }\end{array}$ & $\begin{array}{l}\text { Tipo de } \\
\text { contenido }\end{array}$ & $\begin{array}{l}\text { Fórmula } \\
\text { del } \\
\text { contenido }\end{array}$ \\
\hline $\begin{array}{l}\text { NBA } \\
\text { @nba } \\
\text { 29/07/2019 }\end{array}$ & Sí & $\begin{array}{l}\text { Franquicia } \\
\text { deportiva }\end{array}$ & 12.100 .000 & 270,2 millones & 3859 & $\begin{array}{l}C P=3.722 \\
C O L=137\end{array}$ & $\begin{array}{l}\text { INFO, PUB, } \\
\text { MKT y AMKT }\end{array}$ \\
\hline $\begin{array}{l}\text { Netflix } \\
\text { @netflix } \\
\text { 07/08/2019 }\end{array}$ & Sí & V.O.D. & 11.600 .000 & 158.900 & 547 & $\begin{array}{l}C P=507 \\
C O L=40\end{array}$ & $\begin{array}{l}\text { PUB, MKT, } \\
\text { AMKT }\end{array}$ \\
\hline $\begin{array}{l}\text { Zoo San Diego } \\
\text { @sandiegozoo } \\
\text { 24/12/2018 }\end{array}$ & Sí & $\begin{array}{l}\text { Parques de } \\
\text { atracciones } \\
\text { y animales }\end{array}$ & 1.800 .000 & 22,7 millones & 154 & $C P=154$ & $\begin{array}{l}\text { INFO, MKT, } \\
\text { AMKT }\end{array}$ \\
\hline $\begin{array}{l}\text { Nike } \\
\text { @nike } \\
\text { 13/02/2020 }\end{array}$ & Sí & $\begin{array}{c}\text { Ropa y } \\
\text { accesorios } \\
\text { deportivos }\end{array}$ & 1.300 .000 & 4 millones & 22 & $\begin{array}{l}C P=17 \\
C O L=5\end{array}$ & $\begin{array}{l}\text { PUB, MKT, } \\
\text { AMKT }\end{array}$ \\
\hline $\begin{array}{l}\text { Chipotle } \\
\text { @chipotle } \\
\text { 29/03/2019 }\end{array}$ & Sí & $\begin{array}{c}\text { Alimentación } \\
\text { y bebidas }\end{array}$ & 1.400 .000 & 23,2 millones & 132 & $\begin{array}{l}\mathrm{CP}=89 \\
\mathrm{COL}=43\end{array}$ & $\begin{array}{l}\text { INFO, PUB, } \\
\text { MKT y AMKT }\end{array}$ \\
\hline $\begin{array}{l}\text { The Washington } \\
\text { Post } \\
\text { @washingtonpost } \\
21 / 05 / 2019\end{array}$ & Sí & $\begin{array}{c}\text { Medio de } \\
\text { comunicación }\end{array}$ & 784.600 & 30.7 millones & 664 & $\begin{array}{l}\mathrm{CP}=659 \\
\mathrm{COL}=5\end{array}$ & INFO, AMKT \\
\hline $\begin{array}{l}\text { Tarte Cosmetics } \\
\text { @tartecosmetics } \\
11 / 06 / 2017\end{array}$ & Sí & Cosmética & 467.700 & 8,3 millones & 1185 & $\begin{array}{l}C P=1124 \\
C O L=61\end{array}$ & $\begin{array}{l}\text { PUB, MKT, } \\
\text { AMKT }\end{array}$ \\
\hline $\begin{array}{l}\text { Crocs } \\
\text { @crocs } \\
01 / 10 / 2019\end{array}$ & Sí & $\begin{array}{c}\text { Ropa y } \\
\text { accesorios }\end{array}$ & 318.600 & 2,6 millones & 57 & $\begin{array}{l}C P=39 \\
C O L=18\end{array}$ & $\begin{array}{l}\text { PUB, MKT, } \\
\text { AMKT }\end{array}$ \\
\hline $\begin{array}{l}\text { Foot Locker } \\
\text { @footlocker } \\
06 / 11 / 2019\end{array}$ & Sí & $\begin{array}{c}\text { Tienda de } \\
\text { calzado }\end{array}$ & 246.900 & 768.700 & 74 & $\begin{array}{l}C P=49 \\
C O L=25\end{array}$ & AMKT \\
\hline $\begin{array}{l}\text { Old Navy } \\
\text { @oldnavy } \\
18 / 07 / 2017\end{array}$ & Sí & Ropa casual & 35.800 & 32.700 & 29 & $\begin{array}{l}C P=21 \\
C O L=8\end{array}$ & $\begin{array}{l}\text { PUB, MKT } \\
\text { y AMKT }\end{array}$ \\
\hline
\end{tabular}


En lo concerniente a la flexibilidad que proporciona TikTok a la hora de exportar los contenidos depositados en ella a través de otras plataformas digitales y redes sociales, si bien la mayoría de los casos apuesta por una comunicación adaptada al código del mensaje de cada red, tanto Chipotle como Foot Locker (la primera en mayor medida) (Tabla 1) han trasferido algunas publicaciones de
TikTok a Instagram, que no ocurre a la inversa, por lo menos en la observación realizada en el lapso de tiempo estipulado.

Asimismo, en el caso particular de Tarte Cosmetics y Old Navy (Tabla 1), se aprecia que han derivado apenas un solo contenido de TikTok a la sección «Reels» de Instagram. (Tabla 2).

\section{Tabla 2. Datos de empresas norteamericanas en Instagram hasta el 31 de diciembre 2020}

\begin{tabular}{|c|c|c|c|c|c|}
\hline $\begin{array}{l}\text { Empresa o marca } \\
\text { y fecha de inicio } \\
\text { en Instagram }\end{array}$ & $\begin{array}{c}\text { Perfil } \\
\text { verificado }\end{array}$ & $\begin{array}{c}\text { Total de } \\
\text { seguidores }\end{array}$ & $\begin{array}{c}\text { Total de } \\
\text { contenidos }\end{array}$ & $\begin{array}{l}\text { Vídeos de TikTok } \\
\text { en el «feed» }\end{array}$ & Reels \\
\hline $\begin{array}{l}\text { Nike } \\
\text { @nike } \\
\text { 29/12/2011 }\end{array}$ & Sí & 126.000 .000 & 774 & - & - \\
\hline $\begin{array}{l}\text { NBA } \\
\text { @nba } \\
24 / 01 / 2012\end{array}$ & Sí & 53.100 .000 & 38.000 & - & 133 \\
\hline $\begin{array}{l}\text { Netflix } \\
\text { @netflix } \\
13 / 08 / 2012\end{array}$ & Sí & 25.800 .000 & 3.376 & - & 66 \\
\hline $\begin{array}{l}\text { Foot Locker } \\
\text { @footlocker } \\
24 / 04 / 2012\end{array}$ & Sí & 12.600 .000 & 11.900 & 5 & 26 \\
\hline $\begin{array}{l}\text { Tarte Cosmetics } \\
\text { @tartecosmetics } \\
02 / 07 / 2012\end{array}$ & Sí & 9.900 .000 & 10.900 & 1 & 52 \\
\hline $\begin{array}{l}\text { The Washington Post } \\
\text { @washingtonpost } \\
\text { 24/03/2011 }\end{array}$ & Sí & 4.200 .000 & 7.528 & - & - \\
\hline $\begin{array}{l}\text { Old Navy } \\
\text { @oldnavy } \\
\text { 08/09/2012 }\end{array}$ & Sí & 2.400 .000 & 3.847 & 1 & - \\
\hline $\begin{array}{l}\text { Chipotle } \\
\text { @chipotle } \\
\text { 04/01/2019 }\end{array}$ & Sí & 1.000 .000 & 206 & 18 & 6 \\
\hline $\begin{array}{l}\text { Crocs } \\
\text { @crocs } \\
27 / 07 / 2012\end{array}$ & Sí & 1.000 .000 & 1.486 & - & - \\
\hline $\begin{array}{l}\text { Zoo San Diego } \\
\text { @sandiegozoo } \\
31 / 12 / 2010\end{array}$ & Sí & 663.000 & 2.193 & - & 18 \\
\hline
\end{tabular}


Para el caso de marcas y empresas europeas en TikTok (Tabla 3) destaca que solo una no tiene verificación de perfil pese a que en Instagram sí la ostenta (Tabla 4). Como ocurre con los casos norteamericanos, tampoco se aprecia a primera vista una relación entre la actividad de los perfiles, el número de contenidos, el sector económico o actividad desarrollada y el engagement.

Por su parte, en lo concerniente a la creación de contenidos propios o en colaboración con usua- rios de TikTok, se puede ver que en todos los casos la creación propia supera a la colaboración con usuarios (Tabla 3), y hay casos como Red Bull, Los 40 y Movistar Plus que solo han publicado contenidos propios durante el período de observación.

En el caso de Reebok (Tabla 3), a semejanza de Chipotle (Tabla 1), las publicaciones que corresponden a colaboraciones con otros usuarios y «celebrities digitales» representan una tercera parte de todo el contenido del perfil.

\section{Tabla 3. Datos de empresas europeas en TikTok hasta el 31 de diciembre 2020}

\begin{tabular}{|c|c|c|c|c|c|c|c|}
\hline $\begin{array}{l}\text { Empresa o marca } \\
\text { y fecha de inicio } \\
\text { en TikTok }\end{array}$ & $\begin{array}{c}\text { Perfil } \\
\text { verificado }\end{array}$ & $\begin{array}{l}\text { Tipo de } \\
\text { producto } \\
\text { / Sector } \\
\text { económico }\end{array}$ & $\begin{array}{c}\mathrm{N}^{\circ} \text {. de } \\
\text { seguidores }\end{array}$ & Total «likes» & $\begin{array}{c}\text { Total } \\
\text { contenidos }\end{array}$ & $\begin{array}{l}\text { Tipo de } \\
\text { contenido }\end{array}$ & $\begin{array}{c}\text { Fórmula } \\
\text { del } \\
\text { contenido }\end{array}$ \\
\hline $\begin{array}{l}\text { Red Bull } \\
\text { @redbull } \\
\text { 23/05/2018 }\end{array}$ & Sí & $\begin{array}{c}\text { Alimentación } \\
\text { y bebidas }\end{array}$ & 5.100 .000 & 81,9 millones & 2.434 & $C P$ & PUB, MKT \\
\hline $\begin{array}{l}\text { LaLiga } \\
\text { @laliga } \\
\text { 08/04/2019 }\end{array}$ & Sí & $\begin{array}{l}\text { Franquicia } \\
\text { deportiva }\end{array}$ & 2.100 .000 & 17,8 millones & 673 & $\begin{array}{l}C P=636 \\
C O L=37\end{array}$ & $\begin{array}{l}\text { PUB, MKT, } \\
\text { AMKT }\end{array}$ \\
\hline $\begin{array}{l}\text { Gucci } \\
\text { @gucci } \\
07 / 02 / 2020\end{array}$ & Sí & $\begin{array}{c}\text { Ropa y } \\
\text { accesorios }\end{array}$ & 960.900 & 6,4 millones & 87 & $\begin{array}{l}C P=68 \\
C O L=19\end{array}$ & MKT, AMKT \\
\hline $\begin{array}{l}\text { Sephora } \\
\text { @sephora } \\
\text { 10/10/2017 }\end{array}$ & Sí & Cosmética & 191.300 & 1,1 millones & 283 & $\begin{array}{l}C P=242 \\
C O L=41\end{array}$ & $\begin{array}{l}\text { INFO, PUB, } \\
\text { MKT }\end{array}$ \\
\hline $\begin{array}{l}\text { Movistar Plus } \\
\text { @movistarplus } \\
20 / 04 / 2020\end{array}$ & Sí & V.O.D. & 127.400 & 1,5 millones & 167 & $C P$ & PUB, MKT \\
\hline $\begin{array}{l}\text { Los } 40 \\
\text { @los40spain } \\
\text { 04/09/2016 }\end{array}$ & Sí & $\begin{array}{l}\text { Medio de } \\
\text { comunica- } \\
\text { ción }\end{array}$ & 56.700 & 470.800 & 83 & $C P$ & $\begin{array}{l}\text { PUB, MKT, } \\
\text { AMKT }\end{array}$ \\
\hline $\begin{array}{l}\text { Deichmann } \\
\text { @deichmann_ } \\
\text { schuhe } \\
\text { 27/05/2019 }\end{array}$ & Sí & $\begin{array}{l}\text { Tienda de } \\
\text { calzado }\end{array}$ & 38.800 & 222.000 & 149 & $\begin{array}{l}C P=134 \\
C O L=15\end{array}$ & PUB, MKT \\
\hline $\begin{array}{l}\text { Reebok } \\
\text { @reebok } \\
14 / 04 / 2020\end{array}$ & Sí & $\begin{array}{c}\text { Ropa y } \\
\text { accesorios } \\
\text { deportivos }\end{array}$ & 47.400 & 1,2 millones & 68 & $\begin{array}{l}C P=48 \\
C O L=20\end{array}$ & PUB, AMKT \\
\hline
\end{tabular}


Tabla 3. Datos de empresas europeas en TikTok hasta el 31 de diciembre 2020 (continuación)

\begin{tabular}{|c|c|c|c|c|c|c|c|}
\hline $\begin{array}{l}\text { Empresa o marca } \\
\text { y fecha de inicio } \\
\text { en TikTok }\end{array}$ & $\begin{array}{c}\text { Perfil } \\
\text { verificado }\end{array}$ & $\begin{array}{l}\text { Tipo de } \\
\text { producto } \\
\text { / Sector } \\
\text { económico }\end{array}$ & $\begin{array}{c}N^{0} \text {. de } \\
\text { seguidores }\end{array}$ & Total «likes» & $\begin{array}{c}\text { Total } \\
\text { contenidos }\end{array}$ & $\begin{array}{c}\text { Tipo de } \\
\text { contenido }\end{array}$ & $\begin{array}{c}\text { Fórmula } \\
\text { del } \\
\text { contenido }\end{array}$ \\
\hline $\begin{array}{l}\text { Blue Banana } \\
\text { @bluebanana- } \\
\text { brand } \\
\text { 06/05/2020 }\end{array}$ & Sí & Ropa casual & 50.800 & 669.100 & 291 & $\begin{array}{l}C P=238 \\
C O L=53\end{array}$ & MKT, AMKT \\
\hline \multirow[t]{2}{*}{$\begin{array}{l}\text { Portaventura } \\
\text { World } \\
\text { @portaventu- } \\
\text { raworld } \\
\text { 07/02/2020 }\end{array}$} & No & $\begin{array}{l}\text { Parque de } \\
\text { atracciones } \\
\text { y animales }\end{array}$ & 29.300 & 204.100 & 35 & $\begin{array}{l}C P=34 \\
C O L=1\end{array}$ & $\begin{array}{l}\text { INFO, PUB, } \\
\text { MKT }\end{array}$ \\
\hline & $\begin{array}{l}\text { Sí }=9 \\
\text { No }=1\end{array}$ & & & & & & \\
\hline
\end{tabular}

Fuente: elaboración propia.

\section{Tabla 4. Datos de empresas europeas en Instagram hasta el 31 de diciembre 2020}

\begin{tabular}{|c|c|c|c|c|c|}
\hline $\begin{array}{l}\text { Empresa o marca } \\
\text { y fecha de inicio } \\
\text { en Instagram }\end{array}$ & $\begin{array}{l}\text { Perfil } \\
\text { verificado }\end{array}$ & $\begin{array}{l}\text { Total de } \\
\text { seguidores }\end{array}$ & $\begin{array}{l}\text { Total de } \\
\text { contenidos }\end{array}$ & $\begin{array}{l}\text { Vídeos de } \\
\text { TikTok en } \\
\text { el «feed» }\end{array}$ & Reels \\
\hline $\begin{array}{l}\text { Gucci } \\
\text { @gucci } \\
\text { 09/03/2011 }\end{array}$ & Sí & 42.300 .000 & 7.423 & - & 15 \\
\hline $\begin{array}{l}\text { LaLiga } \\
\text { @laliga } \\
\text { 05/10/2013 }\end{array}$ & Sí & 32.500 .000 & 24.400 & - & - \\
\hline $\begin{array}{l}\text { Sephora } \\
\text { @sephora } \\
\text { 16/02/2012 }\end{array}$ & Sí & 20.500 .000 & 8.388 & - & 59 \\
\hline $\begin{array}{l}\text { Red Bull } \\
\text { @redbull } \\
\text { 05/11/2010 }\end{array}$ & Sí & 13.900 .000 & 8.391 & - & 54 \\
\hline $\begin{array}{l}\text { Reebok } \\
\text { @reebok } \\
\text { 25/06/2012 } \\
\text { @reebokeurope } \\
\text { 01/06/2012 }\end{array}$ & Sí & $\begin{array}{r}2.500 .000 \\
688.000\end{array}$ & $\begin{array}{l}2.677 \\
2.206\end{array}$ & - & - \\
\hline $\begin{array}{l}\text { Deichmann } \\
\text { @deichmann_schuhe } \\
\text { 05/11/2012 }\end{array}$ & Sí & 489.000 & 4.235 & - & 2 \\
\hline $\begin{array}{l}\text { Los } 40 \\
\text { @los40spain } \\
24 / 07 / 2012\end{array}$ & Sí & 405.000 & 4.986 & - & - \\
\hline
\end{tabular}


Tabla 4. Datos de empresas europeas en Instagram hasta el 31 de diciembre 2020 (continuación)

\begin{tabular}{l|l|l|l|}
\hline $\begin{array}{l}\text { Portaventura World } \\
\text { @portaventuraoficial } \\
02 / 04 / 2014\end{array}$ & Sí & 269.000 & 2.148 \\
\hline $\begin{array}{l}\text { Blue Banana } \\
\text { @bluebananabrand } \\
02 / 12 / 2015\end{array}$ & Sí & 273.000 & 759 \\
\hline $\begin{array}{l}\text { Movistar Plus } \\
\text { @movistarplus }\end{array}$ & & & \\
\hline $24 / 06 / 2016$ & Sí & 191.000 & 2.526 \\
\hline
\end{tabular}

Fuente: elaboración propia.

Destaca que el Zoológico de San Diego (Tabla 1) es la única empresa que tiene más seguidores en su cuenta de TikTok comparativamente con la de Instagram (Tabla 2).

Asimismo, en contraste con los perfiles norteamericanos, la mayoría de los casos europeos aquí aludidos no redistribuyó contenido de TikTok hacia el feed principal de Instagram, así como tampoco de manera inversa.
Como excepción, la marca BlueBanana (Tabla 4), que lejos de utilizar el feed o la sección de Reels para tales fines, tiene algunos contenidos de TikTok en el formato de «stories destacadas» (véase http://bit.ly/3obw3Nt).

Las marcas y empresas europeas en líneas generales muestran un manejo de su comunicación en nuevas narrativas, de acuerdo con el código del mensaje que impone cada plataforma, diversificando así su presencia digital.

\section{Tabla 5. Comparativa de contenidos y seguidores totales de perfiles de marcas y empresas en} TikTok en el primer y segundo semestre de 2020

\begin{tabular}{|c|c|c|c|c|c|c|}
\hline Empresa o marca & $\begin{array}{c}\text { Total de } \\
\text { seguidores } \\
\text { hasta } \\
30 / 06 / 2020\end{array}$ & $\begin{array}{c}\text { Total de } \\
\text { seguidores } \\
\text { hasta } \\
31 / 12 / 2020\end{array}$ & $\begin{array}{c}\% \text { seguidores } \\
\text { entre I-2020 } \\
\text { y II-2020 }\end{array}$ & $\begin{array}{c}\text { Total de } \\
\text { contenidos } \\
\text { hasta } \\
30 / 06 / 2020\end{array}$ & $\begin{array}{c}\text { Total de } \\
\text { conteni- } \\
\text { dos hasta } \\
31 / 12 / 2020\end{array}$ & $\begin{array}{c}\% \text { contenidos } \\
\text { entre I-2020 } \\
\text { y II-2020 }\end{array}$ \\
\hline $\begin{array}{l}\text { NBA } \\
@ n b a\end{array}$ & 11.300 .000 & 12.100 .000 & $+7,07 \%$ & 3272 & 3859 & $+17,94 \%$ \\
\hline $\begin{array}{l}\text { Netflix } \\
\text { @netflix }\end{array}$ & 5.700 .000 & 11.600 .000 & $+103,5 \%$ & 209 & 547 & $+161,7 \%$ \\
\hline $\begin{array}{l}\text { Zoo San Diego } \\
\text { @sandiegozoo }\end{array}$ & 1.600 .000 & 1.800 .000 & $+12,5 \%$ & 55 & 154 & $+180 \%$ \\
\hline $\begin{array}{l}\text { Nike } \\
\text { @nike }\end{array}$ & 1.100 .000 & 1.300 .000 & $+18,18 \%$ & 21 & 22 & $+0,47 \%$ \\
\hline $\begin{array}{l}\text { Chipotle } \\
\text { @chipotle }\end{array}$ & 755.700 & 1.400 .000 & $+85,26 \%$ & 69 & 132 & $+91,3 \%$ \\
\hline $\begin{array}{l}\text { The Washington } \\
\text { Post } \\
\text { @washingtonpost }\end{array}$ & 556.400 & 784.600 & $+41,01 \%$ & 402 & 664 & $+65,17 \%$ \\
\hline $\begin{array}{l}\text { Tarte Cosmetics } \\
\text { @tartecosmetics }\end{array}$ & 458.900 & 467.700 & $+1,92 \%$ & 853 & 1185 & $+38,92 \%$ \\
\hline
\end{tabular}


Tabla 5. Comparativa de contenidos y seguidores totales de perfiles de marcas y empresas en TikTok en el primer y segundo semestre de 2020 (continuación)

\begin{tabular}{|c|c|c|c|c|c|c|}
\hline Empresa o marca & $\begin{array}{c}\text { Total de } \\
\text { seguidores } \\
\text { hasta } \\
30 / 06 / 2020\end{array}$ & $\begin{array}{c}\text { Total de } \\
\text { seguidores } \\
\text { hasta } \\
31 / 12 / 2020\end{array}$ & $\begin{array}{c}\% \text { seguidores } \\
\text { entre I-2020 } \\
\text { y II-2020 }\end{array}$ & $\begin{array}{c}\text { Total de } \\
\text { contenidos } \\
\text { hasta } \\
30 / 06 / 2020\end{array}$ & $\begin{array}{c}\text { Total de } \\
\text { conteni- } \\
\text { dos hasta } \\
31 / 12 / 2020\end{array}$ & $\begin{array}{l}\% \text { contenidos } \\
\text { entre I-2020 } \\
\text { y II-2020 }\end{array}$ \\
\hline $\begin{array}{l}\text { Crocs } \\
\text { @crocs }\end{array}$ & 196.000 & 318.600 & $+62,55 \%$ & 30 & 57 & $+90 \%$ \\
\hline $\begin{array}{l}\text { Foot Locker } \\
\text { @footlocker }\end{array}$ & 83.400 & 246.900 & $+196 \%$ & 29 & 74 & $+155,2 \%$ \\
\hline $\begin{array}{l}\text { Old Navy } \\
\text { @oldnavy }\end{array}$ & 32.600 & 35.800 & $+9,82 \%$ & 14 & 29 & $+35,71 \%$ \\
\hline $\begin{array}{l}\text { Red Bull } \\
\text { @redbull }\end{array}$ & 4.400 .000 & 5.100 .000 & $+15,91 \%$ & 2109 & 2434 & $+15,41 \%$ \\
\hline $\begin{array}{l}\text { LaLiga } \\
\text { @laliga }\end{array}$ & 1.600 .000 & 2.100 .000 & $+31,25 \%$ & 473 & 673 & $+42,28 \%$ \\
\hline $\begin{array}{l}\text { Gucci } \\
\text { @gucci }\end{array}$ & 367.200 & 960.900 & $+161,68 \%$ & 12 & 87 & $+625 \%$ \\
\hline $\begin{array}{l}\text { Sephora } \\
\text { @sephora }\end{array}$ & 110.200 & 191.300 & $+73,59 \%$ & 147 & 283 & $+92,52 \%$ \\
\hline $\begin{array}{l}\text { Movistar Plus } \\
\text { @movistarplus }\end{array}$ & 84.600 & 127.400 & $+50,59 \%$ & 83 & 167 & $+101,2 \%$ \\
\hline $\begin{array}{l}\text { Los } 40 \\
\text { @los40spain }\end{array}$ & 41.700 & 56.700 & $+35,97 \%$ & 40 & 83 & $+107,5 \%$ \\
\hline $\begin{array}{l}\text { Deichmann } \\
\text { @deichmann_schu- } \\
\text { he }\end{array}$ & 39.100 & 38.800 & $-0,76 \%$ & 77 & 149 & $+93,5 \%$ \\
\hline $\begin{array}{l}\text { Reebok } \\
\text { @reebok }\end{array}$ & 34.800 & 47.400 & $+37,07 \%$ & 51 & 68 & $+33,3 \%$ \\
\hline $\begin{array}{l}\text { Blue Banana } \\
\text { @bluebananabrand }\end{array}$ & 18.700 & 50.800 & $+171,7 \%$ & 93 & 291 & $+212,9 \%$ \\
\hline $\begin{array}{l}\text { Portaventura } \\
\text { World } \\
\text { @portaventuraworld }\end{array}$ & 14.100 & 29.300 & $+107,8 \%$ & 22 & 35 & $+59,09 \%$ \\
\hline
\end{tabular}

Fuente: elaboración propia.

Comparativamente entre la fecha de corte del primer y segundo semestre de 2020 , en la mayoría de los casos hay un incremento sustancial de contenidos junto a un incremento de seguidores a final de año. La marca Deichmann es una excepción, pues disminuyó ligeramente en el número de seguidores pese a que incrementó notablemente su producción de contenidos.

\section{Discusión}

Al plantear la primera hipótesis sobre la dificultad de que cualquier empresa o marca tenga presencia en TikTok, se hizo preconcibiendo que el particular código de mensaje impuesto en esta red social impediría que algunas marcas no desarrollaran contenidos en ella. 
Sin embargo, se aprecia que los casos referenciados tienen presencia tanto en esta como en Instagram, por aludir entornos digitales con fuerte presencia de Millennials y Generación Z, desarrollando una actividad bastante diferenciada. En este sentido, se puede afirmar que esta primera hipótesis no se cumplió.

Por otra parte, parece haber una estrecha relación entre niveles mayores de engagement y los perfiles que han apostado por el «anti-marketing» (Seavers en Merca 2.0, 2020) como narrativa en sus contenidos (véase https://bit.ly/3kkFrwC y https://bit.ly/3kr62bc).

Este acompañamiento en el que incide Seavers pareciera apostar por un retorno eventualmente a largo plazo, más aún si se trata de perfiles como la NBA (Tabla 1) o Red Bull (Tabla 3) que tienen un ritmo de publicación constante y diario desde hace algunos años, sobre todo este último, que ha apostado por relacionar un amplio abanico de disciplinas y actividades deportivas extremas con la marca de manera tanto directa como indirecta.

De la observación realizada en las tablas 1 y 3 , destaca que la mayoría de los perfiles (19 de 20) intercalan contenidos publicitarios tradicionales o publicaciones con intenciones expresas de marketing, con otras en términos de «anti-marketing» chistosos, frescos, o que intentan distraer y agradar más al usuario que mostrar un producto o servicio en sí (véase https://bit.ly/31osUiU AMKT, https://bit.ly/2C76wC7 MKT).

Por otra parte, en relación con dejar en evidencia hasta qué punto marcas y empresas recurren a usuarios populares de la red con el fin de reforzar el proceso de comunicación, sobre todo de cara a segmentos específicos de público (segunda hipótesis), de los datos obtenidos en las tablas 1 y 3 , la única marca que está casi equilibrada en este sentido es la cadena de comida rápida «tex-mex» Chipotle. Del resto, la proporción de contenido propio desarrollado por cada perfil es superior a la participación de algún influencer, por lo que dicha hipótesis, de momento, no se cumple.

Sin embargo, este tipo de colaboraciones son importantes. La NBA, por ejemplo, recurrió a las hermanas D'Amelio, Charli@charlidamelio (69,9 millones de seguidores)y Dixie @dixiedamelio (28,8 millones de seguidores), así como a Addison Rae @addisonre (49,7 millones de seguidores). Aparte de las publicaciones en el perfil de dicha franquicia deportiva, ellas también publicaron contenidos de su experiencia deportiva en sus propias cuentas con los «tags» $\mathrm{y}$ «hashtags» correspondientes (véase https://bit.ly/30HBMkV y https://bit.ly/3ioBc15), que son variables importantes a la hora en que la inteligencia artificial que opera la red social promocione los contenidos e involucre a más usuarios.

Adicionalmente, la NBA ha explotado el recurso de los «Duets», invitando a usuarios de la plataforma a imitar diversas jugadas de cualquier equipo y cualquier temporada que estuvieran publicadas en su perfil.

Así, mucha gente durante el confinamiento por la COVID-19 buscó representar estos momentos en sus casas, lo cual fue publicado en el perfil oficial de la franquicia deportiva (véase https://bit.ly/2Ocofun) y que sin duda ha constituido un recurso importante para incrementar audiencia y engagement. A esta misma estrategia recurrió Old Navy en gran medida en el segundo semestre de 2020.

Otro ejemplo, Tarte Cosmetics, si bien contó con 61 participaciones de usuarios de la red e influencers, destaca la colaboración de Lele Pons @lelepons, «celebrity» digital de reconocimiento mundial, así como con la participación de la ya mencionada Addison Rae @addisonre.

Al margen de la muestra del estudio y como caso meramente referencial, existen marcas como 
Pizza Hut cuya comunicación en TikTok se ha centrado exclusivamente en la colaboración de perfiles con altos niveles de popularidad y, por tanto, de influencia en dicho entorno.

Finalmente, durante el 2020 pareciera existir en la mayoría de los casos una relación entre el incremento en la producción de contenidos y el incremento de seguidores en los perfiles de las marcas y empresas estudiadas (Tabla 5), presumiblemente debido a la acción del algoritmo que recompensa con mayor exposición en el feed principal de la red social a los creadores consecuentes que obtengan un engagement mantenido en el tiempo, lo que permite confirmar la tercera y última hipótesis sobre la correlación entre el incremento de contenidos de las marcas y empresas, y el aumento de seguidores.

En las tablas 2 y 4 se aprecia un rápido uso del recurso de «Reels» en Instagram, desplegado a nivel global a partir de agosto de 2020 como copia y competencia de TikTok.

Pese a una presunción sobre la intención de marcas y empresas con un trabajo adelantado en TikTok, de derivar estos contenidos a «Reels» a fin de disminuir esfuerzos en una nueva vía digital, no hay evidencias de ello. Por el contrario, Gucci, Red Bull, Deichmann, BlueBanana y Movistar Plus tienen contenidos específicos en esta sección, que no son siquiera compartidos en el feed principal de Instagram.

\section{Conclusiones}

TikTok ha reportado 100 millones de descargas en la India, y 5,4 millones en España en el primer semestre de 2020 según Statista (Mena, 2020). Se trata de una plataforma de comunicación que tiene una penetración muy rápida en amplios segmentos de público, sobre todo muy jóvenes.

Según los datos aquí recogidos y en coincidencia con Bahiyah y Wang (2020) los usuarios están en TikTok buscando una propuesta de contenido distinta al del resto de las redes sociales, por lo que las empresas y marcas asegurarán su éxito de exposición sobre esta premisa.

Del estudio se desprende que los perfiles que han apostado por el «anti-marketing» como fórmula tienen relación con mayores niveles de engagement. Es decir, el contenido fresco y disruptivo pareciera tener mejor acogida por parte de la audiencia.

Y en comparación con Instagram, que es la otra red social donde hay mayor concentración de «Generación $Z$ » y «Millennials», en TikTok la actividad de publicación por parte de actores comerciales y empresariales aún es muy baja. Sin embargo, su presencia se mantiene constante de momento, inclusive con mayor intensidad a partir del segundo semestre de 2020.

Queda en evidencia que marcas y empresas tienen interés en acudir a esta plataforma, así como por innovar narrativamente en la manera de llegar al público, lo cual requiere de dinero y tiempo, es decir, un compromiso que, en comparación con Instagram, aún es incipiente pero ya deja evidencias importantes en cuanto a intensidad, uso y penetración, según cifras de IAB (2020), Ditrendia (2020) y Statista (Mena, 2020).

El 2020 es el año en el que TikTok se ha convertido en tendencia digital global, lo que obligó a marcas y empresas que aún no conocían la plataforma, a explorar un nuevo código de mensaje de cara a nuevos segmentos de público.

El segundo semestre de dicho año reporta una intensa actividad de creación por parte de estos emisores, lo cual se ha traducido en un incremento importante en su comunidad de usuariosclientes, sobre todo, los más digitales.

Las empresas y marcas han comprendido rápidamente que deben realizar un trabajo de comunicación diferenciado en cada red social, adaptando su imagen y mensaje al código que 
impone cada una, con el incremento de trabajo y creatividad que ello representa.

Inclusive, marcas de coches y ropa de alto standing, cuyo público objetivo no es el que acude habitualmente a esta plataforma, están invirtiendo tiempo en generar una imagen y una referencia aspiracional a través de este canal.

Vale destacar que hasta el momento no hay evidencias de que las colaboraciones de usuarios populares pudiesen suponer un problema para la reputación online de las marcas y empresas. Todo lo contrario, es un recurso que pudiese reportar más beneficios en cuanto a visibilidad y contacto con los usuarios.

Independientemente del sector económico en el que se desarrolla o el servicio que presta, cualquier marca o empresa ha venido encontrando en TikTok, en Reels y en otros medios y canales digitales emergentes, vías alternativas e importantes para consolidar su imagen e incrementar su alcance de cara a nuevos segmentos de usuarios.

Pareciera que el modelo tradicional de publicidad resulta inapropiado e inclusive caduco, en este tipo de espacios donde se impone un diálogo más distendido y hasta auténtico entre los participantes, obligando a los interlocutores a innovar a partir del acompañamiento y la interrelación con los usuarios, evitando la promoción explícita. No obstante, la comunicación de empresa sí pareciera quedar reforzada de manera importante, así como la imagen corporativa.

\section{Bibliografía}

Bahiyah, O. y Wang, D. (2020). Watch, share or create: the influence of personality traits and user motivation on TikTok mobile video usage. International Journal of Interactive Mobile Technologies, 14(4), 121-137

Bayer, J. B., Ellison, N. B., Schoenebeck, S. Y. y Falk, E. B.(2016) Sharing the small moments: Ephemeral social interaction on Snapchat. Information, Communication \& Society 19(7), 956-977

Baysal, S. (2014). Working with generations X and Y in generation $\mathrm{Z}$ period: management of different generations in business life. Mediterranean Journal of Social Sciences, 5(19). 218-229

Chaoudhary, N., Gautam, C. y Arya, V. (2020). Digital marketing challenge and opportunity with reference to TikToka new rising social media platform. International Journal of Multidisciplinary Educational Research, 9(10), 189-197

Chengyan, Z., Xiaolin, X., Wei, Z., Jianmin, C. y Evans, R. (2019) How health communication via Tik Tok makes a difference. International Journal of Environmental Research and Public Health 17(1), 192
Del Pino, C., Castelló, A. y Ramos-Soler, I. (2013). La comunicación en cambio constante. Madrid: Fragua.

Ditrendia (2020). Mobiles en España y en el Mundo 2020. Extraído el 14/12/2020 desde https://bit.ly/3iY6iwV

Fundación Telefónica (2020). Sociedad Digital en España 2019. Barcelona: Taurus.

Gil, S. y Miquel, S. (2017). Transmedia y comunicación publicitaria: retos, narrativas y emociones. AdComunica, 14, 23-26

González, G. (2019, 18 de noviembre). «Tiktok alcanza los 1.500 millones de descargas y se coloca por encima de Instagram». En Genbeta. Extraído el 14/12/2020 desde http:// bit.ly/2USvPyB

Hall, J. (2016, 17 de abril). The Influencer Marketing Gold Rush Is Coming: Are You Prepared?. En Forbes. Extraído el 13/12/2020 desde http://bit.ly/3tBvUpG

Hamill, J. (2018, 27 de julio). «Facebook is about to make Instagram really, really annoying». En Metro. Extraído el 14/12/2020 desde http://bit.ly/3hS7Pp6 
Hernández, E. (2019). Análisis textual de Instagram stories. Lectura del fenómeno social. En Las redes sociales como herramienta de comunicación persuasiva (141-166). Madrid: McGraw Hill.

Hernández, J. (2011). Reputación online: necesidad de un marco conceptual y modelo de gestión. En La comunicación empresarial y la gestión de los intangibles en España y Latinoamérica. Madrid: Pearson.

Herranz, J. M.; Caerols, R. y Sidorenko, P. (2019). La realidad virtual y el vídeo $360^{\circ}$ en la comunicación empresarial e institucional. Revista de Comunicación, 18(2, 177-179)

Jones, K. (2020, 7 de abril). How COVID-19 has impacted media consumption, by generation. En Visual Capitalist. Extraído el 12/12/2020 desde http://bit.ly/2z847oR

Kantar (2020, 15 de julio). TikTok is the Brand to watch: BrandZ Global Top 100 2020. En Kantar. Extraído el 12/12/2020 desde http://bit.ly/3al9iXM

IAB España (2020). Estudio de redes sociales 2020. Extraído el 14/12/2020 desde https://bit.ly/2DYfTF6

Li, X., Xiaohui, Y. y Zhengwu, Z. (2019). Research on the causes of the «TikTok» app becoming popular and the existing problems. Journal of advanced management science, 7(2), 59-63

Lijun, M., Jingqiang, F, Zhiyan, F. y Lan, W. (2019). Research on user loyalty of short video app based on perceived value - take tik tok as an example. 2019 16th International Conference on Service Systems and Service Management (ICSSSM), Shenzhen, China, 20191-6

Marzal, J. y Casero, A. (2017). El discurso publicitario: núcleo de la comunicación transmedia. AdComunica, 14, 11-19 Merca2.0 (2020). Guía para usar Tik Tok con tu marca. Ciudad de México: Grupo de Comunicación Kátedra.

Mena R., M. (2020, 9 de julio). TikTok alcanza los 5,4 millones de descargas en España en lo que va de año. En Statista. Extraído el 12/12/2020 desde https://bit.ly/3fh9i65

Muñiz, A. M., y Schau, H. J. (2011). How to inspire valueladen collaborative consumer-generated content. Business Horizons, 54 (3), 209-217

Palley, W. (2012). Gen Z: digital in their DNA. Nueva York: JWT Intelligence

Parry, E. y Urwin, P. (2011). Generational differences in work values: a review of theory and evidence. International Journal of Management Reviews, 13(1). 79-96

Prensky, M. (2001). Digital natives, digital immigrants. On the horizon, 9(5). 1-6Rakoczy, M. E., Bonzeghonb, A., Lo- pes G., A. y Wegrzyn-Wolska, K. (2018). In the search of quality influence on a small scale - micro-influencers discovery. En Hervé Panetto et al. (eds.) On the move to meaningful internet systems. OTM 2018 Conferences (138-153). Springer.

Romero, M. y Fanjul, C. (2010). La publicidad en la era digital: el microsite como factor estratégico de las campañas publicitarias on-line. Comunicar, 34. 125-134

Sehl, K. (2020, 7 de mayo). 20 important TikTok stats marketers need to know in 2020. En Hoosuite Blog. Extraído el 12/2/2020 desde https://bit.ly/31NnOoJ

Seymour, E. (2019, 25 de agosto). «Gen Z about to change the face of the US». En Voice of America. Extraído el 18/12/2020 desde http://bit.ly/2LfVTBt

Shuai, Y., Yuzhen, Z. y Yifang, M. (2019). Analysis of the reasons and development of short video application - Taking Tik Tok as an example. 2019 9th International Conference on Information and Social Science (ICISS 2019). Francis Academic Press, 340-343

Sidorenko, P., Herranz, J. M. y Cantero, J. I. (2020). Use of new narratives for COVID-19 reporting: form $360^{\circ}$ videos to ephemeral TikTok videos in online media. Tripodos, 47(1), 105-122

Stebbins, R. (2001). Investigación exploratoria en ciencias sociales. Thousand Oaks: SAGE Publications Inc.

Turner, A. (2015). Generation Z: technology and social interest. The Journal of individual psychology, 71(2). 103-113

Vásquez, J., Negreira, M. y López, X. (2020). Let's dance the news! How the news media are adapting to the logic of TikTok. Journalism, 1-19

Viens, A. (2019, 2 de octubre). «This graph tells us who's using social media the most». En Worl Economic Forum. Extraído el 18/12/2020 desde http://bit.ly/38nY6nk

Yu-Liang, F. Y. L., Chun-Chin, C. y Shu-Ming, W. (2019). Evaluation of charm factors of short video user experience using FAHP - a case study of TikTok app. IOP Conference Series: Materials Science and Engineering, 688, 1-5

Wymbs, C. (2011). Digital marketing: the time for a new «academic major» has arrived. Journal of Marketing Education. Massachusetts: SAGE journals, 93-106

Zwarts, B. (2018). Quelle est la stratégie sociale/digitale à mettre en place pour développer au mieux une startup?. Louvain School of Management, Université catholique de Louvain, Schuiling, Isabelle. Extraído el 18/12/2020 desde http://hdl.handle.net/2078.1/thesis:15420 



\section{Análisis de las estrategias publicitarias digitales de Inbound marketing de las marcas del sector automoción en YouTube en España}

Analysis of the Inbound Marketing Digital Advertising Strategies of Automotive Brands on Youtube in Spain

Dra. Gema González Carreño Profesora de la Facultad de Tecnología y Ciencia de la Universidad Camilo José Cela gcarreno@ucjc.edu https://orcid.org/0000-0002-3312-0274

Dra. Ana María Rivas Machota Profesora de la Facultad de Comunicación y Humanidades Universidad Camilo José Cela amrivas@ucjc.edu https://orcid.org/0000-0001-8668-4607 Claudia Ortega Pickmans Graduada Universidad Camilo José Cela cortega@ucjc.edu
González Carreño, G., Rivas Machota, A. M. y Ortega Pickmans, C. (2021)

Análisis de las estrategias publicitarias digitales de Inbound marketing de las marcas del sector automoción en YouTube en España

Revista Internacional de Investigación en Comunicación aDResearch ESIC. № $25 \mathrm{Vol} 25$

Monográfico especial, marzo 2021 · Págs. 124 a 147

https://doi.org/10.7263/adresic-025-07 
RESUMEN

\author{
Clasificación JEL: \\ M31, M37 \\ Palabras clave: \\ YouTube, \\ sector \\ automovilístico, \\ Inbound marketing, \\ publicidad, \\ marketing
}

Objetivo: el objetivo principal de este trabajo es analizar el contenido que las marcas más vendidas del sector automovilístico en España en el año 2019 están difundiendo en sus canales propios en YouTube.

Diseño/metodología/enfoque: se sigue la metodología de análisis de contenido para analizar los vídeos más populares de las diez marcas de coches utilitarias más vendidas en el año 2019 en España. Para ello se identifica, en primer lugar, el canal, suscriptores y los vídeos más visualizados desde finales de 2018 y a lo largo de 2019. En segundo lugar, se analiza el contenido de los mensajes y, por último, la interacción de los públicos a través del número de «me gusta» que ha recibido cada uno de los videos analizados.

Resultados: los resultados han permitido entender qué contenido están difundiendo las marcas de automóviles a través de sus canales propios de YouTube en un periodo concreto. Además, de poner de manifiesto que, aunque el contenido más habitual sea el clásico spot publicitario que las marcas utilizan para televisión y otros medios convencionales, también se ha desvelado la utilización de YouTube para apoyar la estrategia de Inbound marketing.

Limitaciones/implicaciones: se trata de una investigación descriptiva, cuyo alcance es exploratorio, por lo que su principal aportación es una revisión novedosa sobre el objeto de estudio que supone un punto de partida para investigaciones posteriores. Asimismo, dada la limitada muestra, 50 videos, y que los datos obtenidos a través del análisis se han acotado a un periodo de tiempo concreto, los resultados no se pueden generalizar, pero sí permiten abrir una reflexión acerca del uso de los canales propios de YouTube por parte de las marcas del sector del automóvil.

Originalidad/contribución: la originalidad de este estudio radica en el estudio de un sector en concreto, el automovilístico, y por su relevancia como anunciante y como sector empresarial.

\section{ABSTRACT}

\section{JEL Classification:}

M31, M37

Key words:

YouTube, automotive sector, Inbound marketing, advertising, marketing
Purpose: the main goal of this paper is to analyse the content that the best-selling brands in the automotive sector in Spain during 2019 are broadcasting on their own YouTube channels.

Design / Methodology / Approach: the content análisis methodology is followed to analyse the most popular videos of the ten best-selling utility car brands in 2019 in Spain. To do this, firstly, the channel, subscribers and the most viewed videos since the end of 2018 and throughout 2019 are identified. Secondly, the content of the messages is analysed and, finally, the interaction of audience by the number of «likes» received by each of the analysed videos.

Results: the results have made possible to understand what content car brands are broadcasting through their own YouTube channels in a specific period. In addition, it is proved that, though the most common content is the classic advertising spot that brands use for television and other conventional media, the use of YouTube has also been revealed to support the Inbound marketing strategy.

Limitations / Implications: this is descriptive research, which scope is exploratory, so its main contribution is a new review of the studied object that provides a starting point for further research. In addition, given the limited sample, 50 videos, and that fact obtained through the analysis have been limited to a specific period of time, results cannot be generalised, but they do allow us to reflect on the use of YouTube channels by brands in the automotive sector.

Originality / Contribution: the originality of this paper lies in the study of a specific sector, the automotive, and its relevance as an advertiser and as a business sector. 


\section{Introducción}

El presente artículo tiene como objetivo entender cómo las marcas del sector del automóvil están utilizando sus canales propios de YouTube dentro de su estrategia de marketing. En concreto, en el presente estudio se analiza la estrategia de marketing seguida en la red social YouTube por las marcas del sector del automóvil en España. El interés de este estudio radica, por un lado, en la complejidad del proceso de compra en este sector, en el que la toma de decisiones por parte del consumidor es de alta implicación y, por otro lado, por la necesidad de conocer la utilización por parte de las marcas de YouTube en contraste con las últimas tendencias de marketing en general y, en particular, del marketing digital, concretamente acciones de Inbound marketing.

La elección del sector de la automoción es relevante puesto que según el Observatorio de la Publicidad en España 2020, el primer sector en inversión es, precisamente, el de la automoción, con 564 millones de euros, de un total en el 2019 de 8.720,2 millones de euros. Asimismo, la inversión publicitaria en 2019 descendió un 0,6\%. Dentro de este dato negativo, el medio digital se sitúa, por primera vez, como el que mayor inversión recibe, con un 38,6 \% del total. De esta manera, el medio Televisión «pierde su hegemonía y pasa a segunda posición con el 33,7 \%».

Para realizar este estudio, se presenta, en un primer momento, una revisión teórica acerca de las últimas tendencias en marketing digital, así como sobre el comportamiento del consumidor y la toma de decisiones en compras de alta implicación, como es el sector objeto de estudio, así como las características y ventajas de YouTube como medio a disposición de los anunciantes del sector automovilístico. Una vez realizada la revisión teórica se llevará a cabo un análisis de contenido de los videos de las principales marcas anunciantes del año 2019. En concreto la muestra estará compuesta por los canales propios de las diez marcas de coches utilitarios más vendidos durante el 2019 y dentro de estos canales se analizarán los 5 vídeos más visualizados desde finales de 2018 y durante 2019.

\section{Marketing y estrategias de marca}

Las nuevas tecnologías han supuesto un reto para todos los sectores, lo que obliga a los marketers a replantearse los caminos más adecuados para llegar a un público cada vez más joven y mucho más acostumbrado a la utilización de dispositivos digitales y a la interacción con las marcas. Así mismo, el marketing ha evolucionado, introduciéndose nuevos conceptos, términos y herramientas; dentro del lenguaje del marketing digital: comunicación 2.0, redes sociales, engagement, marketing, prosumidores, Inbound marketing, entre otros.

El recorrido del cliente se puede definir como un proceso iterativo que incluye interacciones basadas en puntos de contacto con un proveedor o una empresa durante una precompra, una compra, y una fase posterior a la compra (Lemon, 2016).

Este recorrido podría incluir experiencias de compras anteriores y afectan a las compras futuras. Desde este punto de vista, no es necesario un objetivo de compra fijo a priori, sino que el proveedor de servicios intentaría despertar el interés de potenciales clientes en la fase de precompra. En todos los puntos de contacto entre el proveedor y el cliente, hay que distinguir entre la vista del cliente y la vista del proveedor. Debe ser el objetivo del proveedor en cada punto de contacto, crear una situación que conduce a una experiencia de usuario óptima (UX) para el potencial cliente. La experiencia de usuario durante el viaje del cliente a menudo se describe 
como experiencia del cliente. Como extracto y síntesis de anteriores esfuerzos de investigación, la experiencia del cliente puede verse como «una construcción multidimensional» que se centra en «el cliente cognitivo, emocional, conductual, sensorial y social» o reacciones a las ofertas de un proveedor o una empresa «durante todo el recorrido de compra del cliente «(Lemon, 2016), es decir, cómo se comporta un consumidor en el acto de la compra.

Si en el caso del marketing tradicional la atención prestada al consumidor ha sido a veces destronada por la atención prestada al producto, en la estrategia de marketing de la empresa, en el caso del marketing digital, el foco está en el consumidor, en su correcta identificación, en sus necesidades, para sentar las bases de estrategias de comunicación eficaces hacia él. El marketing tradicional se asocia con el Outbond marketing, lo que significa que la estrategia de marketing empuja los productos a los clientes, mientras que el marketing digital es sinónimo del término de Inbound marketing, cuyo objetivo principal es ganar el interés del target (Patrutiu-Baltes, 2016).

Es importante en esa fase de precompra definir el concepto de Inbound marketing. El Inbound marketing es una metodología derivada del marketing digital que, combinando técnicas de marketing y publicidad, busca en primera instancia, atraer a los usuarios al principio de su proceso de compra de manera no intrusiva, generando contenido de valor para así lograr conversiones o registros en la página web de la empresa. A partir de ese primer momento, se les acompaña mediante contenido apropiado y relevante al público objetivo en cada una de las fases del proceso hasta lograr la transacción deseada que es la compra.

Esta metodología es solo una parte de un movimiento más grande en el mundo de los negocios: el movimiento Inbound que se fundamen- ta en atraer prospectos, interactuar con ellos y deleitarlos para así impulsar el crecimiento de una empresa, generando confianza, credibilidad y motivación en los clientes. Con el avance y uso de la tecnología el método Inbound sugiere una forma más útil y humana para hacer negocios, una manera de agregar valor en cada una de las etapas del recorrido del comprador. Un cliente satisfecho es fundamental para el crecimiento de la empresa, ya sea por la recompra de productos o servicios, o por la recomendación hacia otros clientes potenciando la marca (Samsing, 2020).

De hecho, el Outbound marketing pretende promocionar los productos y servicios a la audiencia directamente, mientras que el Inbound marketing ayuda a destacar los productos y servicios de manera indirecta, en el contexto en el que los consumidores se identifican con el objetivo de la empresa (Patrutiu-Baltes, 2016).

El Inbound marketing es principalmente un marketing de contenidos, ya que es el elemento que puede captar la atención del consumidor, empujándolo hacia la compra. En este contexto, una estrategia de marketing que sólo utilice el marketing de contenidos para impulsar las ventas del producto no es eficaz porque la «regla de oro» que practican las empresas dice que el marketing de contenidos debe centrarse en un $80 \%$ en la información y educación del consumidor, y sólo un $20 \%$ en el crecimiento de las ventas (PatrutiuBaltes, 2016)

Por tanto, el marketing digital implica principalmente la creación de una relación de confianza y lealtad con el cliente y el Inbound marketing se convierte en el aspecto principal del marketing digital.

El Inbound marketing permite una comunicación abierta e «inteligente» hacia los clientes que dirigen su atención a los productos o servicios de la empresa y crea una relación personal con ellos 
mediante la promoción de contenidos adaptados a sus necesidades. Desde 2006, el Inbound marketing es el método de marketing más eficaz para hacer negocios en línea. En lugar de los antiguos métodos de marketing tales como la compra de espacios en medios, comprar listas de correo electrónico e intentar conseguir clientes potenciales, el Inbound marketing se centra en crear contenido de calidad que atraiga al público hacia la empresa y el producto, donde naturalmente quieren estar (hubspot, 2021).

Para sacar el máximo partido al Inbound marketing se necesitan tres puntos clave. El primero es la capacidad de escribir contenidos atractivos que atraigan a los clientes a la empresa. El segundo, la capacidad de distribuir esos contenidos para que sean encontrados fácilmente por los clientes potenciales mediante los motores de búsqueda, lo que requiere un conocimiento sofisticado de la optimización de los motores de búsqueda. Y el tercero, la capacidad de atraer y comprometer a una comunidad de seguidores que interactúen con el contenido, añadan sus opiniones en un diálogo continuo y lo difundan a otros. Las empresas que cultivaban una audiencia activa, es decir, que participaban interactuando y recomendando contenido, ganaban credibilidad en el mercado, porque el apoyo de una audiencia confería experiencia en un área determinada (Steenburgh, Avery, y Dahod, 2011).

En esencia, el Inbound marketing consiste en adaptar el contenido al «buyer persona» que ha llegado de forma natural y voluntaria a la empresa. Por eso, en este contexto, la definición del «buyer persona» juega un papel central, ya que, si no se identifica correctamente, toda la estrategia de marketing en base a la definición de ese «buyer persona» se convertirá en un fracaso. Es de lógica decir, por tanto, que el Inbound marketing es una forma de marketing que requiere una selección muy cuidadosa de la audiencia y una comunicación personalizada con ella a través de contenidos de alta calidad.

Es una colección de estrategias de marketing centradas en atraer a los clientes potenciales y a los consumidores hacia una empresa y sus productos. Este nuevo enfoque del marketing complementaba la forma en que los consumidores tomaban realmente las decisiones de compra: utilizando la búsqueda en Internet, los blogs online y las redes sociales para informarse sobre los productos y servicios antes de comprarlos (Steenburgh, Avery, y Dahod, 2011).

Así, «el Inbound marketing es la estrategia de conectar con clientes potenciales a través de materiales y experiencias que les resulten útiles. Utilizando medios como blogs y redes sociales, los profesionales del marketing esperan entretener e informar a los espectadores con contenido que buscan por sí mismos» (marketing-schools.org, 2020).

Según la definición de Inbound marketing facilitada por Hubspot, se pueden definir sus características principales como:

- Creación y distribución de contenidos: crear contenidos específicos que respondan preguntas y necesidades básicas de los clientes, y luego compartir ese contenido a lo largo y ancho.

- Marketing del ciclo de vida: los promotores no surgen de la nada comienzan como extraños, visitantes, contactos y clientes. Las acciones y herramientas específicas de marketing ayudan a transformar a esos desconocidos en promotores.

- Personalización, es decir, adaptar el contenido de la marca a los deseos y necesidades de las personas que lo ven. A medida que se conozca mejor a los clientes potenciales se podrá personalizar y adaptar los mensajes a sus necesidades específicas. 
- Multicanal: el Inbound marketing es multicanal por naturaleza, ya que intenta acercarse a las personas donde están, en el canal en el que quieren interactuar con el cliente.

- Integración. Las herramientas de creación de contenidos, publicación y análisis funcionan como una máquina bien engrasada, lo que le permite centrarse en publicar el contenido adecuado en el lugar adecuado y en el momento adecuado.

En conclusión, «el Inbound marketing convierte a los desconocidos en clientes y luego promotores de tu negocio» (huify, 2021).

Las formas de Inbound marketing más utilizadas son: blogs temáticos, campañas en redes sociales, campañas de email, optimización de motores de búsqueda (SEO), vídeos virales, seminarios, webminar, etc. (marketing-schools.org, 2020). Las redes sociales (Facebook, LinkedIn, Twitter, YouTube, Pinterest, Instagram, etc.) son un entorno específico para el Inbound marketing, ya que con ellas los prospectos pueden sentirse identificados por la empresa y la comunicación se personaliza en función del tipo de red social utilizada y la audiencia. Son específicamente estas campañas de redes sociales el objeto de estudio del presente trabajo y, concretamente, la red social Youtube.

En este caso, el contenido promovido dentro de la estrategia de Inbound marketing juega un papel determinante, porque el éxito o el fracaso de la estrategia de marketing depende de su calidad.

Además, «según Fleishman-Hillard, el 79 \% de los consumidores dijo que les gusta o siguen a las marcas en las redes sociales para obtener más información sobre la empresa y sus productos y servicios» (Griwert, 2021).

No obstante, el Inbound marketing tiene tanto ventajas como desventajas. Como ventajas se pueden señalar (Patrutiu-Baltes, 2016):
- Permite una relación directa, permanente y a largo plazo con el cliente.

- Define de forma rápida y precisa el perfil del «buyer persona».

- Permite obtener mejores resultados en cuanto a la relación beneficios/costes en comparación con el marketing tradicional.

- Permite desarrollar una estrategia de contenidos basada en temas específicos (palabras clave) identificadas con SEO y Google Adwords, por las que existe un interés real de los prospectos.

- Representa una forma avanzada de marketing que se basa en la creación y distribución de contenido de alta calidad.

Aunque las ventajas del Inbound marketing son muy importantes, esta forma de marketing presenta también algunas desventajas como:

- Es más exigente y compleja que el marketing tradicional.

- Requiere el uso de Internet, por lo que las personas que no lo utilizan no pueden convertirse en el público objetivo.

- Permite una comunicación segmentada y no universal.

En conclusión, el Inbound marketing permite que los usuarios y clientes potenciales encuentren en Internet a las marcas y conozcan los productos y servicios. Se trata de ofrecer valor de una forma no intrusiva, a diferencia de la publicidad tradicional, por lo que los consumidores no sienten que el fin es conseguir ventas. Para ello se necesita establecer contacto con el consumidor utilizando el marketing de contenidos a través del storytelling. El principio de «storytelling» es una de las estrategias clave en el marketing digital, este principio se encuentra en estrategias de vídeo marketing, social media, eventos y exhibiciones 
abiertas al público, las cuales buscan interactuar con el público y mostrar su historia (González Romo y Plaza, 2017).

Con este nuevo paradigma los consumidores viven en un entorno complejo y, por tanto, su comportamiento es complejo. Para intentar aclarar este entorno, Howard (1993) desarrolla en su obra El comportamiento del consumidor en la estrategia de marketing, un modelo de decisión del consumidor el cual se constituye por seis componentes y por las relaciones entre ellos: información, reconocimiento de marca, confianza, actitud, intención y compra. Este modelo se puede utilizar de forma cualitativa o cuantitativa. De estas seis variables, los tres componentes centrales (reconocimiento de marca, actitud hacia la marca y confianza en la marca) constituyen la imagen de marca del consumidor y se considera el ABC del comportamiento de consumidor y se forman en la mente de éste, a través del proceso de agrupación y diferenciación de los productos y su categorización.

Hay varios tipos de hechos, de distintas fuentes, a tener en consideración cuando realiza una compra el consumidor. La información permite al consumidor reconocer la marca, evaluarla en términos de sus necesidades, formar una actitud y crear mentalmente un nivel de confianza o certidumbre en la capacidad para juzgar si la marca dará resultados satisfactorios o insatisfactorios (Howard, 1993).

La marca engloba todas las características tangibles e intangibles de la empresa, estas son el logo, el nombre, los productos, los empleados, el ambiente en el que está envuelta la marca, como las tiendas físicas, la web y su presencia en las redes sociales, la publicidad, la reputación de la empresa y la percepción de ésta por el público (Bastien, 2012).

Son muchos los autores que han estudiado dónde reside el verdadero valor de una marca y sus valores de medición (Aaker, Managing Brand Equity: Capitalizing on the Value of Brand Name, 1991), (Aaker, Building Strong Brands, 1996), (Cobb-Walgren, Ruble, y Donthu, 1995), (Crainer, 1997), (Crimmins, 1992), (Kapferer, La marca capital de la empresa, 1992), (Simon y Sullivan, 1993), (Low y Fullerton, 1994), (Park y Srinivasan, A Survey-Based for Measuring and Understanding Brand Equity and Its Extendibility, 1994), (Shocker, Srivastava, y Rueker, 1994). Según Park, Jaworski y Macinnis (1986), el valor de una marca se origina en el consumidor, en el momento en que a éste le resulta familiar y se forman en su mente ciertas asociaciones que por una razón u otra le resultan beneficiosas. El consumidor identifica siempre algún tipo de beneficios, bien sean funcionales (que le permiten resolver situaciones frustrantes tales como vestir, comer o desplazarse); simbólicos (que tienen que ver con el autoconcepto, el rol o la pertenencia grupal); o experienciales (relacionados con la búsqueda de sensaciones, placer, diversidad o estimulación cognitiva) (Park, Jaworski, y Macinnis, 1986).

Como resultado, el individuo llega a desarrollar un vínculo o apego con determinadas marcas, que a menudo se traduce en fidelidad o compromiso. Este es el verdadero valor de una marca, por tanto, conocer qué significa una marca para cada sector de consumidores o el grado de implicación que suscita en ellos, contribuye a una medida más completa del «valor de la marca» (Rial, Varela, Braña, y Lévy, 2000).

Según Kapferer y Laurent (1991), las marcas ejercen para el consumidor las funciones de identificación, garantía, personalización, lúdica y de practicidad (Kapferer y Laurent, 1991). Múgica y Yagüe (1993) postulan que el consumidor presta atención a las marcas debido a que éstas le aportan una serie de utilidades (Múgica y Yagüe, 1993): 
- Utilidad de elección. La marca sirve de apoyo a la toma de decisión del consumidor y anticipa la utilidad funcional (la marca se utiliza para inferir y su constancia temporal) y simbólica (favoreciendo las asociaciones de la marca con grupos de referencia).

- Utilidad funcional. La marca mejora la satisfacción obtenida de las prestaciones funcionales del producto. La utilidad funcional se construye asegurando el uso eficiente del producto.

- Utilidad simbólica. La marca contribuye a la identificación del consumidor a lo largo del tiempo.

En esta misma línea Kapferer y Laurent (1991) opinan que los consumidores no prestan atención a las marcas sólo por la influencia de éstas, sino porque la situación de compra genera en ellos un determinado nivel y perfil de implicación que, a su vez, engendra una demanda de cierto perfil de marca. Por tanto, la utilidad de las marcas para el comprador es contingente, debiéndose considerar la situación de compra a la que éste se enfrente. También apuntan «existirá una sensibilidad a la marca si el consumidor consulta la información que es la marca per se, si tiene en cuenta a la marca en su proceso de decisión» (Kapferer y Laurent, 1991).

La revisión de la literatura de marketing sobre el valor de la marca permite identificar dos enfoques diferentes, a la vez que complementarios. Un enfoque se apoya en el marco teórico que proporciona la economía de la información, el otro, tiene sus fundamentos en los desarrollos de la psicología cognitiva (Erdem, y otros, 1999). Partiendo de la perspectiva de la economía de la información, las marcas contribuyen a las percepciones de calidad de los clientes al reducir el riesgo percibido y el coste de búsqueda de información. La calidad de un producto o servicio puede considerarse como un atributo sobre el que los compradores potenciales poseen información imperfecta. Por tanto, tal y como postulan Erdem y otros (1993), bajo un supuesto de información imperfecta y asimétrica, la reputación de una marca es una señal creíble para el mercado sobre la calidad del producto y permite a las empresas incorporar a los precios de sus productos una prima sobre esa marca. Los estudios acerca de la reputación de la marca se han centrado en el estudio de los bienes de experiencia, en los cuales la apreciación de la calidad por los consumidores requiere su uso. En este caso, las marcas pueden construir su reputación sobre la calidad no observable del producto (Swait, Erdem, Louviere, y Dubelaar, 1993).

En el enfoque de la psicología cognitiva, el valor de marca proviene de dos elementos. Notoriedad de la marca y asociaciones respecto a los atributos. Tal y como dice Keller (1993), el valor de la marca es el resultado de una fuerte, favorable y única asociación en la mente de los consumidores entre la marca y la calidad del producto (Keller, 1993).

Si se aplica el punto de vista de la economía de la información, específicamente al sector del automóvil, cuando los compradores comparan diferentes marcas que componen un mismo conjunto de coches, se enfrentan a pequeñas dificultades de información fácilmente solventables. En esta situación, no existen razones objetivas para suponer que existen diferencias en términos de calidad no observable, lo que conduce a Nora Lado y otros (2004) a hipotetizar que en este caso la reputación de marca pierde su poder diferenciador y los fabricantes de coches disponen de un estrecho margen para su política respecto a las primas de marca (Lado, Licandro, y Pérez, 2004). Aunque los automóviles son esencialmente un bien de experiencia, cuando los consumidores 
comparan un modelo con otro perteneciente al mismo conjunto de coches, el coche se convierte en términos relativos en un bien de búsqueda, puesto que los compradores potenciales pueden determinar previo a la decisión de compra las diferencias en calidad mediante la inspección de las características observables (Lado, Licandro, y Pérez, 2004), es decir, existen motivaciones de compra utilitaristas y hedonistas, y estas motivaciones son relevantes a la hora de establecer las estrategias de marketing digital anteriormente definidas, es decir, las marcas han de desarrollar siguiendo este tipo de motivaciones acciones concretas con las nuevas herramientas de marketing planteadas que ofrecen credibilidad y lealtad a la marca.

Analizando el comportamiento del consumidor online con respecto a la lealtad de la marca hay que tener en cuenta el tipo de producto. Los atributos del producto que se transmiten de forma óptima online ganan importancia en la elección del consumidor, y lo que se transmite de forma deficiente la pierden (Degeratu, Rangaswamy, y Wu, 2000).

Internet posee una gran capacidad para transmitir información sobre atributos informativos y no sensoriales. Sin embargo, tiene grandes dificultades para transmitir información sobre atributos sensoriales, como el color o el olor. Por tanto, en categorías con predominio de atributos sensoriales (productos sensoriales), donde la información disponible online es escasa, y en comparación con categorías de producto con predominio de atributos no sensoriales (productos no sensoriales), el consumidor dará a la marca mayor importancia como señal de calidad (Alba, y otros, 1997), y en consonancia, dará menor importancia a otros atributos como el precio. Además, el consumidor, para reducir el riesgo, tenderá a comprar el mismo producto que en ocasiones anteriores
(Arce y Cebollada, 2011). Y es el concepto de Inbound marketing anteriormente mencionado el que ayuda a transmitir esa información sobre atributos sensoriales.

Existen varias ventajas al realizar acciones publicitarias en las redes sociales, las principales son: la necesidad constante de creación de contenido, puede ser rentable mediante la inserción de publicidad relacionada semánticamente; el seguimiento es casi automático; hay más flexibilidad en el formato del anuncio, con una escasa inversión se puede lograr un gran impacto en los clientes (coste por clic (CPC) es menor en comparación con otros formatos publicitarios), es más fácil segmentar y encontrar el público objetivo; puede crear campañas específicas en función de datos demográficos y sociodemográficos (sexo, edad, intereses o experiencia empresarial) (Fondevila, Polo, Rom, y Mir, 2020), el denominado «buyer persona».

Las mejores estrategias de marketing digital se basan en establecer de forma detallada los buyer persona, y el primer paso es crearlo. Los buyer persona representan clientes ideales y pueden ser creados investigando, encuestando y entrevistando al público objetivo de la empresa según datos objetivos (demográficos) como ubicación del sitio web, edad, ingresos y datos subjetivos o cualitativos (sociales) como objetivos o necesidad del producto o servicio, retos, hobbies y prioridades (Mandal y Joshi, 2017).

\section{Marketing digital en el sector del automóvil}

Si bien es cierto que los consumidores no compran coches online, el $86 \%$ de ellos realiza búsquedas en Internet antes de visitar un concesionario e indagan sobre la marca o sus modelos, prestaciones y precios. Asimismo, también leen opiniones de otras personas o influencers del sec- 
tor. En esta fase de concienciación de marca o brand awareness y la publicidad nativa desempeña un papel fundamental, puesto que ayuda a los consumidores a conocer marcas y modelos de vehículos que por sí mismos no hubieran buscado (IAB, 2020).

En los últimos años la tecnología ha irrumpido en el sector de la automoción, sector que es, a su vez, campo de innovación constante, lo que ha propiciado que el automóvil pase a convertirse de un simple medio de transporte a un espacio cultural y de vida, cambiando el estilo de vida de las personas y, con ello, ha modificado la comunicación. Los vehículos ofrecen funcionalidades avanzadas: navegación GPS, controles de velocidad, asistentes de cambio involuntario de carril, etc. e incluso asistentes por voz, y las grandes marcas lo han incluido en sus comunicaciones como argumentario de venta. Aunque cada marca intente posicionarse en uno u otro valor a través de su estrategia de comunicación -que incluye una u otra elección de medios-, todas las marcas emplean las redes sociales para lograr cobertura. Por tanto, la presencia de las marcas de coches en las redes sociales es cada vez mayor y cada vez más importante. Porque les permite alcanzar a millones de personas e, incluso, saber sus gustos, aficiones y amigos (Liberal y Mañas, 2019).

Las industrias, y más concretamente la automovilística, se han dado cuenta del poder de Internet como herramienta de marketing y están desarrollando nuevas estrategias e invirtiendo en las redes sociales, convirtiéndose éstas en una herramienta a tener en cuenta en la estrategia de comunicación integrada de marketing (CIM) (Martín-Santana, Olarte-Pascula, Reinares-Lara, Reinares-Lara y Samino-García, 2019) de las empresas porque les permite contactar con millones de potenciales clientes que cada vez pasan más tiempo conectados (Hadadi y Almsafir, 2014).
Para realizar una aproximación al estudio de la comunicación de las marcas del sector del automóvil a través de sus canales propios de YouTube es preciso, en un primer lugar, advertir que las empresas gestionan su comunicación desde una visión integrada, es decir, tienen en cuenta todas las formas y medios a su disposición para comunicarse con sus stakeholders. En este sentido, hoy en día, superada la tradicional división de los medios publicitarios en above the line y below the line, se adopta el enfoque through the line (a través de la línea). Desde este enfoque se gestiona de manera coordinada las diferentes comunicaciones empresariales y se explotan sus sinergias, de tal forma que deja de entenderse la comunicación como una amalgama de técnicas no coordinadas entre sí, sino que se pretende maximizar las cualidades intrínsecas de cada instrumento.

Según Martín-Santana et al., (2019) en relación con el enfoque through the line apuntan:

Define los ejes fundamentales para cualquier estrategia de marketing y comunicación integrada en la era digital como POEM, siglas de Paid, Own, Earned Media: medios pagados, medios propios y medios ganados. Estos tres ejes contienen los diferentes instrumentos de comunicación online y offline que cualquier organización debe utilizar, de forma conjunta, para extraer toda la potencialidad de la marca o producto y centrar esfuerzos en crear una relación estrecha con el consumidor a medio y largo plazo (p.44).

Estos mismos autores advierten que «la organización debe centrarse en aquellos medios sobre los que tiene control más directo: los medios pagados y medios propios, pero sin descuidar los medios ganados, ya que la consideración de los últimos puede influir mucho en el éxito de la creación de marca y en las ventas» (p. 44-45). Entre esos medios propios, es decir, aquellos sobre los que la organización tiene un mayor control, se 
puede destacar el perfil de la marca en las redes sociales o, como es el caso de este estudio, los canales propios de la marca en YouTube.

Como se ha comentado, las nuevas tecnologías han propiciado la aparición de medios como las redes sociales, que permiten una mayor interacción con los públicos de forma no intrusiva (uno de los principios del Inbound Marketing), creando contenidos específicos que respondan a las necesidades, haciendo que, los inicialmente desconocidos, se conviertan en clientes y prospectos. Sumadas estas cualidades al hecho de que se tratan de medios propios, es decir, controlados por las organizaciones, YouTube ofrece a las marcas la oportunidad de controlar el entorno del mensaje, trazar estrategias creativas con menos limitaciones, al tiempo que posibilita la creación e interacción con sus comunidades. Además, el marketing de contenidos facilita que los públicos opten voluntariamente por seguir los contenidos de las marcas (Wang y Can-Olmsted, 2020, p.294). Prueba de ello es el número de suscriptores con los que cuentan los canales de YouTube, los cuales deciden suscribirse al canal de forma voluntaria o que según Estudio Anual de Redes Sociales (IAB Spain, 2020) el $52 \%$ de las cuentas que siguen los usuarios de redes sociales pertenecen a marcas.

Asimismo, YouTube al igual que otras redes sociales apoyan al desarrollo y crecimiento de las empresas, permiten generar tráfico a las webs corporativas y que se compartan los contenidos generadas por las marcas (Saefudin Zuhdi, Anshar Daud, Rifki Hanif, Phong Thanh Nguyen, K. Shankar (2019, p.3843). En definitiva, juegan un papel esencial en el conocimiento e imagen de marca (Febriyantoro, 2020, p. 13). De hecho, según el Estudio Anual de Redes Sociales (IAB Spain, 2020) el 33 \% de los usuarios afirma que las marcas que tienen perfil en Redes Sociales les inspiran más confianza.
«En el caso de YouTube prima el formato vídeo, al ser una plataforma en la que se suben exclusivamente vídeos» (Sicilia y Merino, 2020, p.13), pero al igual que otras redes sociales posibilitan nuevas formas de comunicación que aumentan el nivel de participación e implicación de los consumidores frente a otros formatos tradicionales, como, por ejemplo, la web corporativa (Sicilia y Merino, 2020).

En definitiva, YouTube permite a las marcas trazar estrategias innovadoras coherentes con la metodología de Inbound marketing, fortaleciendo la presencia de la marca en el recorrido del comprador. Asimismo, fortalece el conocimiento e imagen de marca y todo ello de forma no intrusiva, a través de estrategias creativas más innovadoras y controladas por la marca que permiten la interacción y la implicación de los públicos.

Todas las cuestiones revisadas anteriormente obligan a plantear las siguientes preguntas de investigación relacionadas con el objetivo general de esta investigación:

- ¿Qué estrategias y acciones de marketing digital en YouTube están realizando actualmente los anunciantes del sector del automóvil?

- ¿Qué tipo de contenidos están generando las marcas de automóviles en sus canales de YouTube?

- ¿Qué objetivos persiguen los contenidos creados por las marcas?

- ¿A través de qué formatos y duración están transmitiendo los contenidos generados por la marca a través de sus canales de YouTube?

\section{Metodología}

Este estudio sigue una metodología basada en el análisis de contenido desde una visión mixta, puesto que se combina el análisis cuantitativo y cualitativo. En este sentido nos servimos de la técnica del análisis de contenido ya que se 
centra en documentos tanto escritos como audiovisuales. Este último tipo de documentos, audiovisuales, son los que nos importan en este estudio, ya que YouTube se basa en vídeos, complementados por los comentarios realizados por los seguidores del canal, cuestión que no se va a tener en cuenta en este trabajo, puesto que el objetivo es entender cómo las marcas del sector del automóvil están utilizando sus canales propios de la red YouTube.

En la revisión sobre la literatura existente que aborda el análisis de YouTube se puede distinguir diferentes trabajos que han servido de referencia para nuestra propuesta metodológica. En este sentido, se destaca principalmente el estudio presentado por Wang y Can-Olmsted (2020) en el que se distinguen 5 aspectos para comprender cómo las marcas utilizan sus canales de YouTube como plataforma de sus estrategias de marketing. Para ello, los autores distinguen dos dimensiones principales, por un lado, el propio contenido de las estrategias de marketing en YouTube, distinguiendo la interactividad, atención, emoción y cognición, y, por otro lado, los factores que influyen en las estrategias de marketing de las empresas, como, por ejemplo, los recursos financieros o la categoría de producto. En el caso concreto del análisis del contenido de los vídeos de YouTube, en el estudio se proponen como variables la presencia de líderes de opinión, el contenido emocional o el estilo del mensaje, entre otras (pp. 297-300).

En esta misma línea se sitúa el trabajo realizado por Sicilia y Merino (2020) con el propósito de conocer el nivel de integración entre la comunicación realizada por parte de El Corte Inglés en sus canales propios, tanto online como offline. Para ello, se realiza un análisis de contenido de la comunicación tanto en la web corporativa de la citada marca y sus perfiles en diferentes redes sociales (Facebook, Twitter, Instagram y YouTube), a la vez que se analiza la comunicación realizada en las tiendas físicas. En este sentido, es de interés para este estudio el análisis realizado del perfil de la marca en redes sociales. En concreto se ha tomado como referencia la «tipología de los posts publicados», en el caso de YouTube, vídeos, en concreto: información de producto, eventos, promocionales, conversaciones, noticias y líderes de opinión. Asimismo, los autores proponen la medición de engagement en función del número de likes de cada una de las publicaciones en las diferentes redes sociales analizadas.

Se puede también resaltar los trabajos presentados por Árevalo Salinas (2014 y 2018), pero en relación con las estrategias discursivas de los movimientos sociales en YouTube. En su propuesta metodológica se plantea la diferenciación entre tres «planos» o áreas de análisis: plano de identificación o emisor, plano de contenido o discurso-mensaje y plano de recepción o receptor. En la propuesta de este autor destaca el análisis de contenido sobre los vídeos de Youtube, en los que apunta tres ámbitos: aspecto técnico, plano discursivo y una tercera parte en la que se enfoca en conocer la relación de los vídeos de los movimientos sociales con aspectos como el cambio social.

Este análisis se basa en la tradición de análisis de contenido a partir del proceso de categorización, definido como «una operación de clasificación de elementos constitutivos de un conjunto por diferenciación, tras la agrupación por género (analogía), a partir de criterios previamente definidos» (2002, p. 90). En este sentido, se tendrá en cuenta tanto categorías formales, es decir, duración, imágenes que aparecen en los videos, textos, elecciones formales, así como aspecto de contenido, es decir, el tema en el que se centra el mensaje, objetivos y estrategia seguida. Asimismo, se ha 
llevado a cabo una lectura inductiva exploratoria para identificar otros aspectos de interés.

A partir de las cuestiones señaladas anteriormente y en coherencia con nuestro objetivo y preguntas de investigación, y dado el marco en el que realizamos este estudio, es decir, el análisis sobre aquella comunicación que utiliza YouTube como lugar con el que interactuar con los públicos, se analizarán las siguientes dimensiones tanto formales como de contenido:

- Emisor: datos identificativos

- Marca

- Canal

- Número de suscriptores del canal

- Mensaje. Se analiza tanto el contenido como la forma del mensaje, por ello, se sugieren las siguientes dimensiones:

- Duración. El tiempo en segundos que dura el video emitido para conocer sobre la muestra analizada las tendencias con relación a la duración de los mensajes emitidos por este medio.

- Contenido del mensaje. Se revisa el tema principal del vídeo. Para ello, se clasifican los vídeos en las siguientes temáticas:

- Producto. Mensajes cuyo contenido principal sea el producto, línea de producto o sus atributos.

- Marca. Mensajes centrados en la imagen de marca o corporativos.

- Eventos. Videos que versen sobre cualquier tipo de evento organizado por la marca.

- Promociones. Información sobre acciones promocionales.

- Líderes de opinión. Vídeos cuyo eje central sea la imagen de un líder de opinión, influencer o experto de prestigio.
- Participación. Mensajes que inviten a los públicos a participar en acciones propuestas por la marca, tanto online como offline. Sean concursos, eventos, acciones de responsabilidad social corporativa, entre otras.

- Estrategias discursivas. A partir del contenido central del video y las elecciones formales para transmitir este mensaje se clasificarán los vídeos en las siguientes estrategias:

- Cognitiva. Aquellos mensajes cuyo tema central es el producto o un aspecto de éste. Los argumentos se apoyan en datos objetivos y tangibles, es decir, aspectos funcionales del producto o del aspecto que se quiera resaltar.

- Emocional. Estrategia centrada en el receptor, su estilo de vida y valores o, dicho de otro modo, en lo simbólico. En este tipo de estrategia el mensaje se transmite a través de argumentos emocionales e intangibles, a diferencia de la estrategia cognitiva.

- Emocional + cognitiva. Estrategia que combina lo emocional y racional, de esta forma la estrategia se basa en aportar información utilitarista y racional, pero combinándola con argumentos emocionales.

- Participativa. En este caso se apela a la relación entre el consumidor y la empresa e invita a la acción e implicación.

- Estilo del mensaje. A partir del contenido central del video, su estrategia y las elecciones formales para transmitir el mensaje se clasificarán los vídeos en las siguientes estrategias creativas: 
- Storytelling. Videos basados en la técnica de la narración de una historia que, normalmente, contará con un personaje o varios y su trama.

- Testimonial. Mensajes que se apoyan en la declaración de un personaje sobre su experiencia con el producto anunciado.

- Líderes de opinión e influencer. Mensajes que basan su estrategia creativa en la presencia de líderes de opinión para conectar con el público al relacionar los valores del líder a la marca.

- Utilitarista. Estrategia creativa basada en argumentos racionales y utilitarista.

- Hedonista. Estrategia que se basa en argumento emocionales.

\section{- Receptor}

- Número de visualizaciones.

- Número de «Me gusta».

\section{Muestra. El sector del automóvil}

El sector del automóvil es uno de los más importantes de España, junto al turismo y la alimentación. Asimismo, como se ha expuesto al inicio de este estudio es, según el Observatorio de la Publicidad en España 2020, el primero en inversión publicitaria.

De las cincuenta marcas más vendidas en España, como así se detalla en la Asociación Española de Fabricantes de Automóviles y Camiones (ANFAC), se han seleccionado las 10 primeras marcas, indicadas en la Tabla 1 , consideradas como adecuadas para el marco de muestreo en el que mediremos sus estrategias de marketing

Para el diseño de la muestra, de las 50 marcas más vendidas en España, se han seleccionado las que ocupan las 10 primeras posiciones. Se ha comprobado que todas tienen canal de YouTube propio en España. En cada canal se ha seleccionado, de cada una de las marcas, los cinco vídeos que tuvieran más visualizaciones y con un año de antigüedad desde su publicación. Por lo que, finalmente, se ha configurado una muestra de 10 marcas y un total 50 vídeos que se han analizado durante un mes (16 de noviembre-16 de diciembre de 2020). De tal forma, que se han definido como unidades de muestro, 10 canales de YouTube de marcas de automóvil y un total de 50 unidades de registro. En el Anexo 1, se puede consultar los canales y los vídeos analizados y la fecha de su publicación.

\section{Tabla 1. Las 10 marcas más vendidas en España en año 2019}

\begin{tabular}{|l|c|c|}
\hline Marca & Ventas & \multicolumn{1}{l|}{ Cuota } \\
\hline Seat & 111.982 & $8,90 \%$ \\
\hline Peugeot & 97.939 & $7,78 \%$ \\
\hline Volkswagen & 94.328 & $7,50 \%$ \\
\hline Renault & 86.419 & $6,87 \%$ \\
\hline Toyota & 71.697 & $5,70 \%$ \\
\hline Marca & Ventas & Cuota \\
\hline Opel & 69.103 & $5,49 \%$ \\
\hline Citroen & 67.151 & $5,34 \%$ \\
\hline Hyundai & 62.766 & $4,99 \%$ \\
\hline Kia & 59.523 & $4,73 \%$ \\
\hline Ford & 57.169 & $4,54 \%$ \\
\hline
\end{tabular}

Fuente: ANFAC, Ideauto, 2019

\section{Resultados}

El análisis de contenido realizado sobre la muestra anteriormente descrita ha arrojado los siguientes datos que se presentan de forma resumida en la siguiente tabla: 


\section{Tabla 2. Resultados del análisis}

\begin{tabular}{|c|c|c|c|c|c|}
\hline \multirow{2}{*}{ Marca } & \multirow{2}{*}{$\begin{array}{l}\mathrm{N}^{\circ} \text { de } \\
\text { suscriptores }\end{array}$} & \multicolumn{2}{|c|}{$\begin{array}{l}\text { Duración } \\
\text { (segundos) }\end{array}$} & \multirow{2}{*}{ Contenido } & \multirow{2}{*}{$\begin{array}{l}\text { Estrategia } \\
\text { discursiva }\end{array}$} \\
\hline & & Mín. & Máx. & & \\
\hline Seat & 75.800 & 20 & 60 & 5 producto & 5 emocional + cognitiva \\
\hline Peugeot & 10.900 & 30 & 76 & $\begin{array}{l}2 \text { producto } \\
3 \text { marca }\end{array}$ & $\begin{array}{l}1 \text { cognitiva } \\
2 \text { emocional } \\
2 \text { emocional + cognitiva }\end{array}$ \\
\hline Volkswagen & 85.500 & 20 & 124 & $\begin{array}{l}3 \text { producto } \\
1 \text { marca } \\
1 \text { eventos }\end{array}$ & $\begin{array}{l}1 \text { emocional } \\
4 \text { emocional + cognitiva }\end{array}$ \\
\hline RENAULT & 78.800 & 17 & 153 & $\begin{array}{l}4 \text { producto } \\
1 \text { marca }\end{array}$ & $\begin{array}{l}4 \text { cognitiva } \\
1 \text { participativa }\end{array}$ \\
\hline Toyota & 45.500 & 17 & 53 & $\begin{array}{l}3 \text { producto } \\
2 \text { marca }\end{array}$ & $\begin{array}{l}2 \text { emocional } \\
3 \text { emocional + cognitiva }\end{array}$ \\
\hline Opel & 99.900 & 20 & 71 & 5 producto & $\begin{array}{l}4 \text { cognitiva } \\
1 \text { emocional }\end{array}$ \\
\hline Citroen & 13.000 & 10 & 192 & $\begin{array}{l}2 \text { producto } \\
3 \text { marca }\end{array}$ & $\begin{array}{l}3 \text { cognitiva } \\
1 \text { emocional } \\
1 \text { emocional + cognitiva }\end{array}$ \\
\hline Hyundai & 68.900 & 20 & 97 & $\begin{array}{l}2 \text { producto } \\
3 \text { marca }\end{array}$ & $\begin{array}{l}1 \text { emocional } \\
4 \text { emocional + cognitiva }\end{array}$ \\
\hline Kia & 164.000 & 30 & 86 & $\begin{array}{l}3 \text { producto } \\
1 \text { marca } \\
1 \text { líderes }\end{array}$ & $\begin{array}{l}2 \text { emocional } \\
3 \text { emocional + cognitiva }\end{array}$ \\
\hline Ford & 22.800 & 30 & 185 & 5 producto & $\begin{array}{l}3 \text { cognitiva } \\
2 \text { emocional }+ \text { cognitiva }\end{array}$ \\
\hline Global & & 10 & 193 & $\begin{array}{l}35 \text { producto }(70 \%) \\
13 \text { marca }(26 \%) \\
1 \text { líderes }(2 \%) \\
1 \text { eventos }(2 \%)\end{array}$ & $\begin{array}{l}15 \text { cognitiva ( } 30 \%) \\
9 \text { emocional }(18 \%) \\
25 \text { emocional + cognitiva } \\
(50 \%) \\
1 \text { participativa ( } 2 \%)\end{array}$ \\
\hline
\end{tabular}




\begin{tabular}{|c|c|c|c|c|}
\hline \multirow{2}{*}{ Estilo } & \multicolumn{2}{|c|}{$N^{0}$ de visualizaciones } & \multicolumn{2}{|c|}{$\mathrm{N}^{\circ}$ de "me gusta" } \\
\hline & Mín. & Máx. & Mín. & Máx. \\
\hline 5 storytelling & 603.423 & $2,1 \mathrm{M}$ & 7 & 1.827 \\
\hline $\begin{array}{l}3 \text { storytelling } \\
1 \text { líderes } \\
1 \text { hedonista }\end{array}$ & 37.708 & 264.379 & 8 & 294 \\
\hline $\begin{array}{l}1 \text { storytelling } \\
2 \text { líderes } \\
1 \text { utilitarista }\end{array}$ & 25.517 & 596.814 & 9 & 191 \\
\hline $\begin{array}{l}1 \text { testimonial } \\
4 \text { utilitarista }\end{array}$ & 152.118 & $3,5 \mathrm{M}$ & 20 & 2.446 \\
\hline $\begin{array}{l}1 \text { storytelling } \\
2 \text { líderes } \\
2 \text { utilitarista }\end{array}$ & 480.273 & $6,9 \mathrm{M}$ & 20 & 53 \\
\hline $\begin{array}{l}4 \text { utilitarista } \\
1 \text { hedonista }\end{array}$ & 5.223 & $2 M$ & 0 & 0 \\
\hline $\begin{array}{l}1 \text { storytelling } \\
4 \text { utilitaristas }\end{array}$ & 11.324 & $2 \mathrm{M}$ & 16 & 105 \\
\hline 5 storytelling & 497.609 & $3,5 \mathrm{M}$ & 24 & 2151 \\
\hline $\begin{array}{l}4 \text { storytelling } \\
1 \text { líderes }\end{array}$ & 851.964 & $5,5 \mathrm{M}$ & 10 & 153 \\
\hline $\begin{array}{l}3 \text { storytelling } \\
2 \text { utilitaristas }\end{array}$ & 8.390 & $1,1 \mathrm{M}$ & 51 & 132 \\
\hline $\begin{array}{l}23 \text { storytelling (46\%) } \\
1 \text { testimonial (2\%) } \\
6 \text { líderes (12 \%) } \\
18 \text { utilitarista (36\%) } \\
2 \text { hedonista (4\%) }\end{array}$ & 5.223 & $6,9 \mathrm{M}$ & 0 & 2.446 \\
\hline
\end{tabular}


De forma global se puede apuntar que solo en tres de las marcas analizadas es coincidente el número mayor de visualizaciones con el mayor número de «me gusta» y de éstos solo dos marcas realizan vídeos con elementos diferenciadores con respecto al resto de vídeos, ya que la mayoría de los mensajes analizados se basan en un contenido centrado en el producto, 35 de los 50 analizados, después 13 de marca de los 50, líderes de opinión 1 y eventos 1 . Las estrategias mayoritariamente utilizadas son 25 emocional y cognitiva, 15 cognitiva y 9 emocional. En relación con el estilo, el mayoritario es storytelling, 23 vídeos.

\section{Discusión y conclusiones}

La originalidad del estudio se basa en realizar una aproximación a la comunicación de marketing que están realizando es sus canales propios las marcas de automóviles, los 50 vídeos más visualizados de las marcas más vendidas en España durante el periodo de un año arrojan conclusiones determinantes, tales como:

- La mayoría de los anunciantes del sector del automóvil utilizan la versión del spot publicitario para incluir vídeos en sus canales de YouTube. No obstante, al spot propiamente dicho se añade la posibilidad de redirigirse a otros perfiles de la marca, la web corporativa u otro contenido, maximizando de esta forma las fortalezas de YouTube, en línea con las conclusiones del estudio de (Saefudin Zuhdi et al., 2019). Junto a esta idea se puede afirmar, asimismo, que las marcas son conscientes de la importancia de ser coherentes en todas sus comunicaciones y apoyar de esta forma la estrategia de comunicación integrada de marketing, como se ha visto, y en línea con los resultados del trabajo de Martín-Santana et al., (2019). Además, junto con el formato spot, entre los mensajes analizados se han encontrado casos en los que se centran en la marca y sus acciones de RSC, reforzando de esta forma la imagen y notoriedad de marca y aportando utilidad al consumidor en su proceso de compra. En este sentido, se confirman los resultados de anteriores investigaciones respecto a la importancia de YouTube en relación con conocimiento e imagen de marca (Febriyantoro, 2020).

- Todos los líderes de opinión que se han encontrado en los vídeos analizados son personas vinculadas al mundo del deporte, tales como Johanan Barmmm, Mieria Belmonte, Rafa Nadal, Nikoloz Sherazadishvili. De esta forma, se refuerza la conclusión anterior, ya que las marcas en todos sus medios se han servido de la imagen de estos deportistas para asociar sus organizaciones a valores como el esfuerzo, constancia, superación, entre otros. Muy enfocado a su «buyer persona» tal y como se define el Inbound marketing y como se ha expuesto en la revisión teórica.

- A pesar de la utilización mayoritaria por parte de las marcas del spot, se han encontrado casos de gran aceptación por parte de los públicos, en los que se encuentran vídeos de mayor duración y que aportan información funcional y propiamente utilitarista de los productos. Este es el caso de dos vídeos de Renault, que son el primero y tercero de los 50 analizados con más «me gusta», en concreto, 2446 y 1902 y que tienen una duración de 114 y 153 segundos, respectivamente. Se puede afirmar que las marcas están aprovechando las ventajas de esta red, es decir, públicos que de forma no intrusiva visualizan voluntariamente los contenidos de las marcas, para suministrar información similar a la que el comprador conseguiría en 
el punto de venta. De esta forma, se apoya, asimismo, la estrategia de Inbound marketing, generando contenido de valor para el público y atrayéndole primero a la lealtad hacia la marca y después, la compra, y su recomendación, en coherencia con las ideas sobre Inbound marketing planteadas en estudios como el de Patrutiu-Baltes (2016).

- Por otra parte, sorprende que son pocos los casos analizados en los que se fomenta una mayor iteración con el público, en concreto, solo uno de los casos cumple estrictamente con esta premisa, la campaña de Renault, \#FeliZiudad. De esta forma, se puede afirmar que, aunque la utilización de YouTube por las marcas es esencial, no se están aprovechando al máximo las ventajas de esta red. De esta forma no se puede afirmar que se esté fomentando la comunicación bidireccional con los públicos, sino que sigue manteniendo, en la mayoría de los casos, el carácter unidireccional del markteting tradicional. Aunque no hay que olvidar que, la premisa fundamental de Inbound marketing es, precisamente, informar adaptando el contenido al «buyer persona», además de educar de manera no intrusiva y utilizando la multicanalidad, quizá si se analizara esos otros canales el resultado sería distinto.
Las conclusiones a las que se ha llegado en este estudio descriptivo y exploratorio permiten abrir nuevas líneas de reflexión alrededor del uso de los canales propios de las marcas y su integración en la estrategia de Inbound marketing. Las limitaciones de este estudio posibilitan abrir futuras líneas de investigación, en concreto, el estudio de una única red no permite ver la estrategia digital global e integrada de las marcas, por lo que resultaría de interés ampliar la investigación a otras redes sociales para ofrecer una visión de la estrategia de comunicación digital en estos canales, identificando coincidencias. Asimismo, la acotación temporal tanto en lo que se refiere a la publicación de los videos, como el momento en el que se produce el análisis, limita la generalización de los datos, por lo que sería pertinente la realización de un análisis longitudinal para comprobar los cambios acaecidos en las estrategias de marketing digital en redes sociales de las marcas del sector del automóvil más vendidas. Por supuesto, otro aspecto pertinente sería incluir otras dimensiones de análisis, como, por ejemplo, los comentarios de los públicos. Otra de las líneas de investigación que quedaría abierta consistiría en analizar el retorno de la inversión para las marcas en estas redes y analizar las otras formas del Inbound marketing como puede ser posicionamiento en SEO, webminar, etc. 


\section{Bibliografía}

Aaker, D. (1991). Managing Brand Equity: Capitalizing on the Value of Brand Name. New York: The Free Press.

Aaker, D. (1996). Building Strong Brands. New York: The Free Press.

Alba, J., Lynch, J., Weitz, B., Janiszewski, C., Lutz, R., Sawyer, A., \& Wood, S. (1997). Interactive Home Shopping: Consumer, Retailer and Manufacturer Incentives to Participate in Electronic Marketplaces. Journal of Marketing $n^{\circ}$ 61, 38-53.

Andrews, J., Durvasula, S., \& Akhter, S. (1990). A Framework For Conceptualizing and Measuring the Invloment Construct in Advertising Research. Journal of Advertising, 19, 27-40.

Arce, M., \& Cebollada, J. (2011). Una comparación del comportamiento del consumidor en los canales online y offline: sensibilidad al precio, lealtad de marca y efecto de las características del producto. Cuadernos de Economía y Dirección de Empresa (CEDE), 14, 102-111.

Arévalo Salinas, A. I. (2014). El movimiento social 15-M de España y la promoción de la protesta a través de sus vídeos en YouTube. Historia y Comunicación Social. Vol. 19. Núm. Especial Marzo, 153-163.

-(2018). Propuesta metodológica para el análisis de YouTube y su relación con los movimientos sociales. Actas del II Congreso Internacional Move.net sobre Movimientos Sociales y TIC, 25-27 de octubre de 2017, Universidad de Sevillla, COMPOLITICAS.

Bastien, V. \&. (2012). The Luxury Strategy: Break the rules of marketing to build luxury brands. Philadelphia: Kogan Page.

Bowman, S., \& Willis, C. (2005). Nosotros, el Medio, Cómo las audiencias están modelando el futuro de la noticias y la información. TheMedia Center at the American Press Institute, Online Journalism Review,.

Cobb-Walgren, C., Ruble, C., \& Donthu, N. (1995). Brand Equity, Brand Preference, and Purchase Intent. Journal of Advertising, 24, 25-40.

Crainer, S. (1997). El verdadero poder de las marcas: Cómo lograr que las marcas sirvan para aventajar a la competencia. Madrid: Eresma.

Crimmins, J. (1992). Better Measurement and Management of Brand Value. Journal of Advertising Research, 32, 11-19.
Degeratu, A., Rangaswamy, A., \& Wu, J. (2000). Consumer Choice Behavior in Online y Traditional Supermarkets. The Effect of Brand Name, Price y Other Search Attributes. International Journal of Research in Marketing, 17, 55-78.

Erdem, T., Swait, J., Broniarczyk, S., Chakravarti, D., Kafferer, J.-N., Keane, M., Zeitelmeyer, F. (1999). Brand Equity, Consumer Learning and choice. Marketing letters 10 (3), 301-318.

Febriyantoro, M.T. (2020). Exploring YouTube Marketing Communication: Brand awareness, Brand image and purchase intention in the millennial generatio. Cogent Business E Management, 7:1, 1787733. https://doi.org/10.1080/233 11975.2020 .1787733

Fondevila, J., Polo, M., Rom, J., \& Mir, P. (2020). Social Media Influence on Consumer Behavior:. Sustainability, 12, 1506.

Gangadharbatla, H. (2013). Facebook Me. Journal of Interactive Advertising, 5-15.

González Romo, Z., \& Plaza, N. (2017). Estrategias de marketing digital en el sector de lamoda de lujo. Interacción y redes sociales comoherramienta necesaria. Hipertext.net, n.15.

Gordon, M., McKeage, K., \& Fox, M. (1998). Relationship Marketing Effectiveness: The Role of Involvement. Psychology $\&$ Marketing, 15, 443-459.

Griwert, K. (11 de febrero de 2021). brafton. Obtenido de brafton: https://www.brafton.com/news/89-percent-of-consumers-use-search-engines-for-purchase-decisions/

Hadadi, K., \& Almsafir, M. (2014). The Impact of Online Advertising on Proton. Procedia - Social and Behavioral Sciences, Volumen 129, pp. 274-281.

Howard, J. (1993). El comportamiento del consumidor en la estrategia de marketing. Madrid: Diaz de Santos.

hubspot. (11 de febrero de 2021). Obtenido de hubspot: https://www.hubspot.com/inbound-marketing

huify. (11 de febrero de 2021). Obtenido de huify: https:// www.huify.com/services/inbound-marketing

IAB. (28 de diciembre de 2020). iabspain. Obtenido de iabspain: https://iabspain.es/estudio/estudio-anual-de-redes-sociales-2019/

Kapferer, J. (1992). La marca capital de la empresa. Bilbao: Deusto.

Kapferer, J., \& Laurent, G. (1991). La sensibilidad a las marcas. En J. Kapferer, \& J. Thoening, La Marca. París: McGraw-Hill. 
Keller, K. (1993). Conceotualizing measuring and managing consumer-based brand equity. Journal of Marketing, 57, 1-22. Lado, N., Licandro, O., \& Pérez, F. (2004). Valor de Marca y Estrategias de Precio en el Sector del Automóvil: El Caso Especial de los coches gemelos. Researchgate.

Lemon, K. V. (2016). Understanding Customer Experience. Journey, J. of Marketing: AMA/MSI, Vol 80, 69-97.

Liberal, S., \& Mañas, L. (2019). Las Redes Sociales como herramienta de comunicación persuasiva. Madrid: McGraw.Hill. Low, G., \& Fullerton, R. (1994). Brands, Brand Management and the Brand Manager System: A Critical-Historical Evaluation. Journal of Marketing Research, 31, 271-288.

Mandal, P., \& Joshi, N. (2017). Understanding Digital Marketing Strategy. International Journal of Scientific Research and Management, vol 5, 6, 5428-5431.

Marketing-schools.org. (20 de noviembre de 2020). Obtenido de marketing-schools.org: https://www.marketingschools.org/types-of-marketing/inbound-marketing/

Martín-Santana, J. D., Olarte-Pascula, C., Reinares-Lara, E., Reinares-Lara, P. y Samino-García, R. (2019). Gestión de la comunicación: un enfoque integral. Madrid: ESIC EDITORIAL.

Mohamad Trio Febriyantoro (2020) Exploring YouTube Marketing Communication: Brand awareness, brand image and purchase intention in the millennial generation, Cogent Business \& Management, 7:1, 1787733.

Múgica, J., \& Yagüe, M. (1993). Impacto del capital comercial en la competitividad empresarial, $n^{\circ} 56$. Papeles de Economía Española, 242-256.

Netemeyer, R., Krishnan, B., Pullig, C., Wang, G., Yaggi, M., Dean, D., \& Ricks, J. (2003). Developing and validating measures of facets of customer-based brand equity. Journal of Business Research, forthcoming.

Park, C., \& Srinivasan, V. (1994). A Survey-Based for Measuring and Understanding Brand Equity and Its Extendibility. Journal of Marketing Research, 31, 271-288.

Park, C., Jaworski, B., \& Macinnis, D. (1986). Strategic Brand Concept-Image Management. Journal of Marketing, 50, 135-145.

Patrutiu-Baltes, L. (2016). Inbound Marketing - the most important digital. Bulletin of the Transilvania Uni- versity of Braşov Series V: Economic Sciences, Vol. 9 (58) No. 2

Rang Wang \& Sylvia Chan-Olmsted (2020) Content marketing strategy of branded YouTube channels, Journal of Media Business Studies, 17:3-4, 294-316, DOI: 10.1080/16522 354.2020.1783130.

Rial, A., Varela, J., Braña, T., \& Lévy, J. (2000). El valor de la marca a partir de su relación con el consumidot. Psicotherma, vol.12, $n^{\circ} 2,247-254$.

Saefudin Zuhdi, Anshar Daud, Rifki Hanif, Phong Thanh Nguyen, K. Shankar (2019). Role of Social Media Marketing in the Successful Implementation of Business Management International Journal of Recent Technology and Engineering (IJRTE), Volume-8, Issue-2S11, September 2019.

Samsing, C. (30 de diciembre de 2020). HubSpot. Obtenido de HubSpot: https://blog.hubspot.es/marketing/que-es-Inbound-marketing-slide-share

Sherif, M., \& Cantril, H. (1947). The Psychology of Ego-Implication, Social Attitudes and Identifications. New York: John Wiley \& Sons, Inc.

Shocker, A., Srivastava, V., \& Rueker, R. (1994). Challenges and Oportunities Facing Brand Management: An Introduction to the Special Issue. Journal of Marketing Research, 16 149-158.

Sicilia Piñero, M. ${ }^{a}$ y Merino Sánchez, J. (2020) Integración de la estrategia de comunicación en canales propios: El Caso de El Corte Inglés. Revista Internacional de Investigación en Comunicación aDResearch ESIC. No 21 Vol 21, 8 a 26.

Simon, C., \& Sullivan, M. (1993). The Measurement and Determinants of Brand Equity: A Financial Approach. Marketing Science, 25, 11-21.

Steenburgh, T., Avery, J., \& Dahod, N. (2011). HubSpot: Inbound Marketing and Web 2.0. Harvard Business School, January $24,3,4$.

Swait, J., Erdem, T., Louviere, J., \& Dubelaar, C. (1993). The equalization price: A mesaure of consumer-perceived brand equity. International Journal of Research of Marketing 10 (1), 23-45

Tutan, T., \& Solomon, M. (2017). Social Media Marketing. London: Sage. 


\section{Anexos}

\section{Canales y vídeos analizados}

\section{Canales España YouTube}

\begin{tabular}{|l|l|c|}
\hline Marca & URL & Número de suscriptores \\
\hline Seat & https://www.youtube.com/user/tuseat & 75.800 \\
\hline Peugeot & https://www.youtube.com/user/PeugeotES & 10.900 \\
\hline Volkswagen & https://www.youtube.com/user/volkswagenesp & 85.500 \\
\hline Renault & https://www.youtube.com/user/RenaultESP & 78.800 \\
\hline Toyota & https://www.youtube.com/user/toyotaes & 45.500 \\
\hline Opel & https://www.youtube.com/user/OpelspainGM & 99.900 \\
\hline Citroen & https://www.youtube.com/user/CitroenEspana & 13.000 \\
\hline Hyundai & https://www.youtube.com/user/HyundaiSpain & 68.900 \\
\hline Kia & https://www.youtube.com/user/KiaMarketing & 164.000 \\
\hline Ford & https://www.youtube.com/user/FordSpain & 22.800 \\
\hline
\end{tabular}

\section{Vídeos más visualizados}

\begin{tabular}{|c|c|c|c|}
\hline Marca & URL & $\begin{array}{l}\text { Fecha } \\
\text { publicación }\end{array}$ & $\begin{array}{l}\text { No } \\
\text { visuali- } \\
\text { zaciones }\end{array}$ \\
\hline \multirow{5}{*}{ SEAT } & https://www.youtube.com/watch?v=0WljudxuyEs & $25 / 02 / 2019$ & $2,1 \mathrm{M}$ \\
\hline & https://www.youtube.com/watch?v=qjGKRbFgXMU & $10 / 11 / 2019$ & $1,1 \mathrm{M}$ \\
\hline & https://www.youtube.com/watch?v=JSagGmLEzZY & $24 / 01 / 2019$ & 989.751 \\
\hline & https://www.youtube.com/watch?v=u50033ASH0k & 24/01/2019 & 621.475 \\
\hline & https://www.youtube.com/watch?v=g55N526co7c & 24/01/2019 & 603.423 \\
\hline \multirow{5}{*}{ PEUGEOT } & https://www.youtube.com/watch?v=5d8licv33ll & $13 / 11 / 2019$ & 264.379 \\
\hline & https://www.youtube.com/watch?v=yYCSa5TaE90 & $13 / 11 / 2019$ & 168.467 \\
\hline & https://www.youtube.com/watch?v=gb9xnoFAUrs & $19 / 06 / 2019$ & 81.212 \\
\hline & https://www.youtube.com/watch?v=ei-rc-wRPOo & 24/06/2019 & 40.303 \\
\hline & https://www.youtube.com/watch?v=RX0t6cMfdXk & $11 / 11 / 2019$ & 37.708 \\
\hline
\end{tabular}




\section{Vídeos más visualizados (continuación)}

\begin{tabular}{|c|c|c|c|}
\hline \multirow{5}{*}{ VOLKSWAGEN } & https://www.youtube.com/watch?v=Q_prZz3kBXM & 10/08/2019 & 596.814 \\
\hline & https://www.youtube.com/watch?v=rEJ3-Es1-rU & 02/10/2019 & 341.332 \\
\hline & https://www.youtube.com/watch?v=P83azvh87Ck & $14 / 06 / 2019$ & 196.345 \\
\hline & https://www.youtube.com/watch?v=laayn4oEnyY & 23/05/2019 & 61.695 \\
\hline & https://www.youtube.com/watch?v=rM_SVELzrPU & 03/06/2019 & 25.517 \\
\hline \multirow{5}{*}{ RENAULT } & https://www.youtube.com/watch?v=91 kmv-7lloE & 04/06/2019 & $3,5 \mathrm{M}$ \\
\hline & https://www.youtube.com/watch?v=bjRqAi-g9Zc & 20/02/2019 & 927.508 \\
\hline & https://www.youtube.com/watch?v=pbNsW_RoxmA & 20/02/2019 & 628.241 \\
\hline & https://www.youtube.com/watch?v=xVrnm9qk76s & 20/02/2019 & 321.980 \\
\hline & https://www.youtube.com $/$ watch?v=6kgH7/2Jqdc & 26/11/2019 & 152.118 \\
\hline \multirow{5}{*}{ TOYOTA } & https://www.youtube.com/watch?v=LxgvNLBgOV4 & $11 / 01 / 2019$ & $6,9 \mathrm{M}$ \\
\hline & https://www.youtube.com/watch?v=9WOegB4J2oc & 03/05/2019 & $4,2 \mathrm{M}$ \\
\hline & https://www.youtube.com/watch?v=49V-mGfceM0 & 30/09/2019 & $1,5 \mathrm{M}$ \\
\hline & https://www.youtube.com/watch?v=9yVw011ZB0Q & 20/11/2019 & 1,3 \\
\hline & https://www.youtube.com/watch?v=9_epm0NvHOw & 28/10/2019 & 480.273 \\
\hline \multirow{5}{*}{ OPEL } & https://www.youtube.com/watch?v=H1hkoqQqW6c & $18 / 12 / 2018$ & $2 \mathrm{M}$ \\
\hline & https://www.youtube.com/watch?v=SHTKNHDX4CY & $04 / 06 / 2019$ & 15.903 \\
\hline & https://www.youtube.com/watch?v=VjnSHsRFyBQ & 21/01/2019 & 5.759 \\
\hline & https://www.youtube.com/watch?v=qlhlty6F7dE & $19 / 12 / 2018$ & 5.312 \\
\hline & https://www.youtube.com/watch?v=63|GZ1dUJUE & $26 / 12 / 2018$ & 5.223 \\
\hline \multirow{5}{*}{ CITROEN } & https://www.youtube.com/watch?v=_zlPr-dokpM & $28 / 05 / 2019$ & $2 \mathrm{M}$ \\
\hline & $\begin{array}{l}\text { https://www.youtube.com/watch?v=SjLeCTOFnlc\&feat } \\
\text { ure=youtu.be }\end{array}$ & 28/11/2018 & 11.324 \\
\hline & https://www.youtube.com/watch?v=zrSY3r63kp8 & 23/04/2019 & 13.280 \\
\hline & https://www.youtube.com/watch?v=ZPxc4HBWve0 & 26/02/2019 & 13.089 \\
\hline & https://www.youtube.com/watch?v=buTXB0_tzSQ & $24 / 04 / 2019$ & 12.369 \\
\hline \multirow{5}{*}{ HYUNDAI } & https://www.youtube.com/watch?v=PJs7EdTLljc & $11 / 09 / 2019$ & $3,5 \mathrm{M}$ \\
\hline & $\begin{array}{l}\text { https://www.youtube.com/watch?v=vRbvz-dUBwU\&ab_ } \\
\text { channel=HyundaiEspa \%C3 \%B1a }\end{array}$ & 16/09/2019 & 497.609 \\
\hline & https://www.youtube.com/watch?v=XgLkAdayG-o & 24/10/2019 & $2,7 \mathrm{M}$ \\
\hline & https://www.youtube.com/watch?v=rYrG2A2qjak & 08/10/2019 & $2,6 \mathrm{M}$ \\
\hline & https://www.youtube.com/watch?v=ixJmDqpTt_w & $16 / 01 / 2019$ & $2,3 \mathrm{M}$ \\
\hline
\end{tabular}




\section{Vídeos más visualizados (continuación)}

\begin{tabular}{|c|c|c|c|}
\hline Marca & URL & $\begin{array}{l}\text { Fecha } \\
\text { publicación }\end{array}$ & $\begin{array}{l}\text { No } \\
\text { visuali- } \\
\text { zaciones }\end{array}$ \\
\hline \multirow{5}{*}{ KIA } & https://www.youtube.com/watch?v=0kNJaTodn80 & $27 / 11 / 2019$ & $5,5 \mathrm{M}$ \\
\hline & https://www.youtube.com/watch?v=s5JchROhsno & 02/10/2019 & $4,2 \mathrm{M}$ \\
\hline & https://www.youtube.com/watch?v=|t|4gEjz5vc & $11 / 11 / 2019$ & $2,9 \mathrm{M}$ \\
\hline & https://www.youtube.com/watch?v=2IWd9yrNM_E & $21 / 11 / 2019$ & $1 \mathrm{M}$ \\
\hline & https://www.youtube.com/watch?v=Ubcvky94mfA & 27/11/2019 & 851.964 \\
\hline \multirow{5}{*}{ FORD } & https://www.youtube.com/watch?v=OE8T0xSzZ2g & $30 / 08 / 2019$ & $1,1 \mathrm{M}$ \\
\hline & https://www.youtube.com/watch?v=utTuuVr8Lpg & $12 / 08 / 2019$ & 18.214 \\
\hline & https://www.youtube.com/watch?v=4gM1AkCr2T4 & 20/03/2019 & 11.741 \\
\hline & https://www.youtube.com/watch?v=zqalSQZSV9Q & $17 / 11 / 2019$ & 10.339 \\
\hline & https://www.youtube.com/watch?v=H4XUB6t3860 & 29/11/2019 & 8.390 \\
\hline
\end{tabular}



다(1) $(-) \div$

\section{TikTok medio de divulgación empleado por los viajeros que realizan turismo sostenible}

TikTok Means of Dissemination Used by Travelers Who Carry out Sustainable Tourism

Dra. Ariana Paola Herrera Pérez

Profesora titular de la Universidad Metropolitana, Ecuador

www.arianaherrera.com.ec

arherr01@ucm.es

https://orcid.org/0000-0002-5627-1948
Herrera Pérez, A.P., (2021)

Tik Tok medio de divulgación empleado por los viajeros que realizan turismo sostenible

Revista Internacional de Investigación en Comunicación aDResearch ESIC. № $25 \mathrm{Vol} 25$

Monográfico especial, marzo 2021 · Págs. 148 a 159

https://doi.org/10.7263/adresic-025-08 
RESUMEN

\author{
Clasificación JEL: \\ M30, M31, L83 \\ Palabras clave: \\ Redes sociales, \\ experiencia del \\ consumidor, \\ turismo sostenible, \\ TikTok
}

Objetivo: La divulgación del turismo sostenible y el mercado de los viajes se han visto beneficiados por las diversas plataformas sociales. El User-Generated Content se ha convertido en el mecanismo más eficiente para transmitir experiencias de los destinos que visitan. El objetivo de la presente investigación es analizar e identificar la influencia que genera TikTok como medio de difusión del sector.

Diseño/metodología/enfoque: La primera fase metodológica es analítica, que explica el contexto sociocultural y el estado de la cuestión. A través, de los temas más relevantes de turismo sostenible, experiencia de los viajeros, TikTok, vídeos cortos y los hashtags más usados en el sector. La segunda fase metodológica es cualitativa, con enfoque interpretativo; se analizan los vídeos con los siguientes hashtags: \#turismo, \#turismosostenible, \#tiktoktravel, \#travel. En este apartado se aplicará una búsqueda online en formato usuario, incorporando las métricas como número de 'me gusta', comentarios y shares.

Resultados: Los resultados evidencian que TikTok genera un impacto relevante sobre la difusión turística, con énfasis en la promoción del turismo sostenible. Los vídeos con los hashtags más relevantes son los siguientes: \#turismo con 299,8 millones de visualizaciones, \#turismosostenible con un total de 101,6 mil visualizaciones, \#tiktoktravel contiene 20,1 millones de visualizaciones y \#travel con 27,3 millones de visualizaciones. El empleo de esta red social para la publicidad del turismo le da un giro productivo, convirtiéndola en una potente herramienta de divulgación.

Limitaciones/implicaciones: Se considera oportuno realizar el análisis de las métricas de TikTok por país, debido a que la implementación de la plataforma se encuentra desarrollada en distintos niveles por parte de los usuarios y los establecimientos. La red social, por el momento, sólo cuenta con un único mecanismo de análisis de las estadísticas y es la analítica de las cuentas Pro, que al ser de carácter privado de los usuarios no permite realizar un análisis profundo de las métricas.

Originalidad/contribución: La investigación se caracteriza por ser pionera en el análisis del impacto de TikTok en la divulgación del turismo sostenible, mediante la revisión de los vídeos cortos con mayor impacto de visualizaciones del sector.

\section{ABSTRACT}

\section{JEL Classification: M30, M31, L83 Key words:} Social media, consumer experience, sustainable tourism Tik Tok
Purpose: The dissemination of sustainable tourism and the travel market in general has benefited from the various social platforms. The User-Generated Content has become the most efficient mechanism for transmitting experiences of the destinations they visit. Therefore, the objective of this research is focused on analyzing and identifying the influence generated by TikTok as a means of disseminating the sector.

Design / Methodology / Approach: The first methodological phase is analytical, which explains the sociocultural context and the state of the question. Through, the most relevant topics of sustainable tourism, traveler experience, TikTok, short videos and the most used hashtags in the sector. The second methodological phase is qualitative, with an interpretive approach; The videos are analyzed with the following hashtags: \#turismo, \#turismosostenible, \#tiktoktravel, \#travel. In this section, an online search will be applied in user format, incorporating metrics such as number of likes, comments and shares.

Results: The results show that the TikTok platform generates a relevant impact on tourist diffusion with an emphasis on promoting sustainable tourism. The videos with the most relevant hashtags are the following: \#turismo with 299.8 million views, \#turismosostenible with a total of 101.6 thousand views, \#tiktoktravel contains 20.1 million views and \#travel with 27.3 million of visualizations. The use of this social network for tourism advertising gives it a productive turn, turning it into a powerful dissemination tool.

Limitations / Implications: It is considered appropriate to perform the analysis of TikTok metrics by country, because the implementation of the platform is developed at different levels by users and establishments. However, the social network at the moment has a single mechanism for analyzing the statistics and that is the analytics of the Pro accounts, which being private to the users, it is not possible to carry out a deep analysis of the metrics.

Originality/Contribution: The research is characterized by being a pioneer in the analysis of the impact of TikTok in the dissemination of sustainable tourism, by reviewing the short videos with the greatest impact of views related to the sector. 


\section{Introducción}

A raíz de los últimos acontecimientos que la humanidad atraviesa, derivados de la pandemia mundial, el turismo es uno de los sectores de la economía de cada país que se ha visto afectado significativamente durante el 2020 y 2021. Según la Organización Mundial del Turismo, durante el 2020, la reducción de turistas internacionales oscila entre el $60 \%$ al $80 \%$, una pérdida de ingresos entre 910 mil millones y 1,2 billones de dólares y una pérdida de empleos de 100 a 120 millones (OMT, 2020). La reducción de la movilidad humana y el riesgo que implica el desplazamiento masivo de turistas ha contribuido en el fomento de otras formas de hacer turismo. Tienen especial énfasis las opciones que facilitan el esparcimiento en áreas abiertas y el contacto con la naturaleza. Es así que el turismo sostenible cada vez toma más protagonismo a nivel de los destinos, establecimientos y viajeros. El cuidado de la naturaleza y a su vez, el brindar una experiencia holística hacia los consumidores es el enfoque de la propuesta de valor que diversos establecimientos brindan a sus clientes.

La difusión del turismo sostenible y el mercado de los viajes en general se han visto beneficiados de las diversas plataformas sociales. La interacción entre los usuarios se ha convertido en el mecanismo más eficiente para transmitir experiencias en los diferentes destinos y propiedades que visitan. Sin embargo, la disruptiva red social TikTok acapara la atención de los internautas y es una de las aplicaciones móviles con más creciente popularidad y descargas (Shutsko, 2020). Su característica principal yace en vídeos muy cortos y sonidos de tendencia, con los que se pueden compartir vivencias cotidianas o recreadas (Rey, 2020). Además, promueven que otros usuarios realicen réplicas de esos vídeos virales, de forma individual o en dúos.

Los principales factores que influyen en la experiencia del usuario en TikTok son los emocio- nales, usabilidad e interactivos, con la siguiente valoración porcentual: «Los factores emocionales representan el 48,77\%, los factores interactivos el 31,23 \% y los factores de usabilidad el 20,00 \%» (Feng, Chen y Wu, 2019, p. 55). Es así, que se recomienda que las campañas publicitarias de viajes estén acompañadas de una alta dosis de emotividad, para generar un impacto significativo en la audiencia.

Cada vez son más los viajeros que optan por esta red social para transmitir rápidamente aspectos puntuales de sus viajes y estilo de vida. Las fotos eran la mejor forma de compartir lugares de interés. Sin embargo, la opción de vídeos cortos ha generado especial revuelo entre centennials y millennials. Millones de vídeos se suben día a día a la red social y se incrementa el número de perfiles. En la actualidad, ya existen influencers de esta red que generan contenido especializado, cautivando la atención y promoviendo la réplica de los mismos.

Diversos lugares del mundo se han convertido en tendencia gracias a TikTok, el uso de hashtags específicos como \#turismo, \#turismo sostenible, \#travel y los nombres de las ciudades y países, que constituyen el formato más frecuente de referencia en los vídeos cortos. En el sector del turismo, los vídeos que se popularizan son de los viajeros con fondos de los destinos. Por esta razón, los TikTokers buscan espacios o lugares que cuenten con bondades naturales únicas o poco comunes.

Por todo lo anterior, la presente investigación se centra en analizar el impacto de esta plataforma social en la difusión de las experiencias de los viajeros que hacen turismo sostenible.

\section{Marco teórico}

\subsection{Turismo Sostenible}

Con el surgimiento de nuevos sectores en la economía del mundo, el sector turístico se ha conver- 
tido en un medio de generación de recursos para diferentes países. En algunos casos, es la principal fuente de riqueza y todo se presenta en relación de las potencialidades y bondades que poseen los destinos. Sin embargo, no se puede ignorar que esta actividad debe ser administrada y desarrollada de forma sostenible para evitar un potencial desequilibrio social y natural (Linares y Garrido, 2014).

Para generar la sostenibilidad de un destino se debe implementar un enfoque sistémico. Sólo así los recursos existentes pueden lograr un alto nivel de satisfacción en los viajeros. A pesar de los esfuerzos que los establecimientos realizan por implementar procesos alineados con la sostenibilidad, aún resulta compleja la identificación y valoración de este concepto por parte de los usuarios (Cabrer et al., 2010).

Para lograr que el turismo sostenible se posicione en la mente del consumidor y se convierta en un requerimiento en los destinos, es necesario que los establecimientos promuevan actividades de interés de los stakeholders. Es así, como se podrá fortalecer un sistema que genere vínculos intangibles con los grupos de interés (Alzate y Orozco, 2018).

\subsection{Experiencias de los viajeros}

Las necesidades de los viajeros cada vez se vuelven más aspiracionales. La búsqueda de atención, reconocimiento y vivencias inolvidables son los factores más influyentes a la hora de escoger un destino (Herrera, 2020). Ante este requerimiento, nacen las experiencias holísticas, como el medio que permite involucrar los cinco sentidos y hacer que la vivencia se vuelva digna de ser recordada. Para ello, es importante buscar tematizar la experiencia y armonizarla con aspectos positivos, involucrar los sentidos y eliminar todo cuanto pueda obstruir el proceso de disfrute del turista (Pine y Gilmore, 1998).
El diseño de la experiencia del consumidor es clave en la definición de la propuesta de valor que se oferta a los viajeros. Es el mecanismo que va a delimitar los aspectos que fomentan interés en los consumidores (Liu et al., 2020). Tampoco se puede olvidar el alto compromiso en el cumplimiento de la oferta realizada, para difundir una promesa consistente durante de la difusión online y la vivencia del servicio en el punto de consumo. Aquí toma especial interés la investigación previa que los viajeros realizan en las diferentes plataformas sociales.

Por estas razones se debe tener especial cautela en el tipo de contenido que se comparte en las redes sociales. Hay que evitar caer en el sobredimensionamiento de las localidades o añadir complementos efectistas y poco realistas sólo para la producción audiovisual. Es necesario ser objetivos e imparciales para evitar causar un impacto negativo en los viajeros (Rialti et al., 2018). Es necesario recordar que uno de los principales intereses de los turistas durante los viajes es generar contenido fotográfico y de vídeo para compartir en sus cuentas personales. Compartir experiencias en diversos formatos es un factor común en este sector y con el surgimiento de la plataforma TikTok se ha incrementado sustancialmente.

\subsection{TikTok una oportunidad para el turismo}

Las personas emplean cada vez más tiempo buscando información en línea. El 59 \% de la población mundial está activa en alguna plataforma social (Dwivedi et al., 2020). Con el confinamiento la estadística de la red social TikTok sigue en crecimiento y en especial, la generación de contenido de viajes se difundió con vídeos cortos desde el lugar en que se encontraban los usuarios. Una de sus desventajas más comentadas es la deficiencia para controlar y prohibir vídeos groseros o vulga- 


\section{Imagen 1. Formato de la presentación de las métricas en Tik Tok}

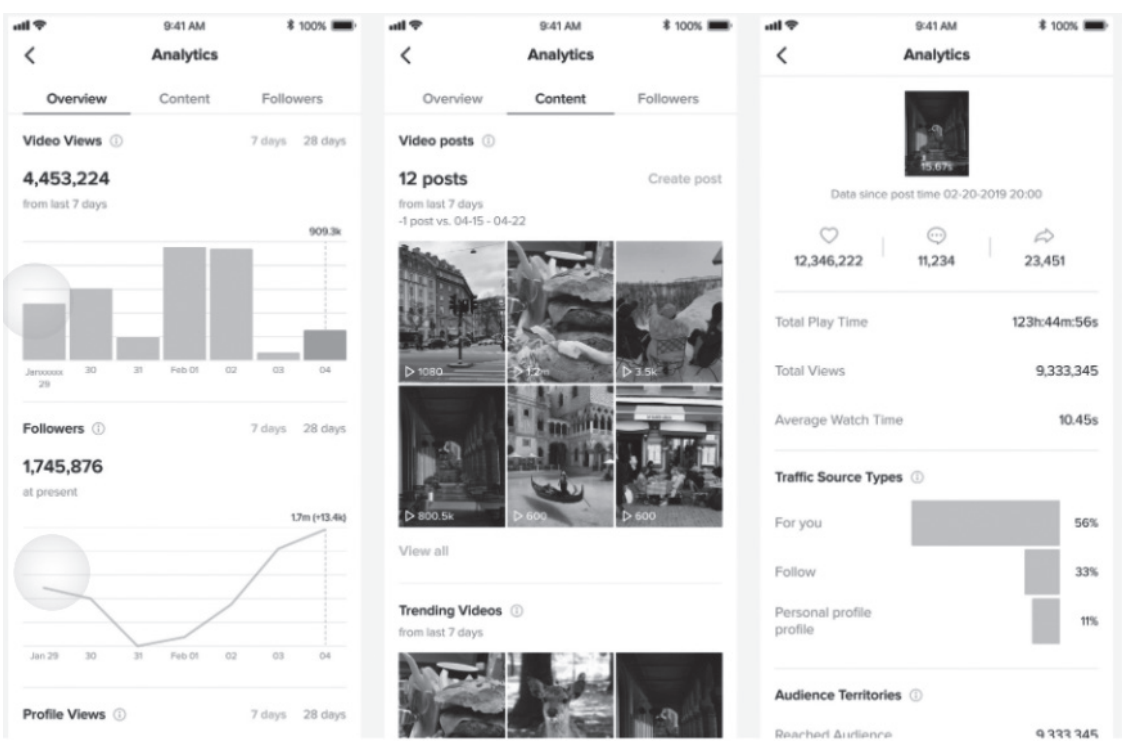

Fuente: Página oficial de Tik Tok (2020). Recuperado de: https://newsroom.tiktok.com/en-us/pro-accounts-offer-new-insightsto-avid-creators/.

res, generando incomodidad en muchos usuarios (Dai y Chen, 2019). No obstante, sus ventajas poseen mayor valor y destaca la versatilidad que provee la plataforma para la creación de vídeos cortos de 30 y 60 segundos, con las opciones de filtros y edición totalmente gratuitos.

Además, facilita que los usuarios se sumerjan en el área multimedia, tomando especial interés entre las generaciones $Z$ y millennial. Sin embargo, a los gerentes de marketing de sectores como el de alimentos y bebidas, viajes, entretenimiento y afines, les cuesta tomar decisiones rápidas y acoplarse a la veloz evolución que los usuarios de este entorno viven (Haenlein et al., 2020).

Esta plataforma social se ha convertido en un potente medio de difusión para el sector turístico. Según datos de la empresa estadounidense de investigación de mercados Forrester Research (2020), las publicaciones en TikTok permite 58 veces más de interacciones que Facebook y 150 veces más que Twitter. A raíz de la escalada exponencial de impacto en los usuarios, empresas de todo el mundo inauguraron sus cuentas e incluso, algunas consideraron esta red social en sus planes de marketing para el 2021.

Es relevante destacar que las estrategias de marketing deben ser específicas para el segmento de usuarios que interactúan en la misma, quienes en su mayoría se encuentran entre las edades de 16 a 25 años. Asimismo, se concentran en las intenciones de viaje de los jóvenes turistas, quienes poseen tres principales motivaciones: ampliación del conocimiento, relajación y autorrealización (Ying y Krishnapillai, 2018). 
Con la escalada de la plataforma, surgió la necesidad de análisis de la evolución de la misma en las cuentas privadas. Por esta razón, desde la página oficial de TikTok (2019), se indica que los usuarios solicitaron una opción que les permita identificar información de su audiencia, rendimiento e impacto de las publicaciones. En base a este pedido, implementaron la opción de Pro Account, una herramienta que facilita obtener métricas de tres aspectos:

- Resumen: Este apartado muestra estadísticas de seguidores, visualizaciones de vídeo y de perfil en dos opciones: 7 días o 28 días.

- Contenidos: Publicaciones de vídeo, vídeos con sus respectivas estadísticas de número de likes, comentarios, shares, reproducciones, visualizaciones, georreferenciación de la audiencia y vídeos que se encuentran en tendencia.

- Seguidores: Esta sección contiene datos relevantes de la audiencia como sexo, ubicación, actividades que realizan o sonidos más escuchados.

Los establecimientos turísticos que disponen de una cuenta Pro pueden acceder a todas las métricas mencionadas. Datos que influyen de forma positiva en la planeación estratégica y operativa del contenido.

La metodología de promoción de las propiedades ha evolucionado y quienes aún se mantienen con la forma tradicional de difusión, ya no es atractiva para los viajeros; quienes buscan vivir una experiencia diferenciadora, sentirse especiales y atesorar recuerdos para compartir. La opción de los vídeos cortos y los beneficios de edición que contiene TikTok ha conquistado a los internautas. Por ende, para ellos es la mejor forma de compartir sus vivencias, autoexpresarse, interactuar con la sociedad y escapar de la presión del día a día (Omar y Dequan, 2020).

\subsection{Los hashtags más empleados en el turismo}

En junio del 2019, TikTok lanzó la campaña \#TikTokTravel como un reto a nivel mundial. La misma fue desarrollada en 100 países con el objetivo de compartir la diversidad que tiene el planeta. El reto planteado por la plataforma debía incluir la canción Summer, con la finalidad de que existiera un elemento en común entre los millones de contenidos que se subieron por parte de los TikTokers. Algunos países adoptaron sus propios hashtags como \#ThisisJapan, \#ThisisMadrid, \#ExperiencePenang. Es importante destacar que al cierre del 2019, el hashtag \#TikTokTravel llegó a 6,2 millones de visitas (Hotelmize, 2019).

En Latinoamérica el primer hotel resort en abrir su cuenta fue @FairmontMayakoba. Su objetivo era atraer a la mayor cantidad posible de turistas a la Riviera Maya. Promueve la interacción con su audiencia generando desafíos que contemplan condiciones específicas. Además, premian a los creadores de contenido relevante con estadías en su establecimiento. Como resultado de estas propuestas han conseguido un alto nivel de interacción con su audiencia.

Otro subsector que posee notoriedad en la plataforma es el de alimentos y bebidas, en el que los vídeos cortos se difunden masivamente (Li et al., 2018). Además de las acciones promovidas por la red social para promover el turismo, los viajeros han empleado sus propios hashtags, como \#turismo, \#turismosostenible, \#travel y \#experience; añadiendo los hashtags tradicionales con los nombres del destino donde se encuentran.

Los creadores de contenido buscan espacios abiertos y en especial, con riqueza natural que les permita, a través de la biodiversidad, tener el escenario perfecto para la generación de los vídeos. La búsqueda de transmitir experiencias diferenciadoras y que aporten valor ha fomentado 
la difusión del turismo sostenible, el cual se centra en disfrutar de la naturaleza, cuidarla y a su vez, brindar una vivencia holística a los turistas.

\subsection{Vídeos cortos de TikTok y la promoción de los destinos}

Los vídeos cortos llegaron para quedarse por una larga temporada, con énfasis en los usuarios entre 16 a 30 años. Quienes están dispuestos a crear vídeos en mayor proporción son la generación Z y millennials, debido a cuán atractivo les resulta el área multimedia. Sin embargo, todas las edades disfrutan visualizándolos. Gracias a la facilidad de descarga, estos vídeos se comparten rápidamente en diferentes plataformas como WhatsApp, Facebook, Instagram y su sección de stories y estados. La tecnología brinda las facilidades para co-crear experiencias, con especial énfasis en el sector del turismo (Zhang et al., 2018).

TikTok ha representado una gran oportunidad para diversas industrias en especial la del turismo, como generador de propaganda de la marca ciudad (Zhang, 2020). Los destinos y establecimientos turísticos ven esta plataforma como un medio estratégico que permite fomentar una positiva forma de viajar. Los vídeos cortos permiten compartir las bondades del destino y transmitir emociones, incluso generar sensaciones en quien los visualiza. Aquí toman relevancia las experiencias holísticas que genera el turismo sostenible, creando un alto grado de fidelización y conexión con los viajeros, en especial cuando las vivencias son memorables.

El nivel de impacto que un vídeo alcanza sobre un viajero es superior que el de las fotografías en sus diferentes formatos. Por ende, el recuerdo del destino, recompra de servicios y recomendación de los diferentes establecimientos son superiores. Las empresas que se encuentran en constante innovación apuestan por los nuevos formatos de difusión y las diferentes metodologías disruptivas de llegar al consumidor. Un área que impacta positivamente TikTok en el individuo es la comunicación y la colaboración, gracias a que después de producir el vídeo se lo comparte con millones de usuarios del área de interés (Carrión, 2020).

Es importante buscar la adaptación para la supervivencia en el mercado turístico. Los jóvenes e intrépidos viajeros van a apostar constantemente por las nuevas tendencias de viajes y de comunicación entre sus comunidades digitales. El camino correcto es estar donde los consumidores y clientes potenciales se encuentran. TikTok se ha convertido en una plataforma que fomenta la comercialización de los diferentes formatos de hacer turismo, entre ellos el turismo rural, y trae consigo un incremento de la demanda de esta forma de disfrutar de la naturaleza (Shen, 2019).

\section{Metodología}

La presente investigación se centra en dos fases:

La primera fase metodológica es de carácter analítica, que explica el contexto sociocultural y el estado de la cuestión.

Tiene como finalidad la recopilación de la información más relevante de turismo sostenible, experiencia de los viajeros, TikTok y los hashtags más usados en el sector, a través de su uso por parte de autores contemporáneos que explican el impacto de la red social en la experiencia de los viajeros.

La segunda fase metodológica es cualitativa, porque se analizan los vídeos y hashtags más significativos de las variables de estudio.

En este apartado se aplicará una búsqueda online en formato usuario, de los vídeos y hashtags más significativos de la industria del turismo, incorporando las métricas como número de me gusta, comentarios y share. El objetivo es explicar y comentar la influencia que genera TikTok en el sector del turismo sostenible. 


\section{Análisis y resultados}

\subsection{Vídeos y hashtags de mayor tendencia en TikTok}

En el presente apartado se analizan los vídeos y hashtags de tendencia en el sector del turismo, turismo sostenible y viajes; además de las características de los vídeos cortos que lideran en métricas en TikTok, a partir de temas previamente expuestos.

El primer hashtag identificado es \#turismo. El mismo dispone de 299,8 millones de visualizaciones al 3 de enero del 2021. El vídeo corto más significativo con este hashtag proviene de la cuenta@edwinsevero, que recoge un total de 600,1 mil 'me gusta', 3261 comentarios y 3267 shares. El área donde fue grabado es en el «anillo de la vida» o el «anillo de la armonía», ubicado en China, en la ciudad de Shenfu. Numerosos viajeros comentan que es un camino para llegar a otra dimensión o que permite conectarse con el cielo.

El segundo hashtag estudiado es \#turismosostenible, con un total de 101,6 mil visualizaciones, al 3 de enero de 2021. El vídeo corto más relevante proviene de la cuenta pública de @oscarrasquilla, con un total de 623 «me gusta, 9 comentarios y 23 shares. El lugar donde se realizó la grabación es el volcán Barú, ubicado en Panamá, en la provincia de Chiriquí. El mismo es visitado por turistas de todo el mundo, quienes buscan captar la mejor toma fotográfica desde los increíbles paisajes y vistas que posee, (Véase figura 3, pag. 156).

El tercer hashtag que se analizó es \#travel, una palabra clave empleada de forma significativa a nivel mundial en el sector de los viajes. Posee 27,3 millones de visualizaciones al 3 de enero de 2021. Uno de los vídeos de mayor tendencia proviene de una cuenta especializada en viajes, denominada@movchal_travel, que contiene un

\section{Imagen 2. Collage del hashtag \#turismo en Tik Tok.}
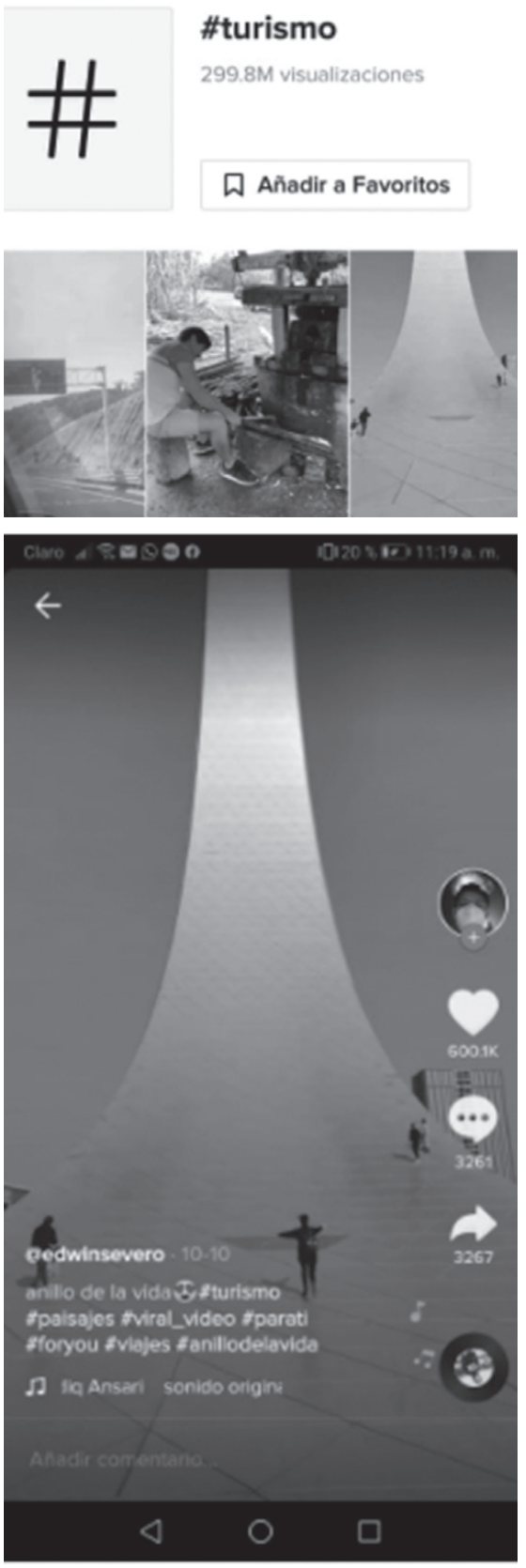

Fuente: Página oficial de TikTok, 3 de enero de 2021. 


\section{Imagen 3. Collage del hashtag \#turismosostenible en Tik Tok}

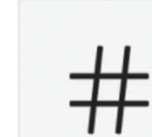

\#turismosostenible

101.6K visualizaciones

Ф Añadir a Favoritos
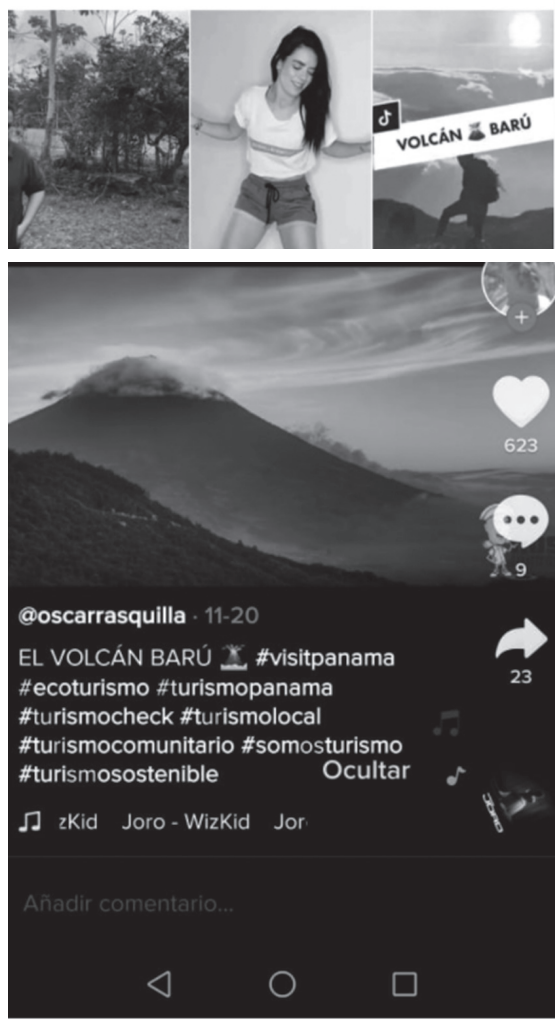

Fuente: Página oficial de Tik Tok, 3 de enero de 2021.

total de 3,8 millones de «me gusta», 18,7 mil comentarios y 103,5 shares. El escenario donde se realizó la grabación fue Suiza, y la viajera promueve su experiencia a bordo de un carrito tipo tren al aire libre, que desciende desde una montaña.

El último hashtag, y no menos importante, es \#tiktoktravel, que nació a raíz del challenge propuesto por la misma plataforma, con el ob-

\section{Imagen 4. Collage del hashtag \#travel en Tik Tok}

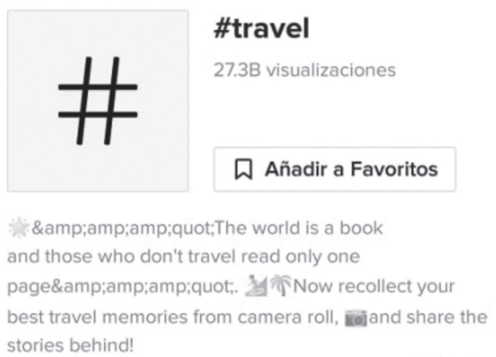
stories behind!

Reducir $\boldsymbol{\Delta}$
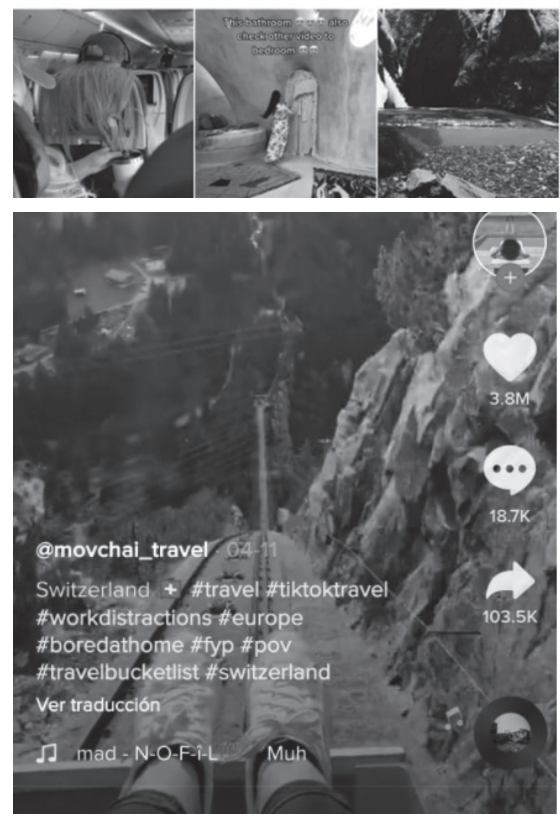

Fuente: Página oficial de Tik Tok, 3 de enero de 2021.

jetivo de motivar la difusión de los destinos por los generadores de contenido. Es así que miles de TikTokers del mundo, desde su creación en el 2019, han generado contenido y lo siguen haciendo nombrando el hashtag de la campaña.

A 3 de enero del 2021, el hashtag \#tiktoktravel contiene 20,1 millones de visualizaciones y uno de los vídeos de mayor tendencia proviene 


\section{Imagen 5. Collage del hashtag \#travel en Tik Tok}

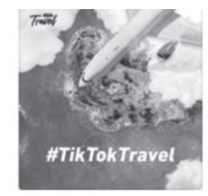

\section{\#tiktoktravel}

$20.1 \mathrm{~B}$ visualizaciones

ヤ Añadir a Favoritos

¡Descubre joyas ocultas de cientos de paises dentro de TikTok y graba tus momentos de viaje en tiempo real para tener la oportunidad de ganar Go Pro! 9 Terms and conditions:http://mrw.so/50Pgm4
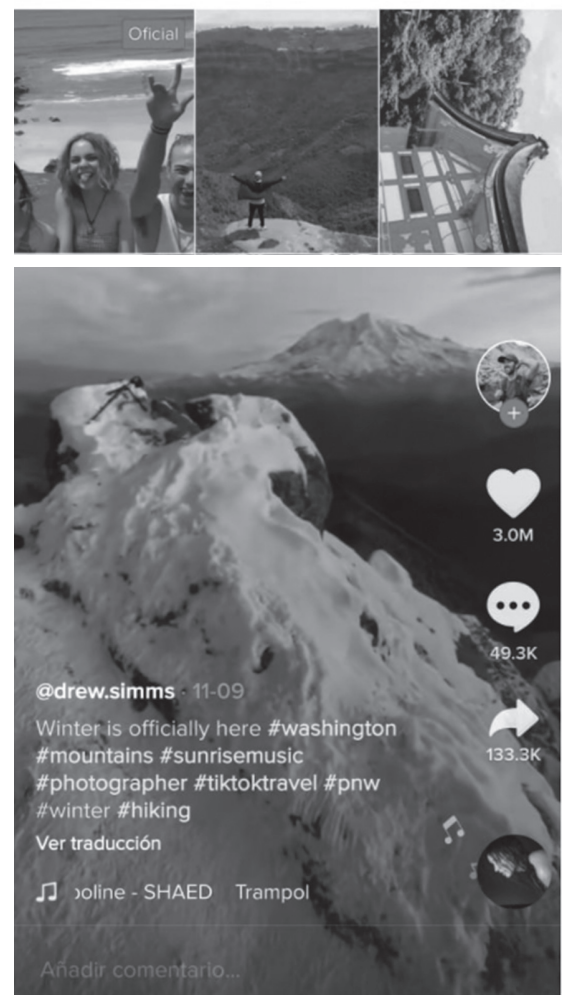

Fuente: Página oficial de Tik Tok, 3 de enero de 2021.

de la cuenta de @drew.simms. Las métricas responden de un total de 3 millones de 'me gusta', 49,3 mil comentarios y 133,3 mil shares. La grabación fue realizada en el Monte Washington, ubicado al norte de los Estados Unidos, en el Condado de Coös, New Hampshire.

\section{Conclusiones y discusión}

Se puede concluir que las plataformas sociales son una herramienta efectiva para la difusión de las experiencias de los viajeros, su alcance masivo y bajo costo agilita el proceso de intercambio de información entre los usuarios. Además, de la influencia que genera en la decisión de elegir un destino.

Existe un importante segmento de viajeros jóvenes que buscan viajes que les permita estar en contacto con la naturaleza y tienen como primer medio de búsqueda de información las redes sociales. Es aquí donde TikTok ha tomado especial relevancia, convirtiéndose en una de las plataformas más empleadas durante 2019 y 2020 por la generación Z y los millennials. Las vivencias compartidas a través de los vídeos cortos sintetizan los paisajes y las posibles experiencias que pueden vivir.

Emplear TikTok como una herramienta que promueve a los jóvenes a involucrarse con el entorno natural y volcarse a vivir experiencias holísticas genera un impacto relevante sobre la cultura de los viajes. Además, permite identificar a los espacios naturales como el camino para escapar del estrés, depresión y todo cuanto puede generar un espacio cerrado. En medio de un mundo digitalizado que gira alrededor de un móvil u ordenador, este es un efecto positivo que se debe rescatar en medio del caos que el mundo vive.

El turismo sostenible se ha convertido en una necesidad, en especial en tiempos donde la seguridad sanitaria sale del control gubernamental y privado. Las familias buscan espacios donde poder compartir tranquilos y sin presión, aislados de las aglomeraciones y posibles contagios. Es así que en el 2021 se puede seguir ratificando que esta forma de hacer turismo es una de las más seguras para todas las edades; sin dejar fuera el 
importante aporte que genera para el bienestar del ser humano.

TikTok representa una oportunidad para impactar positivamente en la forma de hacer turismo, es esencial darle un giro productivo y relevante al uso que normalmente se da a esta plataforma. Hay que emplearlo como un medio de difusión y aprovechando el alcance de audiencia y usuarios que posee. Actores de gobierno, empresarios y colectivo tienen a la mano una plataforma que facilita el fomento de uno de los pocos sectores que se encarga de recrear experiencias para el esparcimiento de las personas y además de reactivar uno de los sectores más golpeados en el mundo, producto de la pandemia.

La investigación no se encuentra exenta de limitaciones. Se considera oportuno realizar el análisis de las métricas de TikTok por país, debido a que la implementación de la plataforma se encuentra desarrollada en distintos niveles por parte de los usuarios y los establecimientos. No obstante, la red social por el momento cuenta con un único mecanismo de análisis de las estadísticas y es la analítica de las cuentas Pro, que al ser de carácter privado de los usuarios no es posible realizar un análisis profundo de las métricas.

\section{Bibliografía}

Alzate, J. y Orozco, J. (2018). Stakeholders, actores estratégicos en la construcción de marca. Anagramas - Rumbos y Sentidos de La Comunicación, 16(32), 95-109. DOI: https:// doi.org/10.22395/angr.v16n32a6

Cabrer, B., Szmulewicz, P., García, G., Gutiérrez, C. y Sancho, A. (2010) . El turismo sostenible, un reto para los destinos emergentes de la región de los ríos en el sur de Chile. Aportes y Transferencias, 14(2), 49-60. Disponible en: https://www.redalyc.org/pdf/276/27621284003.pdf

Carrión, R. (2020). El TikTok, de adicción juvenil a herramienta de aprendizaje. Investigando. DOI: 10.13140/ RG.2.2.29177.49764

Dai, L. \& Chen, P. (2019). Reasons for the popularity of Tik Tok, the shortages and the ways forward. Advances in Social Science, Education and Humanities Research, 345, 544 - 548. DOI: 10.2991/isemss-19.2019.105

Dwivedi, Y. K., Ismagilova, E., Hughes, D. L., Carlson, J., Filieri, R., Jacobson, J., Jain, V., Karjaluoto, H., Kefi, H., Krishen, A. S., Kumar, V., Rahman, M. M., Raman, R., Rauschnabel, P. A., Rowley, J., Salo, J., Tran, G. A. \& Wang, Y. (2020). Setting the Future of Digital and Social Media Marketing Research: Perspectives and Research Propositions. International Journal of Information Management, online, 1-37. DOI: http://dx.doi.org/10.1016/j.ijinfomgt.2020.102168
Feng, Y., Chen, C. \& Wu, S. (2019). Evaluation of Charm Factors of Short video User Experience using FAHP-A Case Study of TikTok APP. In IOP Conference Series: Materials Science and Engineering, 688(5), 55-68. DOI: 10.1088/1757899X/688/5/055068

Haenlein, M., Anadol, E., Farnsworth, T., Hugo, H., Hunichen, J. \& Welte, D. (2020). Navigating the New Era of Influencer Marketing: How to be Successful on Instagram, TikTok, \& Co. California Management Review, 63(1), 5-25. DOI: https://doi.org/10.1177/0008125620958166

Herrera, A. (2020). La comunicación como factor clave en la experiencia del consumidor para la fijación del precio. Revista Internacional de Investigación en Comunicación aDResearch ESIC, 21(21), 84-97. DOI: https://doi.org/10.7263/ adresic-021-05

Li, Y., Xu, X., Song, B. \& He, H. (2020). Impact of Short Food videos on the Tourist Destination Image-Take Chengdu as an Example. Sustainability, 12(17). DOI: https://doi.org/10.3390/su12176739

Linares, H. y Morales Garrido, G. (2014). Del desarrollo turístico sostenible al desarrollo local. Su comportamiento complejo. PASOS. Revista de Turismo y Patrimonio Cultural, 12(2), 453-466. Disponible en: https://www.redalyc.org/ articulo.oa?id=88130205003 
Liu, F, Zhu, Z., Chen, H. \& Li, X. (2020). Beauty in the eyes of its beholders: Effects of design novelty on consumer preference. Journal of Retailing and Consumer Services, 53. DOI: https://doi.org/10.1016/j.jretconser.2019.101969

Omar, B. \& Dequan, W. (2020). Watch, Share or Create: The Influence of Personality Traits and User Motivation on TikTok Mobile video Usage. International Association of Online Engineering, 14(4). DOI: https://doi.org/10.3991/ijim. v14i04. 12429

Pine, B. J. \& Gilmore, J. H. (1998). Welcome to the experience economy. Harvard Business Review, 97-105.

Rey, J. P. (2020). TikTok mucho más que bailecitos y centennials. Interactiva: Revista de la comunicación y el marketing digital, (190), 56-63.

Rialti, R., Caliandro, A., Zollo, L. y Ciappei, C. (2018). Comunidades de marca de medios sociales y co-creación de experiencias. Spanish Journal of Marketing - ESIC, 22(2), 122 141. DOI: https://doi.org/10.1108/SJME-03-2018-0011

Shen, X. (2019). Analysis on the Innovation of Rural Tourism Marketing Strategy-Taking the TikTok as an Example. Ad- vances in Economics, Business and Management Research, 109, 551-554. DOI: 10.2991/aebmr.k.191217.099

Shutsko, A. (2020). User-Generated Short video Content in Social Media. A Case Study of TikTok. Meiselwitz G. (eds) Social Computing and Social Media. Participation, User Experience, Consumer Experience, and Applications of Social Computing. HCII 2020. Lecture Notes in Computer Science, 12195, 108-125. Springer, Cham. DOI: https://doi. org/10.1007/978-3-030-49576-3_8

Ying, K. \& Krishnapillai, G. (2018). Young Domestic Tourists-Are They Motivated to Travel?. Advanced Science Letters, 24(5), 3444-3449. DOI: 10.1166/asl.2018.11405

Zhang, H., Gordon, S., Buhalis, D. \& Ding, X. (2018). Experience Value Co creation on Destination Online Platforms. Journal of Travel Research, 57(8), 1093-1107. DOI: https://doi.org/10.1177/0047287517733557

Zhang, Z. (2020). Infrastructuralization of TikTok: transformation, power relationships, and platformization of video entertainment in China. Media, Culture E Society, online. DOI: $10.1177 / 0163443720939452$

\section{Referencias web}

Hotelmize (2019). Las 5 mejores redes sociales para agencias de viajes y cómo sacarles partido. Recuperado de: https://www.hotelmize.com/es/blog/las-5-mejores-redessociales-para-agencias-de-viajes-y-como-sacarles-partido/ Organización Mundial del Turismo (2020). La OMT pone en marcha un programa de asistencia técnica para la recu- peración del turismo. Recuperado de: www.unwto.org/es/ news/la-omt-pone-en-marcha-un-programa-de-asistenciatecnica-para-la-recuperacion-del-turismo

TikTok (2020). Estadísticas. Recuperado de: https://newsroom.tiktok.com/en-us/pro-accounts-offer-new-insightsto-avid-creators/ 


\section{Estrategia de}

comunicación de

los cuerpos de seguridad

a través de píldoras

audiovisuales en TikTok

Policía Nacional y Guardia Civil

en España

Communication Strategy of Security Forces through Audiovisual Pills in TikTok National Police and Civil Guard in Spain

Dra. Eglée Ortega Fernández

Profesora de la Facultad de Comunicación y Artes. Universidad Nebrija

eortegafe@nebrija.es

https://orcid.org/0000-0001-7103-2403

Jonattan Rodríguez Hernández

Investigador Predoctoral UCM-Banco Santander

(CT63/19-CT64/19) en Universidad Complutense

de Madrid

jonrodri@ucm.es

https://orcid.org/0000-0001-8680-5800
Ortega Fernández, E., y Rodríguez Hernández, J. (2021) Estrategia de comunicación de los cuerpos de seguridad a través de píldoras audiovisuales en TikTok. Policía Nacional y Guardia Civil en España

Revista Internacional de Investigación en Comunicación aDResearch ESIC. No 25 Vol 25

Monográfico especial, marzo 2021 · Págs. 160 a 185 https://doi.org/10.7263/adresic-025-09 
Objetivo: El objetivo principal es conocer el detalle de las píldoras audiovisuales o vídeos cortos de TikTok de los organismos de seguridad españoles: la Policía Nacional y la Guardia Civil.

Diseño/Metodología/Enfoque: Se emplea una metodología cuantitativa y cualitativa a través de una revisión manual en TikTok, en la que se establecen diferentes variables para el análisis, comparando también la actividad de los dos organismos de seguridad.

Resultados: Los resultados subrayan que ambos cuerpos de seguridad han construido una identidad propia en TikTok, adaptando los contenidos, lenguaje y tipo de vídeos a esta red social y a su público que, en mayor medida, se agrupa en la Generación Z.

Limitaciones/implicaciones: La investigación se ve limitada por el espacio de tiempo estudiado, así como por la propia naturaleza de la aplicación. TikTok, por su tipología y reciente expansión, apenas cuenta con herramientas de análisis externas, por lo que la recopilación de los datos se ha realizado de manera manual y se ha tenido que limitar en el tiempo para hacer

Clasificación JEL:

M31, M37

Palabras clave:

TikTok,

Policía Nacional,

Guardia Civil,

comunicación,

redes sociales,

píldoras

audiovisuales un análisis manejable. Por otra parte, las implicaciones de la investigación imbrican con la actualidad, donde las redes sociales conviven con la sociedad y forman parte de nuestras vidas. Hay que tener presente que, con el paso de los años, las distintas evoluciones tecnológicas, la aparición de nuevas redes sociales o cambios en las actuales, las organizaciones varíen sus estrategias digitales ante la ampliación de opciones de las herramientas actuales.

Originalidad/contribución: La investigación será el primer análisis sobre la comunicación de los organismos de seguridad españoles en la plataforma de TikTok. Este aporte puede suponer el inicio de sucesivos estudios sobre la comunicación de seguridad en las aplicaciones emergentes donde residen las nuevas generaciones. Además, el artículo profundiza en el uso de las píldoras audiovisuales en cuentas de TikTok a fin de conocer cómo se plantea el uso de esta herramienta para el acercamiento, engagement y comunicación con la ciudadanía.

\section{ABSTRACT}

\author{
JEL Classification: \\ M31, M37 \\ Key words: \\ TikTok, \\ National Police, \\ Civil Guard, \\ communication, \\ social networks, \\ audiovisual pills
}

Purpose: The main objective is to know the details of the audiovisual pills or short TikTok videos of the Spanish security organizations: the National Police and the Civil Guard.

Design / Methodology / Approach: A quantitative and qualitative methodology is used through a manual review on TikTok, in which different variables are established for the analysis, also comparing the activity of the two security organizations.

Results: The results underscore that both security bodies have built an identity on TikTok, adapting the content, language and type of videos to this social network and its audience, which, to a greater extent, is grouped in Generation Z.

Limitations / Implications: The investigation is limited by the space of time studied, as well as by the very nature of the application. TikTok, due to its type and recent expansion, hardly has any external analysis tools, so the data collection has been done manually and time has had to be limited to make a manageable analysis. On the other hand, the implications of the research overlap with the present, where social networks coexist with society and are part of our lives. It must be borne in mind that, over the years, the different technological evolutions, the appearance of new social networks or changes in the current ones, organizations vary their digital strategies due to the expansion of options of current tools.

Originality / Contribution: The investigation will be the first analysis of the communication of Spanish security organizations on the TikTok platform. This contribution may mean the beginning of successive studies on security communication in emerging applications where new generations reside. In addition, the article delves into the use of audiovisual pills in TikTok accounts in order to know how the use of this tool is proposed for the approach, engagement and communication with citizens. 


\section{Introducción}

El estudio del Interactive Advertising Bureau Spain (IAB Spain) de junio de 2020 señala que un $87 \%$ de los internautas, de entre 16 y 65 años, utilizan las redes sociales, lo cual representa 25,9 millones de usuarios en España. La edad promedio se sitúa en los 40 años. Tras el surgimiento de la pandemia de la COVID-19, el número de usuarios de las redes sociales no ha dejado de crecer en el mundo entero: Facebook cuenta con 2.450 millones de usuarios, YouTube con 2.000 millones, WhatsApp suma 1.600 millones, Facebook Messenger un total de 1.300 millones, WeChat con 1.150 millones, Instagram cuenta con 1.000 millones, TikTok suma 800 millones de usuarios, QQ un total de 730 millones, QZone con 531 millones y Weibo cuenta con 497 millones. Además, la mayoría sigue en aumento, como Instagram y Facebook (IAB Spain, 2020).

En esa línea, el informe Digital 2021 de We are Social \& Hootsuite, advierte que el número de usuarios activos en redes sociales en España es de 37 millones. Si se compara el número de usuarios en redes sociales en 2020 respecto al año anterior, éste ha aumentado en un 27,6 \%. En cuanto al acceso a las redes sociales por dispositivo, el móvil (97 \%) predomina respecto a los demás terminales. Añade que TikTok ha sido la aplicación más descargada para móviles en 2020 (We are Social \& Hootsuite, 2021). Aunque es necesario acotar que los autores de los informes de IAB y We are Social \& Hootsuite indican que tienen una metodología selectiva, tanto en lo que respecta al público, como en las redes sociales analizadas.

El uso de redes sociales durante el confinamiento aumentó en un 51 \% respecto a las primeras semanas del año. España se convirtió en el país europeo que más las consumía en el aislamiento (Comscore, 2020). El informe de Smartme Analytics profundiza sobre el uso por franjas de edad en redes sociales. Su dosier observa un aumento del uso de las aplicaciones para niños o adolescentes en los mayores de 35 años. Entre las tres más destacadas se encuentra TikTok, con un aumento del 51,1 \%. Este hecho lo atribuyen a que los progenitores prestan sus teléfonos a los hijos para que naveguen por esas aplicaciones (Smartme Analytics, 2020). A estos datos hay que añadir que la comunicación no convencional o below the line sigue creciendo exponencialmente cada año e impulsa el branded content, influencers o publicidad nativa digital (InfoAdex, 2021).

La red social china TikTok ha resultado ser la red social más beneficiada por el confinamiento, casi duplicando sus usuarios en el primer semestre de 2020, pasando de un $14 \%$ de conocimiento en 2019 a un 53 \% en 2020, y avanzando de $3 \%$ de usuarios registrados a un $16 \%$ en el año pasado (IAB Spain, 2020). Su éxito ha impulsado a Instagram, Twitter y LinkedIn a implementar vídeos cortos similares a los de TikTok, además de las stories, para que no decreciera su número de seguidores (Padilla-Castillo, 2021).

Tomando en cuenta este entorno, esta investigación se centra en el estudio del uso de las píldoras audiovisuales o vídeos cortos en la red social TikTok por parte de la Policía Nacional y la Guardia Civil española. Estos perfiles nacieron en el último trimestre del año 2020 y es pertinente y necesario su estudio, para entender la estrategia que utilizan y comprender cómo una red social que se entendía cómo lúdica y juvenil puede contribuir a la mejor comunicación digital de los organismos de seguridad que, por tradición, han tenido una comunicación más formal y analógica con los ciudadanos.

\section{Objetivos}

El principal objetivo es analizar los perfiles de TikTok por parte de la Guardia Civil y la Policía 
Nacional, en los primeros meses en la aplicación. El fin principal de la investigación es determinar el alcance y la efectividad de la estrategia elegida por ambas instituciones. Se estudiará si las dos instituciones reconocen TikTok como una herramienta de acercamiento a la ciudadanía, sobre todo a la generación más joven, que es el principal pilar de esta red social.

Como objetivos secundarios categorizaremos los contenidos que se muestran en los casos de estudio, además de la respuesta y el engagement de los usuarios y seguidores; siempre entendiendo que existen detractores, que perciben las redes sociales como un medio de comunicación que resta seriedad a los cuerpos de seguridad.

La revisión se basa en dos pilares: primero, el estudio de conceptos ligados a las redes sociales, las estrategias de los organismos de seguridad y los nuevos usuarios en relación con el consumo de los vídeos cortos; segundo, un análisis de las cuentas@policia y@guardiacivil en TikTok, con variables cuantitativas y cualitativas, de acuerdo a los objetivos comentados. Estas variables y los resultados ofrecen una visión completa y detallada de los primeros meses de estas cuentas, cómo han sido manejadas desde cada organización y cómo han sido recibidas por los usuarios.

\section{Marco teórico y estado de la cuestión}

\subsection{TikTok: el boom de las píldoras audiovisuales}

Para analizar los perfiles de ambas instituciones es necesario revisar el nacimiento y transformación de la aplicación en los últimos años. TikTok surgió de la fusión de Douyin con Musical.ly. Douyin fue fundada en 2016 por la empresa china ByteDance. Un año después de su lanzamiento, lanzó al mercado internacional una primera versión de la aplicación, bajo el nombre de TikTok. Esa aplicación se fusionó después con Musical.ly, creada en 2014 por los desarrolladores Alex Zhou y Louis Yang. La aplicación permitía grabar, editar y compartir vídeos musicales (al estilo playback) de hasta 15 segundos (PérezEscoda y Contreras-Pulido, 2018). A finales de 2017, Musical.ly fue adquirida por ByteDance y se terminaría de erigir TikTok como la conocemos en la actualidad.

La aplicación ha sido calificada como la 'Red Social Revolución' en 2020. Aumenta todas sus métricas por 3 o 4 respecto a 2019 (Weimann y Masri, 2020). Destaca entre los menores de 40 años y más entre mujeres que varones. Entre sus características principales están el humor y la sencillez de los contenidos como aliados del esparcimiento, la facilidad de uso de la plataforma, los mini vídeos como protagonistas, unas piezas de muy corta duración y para cualquier momento del día, y el fomento de la creación de contenidos por parte del usuario partiendo de la imitación del original (Padilla-Castillo, 2021). Otro punto es que fomenta la viralidad de los vídeos sin detenerse en el plagio de música, audio o fondos (Padilla-Castillo, 2021).

Aun cuando el impacto de TikTok es visible en el mundo digital, en lo académico aún son escasas las publicaciones. Algunos autores han escrito sobre la plataforma, sobre todo como modo de entretenimiento. Mohamad (2020) se refirió a los paisajes digitales, donde la información está ampliamente disponible y pueden servir de manera efectiva para comunicar información sobre el COVID-19. Zhang (2020) investigó el proceso de transformación en las relaciones de poder entre los diferentes actores del ecosistema en TikTok. El mismo autor se refiere a la integración de los contenidos de entretenimiento con mensajes educativos o informativos (Zhang, 2020). En línea con el entretenimiento, Pons-Moreno (2020) se 
enfocó en el papel de las nuevas plataformas en la evolución del fanzine, entendidas como publicaciones realizadas por los fans.

Otros autores han estudiado la comunicación del sector de la salud a través de esta red y del uso de los vídeos cortos. Zhu et al., (2020) investigaron cómo los Comités Provinciales de Salud en China se adaptaron a la plataforma para compartir las píldoras audiovisuales. Gracias a ello, TikTok les permite interactuar con los residentes locales y difundir información relacionada con la salud. Fang et al., (2019) analizaron el mecanismo de anestesia que surge en aplicaciones como TikTok, afirmando que la aplicación brinda a los usuarios un sinfín de contenidos para satisfacer la curiosidad psicológica y las necesidades de entretenimiento.

Verma (2020) apunta que «TikTok se ha convertido en un éxito en todos los países, regiones y clases. Hay una gran cantidad de vídeos de TikTok provenientes del centro de las ciudades, pueblos y aldeas de la India con un solo propósito: entretenimiento y autoexpresión». A través de esta afirmación, la autora hace hincapié en la cultura de las redes sociales. Sin embargo, algunos autores observan peligros en el uso de la red social china. Por ejemplo, Subramanian (2020) revela que en la India se realizan peticiones para prohibir TikTok por «degradación en la sociedad»y «perversidad sexual» en los más jóvenes. Por su parte, Milkaite y Lievens (2020) concluyen que en las políticas de uso de TikTok en la Unión Europea existe un lenguaje complejo que dificulta su comprensión, siendo más complicado si esta debe realizarse por usuarios menores de edad.

En 2020, TikTok destaca por ser una de las redes que más ha aumentado su frecuencia de visita (IAB Spain, 2020). Sus contenidos son dinámicos, lúdicos y fáciles de consumir, con vídeos cortos que suelen tener música, humor o contenidos virales como retos (mejor conocidos como challenges). El consumo de las píldoras audiovisuales es una realidad por la que apuestan varias redes sociales. A finales de 2020, Snapchat presentó Spotlight, una modalidad para distribuir vídeos en función de su popularidad, en la línea del gigante chino. A mediados de noviembre, Twitter lanzó Fleets, que son publicaciones efímeras muy parecidas a las historias de Instagram, quien puede calificarse como el padre de los stories. A finales de agosto de 2020, conocimos los reels, la versión de Instagram que más se asemeja a TikTok y también la incorporación en LinkedIn de vídeos cortos, de no más de 30 segundos.

Podríamos afirmar que se trata de una clara adaptación a los nuevos usuarios, aunque hay quienes califican los perfiles de MySpace, de los años 90, como el origen de todo. Lo importante es tener claro que la incorporación de nuevas herramientas es una tendencia que busca imitar el éxito del anterior y la homogeneización puede hacer pensar que todos los mensajes se parecen entre sí, sin importar la red en la que se difundan.

No obstante, el $65 \%$ de los usuarios prefiere el contenido duradero por encima del contenido efímero (IAB Spain, 2020). Esto puede estar relacionado con la capacidad de atención que mantienen los usuarios. La filial canadiense de Microsoft (2015) también impulsó un estudio para conocer cómo variaba la capacidad de atención de las personas según el uso que hacían de las tecnologías digitales. Los resultados demostraron que se había pasado de los 20 segundos de atención en el año 2000 a 8 segundos en 2013 y se marcaba una tendencia de 7 segundos en el 2025. Es así como las píldoras audiovisuales, cortas, sencillas y con mensajes fáciles de encajar, mejor se difunden. 


\subsection{El nuevo usuario}

Los usuarios de las redes sociales cada vez están más acostumbrados a los contenidos cortos y optan por usar las redes de manera constante, siempre que éstas le aporten lo que buscan. El 81\% de los usuarios de redes declara que las utiliza para entretenerse y dentro de este porcentaje, el primer lugar lo ocupa ver vídeos o música (66\%), seguido por chatear/enviar mensajes (62\%) y publicar/colgar contenido (54\%). Otros usos que se hacen de las redes sociales se categorizan en interactuar, según un $77 \%$, e informarse, según un $66 \%$. En la categoría de quienes utilizan las redes sociales como inspiración (33\%), destaca que el $22 \%$ lo hace viendo vídeos o música (IAB Spain, 2020).

Al revisar, en este mismo estudio, el tipo de contenido que tiene más difusión, aparecen los vídeos en primer lugar, ya que 9 de cada 10 usuarios los consume en las redes sociales. El orden es el siguiente: videotutoriales, vídeos de humor y musicales. Igualmente significativo es el tiempo de uso que se dedica por generaciones: los millennials ( 25 a 40 años) suman 1 hora y 13 minutos diarios en redes sociales y un $19 \%$ utilizan TikTok. La Generación Z (16 a 24 años) permanece de media 1 hora y 27 minutos diarios en redes sociales y un $34 \%$ usa TikTok.

La Generación Z se caracteriza por usar más redes sociales pero que son menos masivas que Facebook, LinkedIn o Twitter. Destacan para este rango juvenil: Spotify, TikTok, Snapchat, Twitch, Tumblr, 21 Buttons, Houseparty y Peoople.

\subsection{Los organismos de seguridad en redes sociales}

Al estar expuestos a situaciones de extrema adversidad, los integrantes de los organismos de seguridad pueden tener dificultades al comunicarse de manera directa con la población en momen- tos de conflicto. La institución busca entonces mecanismos de comunicación que acerquen a la ciudadanía estos servidores públicos. SánchezTeruel y Robles-Bello (2014) hicieron un estudio sobre la Policía Nacional, refiriéndose a la personalidad y resiliencia de sus integrantes, a fin de asociar las emociones con las características sociodemográficas de los uniformados. Más allá de los datos cuantitativos del estudio, se repasa la humanización de los profesionales de la seguridad ciudadana, que trabajan con escrupulosidad, perseverancia y control de sus impulsos y emociones (Sánchez-Teruel y Robles-Bello, 2014).

$\mathrm{Al}$ asociar este tema con la realidad del uso de las redes sociales por parte de las marcas y las instituciones, uno de los principales objetivos que buscan es la cercanía, utilizando redes masivas y horizontales, tal como lo plantea Olmedo-Neri (2020). Desde hace algún tiempo, no es suficiente para las instituciones tener solamente una página web. La gente necesita ser escuchada y contar con un canal para canalizar sus inquietudes informativas, sus dudas sobre los servicios o simplemente, aclarar cuestiones de manera directa con su interlocutor.

En el barómetro de abril de 2015 (LópezGarcía, 2020) se reflejaba que los niveles de confianza de los españoles en las instituciones estaban liderados por la Guardia Civil, con 6,02 en valoración y confianza; seguida por la Policía Nacional, con un 5,95 sobre 10; incluso por encima de las Fuerzas Armadas y los medios de comunicación, ubicados en tercer y cuarto lugar, respectivamente. López-García (2020) también menciona datos más recientes de la encuesta de Sociométrica, publicada por El Español el 2 de abril de 2020, en la que se valora con un 8,3 (sobre 10) a la Policía y la Guardia Civil, y con un 8,1 al Ejército, sólo por detrás del personal sanitario, con 9,4 . 
En paralelo, en el año 2020, un $20 \%$ de la ciudadanía declara que sigue los perfiles públicos de las instituciones y de los medios de comunicación (IAB Spain, 2020). Si los medios tradicionales decrecen en usuarios, mientras el consumo de los medios digitales y redes sociales aumenta, éstas últimas se constituyen como complemento o dieta mediática única para un porcentaje significativo de la población (Casero-Ripollés, 2020).

Entre los profesionales, TikTok logra un $66 \%$ de conocimiento como herramienta para las comunicaciones digitales, aunque su uso aún es incipiente, con un 10 \% (IAB Spain, 2020). Todo apunta a que las marcas e instituciones seguirán experimentando con las nuevas opciones de acercamiento de las redes sociales, cada vez más adaptadas a las necesidades de los usuarios. Como señala Rangel (2017), hay que establecer un modelo omnicanal para lograr interactividad dentro y fuera de las redes sociales, basado en la definición de los públicos con objetivos claros.

\subsection{Policía Nacional: Moderno y cercano}

El Cuerpo Nacional de Policía de España, denominado también Policía Nacional, es un instituto armado de naturaleza civil, que depende del Ministerio del Interior. Es el principal responsable y garante de la vigilancia policial de las capitales de provincia y núcleos urbanos. Fue fundado en marzo de 1986. Mantiene las comunicaciones externas a través de varios medios: tradicionales y digitales. Entre las herramientas digitales, cuenta con una página web de varios apartados, como la comisaría virtual y la participación ciudadana, donde facilitan servicios a la ciudadanía. Otro apartado está dedicado a la información sobre la institución y otra categoría enlaza todas las comunicaciones que ofrecen: noticias, galerías de imágenes, vídeos de las actuaciones policiales y redes sociales en las que participan. En este úl- timo apartado se refieren a sus cuentas oficiales: YouTube con 71.500 suscriptores, Telegram con 7.273 miembros, Facebook con 999.318 seguidores, Instagram con 665.000 seguidores y Twitter con 3,4 millones de seguidores.

Es necesario destacar la estrategia comunicativa del perfil @policia en Twitter. Creado en marzo de 2009, en sus publicaciones se recuerda con frecuencia los motivos por los que acudir al Cuerpo. Con una media de más de 8 tuits diarios, mezclan mensajes informativos, explicativos y de advertencia. Muchos de ellos son emitidos y ampliados posteriormente por los medios de comunicación, por la viralidad que consiguen. Es un ejemplo perfecto de adaptación al nuevo paradigma comunicativo en una red social. El evidente éxito, por su modelo disruptivo en la comunicación convencional, ha sido estudiado en varias ocasiones y se ha comparado con organismos de la misma naturaleza en otros países (Boix-Palop, 2016; Padilla-Castillo, 2016; Gouyez-Ben-Allal, 2020; y Rodríguez-Andrés y López-García, 2019).

La cuenta oficial de TikTok, que tiene 180.500 seguidores al cierre de esta investigación, aún no está enlazada en la página web de comunicaciones de la Policía Nacional, ya que fue creada en noviembre de 2020. En el momento de su estreno, y debido a la polémica que generó con opiniones a favor y en contra, el subinspector Víctor Fernández, encargado de las redes sociales, destacó que la intención es que sea el principal canal de llegada a menores de 25 años, argumentando que la policía debe estar donde está la ciudadanía (El Observador, 2020).

\subsection{Guardia Civil: Próximo y tecnológico}

Fundada en mayo de 1884, la Guardia Civil de España es un instituto armado que, junto al cuerpo de Policía, se desarrolla como fuerza de 
seguridad de ámbito nacional. Tiene naturaleza militar y depende de los Ministerios del Interior y de Defensa. Entre sus principales misiones están la atención y el auxilio a los ciudadanos, junto con los servicios de Protección Civil, vigilancia del tráfico, protección de la naturaleza, rescate y ayuda en montaña y mar territorial. Sus funciones están intrínsecamente ligadas al bienestar de la ciudadanía y requiere de una comunicación clara y directa con el público.

Este organismo cuenta con una página web donde se detallan todos los servicios que ofrecen, la información institucional, las categorías de colaboración ciudadana y el gabinete de prensa. Al pie de página también enlaza con las redes sociales en las que tiene presencia. Al repasar dichas redes, encontramos que en Facebook cuenta con 412.857 seguidores, el canal de YouTube suma 77.100 suscriptores, Instagram tiene 564.000 seguidores y Twitter, imponiéndose como la más potente, con 1,6 millones de seguidores. La cuenta de TikTok, inaugurada el 12 de octubre de 2020, cuenta con 215.600 seguidores al cierre de esta investigación. Remarcan en su perfil oficial que no es un canal de denuncias, ya que para comunicar emergencias hay que llamar al 062. Este estreno tampoco estuvo exento de polémica, pues la Unión de Oficiales Guardia Civil Profesional emitió un comunicado, calificando de bochornoso el contenido publicado en TikTok. Pretendían, según sus palabras, trasladar el sentimiento de vergüenza que sintieron algunos uniformados al ver las primeras píldoras audiovisuales (El Confidencial, 2021). Aunque el Cuerpo prefirió apostar por el acercamiento a los más jóvenes, siguiendo la estela de la Policía Nacional (La Razón, 2020).

\section{Metodología de la investigación}

La metodología de esta investigación se basa en dos pilares correlativos, que buscan resultados originales, inéditos y extrapolables a otros trabajos:

- Investigación bibliográfica, donde se repasan los conceptos relacionados con el estudio: TikTok, minivídeos o píldoras audiovisuales, Generación Z o Centennials, Millennials, Guardia Civil y Policía Nacional. Se ha realizado a través de fuentes bibliográficas de primer nivel: Journal Citation Reports (Social Sciences), Scimago Journal Country Rank, Dialnet, Elsevier online, SAGE Journals, Taylor and Francis online, CISNE UCM y Academia.edu.

\section{Figura 1. Perfil de la Policía Nacional en TikTok}

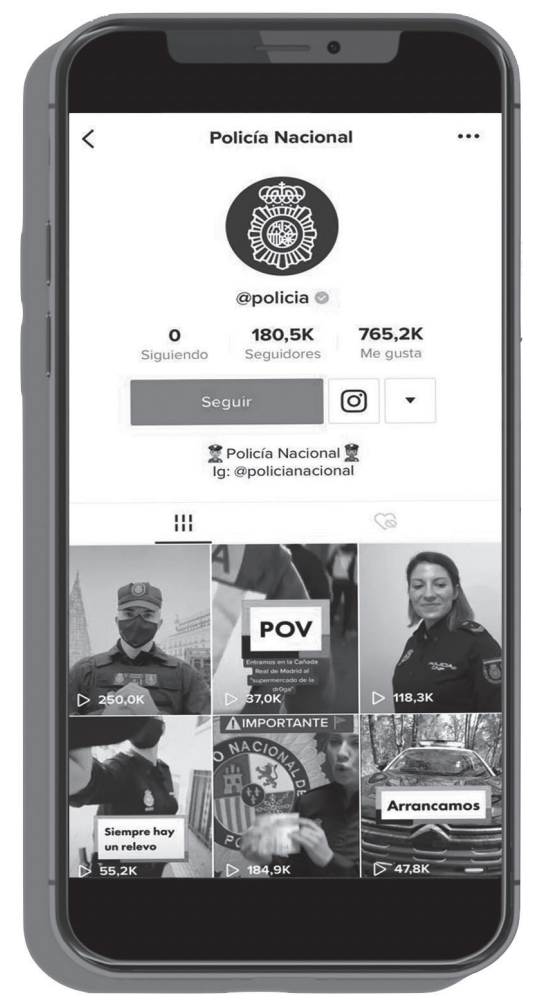

Elaboración propia. 


\section{Figura 2. Perfil de la Guardia Civil en TikTok}

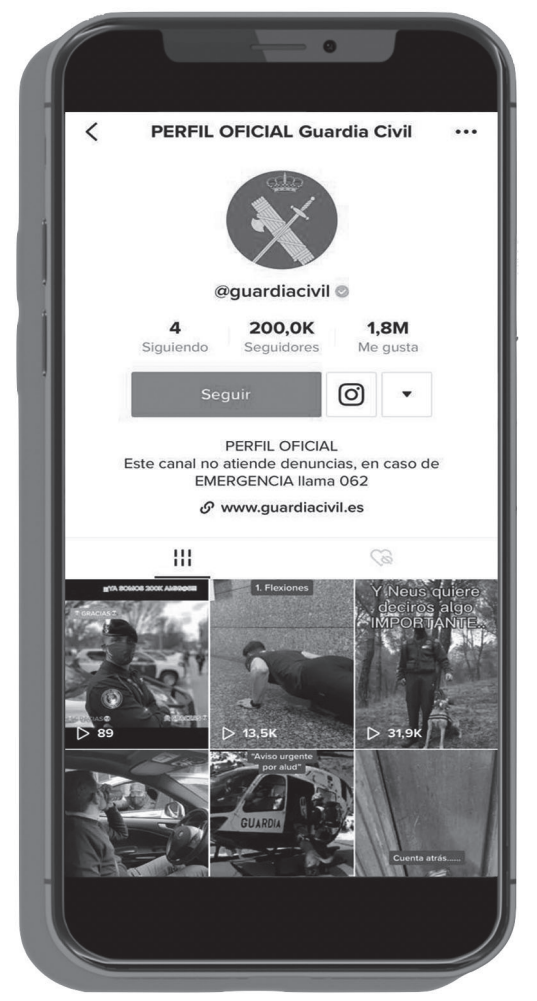

Elaboración propia.

- Análisis de contenido de los perfiles oficiales de TikTok, del Cuerpo Nacional de Policía Nacional (@policia) y de la Guardia Civil (@ guardiacivil), a nivel cuantitativo y cualitativo. El análisis se inició en la fecha de la primera publicación de ambas cuentas. A pesar de que las dos instituciones han estrenado su perfil a finales de 2020, fue la Guardia Civil quien lo hizo antes. Su primer post data del 12 de octubre de 2020, mientras que la Policía Nacional lo inauguró el 7 de noviembre del mismo año. Como fecha final de la investigación se toma el día 27 de diciembre de 2020, jornada en la que se empezó a vacunar contra el SARS-COV 2 a la población española y se esperaba que se iniciara la recuperación paulatina de la crisis socio-sanitaria. Se puede establecer que ese día se cierra un período marcado por la crisis, en la que los entes de seguridad apostaron especialmente por ajustar sus comunicaciones al tema del virus.

En total se ha examinado un corpus formado por 90 publicaciones: 64 de la Guardia Civil, en los 77 días que lleva activo, y 26 de la Policía Nacional, en 51 días. Actualmente, no existe ninguna API (Application Programming Interface) que permita medir todos los parámetros que se necesitan para el análisis, por lo que estos han sido extraídos de forma manual, a través de la aplicación en su versión móvil y en su versión de escritorio, con un doble cribado.

Se ha adaptado la ficha de análisis que utilizó Méndez-Ramón (2020) en el análisis del perfil de TikTok de la Organización Mundial de la Salud (OMS), durante la crisis de la COVID-19. Este tipo de metodología cuantitativa ha sido empleada en numerosos artículos, para analizar perfiles en las diferentes redes sociales. Calleja, Díaz y Vázquez (2017) realizaron una ficha de análisis de contenido para estudiar el uso de Twitter del Gobierno de España durante la crisis del ébola; Jaraba, Tejedor y Cervi (2020) estudiaron los contenidos, temáticas y tendencias de periodistas españoles en Twitter; y Carral y Tuñón-Navarro (2020) desarrollaron un análisis de contenido para investigar la estrategia de comunicación organizacional de la extrema derecha francesa en Twitter. Al tratarse de un trabajo de publicidad social, aquí se han adecuado algunas de las variables para el propósito de la investigación. El modelo de ficha a completar en cada uno de los vídeos ha sido el siguiente: 


\section{Tabla 1. Ficha de análisis individual de cada vídeo en los perfiles de TikTok de la Guardia Civil y la Policía Nacional}

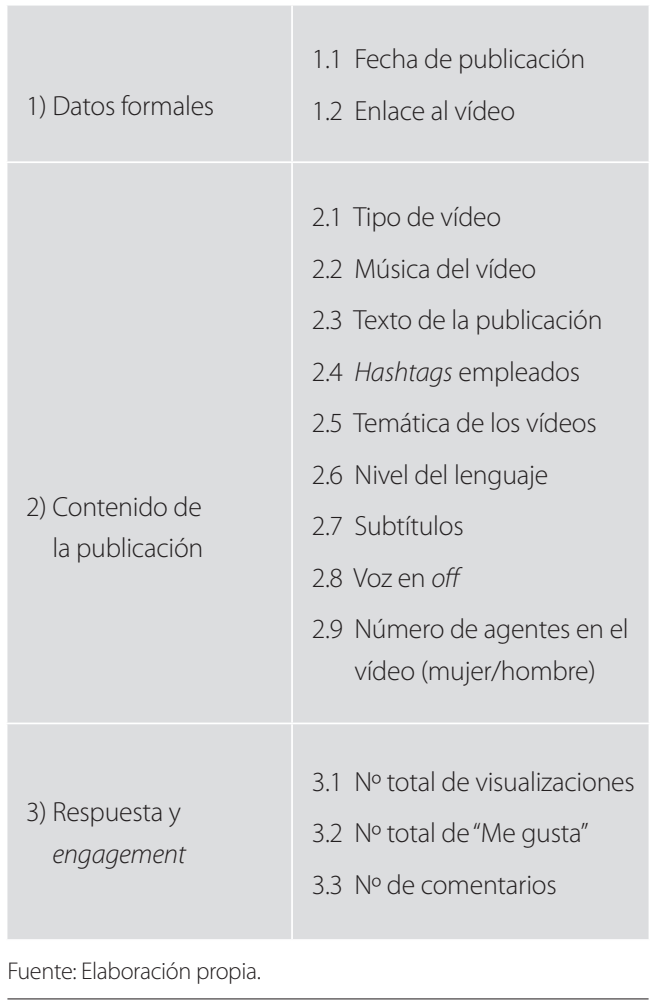

1. Datos formales: se indicará la fecha de publicación y el enlace del vídeo para su correcta comprobación.

\section{Contenido de la publicación.}

2.1 Tipo de vídeo: se definirá qué tipo de contenido tienen las píldoras audiovisuales entre las siguientes categorías:

- Infografía animada.

- Animación.

- Vídeo informativo.

- Imagen estática con música o sonido en off.

- Virales/Challenge.
- Vídeo emotivo.

- Vídeo humorístico.

- Vídeo testimonial.

Es necesario aclarar que los vídeos virales o challenges son los contenidos que se difunden amplia y rápidamente y destacan entre el resto de contenido (Al-Rawi, 2019).

2.2 Música: en esta categoría se identificará si los vídeos están acompañados de música y se señalarán los títulos de las canciones.

2.3 Texto de la publicación: se recopilarán los contenidos escritos que acompañan a las publicaciones.

2.4 Hashtags: se identificarán, si los hubiese, las etiquetas empleadas en cada publicación.

2.5 Temática de los vídeos: para la selección y recopilación de la temática de los vídeos, se han determinado las siguientes categorías:

a) COVID-19.

b) Intervención/Rescate.

c) Animales/Naturaleza.

d) Fechas especiales /Eventos.

e) Bulos/estafa.

f) Ayuda telefónica: acoso, bullying, etc.

g) Información sobre el cuerpo: oposiciones, actividades, etc.

h) Otros: consejos, recomendaciones, etc.

Las categorías se han extraído de las stories destacadas que tienen mayor número de publicaciones en los perfiles oficiales de Instagram de@policianacional y@Guardiacivil062. Estas stories han sido seleccionadas por ambas instituciones para que permanezcan permanentemente en la red social, ya que por su naturaleza efímera desaparecen a las 24 horas de publicarlas: 


\section{Figura 3. Perfil de la Policía Nacional en Instagram. Las stories destacadas se ubican encima de las publicaciones}

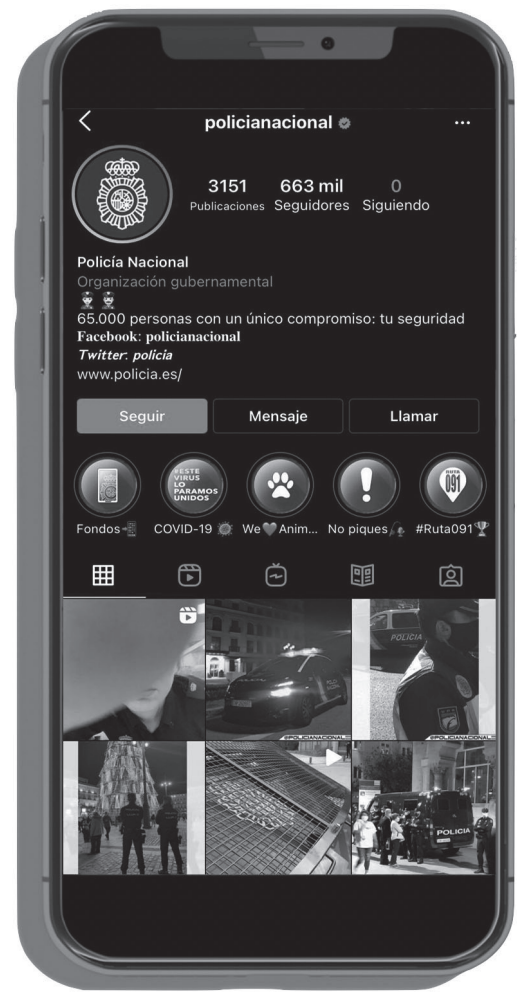

Elaboración propia.

2.6 Nivel del lenguaje: se analizará el nivel del lenguaje en los vídeos, en los pies y en los hashtags, diferenciando entre:

- Culto: para situaciones formales. Transmite contenidos claros y se valora socialmente.

- Estándar: claro y directo. Es el más empleado con desconocidos en situaciones cotidianas. Con corrección léxica y gramatical.
Figura 4. Perfil de la Guardia Civil en Instagram.

Las stories destacadas se ubican encima de las publicaciones

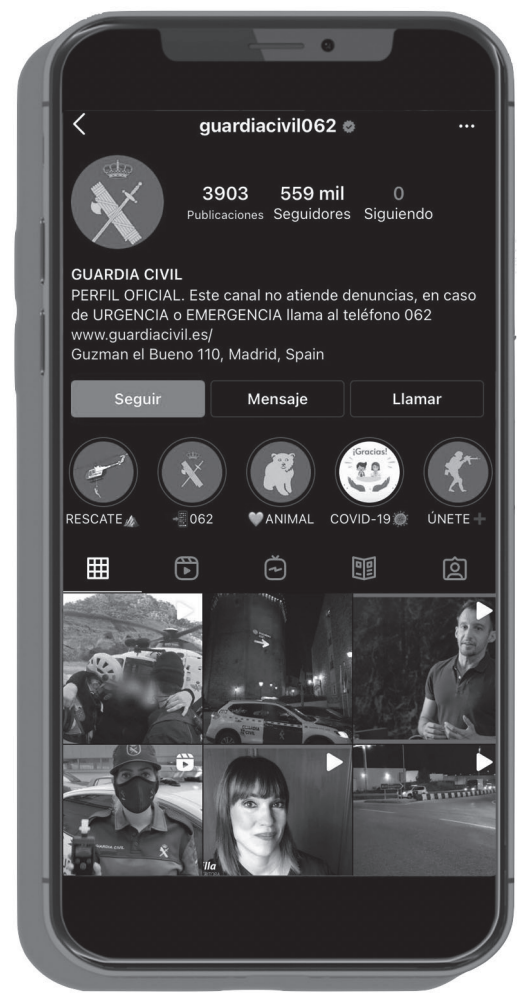

Elaboración propia.

- Coloquial: utilizado en situaciones de comunicación informal. Se basa en la interacción espontánea y sin estructuras muy marcadas.

- Jergal: los hablantes pertenecen a determinados grupos sociales o profesionales. Se trata del lenguaje específico usado por un grupo de personas que comparten unas características comunes por su categoría social, profesión, procedencia o aficiones. 
2.7 Subtítulos: se indicará si hay subtítulos o texto dentro del vídeo. En TikTok es común que se acompañen los contenidos audiovisuales con algún tipo de contenido añadido.

2.8 Voz en off: se tendrá en cuenta si hay una voz en off que acompaña al contenido audiovisual.

2.9 Número de agentes en el vídeo: se contarán los agentes que aparecen en cada vídeo y el sexo de estos.

\section{Respuesta y engagement}

3.1 Número total de visualizaciones: número total de visualizaciones que tiene cada vídeo.

3.2 Número total de «Me gusta»: número total de likes que tiene cada vídeo.

3.3 Número total de comentarios: número total de comentarios que tiene cada vídeo.

\section{Resultados}

\subsection{Policía Nacional}

El perfil de la Policía Nacional cuenta con 180.500 seguidores en TikTok. La cuenta se estrenó el 7 de noviembre de 2020, con una publicación de presentación. Desde el primer post se ha emitido un total de 26 publicaciones hasta el 27 de diciembre de 2020. En 51 días de recorrido en la plataforma, han publicado en el $50 \%$ de esos días.

Si se calculan las reproducciones de los vídeos, en total se han visionado 9.437.500 veces. Como se puede observar en la Figura 5, en los posts de los 15 primeros días se alcanzaron las mayores visualizaciones. En ellas se acumula el $84 \%$ de las reproducciones totales. Las publicaciones de los días restantes se visualizan casi siete veces menos, sumando 1.514 .000 de reproducciones. Entre las causas del mayor número de visualizaciones en los primeros posts, están la gran repercusión que generó la apertura del perfil y la novedad que generaron sus vídeos en TikTok (El País, 2020).

\section{Figura 5. Total de visualizaciones a lo largo de los 51 días de la cuenta de TikTok de la Policía Nacional}

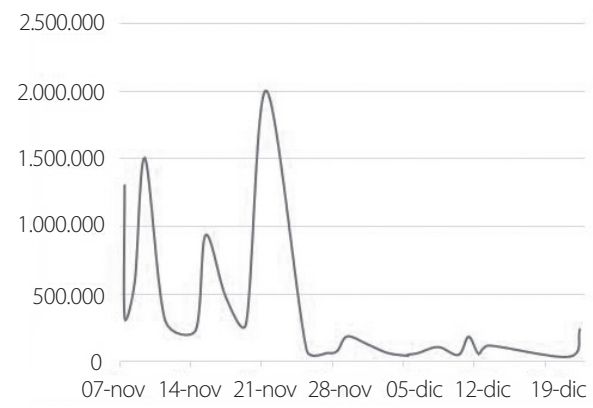

Elaboración propia.

Como se expondrá más adelante, tanto las temáticas, el uso de hashtags o la finalidad de las propias píldoras audiovisuales han seguido patrones similares. Los vídeos más reproducidos son los publicados en los días 7, 9 y 21 de noviembre. Estos posts superan el millón de visualizaciones, llegando a alcanzar los dos millones la publicación del 21 de noviembre.

El vídeo más visualizado, del 21 de noviembre, tiene de protagonistas a dos agentes corriendo mientras suena la canción «Tú me dejaste de querer» del autor español El Madrileño [antes conocido como C.Tangana] que rompió récords de reproducciones en la plataforma Spotify en el mes de noviembre (Woman.es, 2020). Como se advierte en la Figura 6, pág. 172, el lenguaje que utilizan en el pie del vídeo y en los hashtags es jergal, llegando a utilizar expresiones como «+» para indicar «más» o los hashtags \#tumedejastedequerer y \#tumedejastedequererchallenge. Por esa misma razón, la temática de este vídeo es viral o Challenge, ya que la Policía etiqueta la píldora audiovisual con un contenido reproducido por millones de usuarios de la red social (Véase figura 7 en pág. 172). 


\section{Figura 6. Vídeo más reproducido de la Policía Nacional en su perfil de TikTok, realizado el 21 de noviembre de 2020}

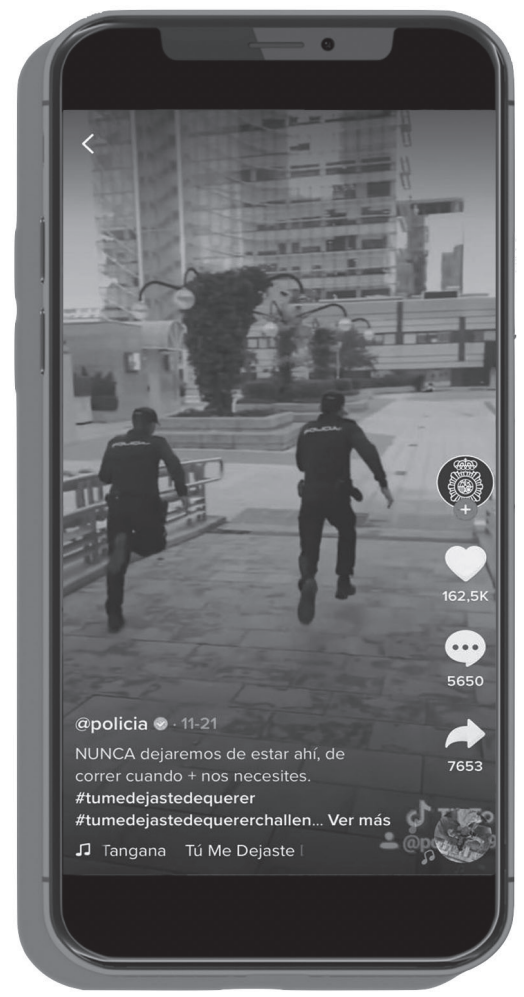

Elaboración propia

En cuanto a los comentarios y «Me gusta» recibidos por los usuarios (Figuras 8 y 9) se advierte que las curvas guardan relación directa con el número de visualizaciones. Dos de los tres vídeos más comentados y con más likes coinciden con los más reproducidos. En total, el $78 \%$ de los «Me gusta» y el $74 \%$ de los comentarios se realizaron en las publicaciones entre el 7 y 21 de noviembre. Esa repercusión inicial que tuvieron las primeras

\section{Figura 7. Visualizaciones del hashtag \#TuMeDejasteDeQuererChallenge}

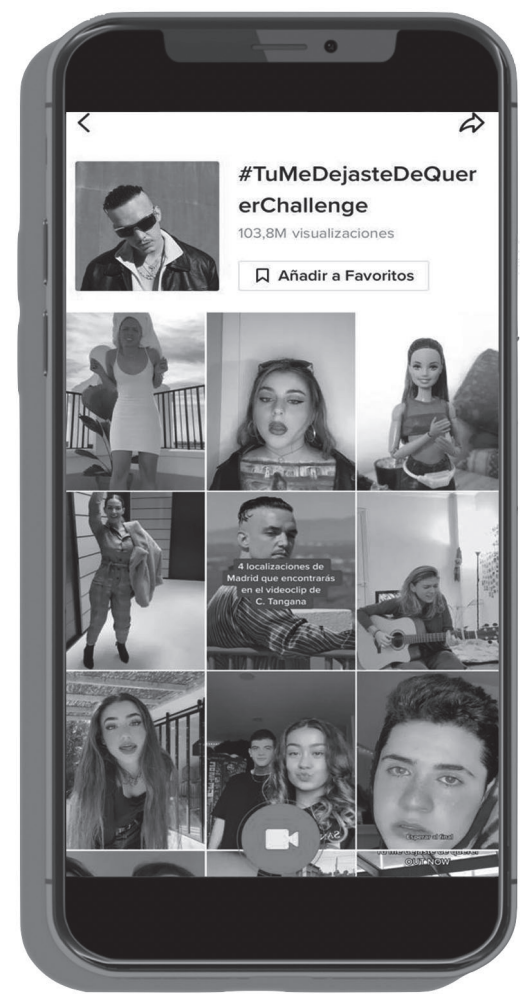

Elaboración propia.

publicaciones se distingue claramente en ambas curvas. Además, si se analiza el tramo desde el 19 de diciembre, existe un pico de comentarios y de «Me gusta». Este aumento se debe a la publicación del 22 de diciembre, en la que diferentes agentes felicitan las fiestas a los internautas.

En cuanto a la tipología de los vídeos, casi la mitad consiste en contenido viral/challenge. Este estilo más despreocupado se adapta a la Genera- 


\section{Figura 8. Total de Me gusta en los vídeos de la Policía Nacional en TikTok}

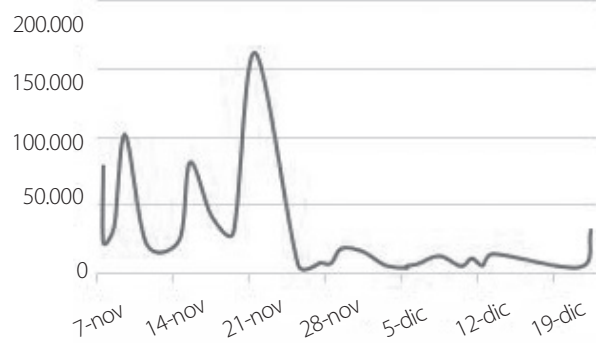

Elaboración propia.

ción Z, que ha crecido consumiendo contenido en Internet. Son jóvenes creativos e innovadores, y están sobreexpuestos a la información. Como se puede observar en la Figura 10, el porcentaje restante lo ocupan los vídeos informativos (42\%), los humorísticos (8\%), la infografía animada (4\%) y los vídeos emotivos (4\%).

\section{Figura 9. Total de comentarios en los vídeos de la Policía Nacional en TikTok}

6.000

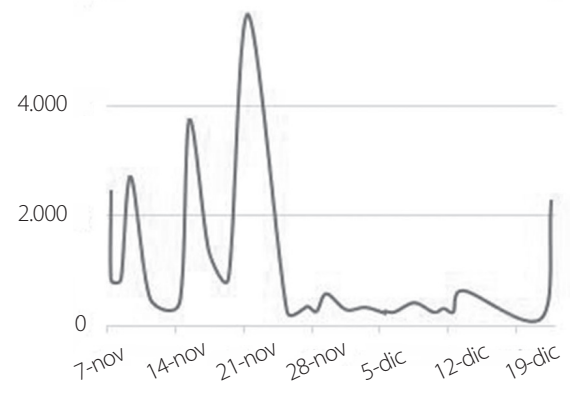

Elaboración propia.

En el apartado de hashtags utilizados, se ha cuantificado un total de 185 etiquetas en las 26 publicaciones. La media por post es de 7 hashtags. Es preciso tener presente que TikTok es una red social en la que el uso de etiquetas permite que cualquier usuario pueda ver e interactuar con el contenido. Estas etique-

\section{Figura 10. Tipología de los vídeos de la Policía Nacional en TikTok}

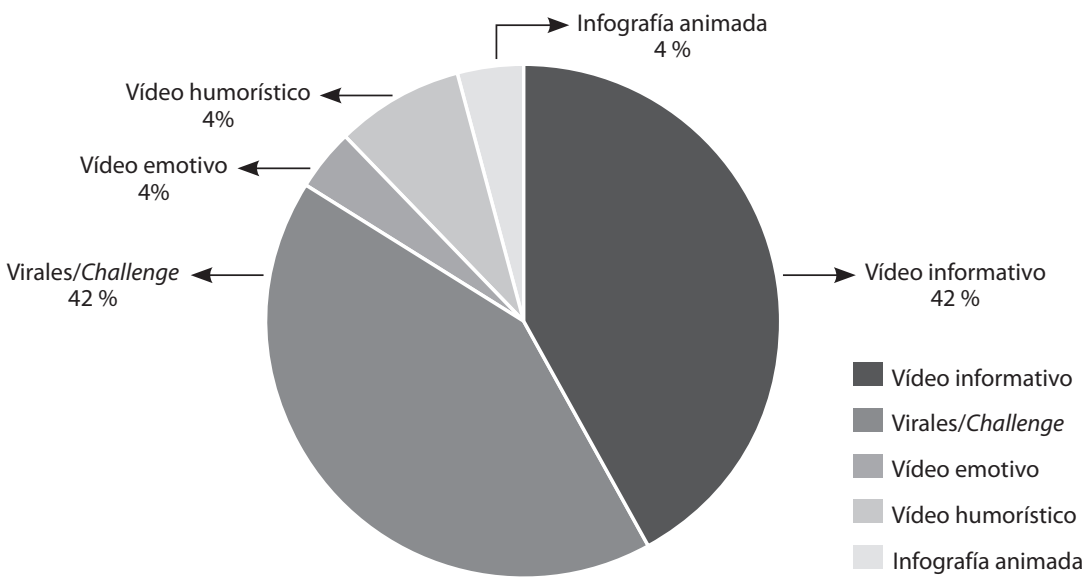


tas pueden ser en cualquier idioma, siendo las de lengua inglesa las más utilizadas. Como se puede ver en la Figura 11, los 5 hashtags más utilizados son: \#policia (24\%), \#foryou (24\%), \#policianacional (18\%), \#foryoupage (18\%) y \#viral (16\%). Las etiquetas \#foryou, \#foryoupage y \#viral, juntas, acumulan más de 12.000 millones de visualizaciones. Este uso de etiquetas virales de la red facilita el aumento de visionados.

En cuanto al tipo de lenguaje empleado, predomina el lenguaje coloquial (50\%) por delante del jergal (23\%), estándar (23 \%) y culto (4\%). En este estudio se ha tenido en cuenta el lenguaje empleado por los agentes, el texto en el pie de los vídeos y los hashtags empleados. De esta forma, a los contenidos virales se suma un tipo de expresión que resulta familiar para los usuarios de TikTok. La Policía Nacional trata de acercar su institución a los jóvenes y la adecuación del lenguaje les permite adaptarse a la cultura propia, ya existente en TikTok.
La temática de los vídeos ha sido muy variada (Figura 13), pues las cinco principales temáticas fueron: vídeos sobre intervenciones y rescates (19\%), vídeos de ayuda telefónica sobre asuntos de acoso, bullying, racismo, etc. (19\%), vídeos sobre animales y naturaleza (15\%) y vídeos sobre la COVID-19 (15\%). Se observa cómo la Policía Nacional pretende evitar que los usuarios sean víctimas de delitos, como el acoso o el bullying. Otra gran parte de los vídeos se dirige a evitar que los usuarios cometan delitos, sobre todo en temas relacionados con la COVID-19, realizando alguna estafa, consumiendo sustancias ilegales, etc.

Por otra parte, el número de total de agentes que aparecen en los vídeos es de 46. Como se detalla en la Figura 14, por sexo, un $57 \%$ de los agentes son hombres y un $43 \%$ son mujeres. Algunos de los agentes aparecen en varios vídeos y es habitual verlos en el perfil.

Por último, en cuanto a los subtítulos y a la voz en off, un 83 \% de los vídeos están acompañados

\section{Figura 11. Top 5 hashtags de los vídeos de la Policía Nacional en TikTok}

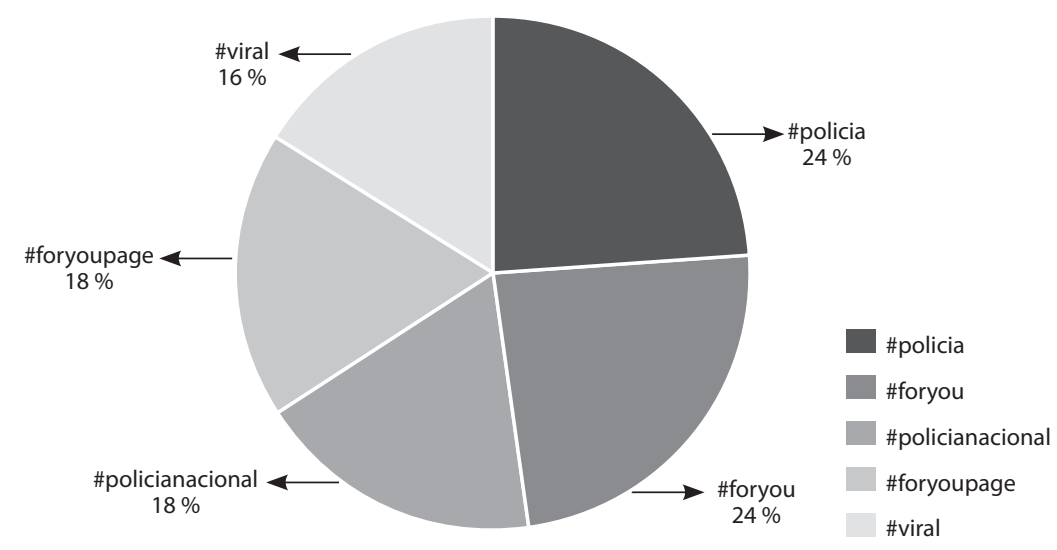

Elaboración propia. 


\section{Figura 12. Lenguaje empleado en los vídeos de la Policía Nacional en TikTok}

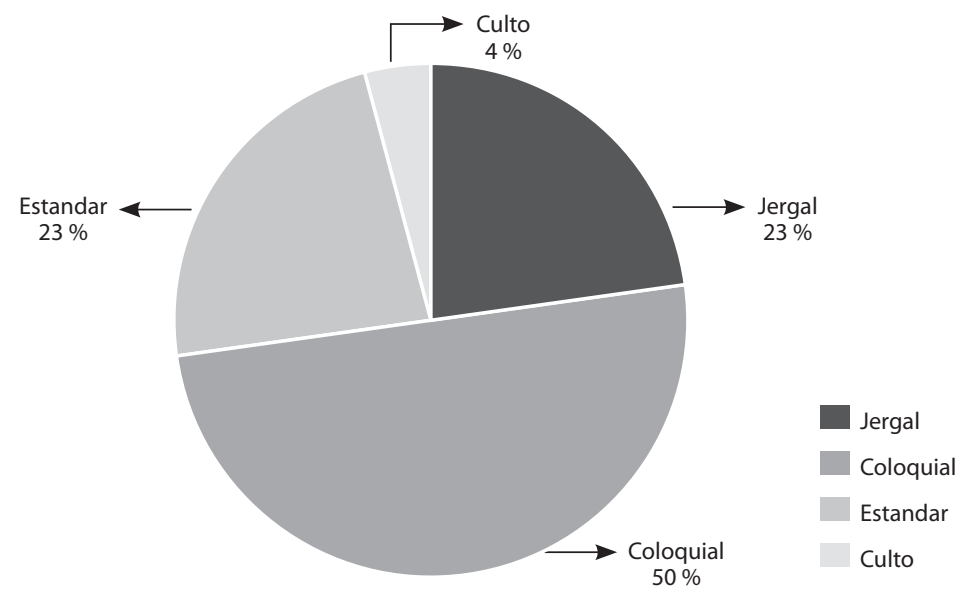

\section{Figura 13. Temática de los vídeos de la Policía Nacional en TikTok}

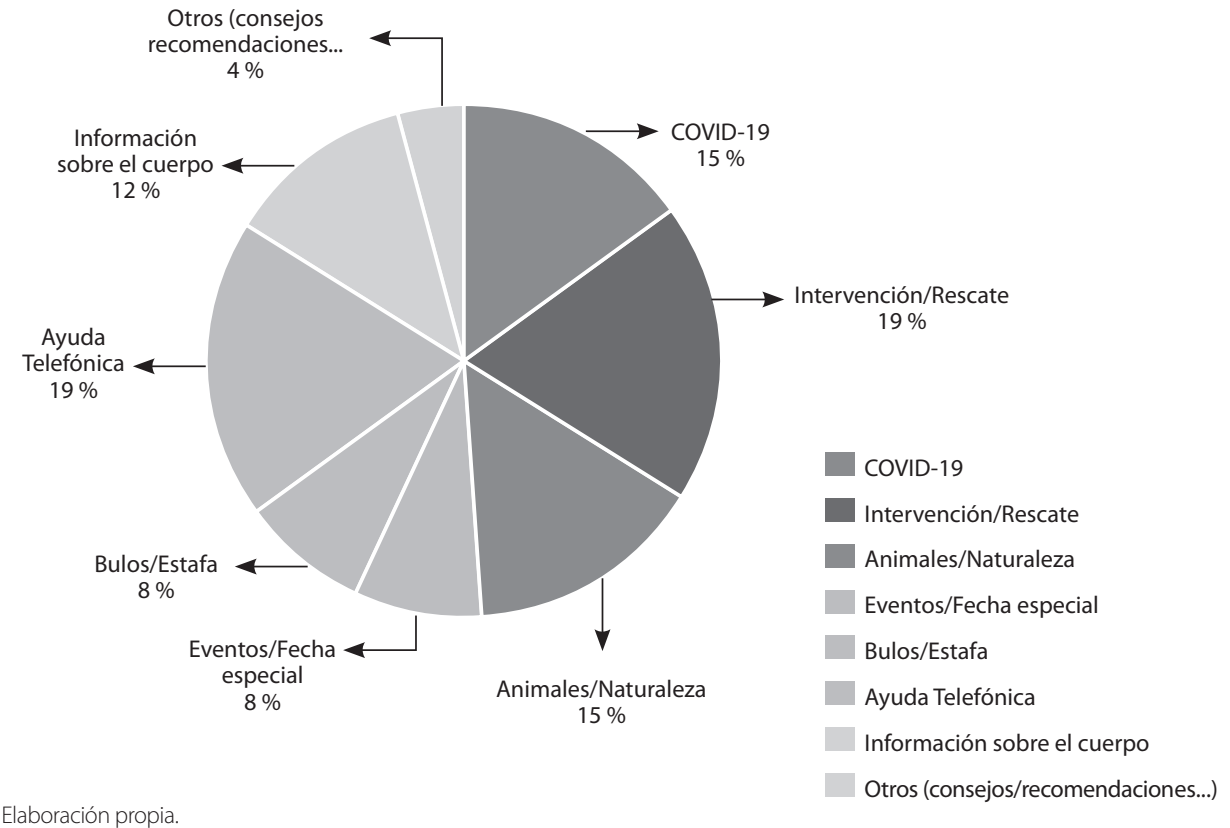




\section{Figura 14. Número de agentes que aparecen en los vídeos de la Policía Nacional en TikTok}

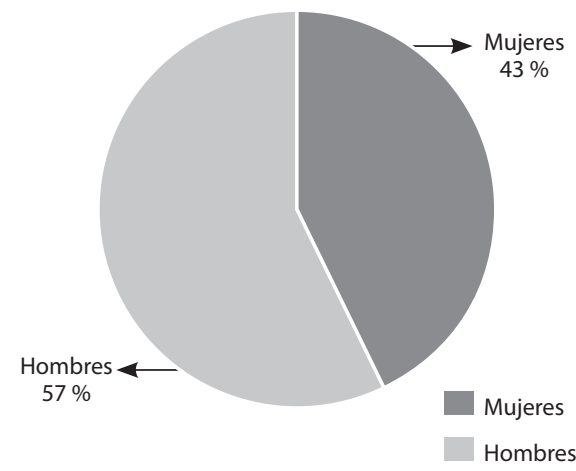

Elaboración propia.

de alguna grafía o subtítulo que acompaña al contenido audiovisual y sólo un 11 \% de ellos tiene una voz en off que acompaña las distintas escenas.

\subsection{Guardia Civil}

El perfil de la Guardia Civil cuenta con 200.000 seguidores en TikTok. La primera publicación es del día 12 de octubre de 2020. Desde el primer post se ha publicado un total de 64 publicaciones hasta el 27 de diciembre de 2020. En 108 días de recorrido en la red social, han publicado en el 59 \% de las jornadas.

Si se calculan las reproducciones de los vídeos, en total se han visionado 18.285.563 veces. Como se puede observar en la Figura 15, las visualizaciones han tenido una distribución muy desigual. No hay un grupo de publicaciones que destaque en un periodo determinado, siendo las visualizaciones muy extendidas a lo largo de los 108 días analizados. No obstante, en la curva de reproducciones se distinguen dos grandes aumentos en los días 28 de octubre y 23 de noviembre.

Las dos publicaciones más destacadas corresponden a dos tipos de vídeos virales. La primera de ellas, del 28 de octubre, superó el millón y

\section{Figura 15. Total de visualizaciones a lo largo de los 108 días de la cuenta de TikTok de la Guardia Civil}

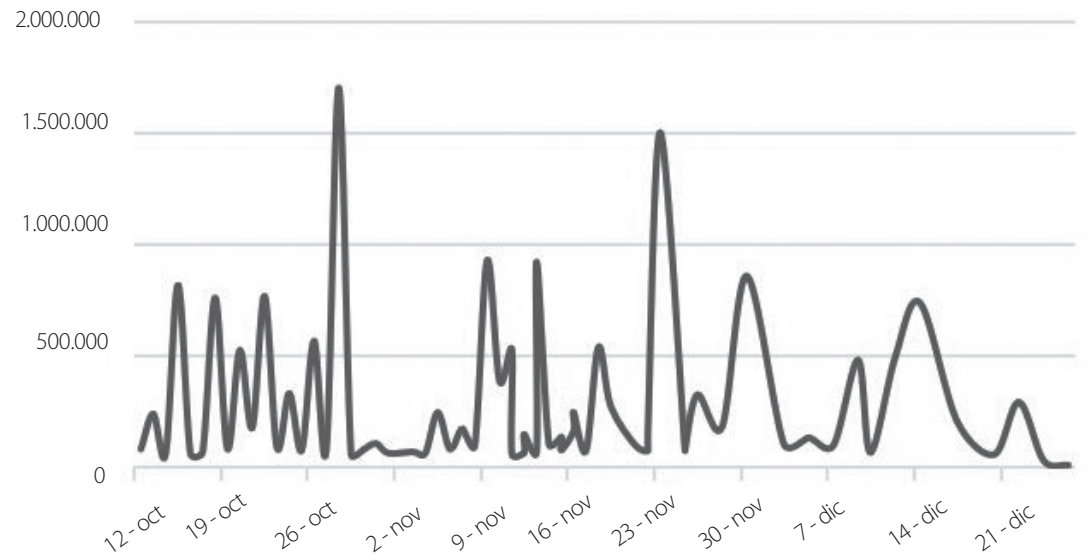


medio de visualizaciones y su temática es sobre la COVID-19. En ella aparece una agente que se coloca la mascarilla, mientras suena la canción creada por Nico Melo, «Ponete así». Con esta melodía se ha realizado casi un millón de challenges en TikTok. El vídeo de la Guardia Civil cuenta con casi 80.000 «Me gusta» y más de 1.500 comentarios. La segunda publicación destacada es del 23 de noviembre de 2020 y alcanzó el millón y medio de visualizaciones. Se trata de una escenificación de violencia machista en una re-

\section{Figura 16. Publicación de la Guardia Civil en TikTok realizada el 28 de octubre de 2020}

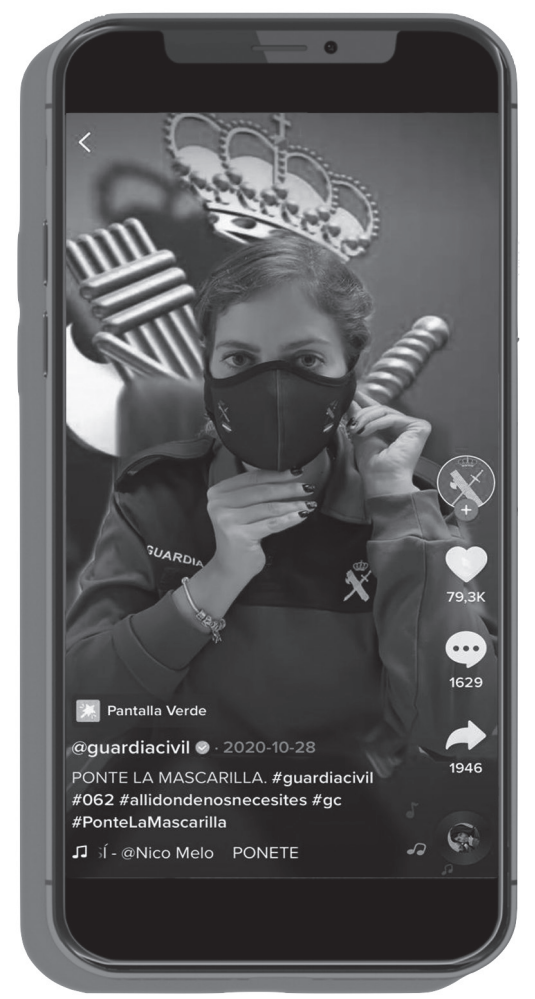

Elaboración propia. lación adolescente. En el vídeo se escucha cómo el joven amenaza con romper el teléfono móvil de su pareja, si ella no le indica la contraseña para desbloquearlo. En la última escena, se divisa cómo la Guardia Civil se lleva detenido al chico, gracias a que ella le denuncia. Durante el vídeo se escucha de fondo la canción de El Madrileño (C. Tangana), «Tú me dejaste de querer». Además, el post es acompañado de etiquetas virales de la red social, como \#tumedejastedequerer, \#parati y \#foryoupage.

\section{Figura 17. Publicación de la Guardia Civil en TikTok realizada el 23 de noviembre de 2020}

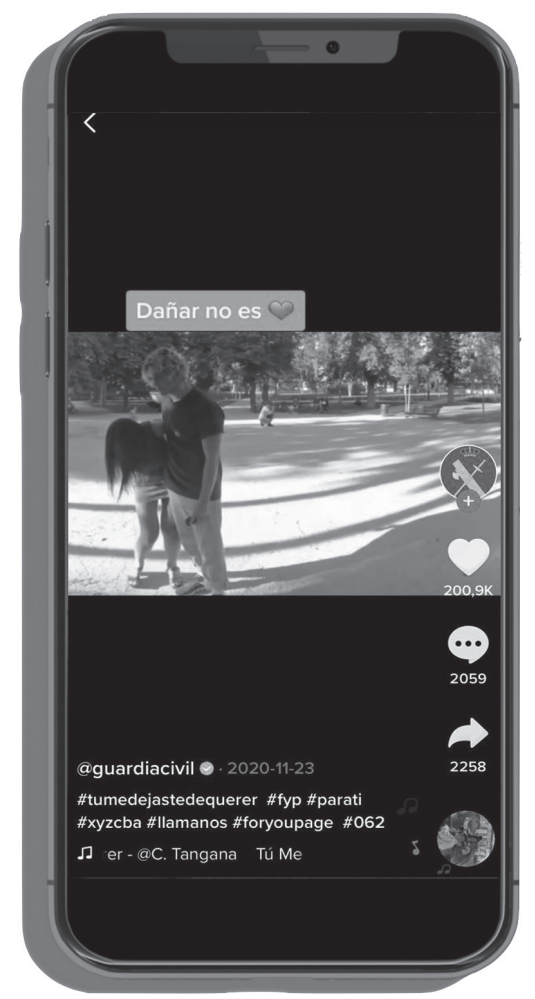

Elaboración propia. 
En cuanto a los comentarios y «Me gusta» recibidos (Figuras 18 y 19) se observan algunas diferencias entre ambas curvas. La publicación con más likes es la del día 23 de noviembre. El post que ha alcanzado más comentarios ha sido el del día 30 de noviembre. Se advierte que la publicación del día 30, pese a ser la más comentada, no es de las publicaciones con más likes. El motivo de este desequilibrio se debe a la polémica generada por el post (La Razón, 2020). En el vídeo se recogen imágenes de miembros de distintas unidades de la Guardia Civil en el País Vasco, bailando la canción «Jerusalema», una canción creada por Máster KG y Nomcebo. El tema acumula más de 275 millones de reproducciones en YouTube y más de 750 millones de visualizaciones en TikTok, con el hashtag \#jerusalema.

En cuanto a la tipología de los vídeos (Figura 20), predominan los informativos con un $45 \%$ del total. Los vídeos virales y challenges suman un 31 \% y los humorísticos, un 19 \%. Por último, las infografías animadas acumulan un $3 \%$ y las imágenes estáticas con sonido en off suponen un $2 \%$. Al igual que con la Policía Nacional, la mitad de los vídeos analizados consisten en contenido viral o humorístico.

En el apartado de hashtags, se ha cuantificado un total de 524 etiquetas en las 64 publicaciones analizadas. La media de hashtags empleados por post es de 8 . Los 5 hashtags más utilizados han sido: \#allidondenosnecesites (22\%), \#gc (21\%), \#guardiacivil (21\%), \#062 (21\%) y \#fyp (15\%). De las 5 etiquetas más empleadas, 4 de ellas se refieren a la propia institución. La primera, \#allidondenosnecesites, acumula más de 14 millones de visualizaciones y todas las publicaciones bajo este hashtag son de la Guardia Civil. Las otras tres etiquetas referidas al cuerpo suman más de 350 millones de visualizaciones. Por último, el hashtag \#fyp (7.000 billones de visualizaciones), es el diminutivo de for your page, una etiqueta muy utilizada en TikTok para la viralización de los vídeos.

\section{Figura 18. Total de «Me gusta» en los vídeos de la Guardia Civil en TikTok}

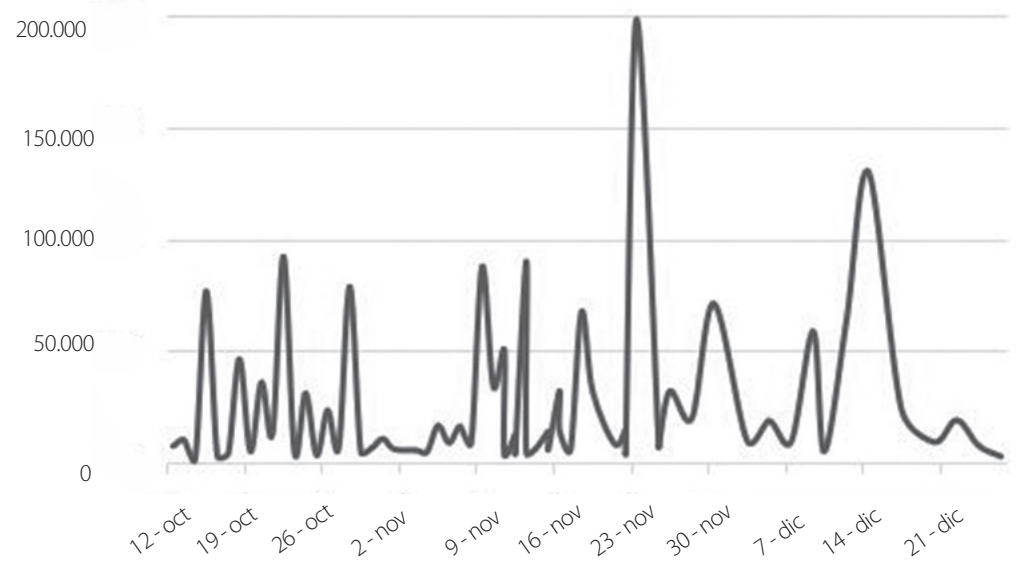




\section{Figura 19. Total de comentarios en los vídeos de la Guardia Civil en TikTok}

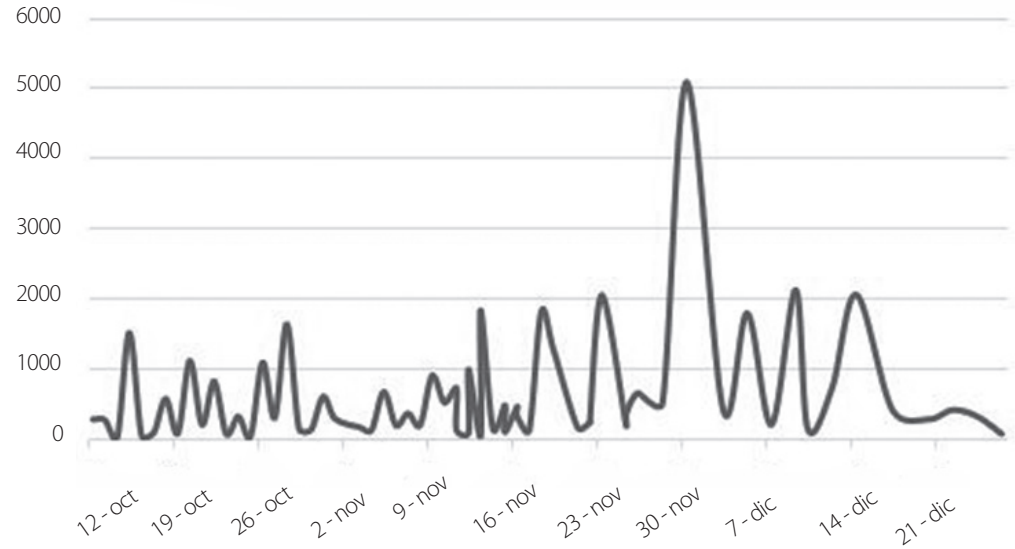

Figura 20. Tipología de los vídeos de la Guardia Civil en TikTok

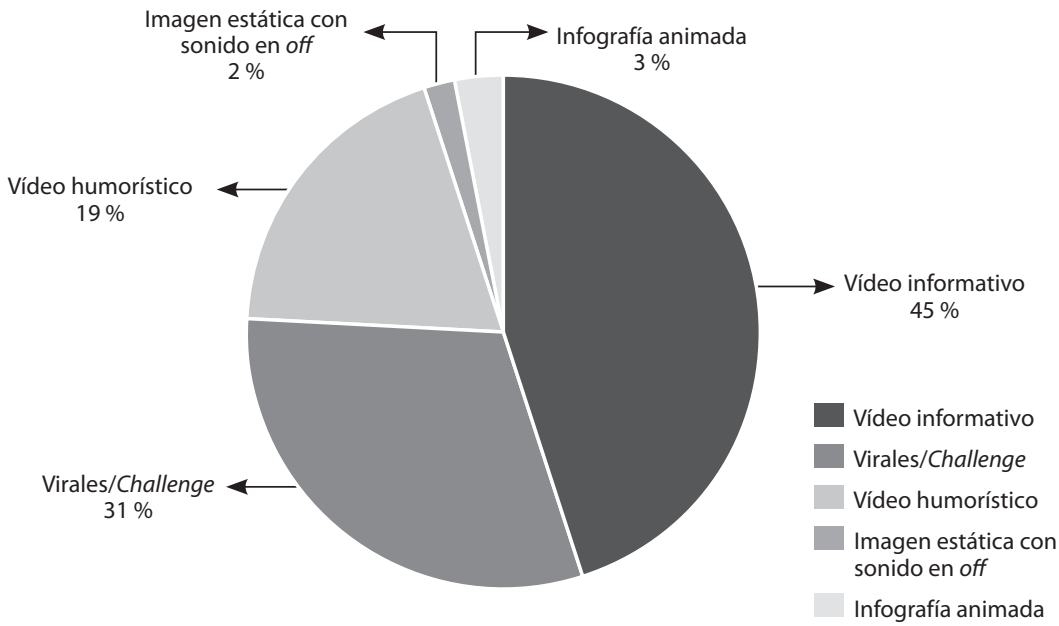




\section{Figura 21. Top 5 de hashtags de los vídeos de la Guardia Civil en TikTok}

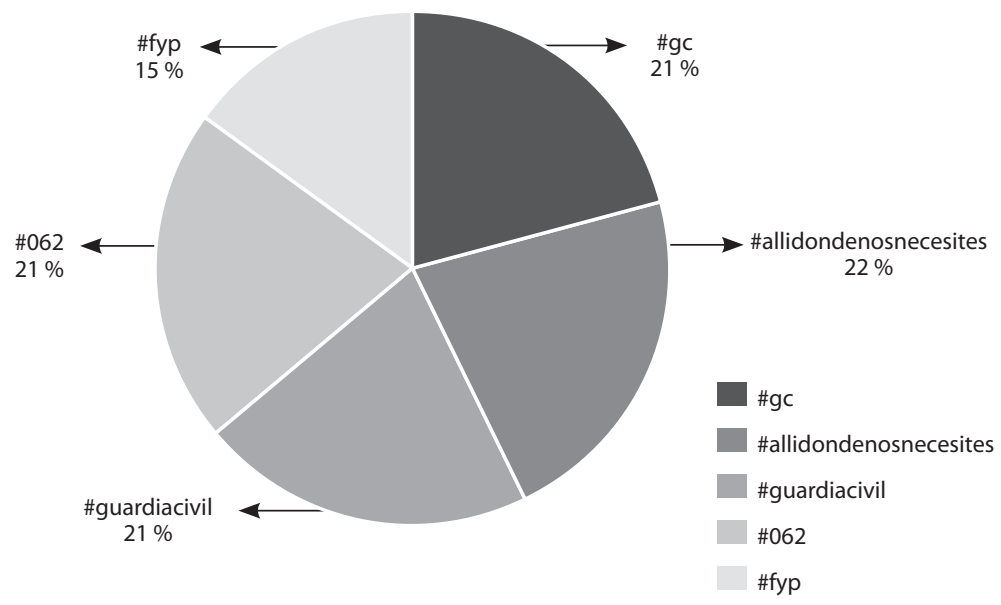

Elaboración propia.

En cuanto al tipo de lenguaje empleado, se observa que predomina el lenguaje coloquial (47\%), por delante del jergal (39 \%) y del estándar (14\%). Con esos datos se obtiene que en el perfil de la Guardia Civil predominan el lenguaje coloquial y

\section{Figura 22. Lenguaje empleado en los vídeos de la Guardia Civil en TikTok}

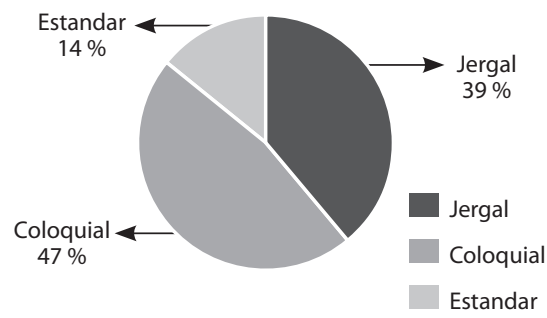

Elaboración propia la jerga, siendo un $86 \%$ del total. No obstante, un 45 \% de los vídeos son informativos y han conseguido integrar un lenguaje con el que la mayoría de los usuarios de TikTok está familiarizada.

La temática de los vídeos ha sido muy variada (Figura 23), pues las cinco principales fueron: vídeos con información sobre la institución o cuerpo de seguridad (25\%), sobre animales y naturaleza (17\%), otros tipos de vídeos como recomendaciones y consejos (14\%), de ayuda telefónica sobre asuntos de acoso, bullying, racismo, etc. (11\%), y sobre intervenciones y rescates (11\%). Se observa que 1 de cada 5 publicaciones tiene como temática informar sobre la Guardia Civil, destacan los vídeos que informan sobre oposiciones para acceder al cuerpo y los entrenamientos con simulacros. Además, una parte de los vídeos está enfocada en contenido relacionado con los animales y la naturaleza. Por ejemplo, enseñan el entrenamiento de los agen- 


\section{Figura 23. Temática de los vídeos de la Guardia Civil en TikTok}

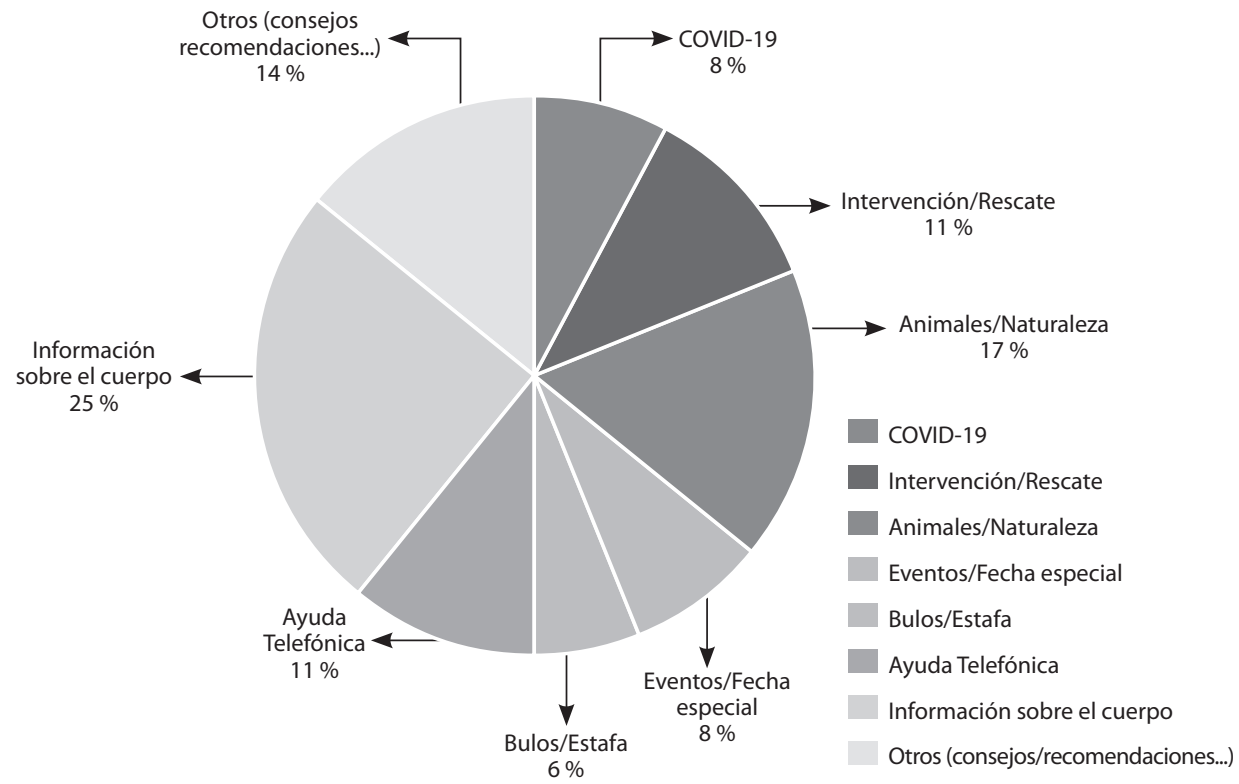

Elaboración propia.

tes caninos o explican los problemas que genera verter basura en espacios naturales.

El número total de agentes que aparece en los vídeos es 103. Por sexo, un $57 \%$ de los agentes son hombres y un $43 \%$ son mujeres. Al igual que en el perfil de la Policía Nacional, hay algunos agentes que aparecen en varios vídeos, siendo habitual verlos en el perfil. En cuanto a los subtítulos y a la voz en off, un 88 \% de los vídeos están acompañados de alguna grafía o subtítulo que acompaña al contenido audiovisual y sólo uno de ellos tiene una voz en off que acompaña a las escenas.

\section{Conclusiones}

Partiendo de la intención de los cuerpos de seguridad de acercarse a la población más joven a través del uso de píldoras audiovisuales en la red TikTok, la cantidad de seguidores que han sumado en las primeras semanas con los canales

\section{Figura 24. Número de agentes que aparecen en los vídeos de la Guardia Civil en TikTok}

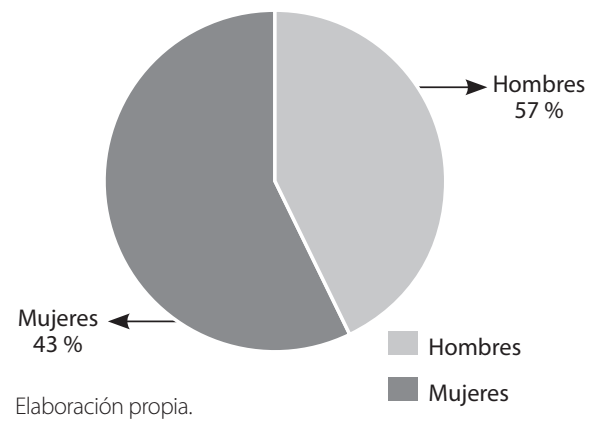


oficiales indica que hay una importante aceptación por parte de los usuarios de la red social, en su mayoría de la Generación Z, quienes están abiertos a recibir por esa vía las informaciones y contenidos de las instituciones de seguridad.

Respondiendo a nuestro objetivo principal, hemos podido completar el análisis de uso de los perfiles de TikTok por parte de la Guardia Civil y Policía Nacional en los primeros meses de su creación, determinando su capacidad de comunicación, alcance y establecimiento de estrategias específicas para esta red, por parte de ambos cuerpos de seguridad. La categorización de los contenidos nos permite conocer el tono editorial que aplican y su clara intención de captar la atención de la generación más joven, que se muestra como pilar esencial para TikTok.

Aunque la Policía Nacional y la Guardia Civil centran sus contenidos en vídeos informativos para aprovechar este canal de comunicación, es evidente que los vídeos virales/challenges son los que tienen mayor receptividad, al incluir canciones que son tendencia y que llaman a la interacción de los seguidores, sumando hasta 2 millones de visualizaciones. Los cuerpos de seguridad deben apostar por estos contenidos para mantener a su público objetivo conectado y avanzar en el engagement de TikTok.

También es importante destacar la adaptación que han tenido ambos cuerpos hacia un lenguaje mayormente coloquial y de jerga, buscando hablar en el mismo estilo que emplean los jóvenes o tiktokers. Más de un 80 \% de las publicaciones de ambos perfiles emplean textos, carteles o grafías que acompañan a los contenidos audiovisuales. Pese a que el lenguaje audiovisual es el predominante en TikTok, ambas cuentas procuran utilizar contenido de texto en sus vídeos.

En este sentido podemos referir el estudio de Sánchez-Teruel y Robles-Bello (2014) sobre la Policía Nacional y la resiliencia de los uniformados, coincidiendo en la humanización de los funcionarios a través de su participación en las publicaciones categorizadas en este estudio. Asimismo, según Olmedo-Neri (2020), las redes sociales masivas y horizontales facilitan la cercanía de las organizaciones con los ciudadanos, lo cual ha quedado demostrado en la receptividad y alcance que han tenido las cuentas de TikTok de los cuerpos de seguridad, en el poco tiempo que llevan creadas para esta plataforma.

A pesar de las polémicas internas y externas, ambos cuerpos dirigen sus temáticas en TikTok a lo que es parte de su esencia, mostrando el cumplimiento de su labor, la prevención de delitos, la alerta sobre estafas y temas específicos por períodos, tal como lo han hecho con el COVID-19. Estos temas, agrupados con el buen uso de los hashtags, pueden congregar a sus seguidores en comunidades bien definidas, lo cual es una oportunidad de mayor acercamiento. En los dos perfiles hacen un uso intensivo de los hashtags, pues de media utilizan entre 7 y 8 por publicación. Entre las etiquetas más empleadas destacan \#allidondenosnecesites de la Guardia Civil y \#policia de la Policía Nacional, con una frecuencia del $22 \%$ y $24 \%$ del total, respectivamente.

Igualmente, destaca el uso del humor en los contenidos. En la Guardia Civil llega a un 19 \% de los vídeos analizados, ya que parte de la necesidad de los jóvenes de mantenerse informados, pero a la vez entretenidos cuando utilizan las redes sociales. Es muy destacable que los uniformados que participan en los vídeos musicales con un tono más lúdico muestran una gran capacidad de adaptación a lo que buscan los ciudadanos más jóvenes. El hecho de crear contenidos originales para TikTok es un acierto y parte de una estrategia diferenciadora en la que se conoce el medio y el público al que va dirigido. 
Con respecto a las limitaciones, la propia naturaleza de la aplicación TikTok, por su tipología y reciente expansión, impide la existencia y validación de herramientas de análisis externas. Hasta ahora, para este tipo de estudios, la recopilación de los datos se ha de realizar de manera manual, lo cual limita el tiempo del análisis para poder hacerlo manejable y comprensible. A pesar de es- ta limitación que, seguramente, estará subsanada muy brevemente, es de gran pertinencia el estudio de las nuevas redes sociales que conviven con la sociedad y forman parte de nuestras vidas. Las organizaciones, en este caso la de seguridad, también deben adaptarse para que su comunicación pueda llegar a la ciudadanía por los canales más adecuados y más demandados por la sociedad de a pie.

\section{Bibliografía}

Al-Rawi, A. (2019). Viral News on Social Media. Digital Journalism, 7(1), 63-79. DOI: https://doi.org/10.1080/2167 0811.2017 .1387062

Ballesteros, R. R. (2021). El uso informativo de TikTok enfrenta a los policías y guardias: «Hacemos el ridículo». El Confidencial. Disponible en: https://bit.ly/3sGZAAx. Consultado el 21.02.2021.

Boix-Palop, A. (2016). La construcción de los límites a la libertad de expresión en las redes sociales. Revista de Estudios Politicos, 173, 55-112. DOI: http://dx.doi.org/10.18042/ cepc/rep. 173.02

Calleja-Reina, M. A., Díaz-Cerveró, E. y Vázquez-Barrio, T. (2017). Dengue en Corrientes (Argentina): Estrategia de comunicación en Twitter durante el brote de 2016. Revista Española de Comunicación en Salud, 8(2), 118-134. DOI: https://doi.org/10.20318/recs.2017.3996

Carral, U. y Tuñón-Navarro, J. (2020). Estrategia de comunicación organizacional en redes sociales: análisis electoral de la extrema derecha francesa en Twitter. El Profesional de la información, 29(6). DOI: https://doi.org/10.3145/epi.2020. nov.08

Casero-Ripollés, A. (2020). Impact of Covid-19 on the media system. Communicative and democratic consequences of news consumption during the outbreak. El profesional de la información, 29(2). DOI: https://doi.org/10.3145/epi.2020. mar.23
El Observador (2020). La policía española debutó en TikTok y generó polémica (11 noviembre). Disponible en: https:// cutt.ly/Bjgz2VI. Consultado el 21.02.2021.

Fang, J., Wang, Z. Y. \& Hao, B. (2019). Analysis of «Anesthesia» Mechanism in Mobile Short Video Applications Take «TikTok» APP as an example. Advances in Social Science Education and Humanities Research, 309, 348-351.

Gouyez Ben Allal, A. (2020). Análisis de la estrategia antiterrorista marroquí: estudio comparativo con las estrategias de España, Francia y Canadá. Observatorio Internacional de Estudios sobre Terrorismo. Disponible en: https://cutt.ly/ vjf72je. Consultado el 21.02.2021.

IAB Spain (2020). Estudio Anual de Redes Sociales 2020. Disponible en: https://iabspain.es/estudio/estudio-redes-sociales-2020/. Consultado el 21.02.2021.

Infoadex (2021). Estudio InfoAdex de la Inversión Publicitaria en España 2021. https://www.infoadex.es/home/wp-content/uploads/2021/02/NP-Estudio-InfoAdex-de-la-Inversi \%C3 \%B3n-Publicitaria-en-Espa \%C3 \%Bla-2021.pdf

Jaraba-Molina, G., Tejedor-Cobo, S. y Cervi, L. (2020). Análisis de las temáticas y tendencias de periodistas españoles en Twitter: contenidos sobre política, cultura, ciencia comunicación e Internet. Cuadernos.info, (47), 111-137. DOI: https://doi.org/10.7764/cdi.47.1773

López-García, G. (2020). Vigilar y castigar: el papel de militares, policías y guardias civiles en la comunicación de la crisis del Covid-19 en España. El profesional de la información 29(3), 1-15. DOI: https://doi.org/10.3145/epi.2020.may.11 
Méndez-Ramón, L. (2020). Publicidad social en TikTok: Análisis del perfil de la OMS durante la crisis del coronavirus. Trabajo de Fin de Grado. Universidad de Valladolid. Disponible en: http://uvadoc.uva.es/handle/10324/43770. Consultado el 21.02.2021.

Microsoft (2015). Attention spans. Consumer insights. Disponible en: https://cutt.ly/njgyzVh. Consultado el 21.02.2021.

Milkaite, I. \& Lievens, E. (2020). Child-friendly transparency of data processing in the EU: from legal requirements to platform policies. Journal of Children and Media, 14(1), 5-21, DOI: https://doi.org/10.1080/17482798.2019.1701055

Mohamad, S. M. (2020). Creative Production of 'COVID-19 Social Distancing' Narratives on Social Media. Tijdschrift Voor Economische en Sociale Geografie, 11(3), 347-359. DOI: https://doi.org/10.1111/tesg.12430

Olmedo-Neri, R. A. (2020). Implicaciones metodológicas sobre el uso del Análisis de Redes Sociales en redes sociodigitales. Quórum Académico, 17(2), 73-94. https://www.produccioncientificaluz.org/index.php/quorum/article/ view/32758/34276

Padilla-Castillo, G. (2016). Redes sociales institucionales de éxito los casos de @policia y @guardiacivil en España. Opción, 32(12), 85-109. Disponible en: https://www.redalyc. org/pdf/310/31048903005.pdf. Consultado el 21.02.2021. Padilla-Castillo, G. (2021). "TikTok como vía de promulgación de la fe católica”. En Comunicación a la vanguardia. Tendencias, métodos y perspectivas. ISBN: 978-84-7074-899-8. Madrid, España: Editorial Dykinson S.L.

Pérez-Colomé, J. (2020). Para qué sirve que la policía esté en TikTok. El País. 11 de noviembre. Disponible en: https:// bit.ly/2XeFQWX. Consultado el 21.02.2021.

Pérez-Escoda, A. y Contreras-Pulido, P. (2018). Smartphone y redes sociales para el desarrollo de competencias mediáticas y digitales en niños y adolescentes: Musical. ly. Aula Abierta, 47(3), 281-290. DOI: https://doi.org/10.17811/rifie.47.3.2018.281-290

Pons-Moreno, A. M. (2020). Experimental cathodic fanzinism from Spain. H-ermes Journal of Communication, 18, 139-162.DOI: https://doi.org/10.1285/i22840753n18p139 Rangel-Pérez, C. y Carretero-Velasco, M. J. (2017). Estudio de la evolución y tendencias de la comunicación estratégica integral. Revista Internacional de Investigación en Comunica- ción aDResearch ESIC, 16(16), 8-33. DOI: https://doi. org/10.7263/adresic-016-001

Rodríguez-Andrés, R. y López-García, J. M. (2019). Aproximación al uso de las redes sociales por las fuerzas y cuerpos de seguridad en España en perspectiva internacional. Index Comunicación, 9(1), 127-148.

Sánchez-Teruel, D. y Robles-Bello, M. A. (2014). Personalidad y resiliencia en un cuerpo especial de la Policía Nacional de España. Revista de Psicología del Trabajo y de las Organizaciones, 30(2), 75-81. DOI: https://doi.org/10.1016/j. rpto.2014.06.003

Smart Analytics (2020). Diferencias del impacto mobile del coronavirus por edad (2020). Disponible en https://bit. ly/3biNMgq. Consultado el 21.02.2021.

Subramanian, S. (2020). Bahujan girls' anti-caste activism on TikTok. Feminist Media Studies, 21(1), online. DOI: https://doi.org/10.1080/14680777.2021.1864875

TikTok del Cuerpo de Policía Nacional (2020). Disponible en: https://www.tiktok.com/@policia?lang=es. Consultado el 28.12.2020.

TikTok de la Guardia Civil (2020). Disponible en: https:// www.tiktok.com/@guardiacivil?lang=es. Consultado el 28.12.2020.

Verma, T. (2020). Cultural cringe: how caste and class affect the idea of culture in social media. Feminist Media Studies, 21(1), 159-161. DOI: https://doi.org/10.1080/14680777.2 021.1864879

We are Social \& Hootsuite (2020). Digital 2020. Disponible en: https://wearesocial.com/blog/2020/04/digital-aroundthe-world-in-april-2020. Consultado el 21.02.2021.

Web de la Policía Nacional (2020). Disponible en: https:// www.policia.es/. Consultado el 21.02.2021.

Web de la Guardia Civil (2020). Disponible en: https://www. guardiacivil.es/es/index.html Consultado el 21.02.2021.

Weimann, G. \& Masri, N. (2020). Spreading Hate on TikTok. Studies in Conflict \& Terrorism, onilne, 1-14. DOI: https://doi.org/10.1080/1057610X.2020.1780027

Woman.es (2020). Esta es la canción que está batiendo récords en España y que todas las «influencers» están eligiendo para sus stories. 11 de noviembre. Disponible en: https:// bit.ly/2XkjYcI. Consultado el 21.02.2021. 
Zhang, Z. (2020). Infrastructuralization of TikTok: transformation, power relationships, and platformization of video entertainment in China. Media, Culture \& Society, online. DOI. https://doi.org/10.1177/0163443720939452

Zhu, Ch.; Xu, X.; Zhang, W.; Chen, J. M. \& Evans, R. (2020). How Health Communication via TikTok Makes a Difference: A Content Analysis of TikTok Accounts Run by Chinese
Provincial Health Committees. International Journal of Environmental Research and Public Health, 17(1). DOI: https://doi.org/10.3390/ijerph17010192

Zuloaga, J. M. (2020). Guardias civiles califican de «espectáculo bochornoso» el vídeo protagonizado por agentes en TikTok. La Razón. 1 de diciembre. Disponible en https://bit. ly/35hFZgW. Consultado el 21.02.2021. 


\section{aDResearch ESIC}

№ 25 Vol 25 · Monográfico especial, marzo 2021 · págs. 186 a 203

(ㄷ)(1) ()$\odot$ 


\section{Miscelánea}


(ㄷ)(1) $(2)$

\section{Evaluación de la eficacia de una política de acción comunicativa a través del modelo EPAC Affinity ${ }^{\circledR}$}

Evaluating the Effectiveness of a Communication Action Polity through the EPAC Affinity ${ }^{\odot}$ Model

Dr. Jesús Varela Mallou

Director de la Unidad de Psicología del Consumidor y Usuario. Catedrático de Metodología de las Ciencias del Comportamiento https://orcid.org/0000-0002-7300-9562

Dra. Teresa Braña Tobío

Titular de Metodología de las Ciencias del Comportamiento.

https://orcid.org/0000-0002-8832-3124

Dr. Antonio Rial Boubeta'

Titular de Metodología de las Ciencias del Comportamiento

https://orcid.org/0000-0003-0129-8606

' Universidad de Santiago de Compostela

Correo de contacto: jesus.varela.mallou@usc.es
Varela Mallou, J., Braña Tobío, T. y Rial Boubeta, A. (2021)

Evaluación de la eficacia de una política de acción comunicativa a través del modelo EPAC Affinity ${ }^{\oplus}$ Revista Internacional de Investigación en Comunicación aDResearch ESIC. № 25 Vol 25

Monográfico especial, marzo 2021 · Págs. 186 a 203

https://doi.org/10.7263/adresic-025-10 
Tema principa del artículo: Eficacia publicitaria o una forma de medir los resultados de una campaña de comunicación. Generalmente, por resultados, se entiende la repercusión o impacto en un público objetivo o target. En general, por eficacia se entiende contribuir a desarrollar la identidad de marca, el posicionamiento del producto o servicio, la diferenciación en su contexto competitivo y a crear demanda. La dificultad es disponer de una medida holística que nos informe de todo ello.

Desarrollo lógico del tema: Una estrategia de comunicación o campaña no puede limitarse únicamente a buscar la superioridad en indicadores de tipo racional como son el contacto y recuerdo, con más o menos nivel de conocimiento (transmitir). Podría suceder que los actuales clientes abandonasen la marca si algún día otra compañía de tu sector dedica un mayor esfuerzo a los puntos de contacto o bien te supera en tu portfolio de productos y/o servicios. Lo recomendable es moverse en el terreno de la credibilidad y, para ello, las campañas deben de procurar la «autenticidad». Ésta se consigue cuando, además de recordarse y asociarse racionalmente con la marca o propiedad, se generen vínculos emocionales en el sentido de conectividad.

\section{Clasificación JEL: M300}

Palabras clave:

Eficacia publicitaria, autenticidad,

contactar,

transmitir,

marcar,

implicar,

generar valor
Punto de vista y aportaciones de los autores: Las Acciones de Comunicación deben de buscar algo más que mensajes racionales, estáticos y unidireccionales. Deben de procurar el diálogo con el consumidor para marcar y crear una serie de vínculos emocionales que los impliquen con lo que están viendo o sintiendo. Cuando esto se produce, diremos que «la Acción» está generando valor comportamental y de prescripción. En este caso habremos superado el valor de uso y transmitido el valor que activa la decisión de compra y adquisición, predisponiendo a experiencias de consumo positivas.

Repercusiones y conclusiones: Si alcanzamos buenos resultados en todos y cada uno de los indicadores mencionados en el modelo, entonces podremos decir que la acción planificada ha sido eficaz. En este trabajo presentamos un modelo empírico de medida de la autenticidad para conocer el nivel de eficacia de una campaña o acción de comunicación.

\section{ABSTRACT}

\section{JEL Classification:}

M300

Key words:

Advertising

effectiveness,

authenticity,

contact, transmitting, branding, engaging, generating value
Main topic subject: Advertising effectiveness or a way to measure the results of a communication campaign. Usually, results are understood as the repercussion or impact on a target audience. In other words, a campaign will be effective as long as it meets the objectives for which it was designed. The objectives are not always easy to determine and, consequently, to measure. In general, effectiveness is understood as the contribution to the development of the brand identity, the positioning of the product or service, differentiation in its competitive context and creating demand. The difficulty is to have a holistic measure that asseses all these aspects.

Logical development of the subject: A communication or campaign strategy cannot be limited to seeking superiority in indicators of a rational type such as contact and remembrance, with more or less level of knowledge (transmitting). This implies the risk that customers leave the brand if one day a competitor company surpasses said brand in the product or in the points of contact. It is advisable to move in the field of credibility and, to do so, campaigns must seek "authenticity" if they want to produce an effect or positive change in attitude and behavior towards what is said in it. The authenticity of a campaign is achieved when, in addition to being remembered and rationally associated with the brand or property, emotional ties are generated in the sense of connectivity.

Authors' point of view and contributions: Communication Actions should seek more than just rational, static, one-way messages. They must seek a dialogue with the consumer to mark and create a series of emotional links that involve them with what they are seeing or feeling. When this occurs, it can be said that "the Action" is generating behavioral and prescription value. Only by being hyperconnected to the public, listening and speaking to them, is created a space of value and differential consumption against possible competition. In this case we will have overcome the value of use and transmitted the value that activates the decision of purchase and acquisition, predisposing to positive consumption experiences.

Implication and conclusions: If all of this occurs (to a greater or lesser degree), we will be able to say that the planned action has been effective. In this study, we present an empirical model for measuring authenticity in order to determine the level of effectiveness of a communication campaign or action. 


\section{Tema principal del artículo}

El propósito de este índice integral de la eficacia de la acción comunicativa es el de ayudar a que los profesionales del Marketing y la Publicidad puedan seguir contribuyendo al crecimiento empresarial, siendo capaces de generar «acciones» que produzcan una influencia real en el consumidor o mercado.

Las distintas Acciones de Comunicación y Marca buscan impactar y tener clientes satisfechos que nos reconozcan y recuerden porque nuestra acción cumple los tangibles e intangibles de la «calidad estándar». Pero podemos ir más allá y preguntarnos si, además, esa campaña sobresale por la denominada «calidad excitante»; esto es, que el trabajo profesional de la agencia tenga también la capacidad de sorprender gratamente al público provocándoles estados emocionales que nos permitan entrar en el dominio de la «calidad experiencial». Se trata de evaluar hasta qué punto hemos sido capaces de conectar con esa nueva demanda del mercado que nos lleva a hablar de «experisumidores» o consumidores de experiencias.

Dado que las personas recuerdan lo que han sentido al relacionarse con una Marca, Campaña o Patrocinio y no tanto los «elementos objetivos» utilizados o consumidos, el índice EPAC Affinity® medirá si hemos sido capaces de generar esa experiencia memorable capaz de tener al consumidor atrapado emocionalmente, provocando una emoción de complicidad que haga que se impliquen hasta el punto de ser, además de fieles, clientes apóstoles que nos recomienden y hablen bien de nosotros.

\section{Desarrollo lógico}

Para conocer la capacidad real de lograr el efecto que se espera, después de llevar a cabo una campaña o acción de comunicación determinada y antes de su ejecución, hemos de tener en cuenta dos cuestiones previas: (1) Con una visión estratégica tenemos que reflexionar sobre el posicionamiento y la diferenciación que buscamos para la marca y después definir una propuesta de valor relevante que tenga en cuenta los ejes y atributos que logren el win to win (Picon, Varela, Rial y Braña, 2013). (2) Una vez que conocemos las expectativas y que sabemos las necesidades del consumidor o usuario que queremos satisfacer, a continuación se trata de apoyarlas con políticas de comunicación que proporcionen hechos visibles y vivibles por los consumidores. Esto es, con una visión táctica y operativa se trata de ser capaz de crear experiencias memorables y positivas en todos los touchpoints. (Shaw, C. y Hamilton, R, 2016)

Este trabajo propone una medida de la percepción e interpretación emocional de cómo se sienten los consumidores, cuando se relacionan con la marca, presencian una campaña o asisten a un evento o patrocinio. En este sentido, hablar de eficacia de una campaña o patrocinio es medir su capacidad para lograr el cumplimiento de los objetivos propuestos de tipo cognitivo y afectivo, pero también comportamentales o de la capacidad que tiene esa acción para «movilizar» a los consumidores o mercado (Sánchez, 2017; Varela, Rial, Braña y Voces, 2008).

\section{Punto de vista y aportaciones de los autores}

Hoy e día existe consenso y suficiente evidencia científica que reconoce como principales objetivos de una Campaña o Patrocinio, los siguientes:

a) Generar PUNTOS DE CONTACTO entre la Marca y el Consumidor gracias a una buena planificación de medios, asistencia en directo a los eventos (on-site) o mediante cualquier otra acción de marketing. 
b. Estos puntos de contacto conectan con los consumidores y refuerzan el CONOCIMIENTO de la campaña en términos de recuerdo y notoriedad, asociaciones con la marca o con el territorio objeto de patrocinio, búsqueda de información, etc.

c. El conocimiento genera ACTITUDES que ayudan a cambiar la percepción que el consumidor tiene de la marca, patrocinio o campaña.

d. Movilizar e influir en las DECISIONES Y COMPORTAMIENTOS del target es el fin último de una campaña.

Apoyándonos en la numerosa investigación empírica publicada por el grupo de investigación en Psicología del Consumidor y Usuario de la Universidad de Santiago (ver apartado de referencias bibliográficas); así como en la participación en numerosos proyectos de transferencia con empresas privadas y administración (véase www. usc.gal/psicom), en este trabajo defendemos la necesidad de disponer de un índice global capaz de evaluar la relación entre estos cuatro elementos clave de la eficacia publicitaria.

En este contexto, el índice EPAC Affinity ${ }^{\circledR}$ debe ser entendido como una medida sinóptica del grado de autenticidad o consecución del nivel de cumplimiento de los aspectos claves en la comunicación: los Cognitivos (puntos de contacto y conocimiento), Afectivos (cambio de actitudes e implicación) y Comportamentales (decisión y prescripción). Más concretamente, nuestra propuesta o modelo de medida integral de la autenticidad de una campaña consiste en estructurar todos estos parámetros en 5 elementos o criterios que se corresponden con cada uno de los 5 lados de un polígono regular. EPAC Affinity® mide el promedio de los logros de una acción de comunicación en las cinco dimensiones básicas de la eficacia o autenticidad.

\section{Figura 1. Modelo de medida integral de la eficacia de una campaña. EPAC affiinity ${ }^{\circledR}$}

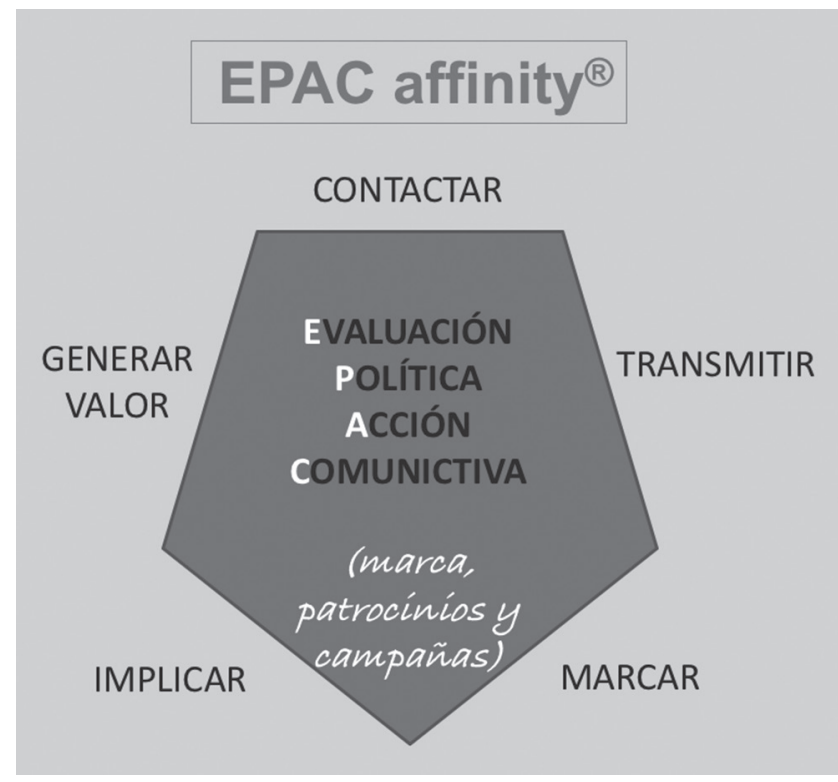


1. CONTACTAR. O generar puntos de contacto entre la Acción y el consumidor a través de la presencia en los medios (incluidos los on-line), la asistencia en directo a los eventos (on-site) o cualquier otra acción de apoyo que refuercen una campaña. Para que estos puntos de contacto sean efectivos deben ser conocidos, recordados, ser capaz de valorar ciertos elementos racionales y, en definitiva, captar la atención del consumidor y establecer una mínima asociación entre esa acción de comunicación y la categoría donde opera la marca o el territorio objeto del patrocinio.

2. TRANSMITIR. Se trata de analizar si el mercado, además de recordar, está comprendiendo lo que queremos transmitirle. Por ello, es necesario hablar de calidad del recuerdo, que proponemos medirla de dos maneras. En primer lugar, el recuerdo del contenido más racional de la marca o acción (la comprensión de sus personajes, eslogan, música, ambiente, etc.). Y, en segundo lugar, desde la perspectiva de interacción con el consumidor, es necesario conocer y medir los posibles valores transmitidos en términos de percepción e imagen de la campaña para saber como estamos contribuyendo al desarrollo y personalidad de la Marca, porque podemos no estar transmitiendo nada o transmitir valores no deseados. Otra cosa distinta es saber si los valores que estamos transmitiendo son coherentes con la identidad de marca y si refuerzan la personalidad buscada. Es muy importante saber si la marca está capitalizando los mensajes de la acción o campaña, pero ello se analiza en el tercer elemento (Marcar). ¿Hasta qué punto se produce o no integración de marca?

3. MARCAR. Mide el nivel de adecuación o ajuste conceptual para que no provoque di- sonancia cognitiva y permita a los consumidores identificarse con esa marca o acción. La percepción de encaje entre la acción y la marca hace más fácil la vinculación y, por tanto, más probable que le guste lo que le estamos proponiendo. Adicionalmente también estudiaremos el componente experiencial de la acción preguntando por el nivel de cumplimiento de sus expectativas mediante la identificación de los inductores de emociones positivas (GAINS) y los de insatisfacción (PAINS), con el fin de saber si estamos conectando y generando asociaciones estratégicas sorprendentes. Buscando experiencias memorables de los consumidores.

4. IMPLICAR. Se trata de medir si la acción está siendo relevante para motivar, si contribuyó a que se establezca un vínculo fuerte y duradero con el consumidor que sea capaz de provocar un cambio de actitud. El encaje o ajuste conceptual (adecuación y coherencia), así como la empatía y satisfacción de las expectativas sin duda contribuyen a que la comunicación consiga despertar interés y establecer un vínculo o compromiso Marca-Consumidor. Y lo sabremos si medimos el nivel de implicación o involvement; esto es, los beneficios simbólicos percibidos, funcionales, de seguridad e informativos. Conseguir un nivel de implicación elevado con la acción de comunicación, será la base para que el mensaje que transmitimos consiga generar o cambiar la actitud hacia la marca haciendo que su percepción y posicionamiento evolucionen en el sentido deseado.

5. GENERAR VALOR en el target. Una campaña, al igual que un patrocinio, debe de contribuir al crecimiento del valor y diferenciación de la marca; esto es, ser capaz de movilizar al consumidor tratando de influir en su com- 
portamiento o decisión de compra, fidelizarlo y conseguir que nos recomiende o prescriba. También contribuir a la potencial extensión de su portfolio de marca entre sus segmentos deseados son algunos de los objetivos que nos permiten saber si estamos generando valor.

En definitiva, estos 5 lados del polígono regular nos van a permitir llevar a cabo una evaluación y seguimiento integral del nivel de AUTENTICIDAD de nuestras acciones de comunicación y patrocinios. Si las herramientas de Marketing tratan de «influir en target», entonces para conocer la autenticidad percibida de una campaña preguntaremos a las PERSONAS si las estamos aburriendo transmitiendo la idea de una marca «cansina» o, por el contario, lo estamos haciendo bien ofreciéndole cosas que le gustan y que le llevan a que se interesen por ti ocupando lugares de privilegio en sus mentes (top of mind) cuando necesitan algo de tu ámbito o territorio.
En este contexto, EPAC affinity ${ }^{\circledR}$ puede ser interpretado como la media geométrica de los 5 elementos anteriores, cuyos índices se calculan por separado con los datos referidos a un conjunto de indicadores parciales que configuran dichos elementos. El resultado final arroja siempre un valor entre 0 y 1 que determina la autenticidad de la acción (eficacia). Los cuatro grados de autenticidad de los que nos informa el índice EPAC affinitiy ${ }^{\circledR}$ los detallamos a continuación:

Muy alto: Campañas con un índice EPAC superior a 0.80

Alto: Campañas con un índice EPAC entre 0.70 y 0.80

Medio: Campañas con un índice EPAC entre 0.55 y 0.70

Bajo: Campañas con un índice EPAC inferior a 0.55

\section{Figura 2. Las dimensiones básicas de la eficacia o autenticidad de una campaña o acción de MKT}

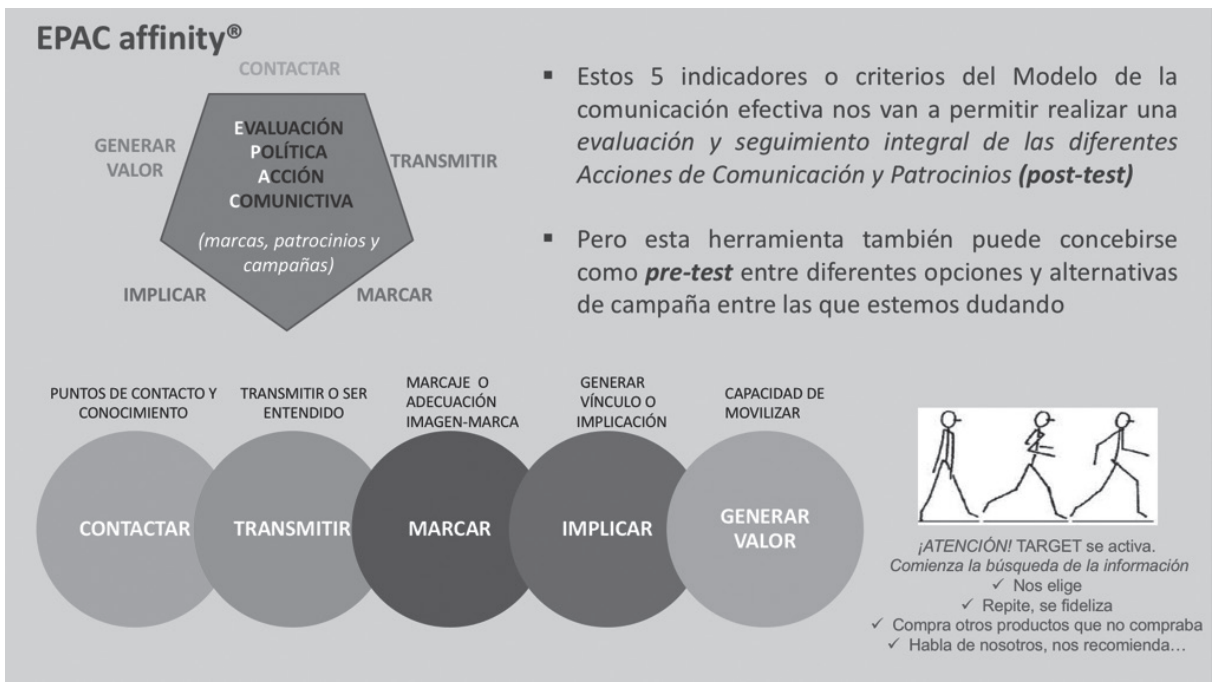


Además de esta información global y cuantitativa, los análisis pueden completarse con información parcial de naturaleza cuantitativa y cualitativa, para todos y cada uno de los elementos, por separado.

Porque sólo aquello que se es capaz de trasladar a target (mensaje y resto de objetivos) se denomina Publicidad, Patrocinio, Mecenazgo, ... Packaging, Merchandising, ... y sólo su evaluación y medida nos permitirá saber si lo conseguimos.

\section{Metodología «PDCA» para la implantación del EPAC affinity ${ }^{\circledR}$}

\section{Fase 1: Deseos y Planes (PLAN)}

- Implica una reflexión a nivel interno sobre qué sabemos de nuestra Marca, cómo es su identidad y cuáles son los rasgos diferenciales. Qué marca queremos, cuáles son los objetivos que se persiguen con la campaña y/o patrocinio, qué valores queremos transmitir al target al que va dirigido, el posicionamiento donde se desea proyectar la marca, etc.

- Para ello puede recurrirse a la realización de dinámicas de grupo y/o entrevistas en profundidad con la propiedad y/o agencia de comunicación. Es importante conocer los hábitos de consumo/uso (frecuencia, motivos, momentos y lugares ....), tipología de consumidores (estilos de vida, características psicográficas, ...), ¿cuáles serán los puntos de contacto entre la marca y el consumidor?, ¿durante cuanto tiempo?, ¿en qué medios: vallas, prensa, tv, radio, redes sociales?. Posible guía de tópicos para estas sesiones: Mi marca tiene algo que no tienen las demás..., Me gustaría parecerme a... pero nunca a..., Nuestros principales valores son..., Nos eligen por..., Nuestro cliente de hoy es..., Nuestro cliente de mañana podría ser..., Lo que el cliente realmente quiere es..., En el mercado falta....

- Por ejemplo, si se pretende desarrollar una identidad de Marca focalizada en los sueños sociales se recomienda reflexionar acerca de los siguientes aspectos que serán cruciales a la hora de diseñar cualquier tipo de acción y, por supuesto, a la hora de su evaluación, (figuras 4 y 5).

\section{Fase 2: Ejecución de Campaña (DO)}

- Esta fase consiste en una revisión o descripción técnica del despliegue realizado para el anuncio o patrocinio concreto. Familiarizarse con los materiales diseñados.

\section{Figura 3. Fases a tener en cuenta para medir la eficacia de una campaña o acción de MKT}
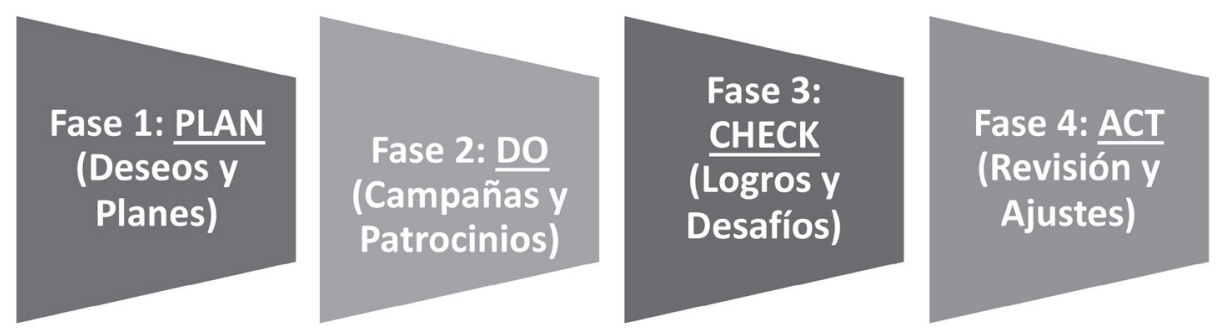
Figura 4. Momentos importantes en la creación y desarrollo de identidad de la marca

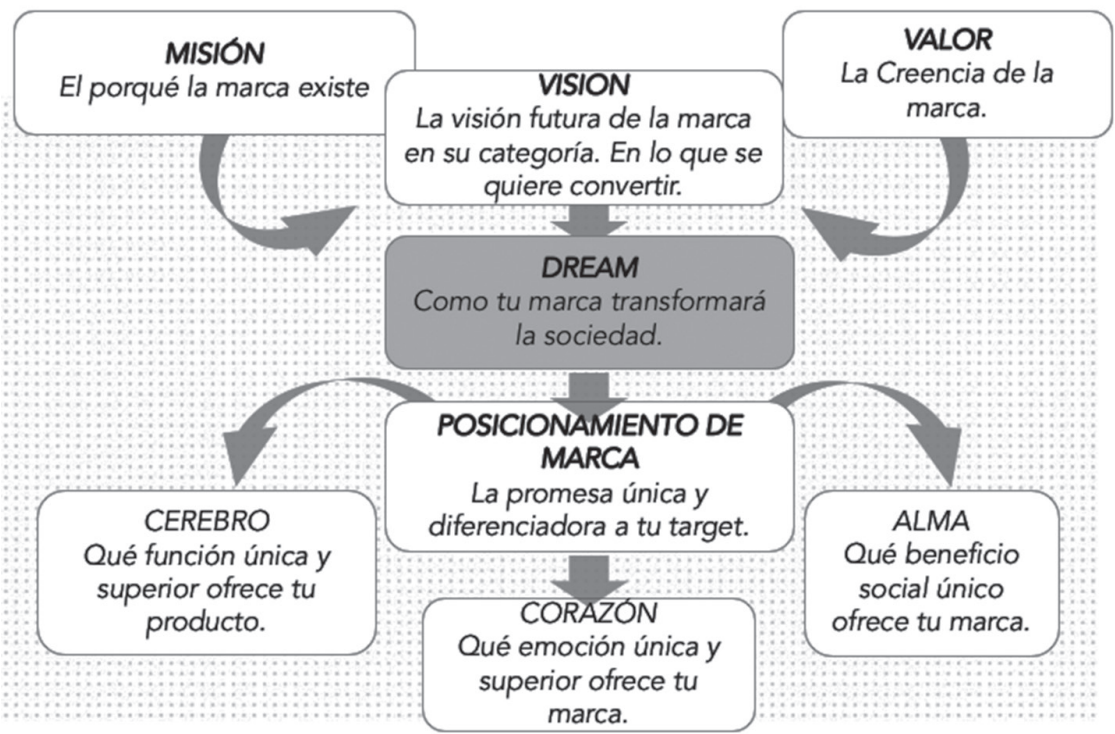

Figura 5. Ejemplo de análisis de la marca

\section{Dove}

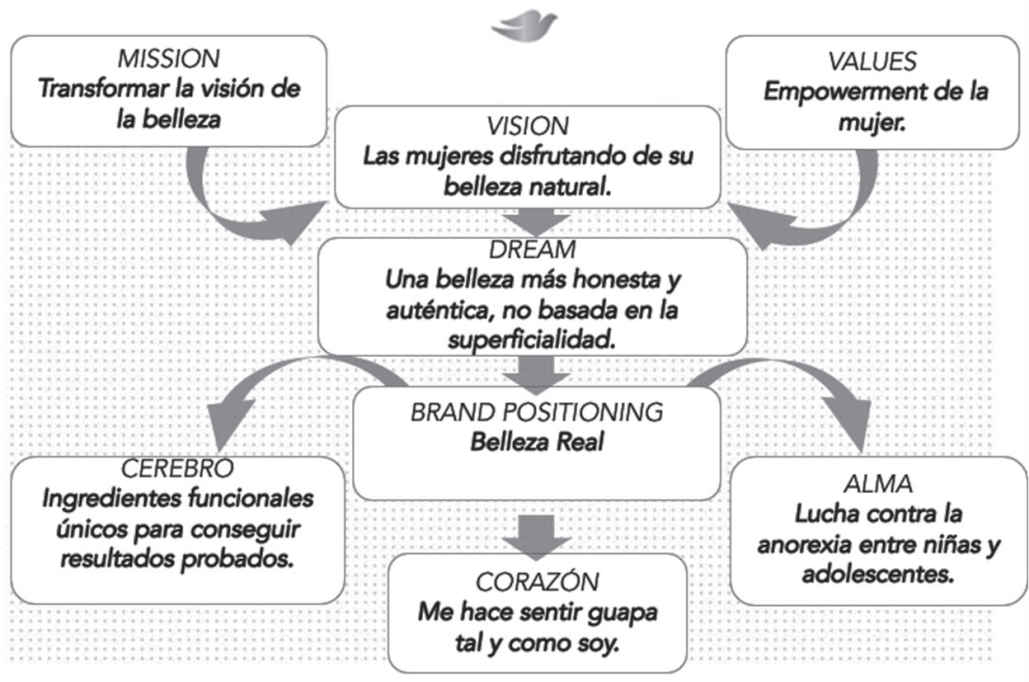


Fase 3: Logros y Desafíos. Evaluación (CHECK)

- Esta Fase es una investigación de mercado en la que se analizan y evalúan los 5 lados del polígono regular del EPAC affinity® (contactar, transmitir, marcar, implicar y generar valor). De esta forma estaremos evaluando el grado de autenticidad de la acción y dispondremos de una línea base para futuras evaluaciones, o para su comparación con un grupo control. Para ello, EPAC affinity® recurre a dos estrategias de recogida de datos diferentes: (1) Cualitativo en el que se analiza el contenido de las respuestas espontáneas a preguntas abiertas, nominales y de preferencia y (2) Cuantitativo en el que se analiza las respuestas a variables de escala, atributos y factores. Con esta información se obtiene el cuadro de mando integral de la autenticidad con todos lo índices y subíndices que conforman la medida global de la eficacia de la campaña o acción de que se trate. Ver figuras 6 y 7.

\section{Fase 4: Revisión y Ajustes (ACT)}

- Esta fase es la del análisis e integración de toda la información disponible (Cuadro de Mando Integral y cheklist de objetivos) con el fin de ir definiendo cómo trabajar la reacción del consumidor y, en general, aprender de los aciertos y errores que ha puesto de manifiesto la evaluación. El objetivo último de esta fase es proporcionar al responsable de la acción de los insights sobre qué hacer y cómo mejorar su eficacia

\section{Repercusión y conclusiones}

El inconveniente de muchas Acciones de Comunicación y Marketing es de credibilidad. Por eso las Campañas deben procurar la autenticidad si quieren producir un efecto o cambio positivo en la actitud y comportamiento hacia lo que en ella se diga. Es por eso que entendemos el trabajo de una Agencia de Publicidad y/o Marketing como la tarea de proponer una estrategia o acción que permita a la marca o propiedad construir un insight de autenticidad (slogan o claim) que se asocie como atributo a esa marca y la dote de capacidad competitiva e, incluso, como un driver de decisión de consumo.

La autenticidad de una campaña se consigue cuando, además de ser recordada y asociarse racionalmente con la marca o propiedad, se generan vínculos emocionales en el sentido de «conectividad». Cuando una estrategia de comunicación o patrocinio se limita a buscar la superioridad en indicadores de tipo racional como el contacto y recuerdo, con más o menos nivel de conocimiento (transmitir), se arriesga a que los consumidores la abandonen si algún día otra compañía la supera en el producto o en los puntos de contacto. Por lo tanto, las «Acciones de Comunicación» deben de buscar algo más que mensajes racionales, estáticos y unidireccionales; deben de procurar el diálogo con el consumidor para marcar y crear una serie de vínculos emocionales que los impliquen con lo que están viendo o sintiendo. Conseguido esto, diremos que «la Acción» está generando valor comportamental y de prescripción.

Solamente si estamos hiperconectados al consumidor, si lo escuchamos y conversamos con él, estamos construyendo un espacio de valor y consumo diferencial capaz de superar el valor de uso y transmitir el valor que activa la decisión de compra y adquisición, predisponiendo a experiencias de consumo positivas, etc.

Es frecuente encontrarse con estudios de eficacia publicitaria que proporcionan a los responsables de la marca gran cantidad de información con tablas y gráficas sin integrar, que no siempre contribuyen a facilitar la toma de decisiones. 
Nuestra propuesta consiste en retener toda esta información en 5 indicadores, uno por cada uno de los elementos de EPAC affinity®: (1) puntos de contacto y conocimiento, (2) transmitir o ser entendido, (3) marcaje o adecuación con la imagen de marca, (4) generar implicación mediante la experiencia de cliente y (5) generación de valor comportamental y de prescripción.

\section{Figura 6. Indicadores de EPAC Affinity}
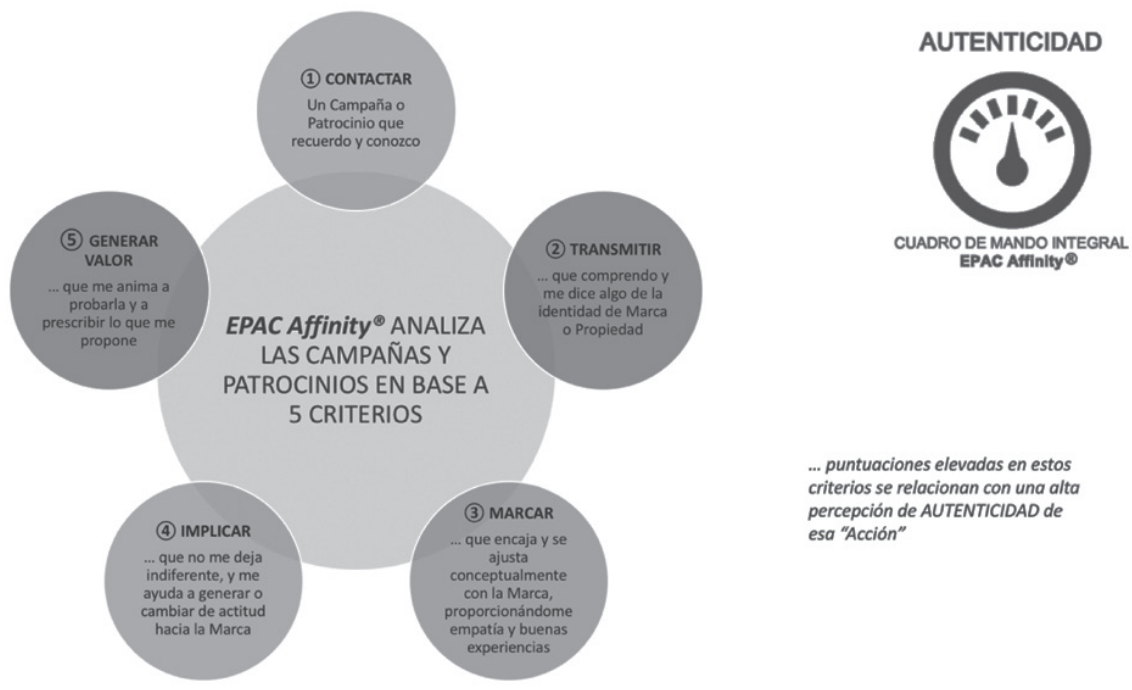

... puntuaciones elevadas en estos criterios se relacionan con una alto percepción de AUTENTICIDAD de esa "Acción"

\section{Figura 7. Ejemplo de cuadro de mando integral de la Autenticidad mediante EPAC Affinity}

Perfil de AUTENTICIDAD

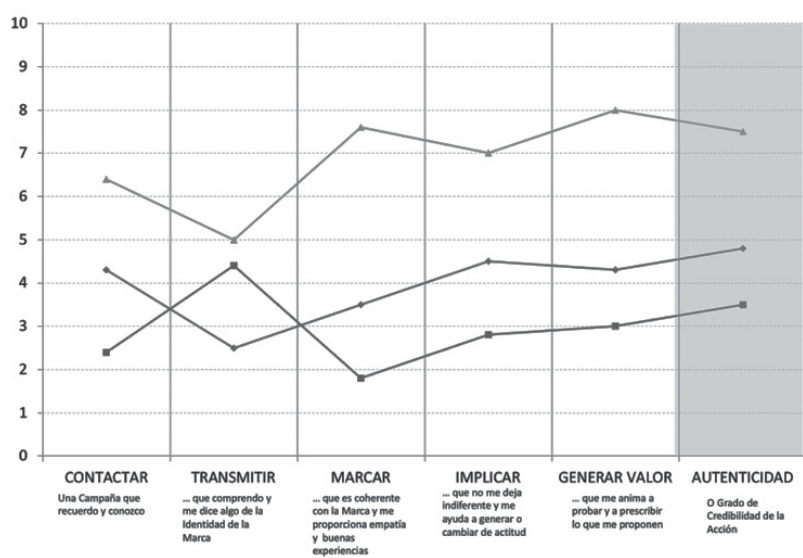

AUTENTICIDAD

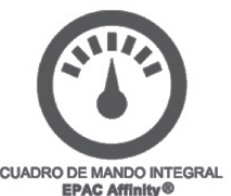


El uso de este índice es instrumental, por lo que nunca debe de condicionarnos los objetivos y su manera de preguntar por ellos (medirlos), su planteamiento o diseño de investigación y, por supuesto, la recogida y análisis de los de los datos.

Para finalizar nos gustaría indicar que lo expuesto hasta aquí se trata de la reflexión e integración de los resultados obtenidos por nosotros mismos en procesos de medida llevados a cabo en el ámbito de la investigación de mercados, tal y como se recoge en la bibliografía adjunta. Efectivamente nuestra propuesta es teórica e incipiente por lo que reconocemos esta debilidad en el presente trabajo. No obstante, queremos transmitir que en la actualidad ya estamos llevando a cabo una investigación empírica donde estamos analizando la fiabilidad y medida de todas y cada una de las escalas de medida que hemos desarrollado para medir los constructos e indicadores mencionados en este trabajo. Esperamos que muy pronto este futuro trabajo pueda ver la luz en esta misma revista.

La propuesta de este Índice EPAC affinity® de eficacia de una campaña o comunicación, es el resultado del trabajo de investigación realizado por la Universidad de Santiago (USC) a partir de la experiencia de colaboración con numerosas empresas y agencias de publicidad durante las dos últimas décadas a través de la Unidad de Psicología del Consumidor y Usuario (PSICOM) (ver Referencias Bibliográficas). Ahora llegó el momento de integrar lo investigado en este ámbito y sistematizarlo en lo que esperamos se convierta en el baremo de referencia capaz de evaluar y tomar el pulso al quehacer diario de los gestores de Marca, agencias de publicidad y marketing, organizadoras de eventos, etc. Para más información sobre los ítems, escalas y cálculo del EPAC affinity ${ }^{\circledR}$, ponerse en contacto con los autores (www.usc.es/psicom) 


\section{Bibliografía}

Abalo, J; A. Rial, A. y Varela, J. (2003). La realización de encuestas en entornos atípicos y situaciones de conflicto. Metodología de Encuestas, 5. 1-12. http://casus.usal.es/pkp/ index.php/MdE/article/view/929

Abalo, J., Varela, J. y Manzano, V. (2007). Importance values for Importance- Performance Analysis: A formula for spreading out values derived from preference rankings. Journal of Bussines Research, 60. 115-121. https://doi.org/10.1016/j. jbusres.2006.10.009

Abalo, J.; Varela, J. Y Rial, A. (2006). El Análisis de Importancia-Valoración aplicado a la gestión de servicios. Psicothema, 18. 730-737. Impact factor 2006: 1.083. 5-years: 1.232. Q2 .http://reunido.uniovi.es/index.php/PST/article/ view/8369

Braña, T.; Varela, J. y Rial, A. (1995). Cómo medir la eficacia de las Promociones de Ventas. Harvard Deusto Marketing y Ventas, 9. 25-29. https://dialnet.unirioja.es/servlet/ articulo? codigo $=5586554$

Ferreira, S.; Rial, A. y Varela, J. (2014). Extensão de Marca: Fatores críticos. Revista Portuguesa de Marketing, 31. 22-34. http://www.rpm.pt/artigo.aspx?a=220

Ferreira, S.; Rial A. y Varela, J. (2012). Minimizing the risks of innovation in bottled water design: an application of conjoint analysis. African Journal of Business Management, 6 (31). 9096-9104. https://doi.org/10.5897/AJBM12.299

Ferreira, S., Varela, J; Rial, A. y Frazao, S. (2011). Mediçao da imagem de marca de Pôrtugal enquanto destino turístico: Uma aproximaçao metodológica mista no contexto do marketing.Turismo \& Desenvolvimento, 16. 115-126. https:// doi.org/10.34624/rtd.v0i16.13375

Ferreira, S; Rial, A. y Varela, J. (2010). Segmentación Post Hoc del mercado turístico español. Aplicación del análisis clúster en dos etapas. Estudios y Perspectivas en Turismo, 19. 592-606. https://www.redalyc.org/articulo.oa?id=1807/180717609001

Ferreira, S.; Rial, A. y Varela, J. (2009). Post Hoc Tourist Segmentation with Conjoint and Cluster Analysis. Pasos. Revista de Turismo y Patrimonio Cultural, 7. 491-501. https:// doi.org/10.25145/J.PASOS.2009.07.035

Ferreira, F; Rial, A.; Picón, E. y Varela, V. (2009). Efecto del orden de presentación de los atributos sobre los resultados del Análisis Conjunto. Metodología de Encuestas, 11. 103-119. http://casus.usal.es/pkp/index.php/MdE/article/view/995
Hollf, E.; Varela, J.; Landa, J.; Lévy, J. P.; García, V. y Pascual, M. (2001). Imperativos metodológicos y contractuales en la investigación de mercados. Metodología de Encuestas, 3. 113-125. http://casus.usal.es/pkp/index.php/MdE/article/ view/899/840

Lévy, J.P. y Varela, J. (Coords) (2010). Modelización con Estructuras de Covarianzas en Ciencias Sociales. Temas Esenciales, Avanzados y Aportaciones Especiales. A Coruña: Netbiblo. ISBN: 978-84-9745-136-9. https://dialnet.unirioja.es/servlet/libro? codigo $=402086$

Levy; J.P. y Varela, J. (Coordinadores) (2003). Análisis Multivariable para las Ciencias Sociales. Madrid: Pearson Prentice Hall (2003). ISBN: 84-205-3727-6. https://dialnet.unirioja es/servlet/libro?codigo $=320226$

López, F; Rial, A.; García, A. y Varela, J. (2002). Aplicación del análisis de contenido al estudio de la imagen de un destino turístico. Metodología de las Ciencias del Comportamiento, 17,.362-72. https://rebiun.baratz.es/rebiun/record/Rebiun00030318

López, R. y Varela, J. (2000). Evaluación de las escalas de respuesta en la Medición Conjunta. Metodología de Encuestas, 2. 185-198. http://casus.usal.es/pkp/index.php/MdE/ article/view/885

Olea, J.; San Martín, R. y Varela, J. (1992). Escalamiento Unidimensional y Multidimensional de diseños creativos Psicothema, 4. 291-296. http://www.psicothema.com/psicothema.asp?id=832

E. Picón, J. Varela, A. Rial y T. Braña (2013). HABI: una nueva herramienta para la representación de la imagen de un producto o servicio. Revista Española de Investigación de marketing ESIC, 17. 83-104. https://doi.org/10.1016/ S1138-1442(14)60020-6

Picón, E. y Varela, J. (2004). Una evaluación empírica del procedimiento de segmentación conjunto de clases latentes. Metodología de las Ciencias del Comportamiento, volumen especial. 491-498. https://rebiun.baratz.es/rebiun/record/Rebiun00030318

Picón, E., Varela, J. y Braña, T. (2011). La representación de los datos mediante el Análisis de Importancia-Valoración: problemas y alternativas. Metodología de Encuestas, 13. 121-142. http://casus.usal.es/pkp/index.php/MdE/article/view/1015 Picón, E., Braña, M. T. y Varela, J. (2002). ¿Quién prefiere un destino como Galicia antes que otro de sol y playa? Predicción de la elección de un destino turístico mediante aná- 
lisis conjunto. Metodología de las Ciencias del Comportamiento, volumen especial. 445-448. http://casus.usal.es/pkp/ index.php/MdE/article/view/1015

Picón, E. y Varela, J. (2000). Segmentando mercados con Análisis Conjunto: Una aplicación al sector turístico. Psicothema, 12. 453-458. http://www.psicothema.com/english/ psicothema.asp?id=603

Picón, E.;. Varela, J. y Braña, T. (2007). Análisis Conjunto. Madrid: La Muralla. ISBN: 84-7133-762-2. https://dialnet. unirioja.es/servlet/libro?codigo=295586

Picón, E.; Varela, J. y J. Levy. J.P. (2004). Segmentación de Mercados. Madrid: Pearson Prentice Hall. ISBN: 84-205-4323-3. https://dialnet.unirioja.es/servlet/libro? codigo $=322760$

Prat, R., Varela, J. y Riba, D. (2002). ¿Por qué es importante la elección del procedimiento de obtención de preferencias en la metodología conjunta? Un estudio de fiabilidad. Metodología de las Ciencias del Comportamiento, 17. 449-451. http://casus.usal.es/pkp/index.php/MdE/article/view/1015

Rial, A.; Torrado, N.; Braña, T. y Varela, J. (2010). Relación entre la calidad asistencial percibida y la actitud frente al tratamiento en drogodependencias. Psicothema, 22. 574580. Impact factor 2010: 0.939. 5-years: 1.232. https:// dialnet.unirioja.es/servlet/articulo? codigo=3318986

Rial, A. y Varela J. (2012). QUAD: una escala sencilla, válida y fiable para evaluar la calidad asistencial en el ámbito de las drogodependencias. International Journal of Psychological Research, 5. 5-13. https://psycnet.apa.org/ record/2015-32205-004

Rial, A.; Ferreira, S. y Varela, J. (2012). Análise Conjunta: Uma Aplicação ao Estudo das Preferências dos Consumidores. Revista Portuguesa de Marketing, 26. 27-37. http://www. rpm.pt/artigo.aspx?a=186

Rial, A.; Varela, J.; Rial, A. y Real, E. (2010). Modelización y medida de la Calidad Percibida en centros deportivos: la escala QSport-10. Revista Internacional de Ciencias del Deporte (RICYDE), 18. 55-73. https://www.cafyd.com/REVISTA/ ojs/index.php/ricyde/article/view/261

Rial, A.; Lamas, L.; Braña, T. y Varela, J. (2009). La evaluación de la Atención al Drogodependiente desde el punto de vista de los propios usuarios. Psicothema, 21. 206-212. http://www.psicothema.com/psicothema.asp?id=3616

Rial, A.; Lamas, L. y Varela, J. (2009). Aplicación de los modelos de ecuaciones estructurales a la identificación de las variables predictoras de la fidelidad a un centro comercial.
Anales de Psicología, 25. 134-141. Impact factor 2009: 0.244. 5-years: 0.687. https://revistas.um.es/analesps/article/view/71591

Rial, A.; Alonso, D.; Picón, E. y Varela; J. (2009). Segmentación Post Hoc en dos fases de los usuarios de centros deportivos. Apunts. Educación Física y Deportes, 95. 82-91. https:// dialnet.unirioja.es/servlet/articulo? codigo $=2987810$

Rial, A.; Rial, J.; Varela, J. y Real, E. (2008). An application of Importance-Performance Analysis (IPA) to the management of Sport Centres. Managing Leisure, 13. 179-188. https://www. tandfonline.com/doi/full/10.1080/13606710802200878?s croll=top\&needAccess=true $\&$

Rial, A.; García, A. y Varela, J. (2008). Una aplicación metodológica para el estudio de la Imagen de Marca de un destino turístico. Pasos. Revista de Turismo y Patrimonio Cultural, 6. 1-10. http://riull.ull.es/xmlui/handle/915/17799

Rial, A.; Ugarte, X.; Braña, T. y Varela, J. (2006). Utilización del Involvement en la evaluación de la eficacia publicitaria. Harvard \& Deusto Marketing y Ventas, Julio/Agosto. 12-18. https://www.harvard-deusto.com/revista/marketing_y_ventas Rial, A.; Varela, J. y García, A. (2001). Identificación de las Variables que Determinan la Evaluación de una Extensión de Marca. Psicothema, 13. 284-289. http://www.psicothema.com/psicothema.asp?id=449

Rial; A.; Varela, J.; Braña, T. y Lévy, J.P. (2000). El valor de la marca a partir de su relación con el consumidor. Psicothema, 12. 247-254. http://www.psicothema.com/psicothema.asp?id=285

Rial, A.; Braña, T.; Varela, J.y Alfaya, E. (1997). Éxito y Fracaso de las Extensiones de Marca. Harvard Deusto Marketing $y$ Ventas, 19. 26-31. https://dialnet.unirioja.es/servlet/ articulo? codigo $=5586378$

Rial,A. y Varela, J. (1996). Criterios de clasificación de las Promociones de Ventas desde la Perspectiva del Consumidor. Revista de Psicología Social Aplicada, 6. 23-38. https:// rebiun.baratz.es/rebiun/record/Rebiun00038240

Rial, A. y Varela, J. (2008). Estadística práctica para la Investigación en Ciencias de la Salud. A Coruña: Netbiblo. ISBN: 978-84-9745-243-4. SPI general: 80 de 272; SPI Psicología: 31 de 77 . https://dialnet.unirioja.es/servlet/ libro?codigo $=760221$

Rial, A.; Varela, J. y Rojas, A. (2001). Depuración y Análisis Preliminares de los Datos en SPSS. Madrid: Ra-Ma. ISBN: 84- 
7897-463-6. SPI general: 160 de 272; SPI Psicología: 45 de 77. https://dialnet.unirioja.es/servlet/libro?codigo $=452073$

Rial, A.; Rial; J.; Varela, J. y Real, E. (2010). An application of Importance-Performance Analysis (IPA) to the management of Sport Centres. En: Performance Measurement and Leisure Management. Alexandris, K. (ed), 45-54. London: Routledge (Francis \& Taylor Group). ISBN: 978-0-41555382-7. SPI general internacional: 3 de 259; SPI Psicología: 5 de 48. https://www.routledge.com/Performance-Measurement-and-Leisure-Management/Alexandris/p/ book/9780415849142

Shaw,C. y Hamilton, R. (2016). The intuitive customer: 7 imperatives form. Moving your customer experience to the next level. Palgrave Macmillan. https://www.palgrave.com/gp/ book/9781137534286\#aboutBook

Sánchez, J. (2017). Eficacia publicitaria. Teorías y modelos aplicados. Pirâmide. Madrid. https://dialnet.unirioja.es/servlet/ libro?codigo $=705236$

Silva, A. y Varela, J. (2014). A influencia da Motivacao na intencao de Escolha de um Destino Turístico em Tempo de Crise Económica. International Journal of marketing, Communication and New Media, Vol. 2. No 2, 5-38. ISSN: 2182 9306. http://u3isjournal.isvouga.pt/index.php/ijmcnm/article/view/24

Varela, J; Rial, A.; Braña, T. y Voces, C. (2008). Aplication of Latent Class Analysis to the investigation of customer loyalty in services companies. Methodology: European Journal of Research Methods for the Behavioral and Social Sciences, 4. 8796. Impact factor 5-years: 2.169. https://psycnet.apa.org/ doi/10.1027/1614-2241.4.3.87

Varela, J.; García, A.; Manzano, V. y Rial, A. (2006). Development of an index to assess the brand image of tourist destinations. Anales de Psicología, 22. 155-160. https://revistas. um.es/analesps/article/view/26691

Varela, J.; Prat, C.; Voces , C. y Rial , A.(2006). Una nueva escala para la evaluación de la calidad de los servicios en hostelería. Psicothema, 18. 135-142. http://www.psicothema.com/psicothema.asp?id=3188

Voces, C.; Varela, J. y Rial. A. (2004). El constructo «Involvement» y la satisfacción del cliente en hostelería: medición y utilidad. Revista de Metodología de las Ciencias del Comportamiento, volumen especial. 631-638. http://casus.usal.es/ pkp/index.php/MdE/article/view/1015
Varela, J., Picón, E. y Braña, M. T. (2004). Segmentation of the Spanish domestic tourism market. Psicothema, 16. 7683. http://www.psicothema.com/psicothema.asp?id=1164 Varela, J.; Rial, A. Y García-Cueto, E. (2003). Presentación de una escala de satisfacción con los servicios sanitarios de atención primaria. Psicothema, 15. 656-661. Impact factor 2003: 0.408. 5-years: 1.232. http://www.psicothema.com/ psicothema.asp?id= 1120 .

Varela, J.; García, A.; Braña, T. y Rial, A. (2002). Imagen y posicionamiento de establecimientos minoristas. Psicothema, 14. 92-99. Impact factor 2002: 1.098. 5-years: 1.232. Q2 http://www.psicothema.com/psicothema.asp?id=691

Varela, J.; Rial, A. y Braña, T. (2001). Consumer Preferences and Brand Equity Measurement of Spanish Daily NewsPapers: A Conjoint Analysis Approach. Spanish Journal of Psychology, 4. 48-54. https://doi.org/10.1017/ S1138741600005643

Varela, J.; Rial, A. y Braña, T. (1999). ¿Qué valora el consumidor en una Promoción de Ventas?.. Revista Internacional de Economía y Empresa, Esic Market, 10. 177-193. https://www.esic.edu/documentos/revistas/ esicmk/060130_888473_E.pdf

Varela, J.; Rial, A. y Braña, T. (1998). El valor de la marca en los folletos publicitarios. Revista Europea de Dirección y Economía de la Empresa, 7. 91-97. https://dialnet.unirioja.es/ servlet/articulo? codigo $=497503$

Varela, J.; Rial, A.; Braña, T. y De la Flor, M. (1998). Presentación del EIM: Un instrumento para medir la implicación de los consumidores con marcas comerciales. Anuario de Psicología, 29, 17-34. https://revistes.ub.edu/index.php/ Anuario-psicologia/article/view/8983

Varela, J.; Rial, A. y Braña, T. (1998). ¿Cómo valoran los consumidores las Extensiones de Marca?. Revista de Psicología Social,13. 45-54. https://dialnet.unirioja.es/servlet/ articulo?codigo $=111854$

Varela, J.; Rial A.; Braña, T. y Domínguez, J.L. (1998). ¿Cómo Medir la Implicación de los Consumidores con la Marcas Comerciales?. Adaptación Española del CIP de Laurent y Kapferer (1985). Revista de Psicología Social Aplicada, 8. 71-79. https://dialnet.unirioja.es/servlet/articulo?codigo=2994334

Varela, J.; Braña, T.; García, A.; Rial, R. y Vázquez, X.G. (1998). Estimación de la respuesta de los «no sabe / no contesta» en los estudios de intención de voto. Revista Española 
de Investigaciones Sociológicas -REIS-, 83. 269-287. https:// dialnet.unirioja.es/servlet/articulo? codigo $=758017$

Varela, J.; Braña, T. y Rial, A. (1997). Diseño del producto ideal mediante Análisis Conjunto. Esic Market. Revista Internacional de Economía y Empresa, 98. 67-74. https://www. esic.edu/editorial/editorial_revista_esic.php?num=118

Varela, J.; Rial, A. y Braña, T. (1997). El nuevo reto de los supermercados: La implicación del ama de casa. Harvard Deusto Marketing y Ventas, 23. 30-34. https://www.harvarddeusto.com/el-nuevo-reto-de-los-supermercados-la-implicacion-del-ama-de-casa

Varela, J.; Rial, A.; García, C.; Braña, T. y Olea, J. (1996). Una Medida de la Implicación de los Consumidores con las Marcas Comerciales. Psicothema, 8. 543-551. http://www. psicothema.com/psicothema. $a s p ? i d=52$

Varela, J., Olea, J. y San Martín, R. (1991). Dimensiones de evaluación de productos creativos: ¿dualismo o bipolaridad? Psicothema, 3. 97-109. http://www.psicothema.com/ psicothema.asp?id=2008

Varela, J.; Rial, A, Abalo, J. y Braña, T.(2006). Análisis Factorial Confirmatorio de Segundo Nivel. En: Modelización con Estructuras de Covarianzas en Ciencias Sociales. Temas Esenciales, Avanzados y Aportaciones Especiales. Lévy, J.P. y Varela, J. (coord.). A Coruña: Netbiblo. ISBN: 978-84-9745-136-9. SPI general: 80 de 272; SPI Psicología: 31 de 77. https:// dialnet.unirioja.es/servlet/articulo? codigo $=4703947$

Picón, E. y Varela, J. (2003). Clasificación y segmentación post hoc mediante el análisis de conglomerados. En J. P.Lévy y J. Varela (Coords). Análisis Multivariable para las Ciencias Sociales. Madrid: Prentice Hall, ISBN: 84-2053727-6. (pp. 417-450). https://dialnet.unirioja.es/servlet/ articulo?codigo $=4548206$

Varela, J. (2000). Modelización de atributos múltiples: Escalamiento Multidimensional y Análisis Conjunto. En AEDE-
MO (Asociación Española de Estudios de Mercado Marketing y Opinión) (2000). La Investigación en Marketing (Volúmen II). Celeste Edición. Barcelona.. ISBN: 84-8211281-3, DL: M-38.815-2000. (pp. 609-677). https://dialnet. unirioja.es/servlet/articulo?codigo $=570527$

Varela, J.; Vázquez, X.G. y Rial, A. (1998). Combinación del Escalamiento Multidimensional y el Análisis de Conglomerados para el estudio de las representaciones mentales del consumidor. Un caso práctico, en Investigación del comportamiento. Innovaciones metodológicas y estratégicas de docencia; Manzano, V. y Sánchez, M. Almería: Instituto Psicológico Andaluz de Investigaciones. ISBN: 84-930-2470-8.

Varela, J. y Rial, A. (1996). La estimación de la demanda de un nuevo producto, en Análisis Conjunto aplicado a la Investigación Comercial; Varela, J. y Braña, T. Madrid: Pirámide. ISBN: 84-368-1024-4. https://dialnet.unirioja.es/servlet/ libro? codigo $=238218$

Varela, J. y Braña, T. (1996). Análisis Conjunto aplicado a la Investigación Comercial. Madrid: Eudema. (1996). ISBN: 84-368-1024-4. https://dialnet.unirioja.es/servlet/libro? codigo $=238218$

Voces, C.; Varela, J.; Rial, A. y Real, E. (2007). La búsqueda de la lealtad verdadera como meta estratégica de las organizaciones de servicios. En: Perspectivas y retrospectivas de la psicología social en los albores del siglo XXI. Romay, J. (coord), 287-294. Madrid: Biblioteca Nueva (2007). ISBN 978-84-9742-777-7. SPI general: 21 de 272; SPI Psicología: 17 de 77. https://dialnet.unirioja.es/servlet/articulo?codigo=2550395

Ugarte, X.; Rial, A. y Varela, J. (2004). Aplicación del Involvement al análisis de la eficacia publicitaria. Revista de Psicología Social Aplicada, 14. 5-29. https://dialnet.unirioja.es/ servlet/articulo? codigo $=2016840$ 



\section{aDResearch ESIC}

(ㅇ)(1) $\circledast$

Revista de libros 


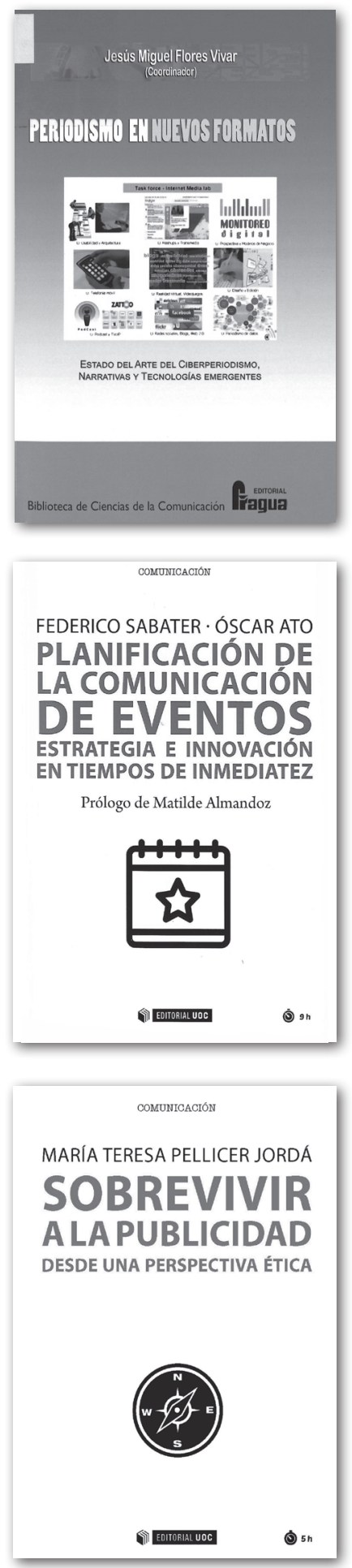

\section{Periodismo en nuevos} formatos

Estado del Arte del

Ciberperiodismo, Narrativas

y Tecnologías Emergentes

Jesús Miguel Flores Vivar

(Coordinador)

Editorial Fragua, Madrid, 2017

\section{Planificación de la comunicación de eventos}

Estrategia e innovación en tiempos de inmediatez

Federico Sabater y Óscar Ato

Editorial UOC, 2020

Sobrevivir a la publicidad desde una perspectiva ética María Teresa Pellicer Jordá Editorial UOC, 2019 


\section{Periodismo en nuevos formatos}

Estado del Arte del Ciberperiodismo, Narrativas y Tecnologías Emergentes Jesús Miguel Flores Vivar (Coordinador)

\section{Editorial Fragua, Madrid, 2017}

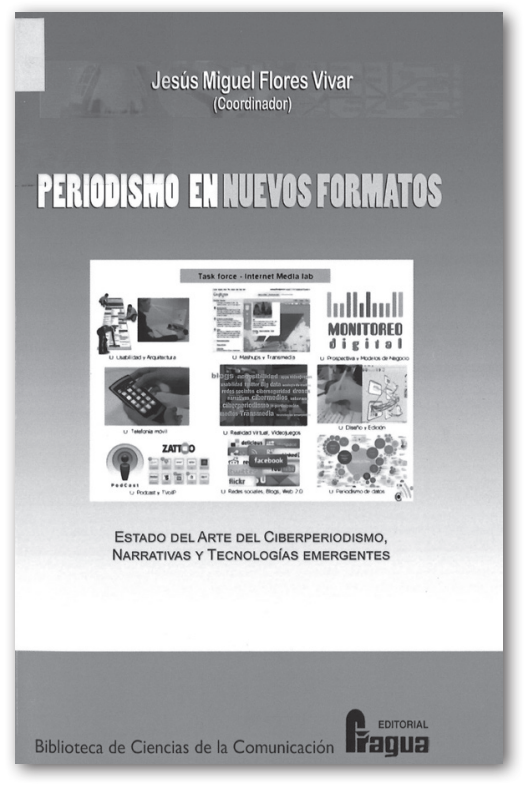

\section{Por: Ignacio Soret Los Santos}

ESIC Business \& Marketing School

$P$ eriodismo en nuevos formatos. Ante todo, periodismo. Por ello, antes de empezar a leer el libro, parto con varias dudas. ¿El periodismo cambia con el formato, con las nuevas tecnologías? ¿Y cuando digo cambia el periodismo, digo cambia el objetivo, el propósito, el fin... la función? Nada fácil de responder a las preguntas. Pero insisto: cambia la forma, puede ser; pero, vuelvo al ataque, icambia el periodismo?

El libro añade como subtítulo Narrativas y Tecnologías Emergentes, como anunciando que lo emergente implica nuevas cosas. Y añade también lo de Ciberperiodismo; es decir, periodismo en la red, digital. Esto es lo que dice nuestra Wikipedia, a la que, de ninguna manera, podemos ya obviar: «El ciberperiodismo es una nueva forma de hacer periodismo que surge a mediados de la década de los noventa. El periodismo digital, como también se denomina al ciberperiodismo, se basa en Internet, redes y dispositivos digitales para investigar, producir y publicar contenidos periodísticos». Todo parece apuntar a que el periodismo sigue siendo periodismo, a pesar de que el medio cambie e incluso obligue a formatear, permítaseme la expresión como neologismo de «dar forma», el texto.

Pero vayamos al libro propuesto. El contenido de dicho libro corresponde a los resultados de investigaciones y aportaciones sobre el estado del arte del futuro del periodismo y calidad informativa en nuevos formatos, realizados por docentes, investigadores, especialistas y expertos del entorno digital y multimedia pertenecientes a diversas instituciones y universidades españolas e internacionales, en forma de comunicaciones y ponencias presentadas y leídas en el marco del Sexto Congreso Internacional de Periodismo en Red, celebrado en la Facultad de Ciencias de la Información de la Universidad Complutense de Madrid.

El libro se estructura en cinco grandes bloques: (I) Multidisciplinariedad y periodismo de datos, (II) Transmedialidad y narrativas multimedia, (III) Hiperlocalismo y medios sociales, (IV) Modelos de negocio, especialización y nuevos perfiles, (V) Apps, drones, videojuegos y tecnologías emergentes.

Hay que destacar que en cada bloque se recogen aproximadamente ocho ponencias o comunicaciones presentadas en el Congreso anteriormente citado. Por tanto, cada una de ellas comienza con una introducción, a modo de abstract, donde se justifica la importancia del estudio o trabajo, también, a veces, el «estado del arte», 
una revisión bibliográfica o se presenta un marco conceptual; después, puede establecerse una propuesta de modelo, si procede, o una exposición del procedimiento, método o técnica de investigación utilizada; metodología, muy generalmente consistente en un cuaderno de campo, focus group o entrevistas en profundidad para realizar, después, un análisis cualitativo; y, con todo rigor, se termina con unas conclusiones o, mejor aún, con la contribución científica del trabajo.

Podemos anticipar algunos de los títulos de las comunicaciones: El periodismo de filtraciones en España; Convergencia interdisciplinar: técnicas antropológicas y etnográficas en el desarrollo del ciberperiodismo; ¿caben todas las noticias en los periódicos digitales?; Integración de lenguajes y formatos en una empresa de comunicación; Iniciativas colaborativas en el periodismo de investigación: estado de la cuestión e iniciativas específicas de carácter transnacional; Usabilidad, accesibilidad y arquitectura de la información en el diseño web. Fundamentos y nociones básicas para el profesional de la información; La reformulación de los medios ante la convergencia digital; Conectividad y lenguaje para el Neuroperiodismo; Narrativa Neotelevisiva versus Narrativa Multimedial; Periodismo multiplataforma: transmedia y crossmedia; Snapchat y el periodismo. Estudio del perfil del Lab de RTVE; El periodismo de divulgación científica en la red; Periodismo de las cosas: lenguajes y formatos en relojes inteligentes: El caso de CNN internacional, ESPN y Flipboard con Gear S2; Seguridad de la información en las tecnologías emergentes; Periodismo dron en los planes de estudio de las universidades españolas; el empleo de drones en la práctica periodística: ¿plasticidad o utilidad?

El coordinador de la obra, Jesús Miguel Flores Vivar, titula el prefacio: La transformación del periodismo y de su enseñanza, una realidad. Co- mienza diciendo que, en los tiempos actuales, nadie duda ya de que Internet haya democratizado el acceso a la información y a las noticias. Pero también ha desestabilizado los viejos modelos de negocio de los medios que han sostenido el periodismo de calidad durante décadas, llevando a las empresas periodísticas —u organizaciones de noticias - a una fase de incertidumbre y expectación. Excelente reflexión para un cambio en el ecosistema de medios.

Sin embargo, no se olvida de que la enseñanza-aprendizaje del periodismo tiene que adaptarse a estas transformaciones y apostar por la innovación docente, lo que implica a su vez un cambio en los planes de estudio. La transformación del periodismo es una cuestión de gran transcendencia social, profesional y científica. Las facultades de comunicación deben asumir y convertirse en motores del conocimiento científico y teórico, en laboratorios de prueba y error. De hecho, en el Lab de la Universidad de California Berkeley (EE.UU.) se experimentan con las tecnologías más vanguardistas que pueden aplicarse al periodismo: drones, realidad virtual, narrativa transmedia, algoritmos, glass u Occulus.

Con la publicación de este libro, Periodismo en nuevos formatos, se trata de mostrar una radiografía actual por la que atraviesan los medios, el periodismo y la formación de esta disciplina en un entorno evolutivo y flexible en donde las aplicaciones sociales y diversas tecnologías emergentes se han convertido en herramientas informativas para el ejercicio de la profesión periodística. Termina el coordinador del libro diciendo que se vislumbran las bases para la reestructuración del modelo informativo y de negocio, la importancia de la interactividad y participación ciudadana y los retos formativos de la disciplina del periodismo. 


\section{Planificación de la comunicación de eventos}

Estrategia e innovación en tiempos de inmediatez

Federico Sabater y Óscar Ato

Editorial UOC, 2020

COMUNICACIÓN

\section{FEDERICO SABATER · ÓSCAR ATO \\ PLANIFICACIÓN DE LA COMUNICACIÓN DE EVENTOS}

ESTRATEGIA E INNOVACIOON

EN TIEMPOS DE INMEDIATEZ

Prólogo de Matilde Almandoz
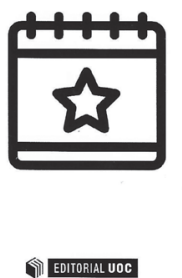

(อ) 9 n

\section{Por: Julio Alard Josemaría, Phd}

ESIC Business \& Marketing School

$H^{\prime}$ ablar de los eventos, y por extensión de la denominada industria MICE (Meetings, Incentives, Conventions y Events) es referirnos a una de las herramientas más puras y típicamente de comunicación.

Efectivamente, los eventos es un tipo de comunicación estratégica. Una acción específica, integrada dentro del plan de comunicación de marketing, que busca interactuar con los diferentes grupos de interés para transmitirles los valores de la compañía o institución. Todo ello con el reto de alcanzar los objetivos de posicionamiento y de negocio (fomentar las ventas, hacer promoción y atraer nuevos clientes).
Por otro lado, a ningún profesional o técnico del sector se le escapa que planificar y diseñar un evento es una tarea ciertamente compleja. Exige tener en cuenta factores y variables tan importantes como la definición de los objetivos, la determinación del presupuesto, el análisis del sector, la mejor fecha para lanzarlo, el plan de medios de apoyo, así como los contenidos que a través de la propia dinámica del evento se generan y que será necesario amortizar a través de su difusión en los distintos canales propios.

Todo ello hace necesaria una reflexión, desde el punto de vista profesional y académico, sobre los aspectos organizativos y estructurales que conlleva el plan de comunicación de esta herramienta. Y más si cabe, si tenemos en cuenta los grandes cambios que han introducido la expansión que las tecnologías, la revolución permanente de las redes sociales, y también, como no, los cambios producidos por la pandemia de coronavirus COVID-19. Una crisis sanitaria a escala global que ha venido a alterar de manera importante la forma de preparar y organizar los eventos, donde inevitablemente las tecnologías digitales han tenido que afinarse para seguir captando la atención y ampliar las experiencias de los grupos a los que se dirigen estos eventos.

En este sentido, la obra «Planificación de la Comunicación de Eventos. Estrategia e Innovación en Tiempos de Inmediatez» de los profesores y especialistas en el sector, Sabater y Ato, nos traen una visión holística de la comunicación en eventos, haciendo hincapié en las acciones que de manera organizada es necesario repensar para alcanzar los objetivos propuestos. Para ello, además de entrevistas a profesionales, los autores conceden peso a la documentación bibliográfica y a testimonios de académicos seleccionados, que ayudan a entender desde todos los puntos de vista la tarea 
compleja que significa planificar la comunicación de un evento.

La publicación se divide en diez capítulos, más uno final de entrevistas a profesionales y académicos del sector. Todos los capítulos incluyen al final fuentes bibliográficas actualizadas, a través de las que se puede ampliar los contenidos de cada sección.

En el primer capítulo los autores se detienen en la definición terminológica del concepto de evento, así como en la profusa clasificación de estos según la función que cumplen. Es este punto conviene destacar que además de los eventos que ponen en marcha las empresas, existen otros que son productos en sí mismo, como festivales de música, conciertos, etcétera y que hace que su gestión y puesta en marcha tenga un punto de especificidad. En este sentido el evento puede ser un fin en su mismo, una actividad cultural, empresarial o de ocio, pero también una herramienta eficaz de marketing para aquellas organizaciones que los utilizan como promoción de sus actividades, productos y servicios, o como parte de su responsabilidad social corporativa o para asociarse a una imagen de marca determinada. Además, este capítulo aborda tres cuestiones de interés como son la comunicación de eventos en España, sus principales problemas de comunicación y los factores de innovación. La profesionalización del sector se ha hecho palpable desde el nacimiento de la Federación Española de Asociaciones de Empresas de Organización Profesional de Congresos (OPC), que ha ido sentando las bases de un cambio de tendencia.

Los siguientes capítulos abordan el contenido más práctico y extenso de la obra. Recogen de manera precisa los pasos y actividades, de manera organizada y secuencial, a la hora de realizar el plan de comunicación de cualquier evento, congreso, feria, jornada o presentación. En este sen- tido el capítulo II arranca con una explicación sobre los factores claves a analizar sobre el contexto en que se va a desarrollar el evento. Se trata de un ejercicio de inmersión, tanto a nivel interno como externo de las cuestiones a tener en cuenta en el inicio del desarrollo de las tareas de planificación y organización del evento. En este punto, entender cómo se configura el briefing, como documento que recoge la información que vamos a necesitar, resulta clave para el éxito de la planificación del evento. A partir de este primer análisis y con el briefing, se tendrá información de primera mano para saber a quién nos dirigimos, contra qué eventos vamos a competir, y en definitiva conocer las oportunidades para lograr un plan de comunicación exitoso.

Pero toda esta información no sería suficiente, si al final no determinamos los puntos fuertes y oportunidades, así como las debilidades y oportunidades de nuestro evento. En este sentido el capítulo III recoge la fase de diagnóstico DAFO (Debilidades, Amenazas, Fortalezas y Oportunidades), un modelo básico de diagnóstico que aportará una información precisa sobre la mejor manera de rentabilizar la comunicación del evento.

Con la información de este diagnóstico, estaremos en condiciones de determinar los objetivos que pretendemos alcanzar. La definición de objetivos, tal y como señala el Capítulo IV, es una tarea imprescindible, ya que se convierten en la hoja de ruta, además de aportar un instrumento clave para medir su nivel de consecución. En este sentido, los objetivos tienen que cumplir con la regla MARTE (SMART en su definición en inglés), un acrónimo que marca los parámetros en los que basar nuestros objetivos (Medibles, Alcanzables, Realistas, Temporales y Específicos).

Tras definir lo que pretendemos alcanzar con la celebración del evento, estaremos listos para 
determinar la estrategia y decidir las acciones necesarias para llevarla a cabo. En este sentido el Capítulo V «Estrategias y acciones de implementación del plan», recoge tanto la tipología de estrategias como de acciones a implementar, adaptadas a un amplio espectro de eventos, y teniendo en cuenta además, tal y como señalan los autores de manera gráfica, que tanto las estrategias como las acciones deben estar relacionadas con los objetivos y alineados con la propuesta de marca.

No menos importantes son los capítulos VI, VII y VIII, en los que se abordan respectivamente aspectos de la organización y reparto de funciones de los equipos implicados en el evento, el calendario, necesidades y presupuesto; los protocolos a actuar en situaciones de crisis de comunicación, así como los detalles de la medida de los resultados y los indicadores (KPI's Key Performance Indicator) que darán información sobre el rendimiento y grado de consecución de los objetivos.

El capítulo X aborda otra serie de aspectos de interés en el desarrollo del plan de comunicación. Aspectos no menores y que pueden ser los detalles que apuntalen el éxito del plan de comunicación de los eventos.

Por último, y especialmente importante por el nivel de profesionales y académicos seleccionados, de detallan las cuestiones que estos expertos van desgranando desde la práctica profesional y académica.

Si bien, y tal como señalan los autores, existe una profusa bibliografía de este tema, el tiempo y trabajo dedicado en la selección de los expertos consultados, el apoyo bibliográfico, el enfoque práctico de la obra y su facilidad de lectura, la convierte en un una herramienta que permite analizar los posibles puntos débiles a detectar en la puesta en marcha y desarrollo de esta actividad.

\section{Sobrevivir a la publicidad desde una perspectiva ética}

\author{
María Teresa Pellicer Jordá \\ Editorial UOC, 2019
}

COMUNICACIÓN

MARÍA TERESA PELLICER JORDÁ

SOBREVIVIR ALAPUBLICIDAD DESDE UNA PERSPECTIVA ÉTICA
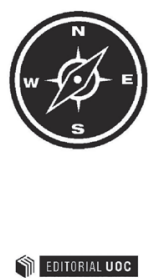

() $5 \mathrm{~h}$

\section{Por: Oliver Carrero Márquez}

ESIC Business \& Marketing School

Sética se antoja como una obra de obligada lectura, al ofrecer una visión clara y concisa de dónde se encuentran los límites éticos, deontológicos y legales de esta disciplina profesional. No recomendada para los amigos del todo vale, su objetivo no es ofrecer una visión metafísica de la ética, sino la de aplicarla a una realidad competitiva, donde no suele haber segundas oportunidades para las primeras impresiones.

Su autora, María Teresa Pellicer Jordá, entiende este trabajo como una especie de manual de supervivencia en aras de la consecución de una sociedad mejor, donde la ética publicitaria aporte una serie de códigos éticos que permitan regular su actividad, siempre con la mirada puesta en 
la defensa de los consumidores antes anuncios no adecuados por su carácter sexista o engañoso, entre otros.

Y para llevar a buen puerto dichas expectativas, esta profesora de Publicidad y Relaciones Públicas de la Universidad de Murcia, le propone al lector un itinerario que arranca con una aproximación al concepto de Ética y Moral, para luego continuar con un repaso sobre las principales percepciones éticas de los grandes filósofos de la historia, como antesala, para entrar de lleno en los nuevos retos éticos que debe afrontar la publicidad, ya que se trata de una disciplina en constante cambio, donde se consolidan conceptos como el de neuromarketing y psicobiología.

Pero como en todo proceso iniciático, en este caso, centrado en la ética publicitaria, se precisan de una serie de metodologías de análisis que permitan discernir si existe, o no, mala praxis a la hora de usar estrategias persuasivas. Una circunstancia que no pasa inadvertida para la autora que, desde unas pinceladas sucintas, esboza las sinergias necesarias que se deben establecer entre técnicas de análisis cuantitativas y cualitativas, a la hora de afrontar una investigación social.

Tras asentar las bases teóricas sobre las que se fundamenta la necesidad de este texto, se aborda el ámbito de la autorregulación publicitaria, marcando la divisoria entre autorregulación y deontología. En esta línea, presenta el Código de Conducta Publicitaria del que desgrana aspectos a salvaguardar tales como el respeto por el buen gusto, la condena de la publicidad discriminatoria o engañosa, así como la condena de argumentos que se aprovechen del miedo, temor o supersticiones de los destinatarios.

Nos encontramos ante un breve manual que, por su reciente publicación, aporta información sobre casuísticas actuales, tales como la regulación de la publicidad en internet, donde se salvaguar- dan públicos vulnerables, que regula el Código ético de confianza Online. A esto hay que añadir que no se desdeñan las problemáticas clásicas, vinculadas a la autorregulación de bebidas alcohólicas, de cerveceros de España, la publicidad infantil de juguetes, la publicidad de alimentos o bebidas dirigida a menores, la publicidad de productos de software interactivos, o el modo de comunicar comercialmente las actividades de juego, entre otros.

Pellicer Jordá invita a la reflexión, desde un repositorio de casos de uso para investigadores y docentes, en los que presenta un buen número de ejemplos punibles desde el punto de vista ético, en el ámbito de la publicidad engañosa y publicidad discriminatoria. Una realidad, en cuya denuncia, asegura la autora, juega un papel primordial Autocontrol, como organismo encargado de velar por una publicidad responsable bajo los principios de la veracidad, la legalidad, la honestidad y la lealtad.

Este interesante trabajo finaliza con la opinión de algunas figurares relevantes del sector tales como Fernando Cerezo, Begoña Moreno, José Carlos del Pozo y Xavi de la Cruz. Todos ellos deben contestar a dos preguntas. En primer lugar, si creen que la ética publicitaria es necesaria. En segundo, si creen que el marco de autorregulación publicitaria es efectivo. En los tres casos las respuestas son coincidentes en ambas cuestiones. Los tres ven necesaria la existencia de este órgano de regulación, aunque creen que su efectividad dista mucho de cumplir los ideales para los que fue creado.

De este modo, nos encontramos ante un breve e interesante libro que entra en un terreno delicado como es el de la deontología en el desempeño de la profesión publicista, donde, en el mismo momento en el que la agencia, a petición del cliente, intenta influir en las decisiones de su público objetivo, complica de un modo exponen- 
cial una ecuación en la que intervienen un sinfín de variables que entroncan con la ética, la moral, los valores, la psicología y la sociología.

Pero como la propia autora indica, el análisis de esta praxis es necesaria, por el calado social intrínseco de la materia que nos ocupa, ya que la publicidad juega un papel fundamental en la vida de los ciudadanos como configurador de su personalidad y de sus estilos de vida.
Por tanto, nos encontramos ante una lectura imprescindible, máxime, en un contexto, donde las líneas entre comunicación, publicidad y propaganda son cada vez más difusas, la competencia por hacerse con un nicho de mercado cada vez más ardua y los avances técnicos puestos al servicio de desentrañar los entresijos del comportamiento humano, cada vez más avanzados. 



\section{aDResearch ESIC}

№ 25 Vol 25 · Monográfico especial, marzo 2021 · págs. 214 a 223

(ㄷ) (1) ()$\odot$ 


\section{Proyectos de investigación en comunicación y publicidad}




\section{Produsage cultural en las redes sociales: Industria, consumo popular y alfabetización audiovisual de la juventud española con perspectiva de género}

\section{Datos generales}

- Coordinadora: Asunción Bernárdez Rodal.

- Fecha de inicio: 01/01/2018.

- Departamento y centro al que está adscrito: Instituto de Investigaciones Feministas, Universidad Complutense de Madrid. Departamento de Periodismo y Nuevos Medios.

- Datos de Contacto:

- Avda. Complutense, s/n. Ciudad Universitaria, 28040 Madrid.

- Teléfono: 913942236

- Correo: asbernar@ccinf.ucm.es

\section{Ámbito de investigación}

- Líneas de investigación:

Jóvenes, redes sociales y género; Redes sociales y violencia de género; Contexto y dimensión educativa del produsage (audiovisual) en las redes sociales; Gobernanza de datos y big data.

- Palabras clave: Redes sociales, produsage, juventud, identidad sexual, desigualdad, violencia de género, alfabetización mediática, empoderamiento, recepción.

\section{Miembros del grupo}

- IP: Asunción Bernárdez Rodal

- Investigadoras:

Asunción Bernárdez Rodal, Graciela Padilla Castillo, María José Camacho Miñano, Carmen Vaquero Cañestro, Laura Triviño Cabrera, Dimitrina Jivkova Semova.

- Equipo de trabajo:

Nuria López Priego, Dunia Etura Hernández, Paula Requeijo Rey, Borja
Quintana Fernández, Paula Díaz Altozano, Eglée Ortega Fernández, Jonattan Rodríguez Hernández, Yanna G. Franco, Ignacio Moreno Segarra, Víctor Gutiérrez Sanz.

\section{Resumen del proyecto y situación actual}

La construcción de la identidad es un fenómeno complejo y multicausal que tiene lugar a lo largo de la vida. Este proyecto se centra en algunos de los aspectos más relevantes de este proceso, estudiando cómo se gestiona en Facebook, Instagram y YouTube a través de las prácticas de producción y uso (produsage) de los adultos emergentes en las redes sociales. .

\section{Proyectos, contratos y convenios de I+D+I}

- Patentes, registros y modelos de utilidad

- Artículos en revistas de investigación

Bernárdez-Rodal, A.; Menéndez-Menéndez, I. (2021). «Ageing and the Creative Spirit of Women in the Audiovisual Market: The Case of Olive Kitteridge (2014)». International Journal of Communication, 15, pp. 563 - 580. https://ijoc.org/ index.php/ijoc/article/view/14908/3338

Bernárdez-Rodal, A.; López-Priego, N.; PadillaCastillo, G. (2021). «Culture and social mobilisation against sexual violence via Twitter: the case of the "\#LaManada" court ruling in Spain». Revista Latina de Comunicación Social, 79, DOI por determinar.

Cerdán-Martínez, V.; Padilla-Castillo, G.; VillaGracia, D. (2021). «Isekai (異世界): el confinamiento autoimpuesto en Japón y Latinoamérica». Arte, Individuo y Sociedad, 33(2). DOI: https:// dx.doi.org/10.5209/aris.69123

Bernardez-Rodal, A.; Requeijo-Rey, P. \& G. Franco, Y. G. (2020). «Radical right parties and antifeminist speech on Instagram: Vox and the 2019 Spanish general election». Party Politics. October 2020. DOI: 10.1177/1354068820968839 
Bernárdez Rodal, A.; Congosto, M. L.; Lopez Priego, N. (2020). «The World's First Mainly Female Cabinet: The Council of Female Minister's in the Spanish Cabinet (2019) on Twitter». Communications: The European Journal of Communication Research, 2, pp. 1-20.2020.

Triviño-Cabrera, L. y Bernárdez-Rodal, A. (2020). «The Philosoclips Project: Teaching Feminist Philosophy through Popular Culture in Spain». Gender and Education, 8, online. https://doi.org/10.1 080/09540253.2020.1837348

Bernárdez Rodal, A. (2020). «Rosario de Acuña: una genealogía del animalismo en la literatura decimonónica». Historia y Comunicación Social, 25(2), pp. 463-472. DOI: https://doi. org/10.5209/hics.72277

Bernárdez-Rodal, A. (2020). «Discursos sobre política y desigualdad: nuevas directoras en tiempos de crisis». Cuadernos Hispanoamericanos, 834, pp. 72-84. Disponible en: https://cuadernoshispanoamericanos.com/discursos-sobre-politica-y-desigualdad-nuevas-directoras-en-tiempos-de-crisis/ Cerdán-Martínez, V.; García-Guardia, M. L.; Padilla-Castillo, G. (2020). «Alfabetización moral digital para la detección de deepfakes y fakes audiovisuales». CIC Cuadernos de Información y Comunicación, 25, pp. 165-181. DOI: https://doi. org/10.5209/ciyc.68762

Ortega-Fernández, E. A; Padilla-Castillo, G. (2020). «Diálogo transmedia de las series de televisión. La superación de la Quinta Pared en House of Cards». Revista Estudios sobre el Mensaje Periodístico, 26(3), 1101-1120. DOI: https://doi. org/10.5209/esmp.67783

Camacho-Miñano, M. J.; McIsaac, S.; Rich, E. (2019). «Postfeminist biopedagogies of Instagram: young women learning about bodies, health and fitness». Sport, Education and Society, 24(6), pp. 651-664.
Cerdán-Martínez, V.; Padilla-Castillo, G. (2019). «Historia del fake audiovisual: deepfake y la mujer en un imaginario falsificado y perverso». Historia y Comunicación Social, 24(2), 505-520. DOI: https:// doi.org/10.5209/hics.66293

Bernárdez-Rodal, A.; Padilla-Castillo, G.; Sosa Sánchez, R. P. (2019). «From Action Art to Artivism on Twitter and Instagram: relocation and instantaneity for a new geography of protest». Catalan Journal of Communication \& Cultural Studies, 11.1, pp. 23-37. DOI: 10.1386/cjcs.11.1.23_1

Bernárdez-Rodal, A.; Padilla-Castillo, G. (2018). «Mujeres cineastas y mujeres representadas en el cine comercial español (2001-2016)». Revista Latina de Comunicación Social, 73, pp. 1247-1266. DOI: 10.4185/RLCS-2018-1305

Muñoz-Guerado, A. y Triviño-Cabrera, L. (2019). «The erasure of female representation in geek spaces as an element for the construction of Geek identity: The case of Warhammer 40.000". Catalan Journal of Communication \& Cultural Studies, 10, pp. 193-211. DOI: 10.1386/cjcs.10.2.193_1 Padilla-Castillo, G. y Oliver-González, A. B. (2018). «Instagramers e influencers. El escaparate de la moda que eligen los jóvenes menores españoles». ADResearch, 18(18), pp. 42-59. DOI: https://doi.org/10.7263/adresic-018-03

Padilla-Castillo, G. y Sosa-Sánchez, R. P. (2018). «Ruptura de los estereotipos de género en la ficción televisiva sobre el poder político: El caso Borgen». Autoras: Graciela Padilla y Roxana P. Sosa. Revista de Comunicación Vivat academia. ISSN: 1575281354.

Aladro-Vico, E.; Cavadas-Gormaz, M. J.; Semova, D. J.; Padilla-Castillo, G.; Sosa Sánchez, R. P.; Requeijo-Rey, P. (2018). «Artivismo como herramienta de transformación social: dos iniciativas en los barrios de La Latina y Lavapiés (Madrid)». 
Comunitaria: Revista Internacional de Trabajo Social y Ciencias Sociales, 15.

Sosa-Sánchez, R. P. y Semova, D. J. (2018). «Espacios y realidades urbanas: procesos de intervención a través de la práctica social». Icono 14 , 16(2), pp. 47-71.

Triviño-Cabrera, L. (2019). «Le processus d'enseignement- apprentissage multimodal des sciences sociales». Spiral. Revue de Recherches en Éducation, 63, pp. 67-84.

Triviño-Cabrera, L. y Requena-Palacios, C. (2019). «Investigación e innovación educativa desde el Máster de Formación del Profesorado de Ciencias Sociales a las prácticas curriculares en Educación Secundaria». Contextos educativos: Revista de educación, 23, pp. 83-99.

Triviño-Cabrera, L. (2018), «La Cámara de las Maravillas» de Mark Ryden: formación del profesorado de Ciencias Sociales en educación estética, cultura popular y literacidad crítica. Enseñanza E Teaching: Revista Interuniversitaria de Didáctica, 36, pp. 223-248

Triviño-Cabrera, L. (2018), «Clara Peeters y sus otras historias: propuesta de innovación docente para afrontar resistencias y prejuicios en la formación del profesorado del máster de profesorado de educación secundaria y bachillerato», Revista Complutense de Educación, 29, pp. 33-53.

\section{Libros completos}

Bernárdez-Rodal, A. y Padilla-Castillo, G. (2021). Deshaciendo nudos en el Social Media: Redes, feminismos y políticas de la identidad. Tirant Lo Blanch, colección Tirant Humanidades.

Bernárdez-Rodal, A. (2020). Desafíos Feministas. Temas y tramas para pensar en un mundo en crisis. Tirant Lo Blanch, colección Tirant Humanidades. ISBN: 978-84-1815-513-0.
Semova, D. J.; Aladro-Vico, E. y Sosa-Sánchez, R. P. (Coord.) (2019). Entender el Artivismo. Peter Lang Publishing Group. Londres, Reino Unido. Padilla-Castillo, G. y González-Vallés, J. E; Sánchez Rodríguez, V. (2019). La cultura como herramienta de expresión humana. Editorial Gedisa (colección Herramientas Universitarias). ISBN 978-84-17690-24-3. Páginas: 1-519.

\section{Capítulos de libros}

Bernárdez-Rodal, A. y Padilla-Castillo, G. (2021). Capítulo «Usos no éticos de Instagram». En libro Aspectos éticos y marcos legales de la comunicación. Editorial Tirant Lo Blanch, colección Tirant Humanidades. ISBN: Por determinar.

Bernárdez-Rodal, A. y Padilla Castillo, G. (2019). «Liderazgo feminista en hashtags: etiquetas virales del nuevodebate político y social en España». En libro The Time Is Now. Feminist Leadership for a New Era. La hora del liderazgo feminista. Editado por Araceli Alonso y Teresa Langle de Paz. Global Network of UNESCO Chairs on Gender (Buenos Aires) and the United Nations Educational, Scientific and Cultural Organization (Paris). ISBN 978-950-9379-50.

Bernárdez Rodal, A. y López Priego, N. (2019). «Artivismo en redes sociales: análisis del discurso de las ilustradoras en la huelga de mujeres del 8 de marzo de 2018 en España», en Aladro, E. et alt. Entender el Artivismo, Peter Lang, Reino Unido. Páginas: 137-156. ISBN: 978-1-78874-436-2. DOI: https://doi.org/10.3726/b13498

Padilla-Castillo, G. (2019). «Desgeolocalización y viralización del artivismo en redes sociales». En libro Entender el Artivismo. Editorial Peter Lang. Oxford, Reino Unido. ISBN 978-1-78874-434-8. Páginas: 269-284.

Padilla-Castillo, G. (2019). «Instagram como nueva herramienta docente en las aulas». En li- 
bro Cultura digital y las nuevas politicas educativas. Editorial Gedisa (colección Herramientas Universitarias). ISBN 978-84-17690-20-5. Páginas: 315-325.

Triviño-Cabrera, L. y Vaquero-Cañestro, C. (2019). «Didáctica de la Eutopía o cómo enseñar y aprender pensamiento crítico-creativo a través del artivismo». En Dimitrina Jivkova Semova, Eva Aladro Vico y Roxana Popelka Sosa Sánchez (eds.). Entender el Artivismo. Oxford y Londres: Peter Lang. Padilla-Castillo, G. (2018). «Instagram y la cultura de la imagen en la moda española». En libro Senderos de Historia Cultural. Serie Didáctica (volumen II). Editorial Universidad Metropolitana de Venezuela. ISBN: 978-980-247-265-9. Páginas: 169-193.

Padilla-Castillo, G. (2018). «El papel de las nuevas tecnologías y los medios sociales en las campañas electorales de 2015 y 2016». En libro La comunicación de los partidos políticos en España tras el bipartidismo. Editorial Pearson. ISBN: 978-84205-7064-8. Páginas: 73-97.

\section{Tesis doctorales leídas}

Doctora: Ariana Paola Herrera Pérez

Directora: Graciela Padilla Castillo

Título: La experiencia del consumidor y reputación online: el caso del sector hotelero de régimen «todo incluido» en Ecuador

Calificación: Sobresaliente cum laude

Facultad de Ciencias de la Información, Universidad Complutense de Madrid

Defensa: 20 de enero de 2021

Doctor: Félix Urosa Barreto

Directora: Graciela Padilla Castillo

Título: Posicionamiento orgánico en buscadores (SEO): Estudio sobre el ranking de resultados en Google.es del sector educativo superior
Calificación: Sobresaliente cum laude Facultad de Ciencias de la Información, Universidad Complutense de Madrid

Defensa: 27 de enero de 2021

Doctora: Nuria Espinosa Morueco

Directora: Asunción Bernárdez Rodal

Título: La construcción del género en los perfiles de Facebook de los principales partidos politicos durante las campaña de las elecciones generales de 2016 (26J) Y 2019 (28A)

Calificación: Sobresaliente

Organismo: Universidad Complutense de

Madrid el día 25 de noviembre de 2019

Doctor: Enrique Vaquerizo Domínguez

Directora: Graciela Padilla Castillo

Título: La construcción de identidad cultural de los migrantes mexicanos en los Estados Unidos a partir de comunidades virtuales.

Calificación: Sobresaliente cum laude Facultad de Ciencias de la Información, Universidad Complutense de Madrid

Defensa: 14 de diciembre de 2018.

Doctora: Eglée Andreína Ortega Fernández

Directora: Graciela Padilla Castillo

Título: El lenguaje social de la ficción televisiva y sus antihéroes. La Quinta Pared en House of Cards Calificación: Sobresaliente cum laude Facultad de Ciencias de la Información, Universidad Complutense de Madrid

Defensa: 13 de diciembre de 2018

Doctora: Laura Elisa Mora Afonso

Directora: Graciela Padilla Castillo

Título: Mujeres sin hogar y redes sociales: visibilidad y auto percepción

Calificación: Sobresaliente

Facultad de Ciencias de la Información, Universidad Complutense de Madrid.

Defensa: 14 de diciembre de 2018 . 


\section{Comunicaciones en congresos}

Asunción Bernárdez Rodal y Paula Requeijo Rey. Congreso: «Infrastructures and Inequalities: Media Industries, Digital Cultures and Politics», which took place in Helsinki, 21-22 October 2019. During the conference. Paper «The Use of Social Networks Against Feminism: the Case of Vox Political Party in Spain».

Asunción Bernárdez Rodal y Dunia Etura, Título del trabajo: Young people and the (re)creation of gender stereotyping in Creepypastas on YouTube. Nombre del congreso: Youth and Media and hosted by the Faculty of Communication and Media Studies; Atenas, Grecia 24 y /05/2019 Entidad organizadora: ECREA TWG Children Youth and Media; Kapodistrian University of Athens

Bernárdez Rodal, Asunción y Triviño Cabrera, Laura (2019). Brecha digital, redes sociales y la figura del prosumer en contextos educativos. $5^{\circ}$ Congresso Literacia, Media e Cidadania. Universidade do Minho y UNESCO. Aveiro, Portugal.

Bernárdez Rodal, Asunción y Triviño Cabrera, Laura (2018). The Case of Ter: From Spanish YouTuber to Education Influencer from the Critical-feminist Pedagogy. Fifth Annual ACGS Conference: Global Critical Pedagogies. Universiteit Van Amsterdam. Ámsterdam, Países Bajos.

Bernárdez Rodal, Asunción y Padilla Castillo, Graciela. Ponencia «Artivism: Autonomy, Disobedience, Resistance through Artistic Expressions». MeCCSA Annual Conference. London South Bank University, Londres, Reino Unido. 2018

Camacho Miñano, $\mathrm{M}^{\mathrm{a}}$ José. «Young women, Instagram and Physical Education: learning about bodies, health and fitness». Workshop: Training seminar for PE teachers, Edinburgh, 05/03/2019, Entidad organizadora: The Physical Education Research Forum.

Camacho Miñano, $\mathrm{M}^{\mathrm{a}}$ José. Ponencia «Biopedagogías postfeministas en Instagram: aprendizajes de las chicas jóvenes sobre el cuerpo, la salud y el ejercicio físico», XIII Congreso Español de Sociología, Valencia, 05/07/2019, Federación Española de Sociología. Universidad de Valencia.

Chaves Guerrero, Elisa Isabel y Triviño Cabrera, Laura (2020). La mecha prendida hacia la igualdad real: la identidad feminista de las futuras maestras de educación infantil en la era \#METOO. XXXI Simposio Internacional de Didáctica de las Ciencias Sociales. AUPDCS y Universidad de Valencia.

López Priego, N. (2019), Asistencia a la Cumbre Mundial de Comunicación Política. Celebrada en Madrid. Universidad Complutense del 19 al 21 de febrero de 2019.

Padilla-Castillo, Graciela. 2019 (23 y 24 de octubre): Ponencia «Instagram vs. YouTube. Claves del éxito de los vídeos cortos o Instagram Stories». Resumen opcional en inglés «Instagram vs. Youtube. Keys to the success of short videos or Instagram Stories» en proceedings Scopus SJR. CUICIID 2019.

Padilla-Castillo, Graciela D, del Valle, María Elena; Sánchez- González Sánchez, Pilar. 2019 (6 de julio): Ponencia «Las conquistas del género femenino simbolizadas y materializadas en El Cuento de la Criada (HBO)». Pre-conference Ciudadanía y Derechos Digitales. La movilización de los usuarios de la comunicación como estrategia de futuro. IAMCR 2019: «Communication, 
Technology and Human Dignity: Disputed Rights, Contested Truths». Madrid, España.

Padilla- Castillo, Graciela; Quintana Fernández, Borja. 2019 (24 y 25 de mayo): Ponencia «Creepypasta HBO Distributed Series and their viral marketing in Spain. A new view of a risk children's social media literacy for self-performance and identity construction from madness and genre stereotypes». Congreso Children's Online Worlds, Digital Media and Digital Literacy organized by the ECREA TWG Children, Youth and Media. Faculty of Communication and Media Studies of the National and Kapodistrian University of Athens.

Padilla- Castillo, Graciela. 2019 (1 y 2 de febrero): Ponencia «Profesores instagramers: fotografías y hashtags como innovaciones educativas». Congreso Internacional Virtual. Educación y Comunicación en la sociedad actual. CIVECSA 2019. Fundación Ponte Italiano, UNAD, Universidad del Atlántico, UNIMET, Universidad Libre de Barranquilla, Universidad del Sinú, UPEL, Universidad de Granada, UCM, SEECI y Fórum Siglo XXI.

Padilla Castillo, Graciela. Comunicación «Instagram. ¿Brecha digital entre docentes y estudiantes universitarios de comunicación?». CUICIID 2018. Actas en español, publicadas con ISBN 978-84-09-04679-9, página 559. Conference proceedings publicados en inglés, con ISBN 978-84-09-04967-7, páginas 695-696. 2018 (24 y 25 de octubre):

Triviño Cabrera, Laura y Vaquero Cañestro, Carmen (2019). Alfabetización audiovisual del profesorado de formación inicial en Educación Ciudadana y Educación Artística desde el videoclip Malamente. $5^{\circ}$ Congresso Literacia, Media e Cidadania. Universidade do Minho y UNESCO, Aveiro, Portugal.
Triviño Cabrera, Laura (2019). Utopías modernas, distopías mediáticas y heterotopías educativas en la formación inicial del profesorado de Ciencias Sociales. XVI Jornades Internacionals de Recerca en Didàctica de les Ciències Socials. Universidad Autónoma de Barcelona. España

Triviño Cabrera, Laura (2018). Producción de recursos didácticos por parte del profesorado en formación a través de la alfabetización audiovisual y la práctica performativa. X Jornadas de Investigación en Innovación Docente de la UNED. UNED. Madrid, España.

Triviño Cabrera, Laura (2018). Beyoncé y Katy Perry: ¿Obstáculos u oportunidades para la formación inicial del profesorado de Ciencias Sociales en perspectiva feminista? III Jornadas noviembre feminista: Investigando para la acción. Universidad Complutense de Madrid. Madrid, España.

Triviño Cabrera, Laura y Vaquero Cañestro, Carmen (2018). Pedagogy of Eutopia: From the Global Cave to the Glocal Gathering Places. Fifth Annual ACGS Conference: Global Critical Pedagogies. Universiteit Van Amsterdam. Ámsterdam, Países Bajos.

Triviño Cabrera, Laura (2018). Multimodality and historical thinking for the empowerment of the social sciences teacher in training. Agency, Citizenship and Historical Thinking: Empirical Research. Université du Québec. GatineauOtawa, Canadá.

Triviño Cabrera, Laura y Vaquero Cañestro, Carmen (2018). Hetero(u)topías audiovisuales para nuevos espacios educativos. III Taller de Alfabetización Audiovisual y Mediática. Consejo Audiovisual de Andalucía y Universitat Autònoma de Barcelona. Málaga, España. 
Triviño Cabrera, Laura (2018). Educación estética, empatía audiovisual y empoderamiento feminista. De cómo Formation formó al profesorado en formación. Ciclo de conferencias «Itinerâncias Críticas». Universidade do Minho. Braga, Portugal.

Triviño Cabrera, Laura y Chaves Guerrero, Elisa Isabel (2020). Los problemas sociales relevantes a través del doble proceso literacidad crítica-práctica performativa en formación inicial de maestras y maestros. XXXI Simposio Internacional de Didáctica de las Ciencias Sociales. AUPDCS y Universidad de Valencia.

Triviño Cabrera, Laura (2019). Una educación ciudadana para una sociedad postmoderna: retos y propuestas. IX Simposio Internacional de
Didáctica de las Ciencias Sociales en el Ámbito Iberoamericano. Universitat de Barcelona.

Triviño Cabrera, Laura (2019). Un patrimonio feminista para una educación ciudadana feminista. III Congreso Internacional Prácticas y Reflexiones en Educación Patrimonial. Universidad de Huelva.

\section{Entidades financiadoras (si las hubiera) Proyecto I+D Programa de excelencia, Subprograma estatal de generación de conocimiento.}

Ministerio de Economía, Industria y Competitividad.

Referencia: FEM2017-83302-C3-3-P.

Duración: 01/07/2018-01/01/2022. 



\section{aDResearch ESIC}

№ 25 Vol 25 · Monográfico especial, marzo 2021 · págs. 224 a 229

(ㄷ) (1) ()$\odot$ 


\section{Tesis doctorales en comunicación} ESIC Business \& Marketing School 


\section{Construcción de ciudadanía en escenarios actuales:}

actores políticos emergentes en

la era digital desafíos para la teoría y la metodología de la comunicación política

Autor:

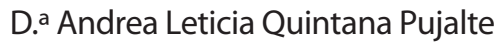

Universidad:

Universidad de Málaga

\section{Departamento:}

\section{Comunicación audiovisual y publicidad}

\section{Resumen}

El presente estudio pretende ser un aporte a la reflexión sobre las relaciones complejas que existen entre los actores políticos, el espacio público y la comunicación, para la construcción de un nuevo tipo de ciudadanía. Estos tres elementos conjugan la base desde la cual se analizan vínculos que representan disputas por el poder simbólico en el marco de una sociedad postmaterial. Este escenario está signado por la permanente transformación de las relaciones que significan las nuevas tecnologías de la comunicación y la información.

En este contexto surge la pregunta acerca de las características de ese nuevo escenario, compuesto por un mapa cada vez más complejo de actores políticos tradicionales y emergentes, y ciudadanos infocomunicados, que lleva a repensar el rol que cumple la comunicación en aspectos relevantes de la vida en sociedad, particularmente, desde los procesos de construcción ciudadana en escenarios políticos determinados. La emergencia de nuevos actores políticos y herramientas que empoderan al ciudadano, favorece la construc-
Fecha de lectura: 15/12/2020

Programa de doctorado:

En Comunicación por la Universidad

de Cádiz; la Universidad de Huelva; la Universidad de Málaga y la Universidad de Sevilla

\section{Dirección:}

D. Antonio Castillo Esparcia

Por Marta Gimeno Pascual

ESIC Business \& Marketing School ción de un tipo de ciudadanía atravesada por los espacios digitales. La complejidad de estos fenómenos se acentúa cuando se evalúa que estos procesos comparten espacio con las corrientes tradicionales de construcción de ciudadanía que buscan validar antiguos modelos con categorías analíticas que, en definitiva, deben repensarse.

El estudio busca profundizar sobre los modos en que la comunicación política de actores relevantes de la sociedad se expresa en los espacios digitales, con el fin de conocer si existen modelos particulares de comunicación que permitan considerar la emergencia de un nuevo modelo de participación ciudadana.

Para ello, se toma como eje empírico del análisis a las organizaciones no gubernamentales españolas (ONG). A partir de estos actores considerados no tradicionales y en algunos casos, emergentes, se analizan por un lado los discursos sociales que ponen en disputa en el espacio público político y por otro, el rol que adquieren estos actores en el proceso de su permanente consolidación. 


\section{Tecnopolítica, participación electrónica y comunicación digital:}

cartografía del movimiento de la cultura libre en España

Autor:

D. a Dafne Calvo Miguel

Universidad

Universidad de Valladolid

\section{Departamento:}

Historia moderna, contemporánea y de

América, periodismo y comunicación

audiovisual y publicidad

\section{Resumen}

Las características de Internet como un espacio abierto y descentralizado despertaron en sus primeros años la esperanza de una mayor autonomía y libertad de la ciudadanía ciberconectada. Sin embargo, esta etapa económica, vertebrada por las capacidades para la producción, extracción y gestión de datos, ha generado un nuevo escenario en el que las corporaciones tecnológicas controlan los flujos de información en Red $y$, como consecuencia, el diseño e infraestructura de la esfera pública online, así como la vigilancia de los y las internautas que interaccionan y se organizan en ella. El desarrollo de Internet en plataformas comerciales y privativas genera condiciones específicas para la participación política de la sociedad civil y la transformación social contemporánea. Ante estas relaciones de poder, los Estados no han logrado resolver con efectividad la crisis de legitimidad del sistema político en el que se inscribe, ni fomentar formas de participación superadoras de la democracia representativa.

Paralelamente, e impulsada por el espíritu colaborativo y autónomo en el que se originó
Fecha de lectura: 13/10/2020

Mención Europeo / Mención Internacional:

Concedido

Programa de doctorado:

Doctorado en Español: Lingüística, Literatura

y Comunicación por la Universidad de

Valladolid

Dirección:

D. ${ }^{a}$ Eva María Campos Domínguez,

\section{Por Marta Gimeno Pascual}

ESIC Business \& Marketing School

la Red, la sociedad civil ha articulado espacios alternativos relacionados con los valores de libertad, descentralización y cooperación entre las multitudes de Internet, que no se encuentran exentos de las tensiones producidas entre su posicionamiento ideológico y el contexto económico y político donde operan. Esta tesis doctoral se centra en este último grupo, las comunidades de software y cultura libre en el Estado español, a fin de estudiar sus valores, su relación con las corporaciones tecnológicas y las instituciones públicas, su repertorio de acción colectiva y sus estrategias e instrumentos para la comunicación.

Con estos objetivos, planeamos una metodología combinada, participativa y orgánica, donde cada una de las fases procuran profundizar en los datos obtenidos en la anterior, así como contar con la colaboración y validación de las comunidades investigadas, para de esa forma acercar la discusión teórica a las lógicas de los propios colectivos y orientarla hacia la transformación social. En una primera fase, realizamos un mapeo de los grupos de cultura libre a través de 
la observación documental en línea, la técnica de bola de nieve y la distribución de un cuestionario online para la recolección de información esencial sobre dichas iniciativas, respondido por 290 colectivos. En la segunda fase, aplicamos la investigación-acción-participativa con 38 de las comunidades previas, seleccionadas mediante muestreo intencional.

Los resultados arrojan una detallada cartografía sobre la cultura libre en el territorio estatal. Las comunidades adquieren diversos modos organizativos, modelos de financiación y lazos de colaboración con otras entidades, que en buena medida puede interpretarse dentro de sus diversas formas de comprender la acción colectiva y la relación con los poderes institucionales y económicos. Así, por ejemplo, mientras algu- nas iniciativas son comunidades informales que autogestionan sus recursos, otras se configuran como asociaciones o fundaciones para llevar a cabo trámites burocráticos y recibir financiación de las administraciones públicas. El uso generalizado de herramientas privativas, la remuneración de quienes participan en los proyectos para evitar su precarización o la infrarrepresentación de grupos sociales concretos explicita las tensiones existentes entre el encaje ideológico y las posturas prácticas de los colectivos. Frente a un Internet crecientemente privatizado, estos, bajo las lógicas del aprendizaje digital, la privacidad de las comunicaciones, la producción en común, la descentralización y el acceso al conocimiento, expresan una diversidad de maneras de entender y practicar la cultura libre en Internet. 


\section{Comunicación online de las universidades de Ecuador}

Autor:

D. a Adriana Graciela Segura Mariño

Universidad:

Universidad de Málaga

Departamento:

Periodismo

\section{Resumen}

Las universidades reflejan el cumplimiento de su misión en la imagen que perciben sus stakeholders y en los rankings académicos. En estos predominan las universidades de países desarrollados, por consiguiente, las de países en vías de desarrollo han sido escasamente estudiadas. El objetivo de esta tesis doctoral es evaluar la comunicación institucional de las 60 universidades de Ecuador en el entorno online. Para comprender su desempeño y proponer mejoras, se han incluido a la prensa escrita y a las 60 universidades que lideran los rankings mundiales. Como contribución, se proponen metodologías con base en los elementos del sistema de comunicación, se detallan los resultados del empleo de cada metodología, propuestas de estrategias, limitaciones y sugerencias sobre futuros estudios. Entre los resultados, se destaca que la comunicación universitaria en Ecuador es un recurso operativo y no estratégico; los DirComs valoran más los canales online, pero reconocen carencias en competencias emergentes. En la prensa so-
Fecha de lectura: 07/10/2020

Programa de doctorado:

Doctorado en Educación y Comunicación

Social por la Universidad de Málaga

Dirección:

D. Francisco Javier Paniagua Rojano

Por Marta Gimeno Pascual

ESIC Business \& Marketing School

bresalen temas promocionales; los sitios web de universidades líderes tienen más calidad y tráfico web; las redes sociales más empleadas son Facebook y Twitter, las universidades líderes interactúan con los receptores sobre temas de su interés, las ecuatorianas mantienen la misma estrategia que en la prensa. Las principales audiencias son estudiantes potenciales y actuales; durante el proceso de decisión de los primeros, los canales más presentes fueron tanto online (redes sociales, sitios web) como offline (ferias de universidades, visitas al campus), los segundos valoran mucho más los canales online para mantenerse informados; la satisfacción sobre la comunicación está correlacionada con el compromiso. Entre las conclusiones se destaca que la comunicación estratégica integra canales online y offline que se ajustan a las necesidades de los stakeholders; por tanto, una gestión correcta depende de la importancia que las autoridades universitarias otorguen a la comunicación institucional. 


\section{aDResearch ESIC}

№ 25 Vol 25 · Monográfico especial, marzo 2021 · págs. 230 a 233

(ㄷ) (1) $)=$ 


\section{Agenda de congresos}




\section{Agenda de congresos}

Francisco Moreno Rey • ESIC Business \& Marketing School

\section{IMAT 2021. VII Congreso Internacional de Innovación Aplicada}

Organizaciones inteligentes y sostenibles: nuevas necesidades sociales y económicas

Evento online a nivel internacional

Valencia, España

1 y 2 de julio de 2021

https://imat.esic.edu/

EESICIMAT

Trumperming penple.

\section{$8^{\text {th }}$ European Communication Conference (ECREA)}

University of Minho (Campus de Gualtar)

6-9 september 2021

Braga, Portugal

https://www.ecrea2020braga.eu/

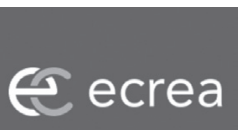

\section{Congreso Internacional ULEPICC-2021}

El futuro de los medios públicos

Ciudad de México

Días 11, 12 y 13 de octubre de 2021

https://ulepicc.org

\section{ulepicc}

\section{Congreso Internacional de Innovación en Comunicación y Medios Audiovisuales}

Universidad de Salamanca y Alicante (Formato virtual y, si es posible, presencial)

Del 19 al 26 de octubre de 2021

https://cincoma.org/

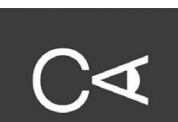

CINCOMA 


\section{Congreso Internacional sobre la Imagen}

Escuela Superior de Educación de Lisboa

Septiembre 13-14 2021

Lisboa, Portugal

https://sobrelaimagen.com/congreso-2021

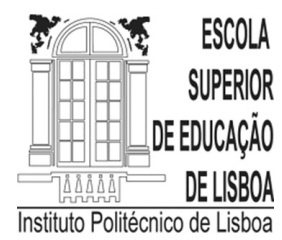

\section{EUPRERA-CICOM}

El camino de la comunicación estratégica

Del 7 al 9 de octubre de 2021

Universidad de Navarra

Navarra, España

https://www.unav.edu/web/cicom

\section{Heuprera}

European Public Relations Education and Research Association

\section{$4^{\text {th }}$ International Conference on Semiotics and Visual Communication}

Myths today

Cyprus University of Technology

12-14 November 2021

https://www.cyprus-semiotics.org

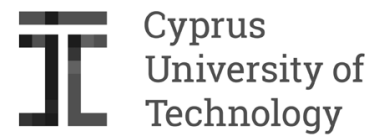




\section{aDResearch ESIC}

№ 25 Vol 25 · Monográfico especial, marzo 2021 · págs. 234 a 243

(ㄷ)(1) ()$\odot$ 


\section{Normas de publicación Guidelines for Authors}




\section{Normas de publicación}

\section{Pautas generales}

La política editorial de la revista aDResearch ESIC contempla la publicación de artículos de diferentes perspectivas sobre temas relacionados con la comunicación empresarial; el objetivo es servir de intermediario para compartir conocimientos, aplicaciones y metodologías en esta área, ampliando las aportaciones científicas de las diversas facetas de la comunicación. Por ello, los artículos a publicar deben ser relevantes y novedosos, pudiendo ser de diferentes tipos:

- Artículos de investigación. Este tipo de artículo presenta de forma detallada los resultados de un proyecto de investigación original. Por tanto, debe incluir varios apartados importantes: introducción, revisión bibliográfica, metodología de la investigación, resultados y conclusiones. Al menos el 60\% de cada número de la revista estará formado por este tipo de artículos.

- Artículos de reflexión. Este tipo de artículo plantea los resultados de una investigación crítica del autor, desde una perspectiva analítica o interpretativa; para ello, debe recurrirse a las fuentes originales.

- Artículos de revisión. Este tipo de artículo presenta los resultados de una investigación basada en una cuidadosa revisión bibliográfica de al menos 50 referencias. En el artículo se deben analizar, sistematizar o integrar los resultados de las diferentes investigaciones publicadas o no publicadas, sobre un campo relacionado con la comunicación, con el fin de aportar los avances y tendencias más interesantes.

\section{Directrices para los abstracts de los artículos}

\section{Extensión}

Los abstracts o resúmenes deben tener entre 200 y 300 palabras, siguiendo la estructura indicada según el tipo de artículo.

\section{Redacción}

El resumen debe ser claro y fácil de leer, aportando la información suficiente para que los lectores comprendan cuál es el contenido del artículo. Debe escribirse en un español gramaticalmente correcto y con una ilación lógica. No debe incluir datos innecesarios ni contener tablas, figuras o referencias. Los elementos a incluir en el resumen son los siguientes:

\section{- Artículos de investigación:}

- Objetivo del estudio.

- Diseño / Metodología / Enfoque.

- Resultados.

- Limitaciones e implicaciones.

- Originalidad / Contribución.

- Artículos de reflexión:

- Tema principal del artículo.

- Desarrollo lógico del tema.

- Punto de vista y aportaciones del autor.

- Repercusiones y conclusiones.

\section{- Artículos de revisión:}

- Alcance de la revisión.

- Período de las publicaciones revisadas.

- Origen y tipos de documentos revisados.

- Aportación del autor sobre las publicaciones analizadas.

- Conclusiones sobre las líneas de investigación estudiadas. 


\section{Directrices para la elaboración de los artículos}

El Consejo de Redacción de aDResearch ESIC tendrá en cuenta los siguientes aspectos para aceptar o rechazar la publicación de los artículos recibidos:

1. Solo se considerarán los trabajos inéditos debidamente estudiados y aprobados por el Consejo.

2. El contenido de los artículos es responsabilidad de los autores, y la política editorial es abierta.

3. Los autores deben ser profesionales docentes e investigadores, además de expertos en el tema a tratar.

4. El título del artículo debe ser conciso y específico del tema a estudiar.

5. Todas las aclaraciones sobre el artículo (agradecimientos, colaboradores, etc.) se indicarán con un asterisco en la introducción, remitiendo al pie de esa página.

6. Para cada artículo se debe adjuntar la clasificación del Journal of Economic Literature (JEL Classification) según el tema al que corresponda, de acuerdo con los códigos establecidos para búsquedas internacionales de producción bibliográfica. Los códigos deben ser específicos y no deben indicarse más de tres. La clasificación se puede consultar en: http://www. aeaweb.org/journal/jel_class_system.html

7. La extensión de los artículos no superará las 8000 palabras, con un tipo de letra Calibri, un interlineado de 1.15 y un cuerpo de letra 11 .
8. El artículo debe enviarse en formato Word y en formato PDF al correo electrónico articulos.adresearch@esic.edu. En el artículo debe incluirse el texto del artículo, el resumen y las palabras clave (cuatro como mínimo).

9. Las gráficas, tablas, imágenes y demás elementos deben incluir un título y deben enumerarse de forma consecutiva.

10. Las gráficas, tablas, imágenes y demás elementos deben adjuntarse, además, en los programas originales en los cuales se realizaron.

11. Los datos del autor se indicarán en la primera página, con una nota al pie, incluyendo la siguiente información: nombre del autor, nivel de estudios, empleo actual, lugar de trabajo, y correo electrónico.

12. Las notas a pie de página se utilizarán para aclarar o ampliar información.

13. Las referencias bibliográficas que se incluyan dentro del texto seguirán el sistema parentético (apellido, año, página): Sánchez, 2005, p. 27.

14. Las referencias bibliográficas completas se incluirán al final del artículo, en orden alfabético y con el siguiente formato, teniendo en cuenta mayúsculas, cursivas, comas, puntos y paréntesis:

\section{Libros:}

Apellido, Inicial del nombre. (año). Título. Ciudad: Editorial.

Suárez, A. y Martínez, D. (2003). Comunicación en la Unión Europea (2a. ed.). Madrid: Editorial CEAB. 
White, D. (2006). La economía digital. Barcelona: M. Louston. (Original en inglés, 2004)

\section{Capítulo de un libro:}

Apellido, Inicial del nombre. (año). Título de artículo. En Título de libro (páginas correspondientes al artículo). Ciudad: Editorial.

Hown, R. y Smith, J. (1999). Historia de la publicidad. En Comunicando (pp. 25-80). Madrid: Editorial CEAB.

Esquirol, J. (2007). La imagen en la sociedad. En Pascual, M. y Rodríguez, C. (Eds.). Imagen actual en las sociedades (pp. 93-102). Madrid: HG Editorial.

\section{Artículos de revistas profesionales o journals:}

Apellido, Inicial del nombre. (año). Título del artículo. Nombre de la revista, volumen (número de la edición), números de páginas.

Williams, O. (2002). Advertising and senses. Journal of Advertising Perspectives, 16(3), 181-205.

Pérez, L. (2008). Promoción en mercados internacionales. Promoción y empresa, 21, 31-36.

\section{Artículos de diarios:}

Apellido, Inicial del nombre. (año, día de mes). Título del artículo. Nombre del diario, $\mathrm{p}$.

Méndez, M. (2009, 26 de febrero). Temor por la crisis publicitaria. El Periodista, p. 1-6.
Relaciones públicas en ONGs (2003, 26 de abril). Noticias hoy, pp. 1/2-6.

\section{Tesis de grado no publicadas:}

Apellido, Inicial del nombre. (año). Título. Tesis no publicada, Institución, Facultad, Ciudad.

Vázquez, B. (2008). Mujeres en la comunicación. Tesis de doctorado no publicada, Universidad Complutense de Madrid, Facultad de Ciencias de la Información, Departamento de Comunicación, Madrid.

\section{Contribución no publicada y presentada a un evento:}

Apellido, Inicial del nombre. (año, mes días). Título. Evento, Ciudad, País.

Hernández, T. (2007, septiembre 6-7). Marketing relacional para empresas de servicios. Ponencia presentada al Encuentro de Investigadores de Estudios de Marketing Relacional, Barcelona, España.

\section{Trabajo no publicado:}

Apellido, Inicial del nombre. (año). Título. Trabajo no publicado, Entidad, ciudad.

Sanz, G. (2001). La comunicación interna en situaciones de crisis. Cortasa, Universidad Nacional de Colombia, Bogotá.

\section{Documentos electrónicos:}

Apellido, Inicial del nombre. (Fecha de publicación o revisión de la página, si está disponible). Título del docu- 
mento o artículo. En Nombre del trabajo completo. Extraído el (fecha) desde (especifique la vía del sitio).

Muñoz, A. (2007, 5 de agosto). El patrocinio llega al deporte minoritario. Patrocinio. Disponible en:

http://www.patrocinio.com

Si hay más de una referencia de un mismo autor no se utilizará el sistema de guiones largos para indicar las diferentes entradas. En cada caso se pondrá el apellido y la inicial del autor:

Pérez, I. (2003). Merchandising y comunicación en el punto de venta. Madrid: Libros Actuales.

Pérez, I. (2003). La persuasión y la emoción. Barcelona: Editorial BN.

Pérez, I. (2000). Introducción a la comunicación empresarial. Madrid: Libros Actuales.

15. Los artículos se recibirán de forma continua a lo largo de todo el año.

16. La dirección de la revista acusará recibo de los trabajos, en un plazo máximo de diez días hábiles.

17. Posteriormente, empezará la evaluación del artículo, sin los datos del autor, enviándose a dos revisores externos (peer review) en el tema, para que de forma anónima e independiente, analicen la posible publicación, teniendo en cuenta los si- guientes aspectos: calidad y nivel académico del artículo, aportación al conocimiento y a la docencia, claridad en la presentación y en la redacción, originalidad, interés y actualidad del tema.

18. El autor recibirá ambas revisiones en el plazo máximo de seis meses.

19. El artículo puede ser de aceptación plena, aceptación con modificaciones o rechazado.

20. Cuando ambos expertos hayan evaluado el artículo, el resultado se comunicará al autor, para que realice las modificaciones correspondientes, si son necesarias. Una vez incorporadas las correcciones solicitadas, los artículos se enviarán a un corrector de estilo para iniciar el proceso de edición.

21. El autor cede los derechos de publicación a aDResearch ESIC, Revista Internacional de Investigación en Comunicación.

22. El artículo no puede aparecer en ningún medio masivo de comunicación sin la autorización expresa de aDResearch ESIC, Revista Internacional de Investigación en Comunicación.

23. El envío de los artículos no obliga al comité editorial de aDResearch ESIC, Revista Internacional de Investigación en Comunicación, a su publicación.

24. Los artículos se podrán publicar en castellano y en inglés. 


\section{Guidelines for authors}

\section{General rules}

The editorial policy of aDResearch ESIC contemplates the publishing of articles which deal with topics having to do with business communication from different perspectives. The objective is to serve as a go-between where knowledge, applications and methodology can be shared in this area by furthering scientific contributions in diverse facets of communication. For this reason, the articles to be published should be relevant and novel, with the possibility of being of different types:

Research articles. This kind of article presents the outcome of an original research project in detail. As a result, it should include several different sections: introduction, bibliographical review, research methodology, results and conclusions. At least $60 \%$ of each issue of the journal will be made up of this type of article.

Reflection articles. This type of article puts forth the results of critical research done by the author, from an analytical or interpretative perspective. Thus it should refer to original sources.

Review articles. This type of article presents the outcome of research based on a careful bibliographical review of at least 50 references. In the article the results from the different research published or unpublished should be analyzed, systemized or integrated to a field related to communication with the purpose of contributing the most interesting advances and techniques.

\section{Guidelines for the abstracts of the articles}

\section{Length}

The abstracts or summaries should have between 1500 and 2000 characters, being proportional to the size of the article.

\section{Style}

The summary should be clear and easy to read, supplying enough information for the readers to be able to understand what the content of the article is. It should be written in grammatically correct Spanish and with a logical flow. It should not include unnecessary facts or contain tables, figures or references. The elements to be included in the summaries are the following:

\section{Research Articles:}

- Purpose.

- Design / Methodology / Approach.

- Results.

- Limitations / Implications.

- Originality / Contribution.

\section{Reflection Articles:}

- Main topic / Subject.

- Logical development of the subject.

- Author's point of view and contributions.

- Implications and conclusions.

\section{Review Articles:}

- Reach of the review.

- Period of the publications reviewed.

- Origin and types of documents reviewed. 
- Author's contribution on the publications analyzed.

- Conclusions on the lines of research studied.

\section{Guidelines for the development of the articles}

The Board of Editors of aDResearch ESIC will take into account the following aspects when accepting or rejecting the articles received:

1. Only unpublished works will be considered after careful perusal and final approval by the Board.

2. The content of the articles is the author's responsibility; the editorial policy is open.

3. The authors should be professional teachers and researchers as well as experts in the topics to be dealt with.

4. The title of the article should be concise and specific to the topic studied.

5. All of the clarifications about the article (thanks, collaborators, etc.) will be indicated with an asterisk in the introduction with reference at the foot of that page.

6. Each article should attach the classification of the Journal of Economic Literature (JEL Classification) according to the topics it corresponds to in accordance with the established codes for international research of bibliographical production. The codes should be specific and no more than three should be indicated. The classification can be consulted at: http://www.aeaweb.org/journal/jel_class_ system.html

7. The length of the articles should not go beyond 20 pages using Calibri font,1.15 interlineal space and 11 font size.
8. The article should be sent in Word and PDF format to the e-mail articulos.adre search@esic.edu. The article should include the text of the article, the summary, and the key words (minimum of four).

9. Graphs, tables, images and other elements should have a title and be numbered consecutively.

10. Graphs, tables, images and other elements should also be attached on the original program where they were developed.

11. The author's personal information will be indicated on the first page with a footnote including the following information: author's name, studies, current job, place of work, and e-mail.

12. Footnotes will be used to clarify and to give further information.

13. Bibliographical references which are included in the text will follow the parenthetical system (surname, year, page): Sánchez, 2005, p. 27.

14. Complete bibliographical references will be added at the end of the article, in alphabetical order and with the following format, taking into account capital letters, italics, commas, periods and parenthesis:

\section{Books:}

Surname, first name initial. (year). Title. City: Publisher.

Suárez, A. y Martínez, D. (2003). Comunicación en la Unión Europea (2a. ed.). Madrid: Editorial CEAB.

White, D. (2006). La economía digital. Barcelona: M. Louston. (Original en inglés, 2004). 


\section{Chapter of a book:}

Surname, first name initial. (year). Title of the article. In Title of book (pages corresponding to article). City: Publisher.

Hown, R. y Smith, J. (1999). Historia de la publicidad. En Comunicando (pp. 25-80). Madrid: Editorial CEAB.

Esquirol, J. (2007). La imagen en la sociedad. En Pascual, M. y Rodríguez, C. (Eds.). Imagen actual en las sociedades (pp. 93-102). Madrid: HG Editorial.

\section{Articles from professional magazines or journals:}

Surname, first name initial. (year). Title of the article. The Name of the magazine, volume (issue number), number of pages.

Williams, O. (2002). Advertising and senses. Journal of Advertising Perspectives, 16(3), 181-205.

Pérez, L. (2008). Promoción en mercados internacionales. Promoción y empresa, 21, 31-36.

\section{Articles from newspapers:}

Surname, first name initial. (year, date ). Title of the article. Name of the newspaper, p.

Méndez, M. (2009, 26 de febrero). Temor por la crisis publicitaria. El Periodista, p. 1-6.

Relaciones públicas en ONGs (2003, 26 de abril). Noticias hoy, pp. 1/2-6.

\section{Unpublished undergraduate thesis:}

Surname, first name initial. (year). Title. Unpublished thesis, Institution,School, City.

Vázquez, B. (2008). Mujeres en la comunicación. Tesis de doctorado no publicada, Universidad Complutense de Madrid, Facultad de Ciencias de laInformación, Departamento de Comunicación, Madrid.

\section{Unpublished contribution presented at an event:}

Surname, first name initial. (year, dates ). Title. Event, City, Country.

Hernández, T. (2007, septiembre 6-7). Marketing relacional para empresas de servicios. Ponencia presentada al Encuentro de Investigadores de Estudios de Marketing Relacional, Barcelona, España.

\section{Unpublished work:}

Surname, first name initial. (year). Title. Unpublished work, Entity, city.

Sanz, G. (2001). La comunicación interna en situaciones de crisis. Cortasa, Universidad Nacional de Colombia, Bogotá.

\section{Electronic Documents:}

Surname, first name initial. (Date of publication or review of the page if available). Title of the document or article. In Name of the complete work. Taken(date)from (specify the site).

Muñoz, A. (2007, 5 de agosto). El patrocinio llega al deporte minoritario. Patrocinio. Disponible en: http://www.patrocinio.com

If there is more than one reference to the same author hyphens will not be used to indicate the different entries. In each case the surname and the initial of the author will be put:

Pérez, I. (2003). Merchandising y comunicación en el punto de venta. Madrid: Libros Actuales.

Pérez, I. (2003). La persuasión y la emoción. Barcelona: Editorial BN.

Pérez, I. (2000). Introducción a la comunicación empresarial. Madrid: Libros Actuales.

15. Articles will be received continuously throughout the year. 
16. Receipt of the works will be notified within ten working days.

17. Afterwards, the assessment of the article will begin, without knowledge of who the author is. The evaluation of the article will follow a double blind peer review process by two experts on the topic for the possible publication to be analyzed anonymously and independently. The following aspects will be taken into account: quality and academic level of the article, contribution to knowledge and teaching, clarity in both the presentation and composition, originality, interest and topicality of the theme.

18. The author will receive both reviews in the following six months.

19. The article may be fully accepted, accepted with modifications or rejected.

20. When both experts have assessed the article, the author will be notified of the result so that the corresponding modifications can be made if necessary. Once the corrections have been incorporated, the articles will be sent to a proofreader in order for the publishing process to begin.

21. The author cedes the publishing rights to aDResearch ESIC, International Journal of Communication Research.

22. The article cannot appear in any means of mass communication without the express authorization of aDResearch ESIC, International Journal of Communication Research.

23. Sending articles does not bind the editorial committee of aDResearch ESIC, International Journal of Communication Research, to publish it.

24. The articles will be published in English or Spanish. 


\section{aDResearch ESIC}

№ 25 Vol 25 · Monográfico especial, marzo 2021 · págs. 244 a 249

(ㄷ)(1) ()$\odot$ 


\section{Política editorial} Editorial Policy 


\section{Política editorial}

aDResearch ESIC, fiel a su compromiso con la comunidad científica y con la sociedad, garantiza tanto la ética, como la calidad de los artículos publicados, garantizando la respuesta a las necesidades de los lectores e investigadores, al tiempo que asegura la calidad de lo publicado, respetando en todo momento el contenido e integridad de los artículos.

Para ello aDResearch ESIC tiene como punto de referencia el Código de conducta y buenas prácticas recogido en el Comité de Ética en $\mathrm{Pu}$ blicaciones (COPE), para autores, revisores y editores.

http://publicationethics.org/files/Code_of_ conduct_for_journal_editors.pdf

\section{Compromisos de los Autores Originalidad y plagio}

Los autores de los artículos enviados a aDResearch ESIC afirman que sus trabajos son originales, y que no contienen partes de otros autores o de otros fragmentos de trabajos ya publicados por los autores. Además, aseguran la veracidad de los datos empíricos, en el sentido que no hayan sido modificados o alterados para la validación o refutación de hipótesis.

\section{Publicaciones múltiples y/o repetitivas}

El autor no debe publicar artículos en los que se repitan los mismos resultados en más de una revista científica. La propuesta simultánea de la misma contribución a diferentes journals es considerada éticamente incorrecta y reprobable.

\section{Lista de fuentes}

El autor debe proporcionar siempre la correcta indicación de las fuentes y los aportes mencionados en el artículo.

\section{Autoría}

El autor o autores del artículo garantizan la inclusión de aquellas personas que hayan realizado una contribución científica y académica considerable, tanto en el diseño de la investigación, planificación del trabajo, interpretación de los resultados y redacción del mismo. Por otra parte, el autor o autores, asegura haber jerarquizado la distinta autoría del artículo en base al nivel de responsabilidad e implicación.

\section{Acceso y retención}

Si el Consejo editor lo considera apropiado, los autores de los artículos deberán poner a su disposición también las fuentes o los datos en que se basa la investigación. Estos podrán conservarse durante un período razonable de tiempo después de la publicación y posiblemente hacerse accesible.

\section{Conflicto de intereses y divulgación}

Todos los autores están obligados a declarar explícitamente que no hay conflictos de intereses que puedan haber influido en los resultados obtenidos o las interpretaciones propuestas. Los autores también deben indicar cualquier financiación de agencias y/o de proyectos de los que surge el trabajo de la investigación.

\section{Errores en los artículos publicados}

Cuando un autor identifique en su artículo un error sustancial, o una inexactitud, deberá informar de manera inmediata al Consejo editor de aDResearch ESIC suministrándole toda la información necesaria para subsanar las incorrecciones.

\section{Responsabilidad}

Todos los autores aceptan la responsabilidad de lo que se ha escrito, asegurando además que 
se ha realizado una revisión de la literatura científica más actual y relevante del tema analizado. Por otra parte deberán tener presente de forma plural las diferentes corrientes del conocimiento.

\section{Compromisos de los Revisores}

\section{Contribución a la decisión editorial}

La revisión doble ciega es una metodología que ayuda, por una parte al Consejo editor a tomar mejores decisiones sobre los artículos propuestos, y por otra parte, al autor a mejorar su trabajo académico para su publicación.

Los revisores asumen el compromiso de realizar una revisión crítica, honesta, constructiva evitando sesgos, tanto en lo referente a la calidad científica como literaria del escrito.

\section{Respeto de los tiempos}

Si un revisor no se siente competente en la temática o área de conocimiento del artículo a revisar, lo notificará de manera inmediata al Consejo editor, para que busquen otra alternativa.

Por otra parte, el revisor, también deberá proceder de igual manera si presupone que no va a entregar el resultado de la evaluación en el tiempo comprometido con la revista y los autores.

Los revisores se comprometen a evaluar los trabajos en un tiempo razonable, respetando en todo caso los plazos de entrega.

\section{Confidencialidad}

Cada artículo asignado a un revisor es considerado confidencial. En este sentido, el manuscrito, textos, resultados, conclusiones, etcétera, no deben ser discutidos, ni puestos en común con otras personas sin consentimiento previo del Consejo editor.

\section{Objetividad}

La revisión doble se realizará de manera objetiva. No se considerará adecuado ningún juicio personal sobre el autor o autores de los artículos.

Por otra parte, los revisores están obligados a dar razones suficientes para sus valoraciones, entregando un informe crítico y pormenorizado completo con referencias adecuadas según plantilla de revisión de aDResearch ESIC.

Así mismo están obligados a advertir a los editores si partes sustanciales del trabajo ya han sido publicadas o están bajo revisión para otra publicación.

\section{Visualización de texto}

Los revisores se comprometen a indicar con precisión las referencias bibliográficas de obras fundamentales posiblemente olvidadas por el autor. El revisor también debe informar a los editores de cualquier similitud o solapamientos del manuscrito con otros trabajos publicados.

\section{Conflicto de intereses y divulgación}

Información confidencial o información obtenida durante el proceso de revisión por pares debe considerarse confidencial y no puede utilizarse para propósitos personales Los revisores solo revisarán un manuscrito si no existen conflictos de interés.

\section{Compromisos del Consejo editor} Decisión de publicación

El Consejo editor garantizará la selección de los revisores más cualificados y especialistas académicos para emitir una apreciación crítica y experta del trabajo, con los menores sesgos posibles. aDResearch ESIC, opta por seleccionar al menos 2 revisores por cada trabajo de forma que se garantice una mayor objetividad en el proceso de revisiones. 


\section{Honestidad}

El Consejo editor evalúa los artículos enviados para su publicación solo sobre la base del mérito científico de los contenidos, sin atender a ninguna otra razón de raza, sexo, religión.

\section{Confidencialidad}

El Consejo editor se compromete a no divulgar la información relativa a los artículos enviados para su publicación a otras personas que no sean autores, revisores y editores. Los editores y el Consejo editor se comprometen a la confidencialidad de los manuscritos, sus autores y revisores, de forma que el anonimato preserve la integridad intelectual de todo el proceso.

\section{Conflicto de intereses y divulgación}

El Consejo editor se compromete a no utilizar en sus investigaciones contenidos de los artículos enviados para su publicación sin el consentimiento por escrito del autor.

\section{Respeto de los tiempo}

El Consejo editor es responsable máximo del cumplimiento de los límites de tiempo para las revisiones y la publicación de los trabajos aceptados, para asegurar una rápida difusión de sus resultados. Se comprometen fehacientemente a cumplir los tiempos publicados (máximo de 30 días en la estimación/ desestimación desde la recepción del manuscrito) y máximo 60 días desde el inicio del proceso de revisión científica por expertos).

Asimismo, los trabajos no permanecerán aceptados sin publicarse en listas de espera más allá del tiempo justo para su edición en el siguiente número.

La revista aDResearch ESIC se adhiere a las normas éticas de Comité de Ética en Publicaciones (COPE). 



\section{aDResearch ESIC}

№ 25 Vol 25 · Monográfico especial, marzo 2021 · págs. 250 a 256

다 (1) $(5)$ 


\section{Contenidos \\ de la revista}

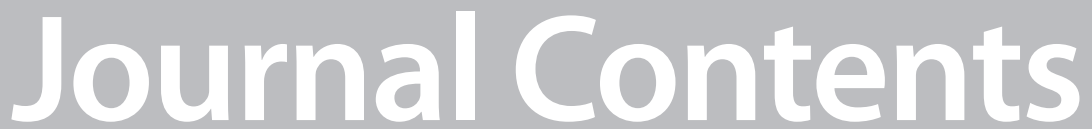




\section{Contenidos de la revista}

- Aspectos generales de la comunicación comercial:

- Fijación de objetivos de comunicación.

- Definición y elección de públicos objetivos.

- Planificación de la comunicación.

- Desarrollo de la estrategia de comunicación.

- Métodos de investigación en la comunicación: medida de la eficacia, investigación de medios, investigación de audiencias, evaluación de públicos objetivos, análisis de estrategias.

- Comunicación integrada / 360 .

- Comunicación corporativa/institucional.

- Comunicación de marca/branding.

- Identidad e imagen corporativa.

- Impacto de la comunicación y los medios en la sociedad.

- Publicidad:

- Estrategia creativa.

- Estrategia de medios.

- Eficacia publicitaria.

- El mercado publicitario: el anunciante, agencias, centrales de medios, medios, servicios de investigación, instituciones de control.

\section{- Relaciones públicas:}

- RRPP internas.

- RRPP externas.

- RRPP con los medios de comunicación.

- Instrumentos de RRPP.

\section{- Marketing directo:}

- Mailing.
- Telemarketing/marketing telefónico.

- Marketing relacional.

- Marketing one to one.

- Programas MGM.

- Patrocinio - mecenazgo:

- Elección de campañas.

- Tipos de patrocinio.

- Eficacia del patrocinio.

\section{- Promociones:}

- Tipos de promociones en comunicación.

- Promociones del fabricante y del anunciante.

- Los públicos de la promoción.

- Eficacia de las promociones.

- Comunicación en el punto de venta:

- Merchandising.

- PLV.

- La comunicación para distribuidores.

- Comunicación especializada:

- Comunicación de crisis.

- Comunicación política.

- Comunicación financiera.

- Comunicación social.

- Comunicación internacional.

- Nuevas tendencias en comunicación:

- Comunicación en Internet.

- E-mail marketing.

- Marketing viral.

- Mobile marketing.

- Tendencias en B2B.

- Evolución de las técnicas de comunicación.

- Nuevos medios de comunicación. 


\section{Journal contents}

- General aspects of commercial advertising:

- Setting advertising objectives.

- Defining and choosing target public.

- Advertising Plan.

- Development of advertising strategy.

- Advertising research methods: effectiveness test, media research, audience research, evaluation of target public, strategy analysis.

- Integrated advertising/360 .

- Corporate/institutional advertising.

- Brand advertising/branding.

- Corporate image and identity.

- Advertising and media impact on society.

\section{- Advertising:}

- Creative strategy.

- Media strategy.

- Advertising effectiveness.

- The advertising market: the advertiser, agencies, media centres, the media, research services, regulatory institutions.

\section{- Public relations:}

- Internal public relations.

- External public relations.

- Public relations with the media.

- Public relations tools.

\section{- Direct marketing:}

- Mailing.

- Telemarketing.

- Relationship marketing.

- One to one Marketing.

- MGM programmes.

\section{- Sponsorship/patronage:}

- Campaign choice.

- Types of sponsorship.

- Sponsorship effectiveness.

\section{- Promotions:}

- Types of promotions in advertising.

- Manufacturer and advertiser promotions.

- The promotion's public.

- Effectiveness of promotions.

- Advertising at the point of sale:

- Merchandising.

- POS.

- Advertising for distributors.

- Specialised advertising:

- Crisis advertising.

- Political advertising.

- Financial advertising.

- Mass media.

- International advertising.

- New advertising tendencies:

- Internet advertising.

- E-mail marketing

- Viral marketing.

- Mobile marketing

- B2B tendencies.

- Evolution of advertising techniques.

- New means of advertising. 


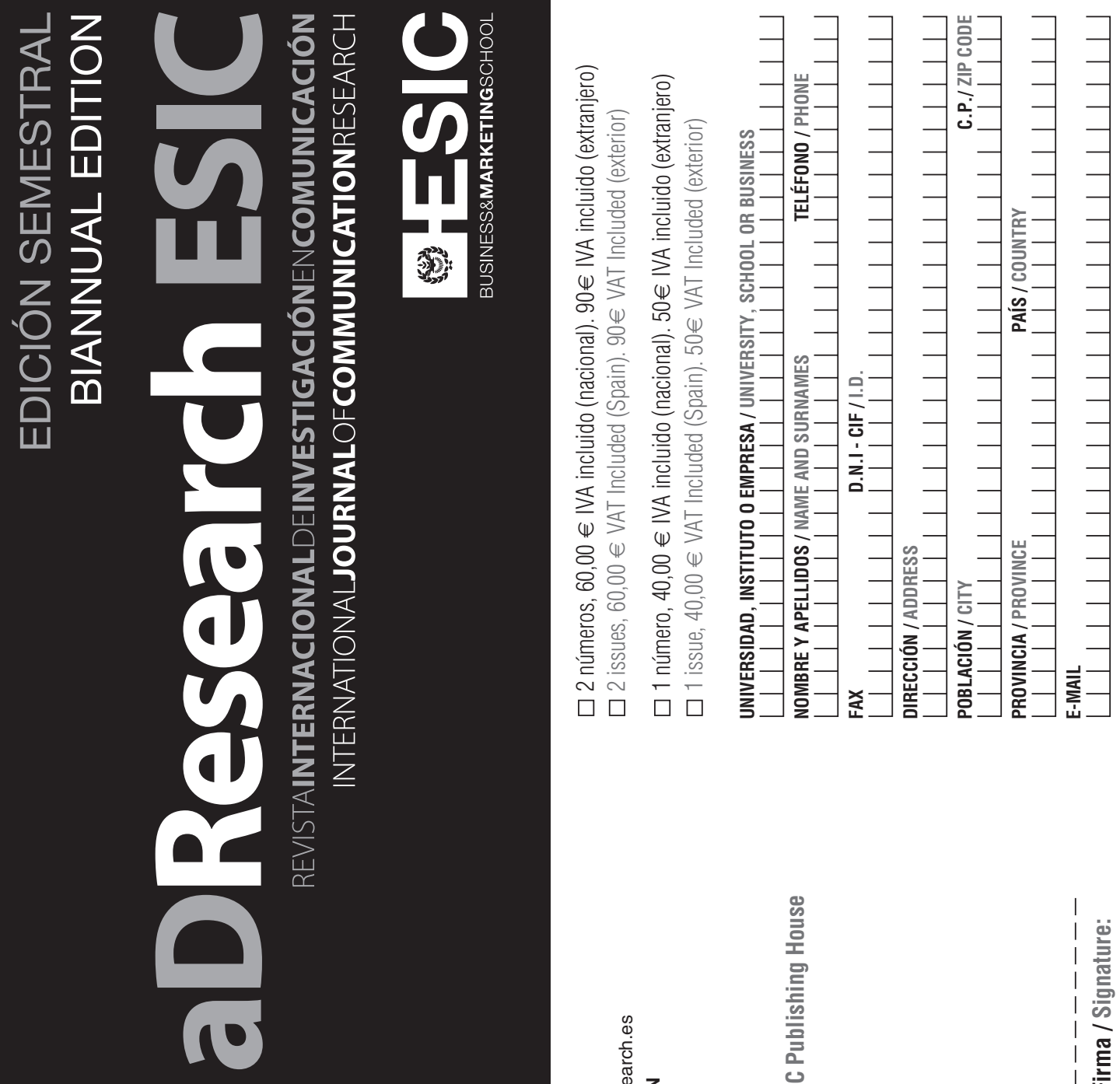

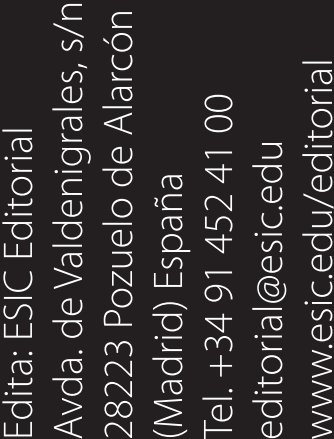
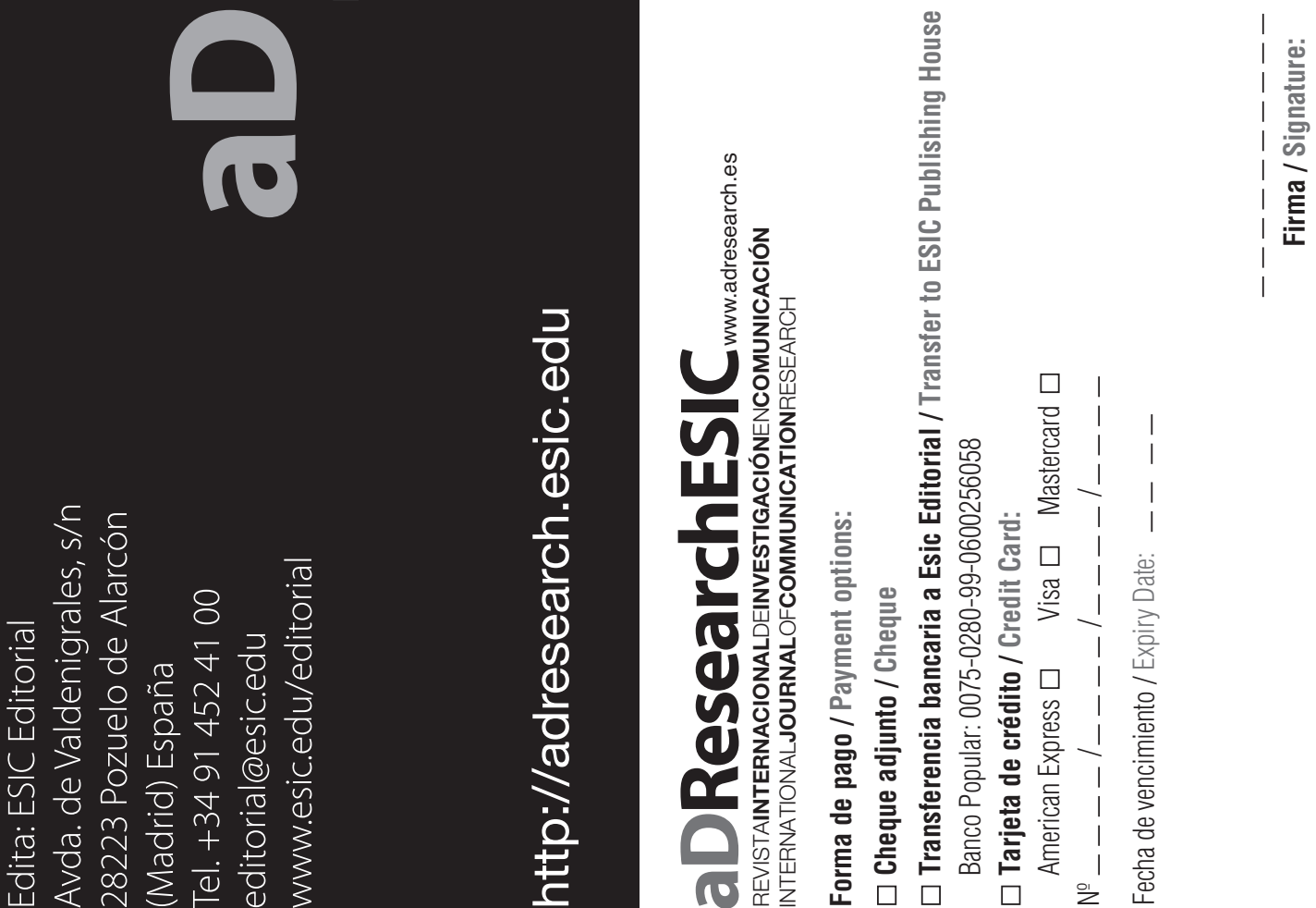
aDResearch ESIC

http://adresearch.esic.edu

Volumen $25 \cdot$ Número 25

Precio ejemplar/Issue Price $40 €$

ISSN: 1889-7304

\section{Monográfico Especial}

Nuevos Formatos en

Comunicación

Special lssue, New Forms

in Communication

Coordinadora / Coordinated by:

Dra. Graciela Padilla Castillo
8 Prólogo

12 "Shockvertising" as a Method to Advertise Content in Video on Demand Streaming Services

26 El engagement y la sorpresa en la comunicación digital de las marcas. Estudio del impacto emocional de los GIFs en los usuarios de redes sociales.

44 La estrategia de contenidos en YouTube de los principales anunciantes españoles

70 Using Virtual Assistants and Chatbots for Crisis Communication

92 El impacto de las plataformas de podcast en redes sociales: Estudio de caso en las cuentas oficiales de iVoox y Anchor en Instagram, Facebook y Twitter

106 Análisis de la comunicación de empresas europeas y norteamericanas en TikTok

124 Análisis de las estrategias publicitarias digitales de Inbound marketing de las marcas del sector automoción en YouTube en España

148 Tik Tok medio de divulgación empleado por los viajeros que realizan turismo sostenible

160 Estrategia de comunicación de los cuerpos de seguridad a través de píldoras audiovisuales en Tik Tok. Policía Nacional y Guardia Civil en España

186 MISCELÁNEA

188 Evaluación de la eficacia de una política de acción comunicativa a través del modelo EPAC Affinity ${ }^{\circledR}$

204 REVISTA DE LIBROS

206 Periodismo en nuevos formatos. Estado del Arte del Ciberperiodismo, Narrativas y Tecnologías Emergentes

208 Planificación de la comunicación de eventos. Estrategia e innovación en tiempos de inmediatez

210 Sobrevivir a la publicidad desde una perspectiva ética

214 PROYECTOS DE INVESTIGACIÓN EN COMUNICACIÓN Y PUBLICIDAD

224 TESIS DOCTORALES EN COMUNICACIÓN

230 AGENDA DE CONGRESOS

234 Normas de publicación

244 Política editorial

250 Contenidos de la revista 